\title{
Exercise capacity, muscle strength and fatigue in sarcoidosis
}

Citation for published version (APA):

Marcellis, R. G. J. (2015). Exercise capacity, muscle strength and fatigue in sarcoidosis. [Doctoral Thesis, Maastricht University]. Datawyse / Universitaire Pers Maastricht. https://doi.org/10.26481/dis.20150626rm

Document status and date:

Published: 01/01/2015

DOI:

10.26481/dis.20150626rm

Document Version:

Publisher's PDF, also known as Version of record

\section{Please check the document version of this publication:}

- A submitted manuscript is the version of the article upon submission and before peer-review. There can be important differences between the submitted version and the official published version of record.

People interested in the research are advised to contact the author for the final version of the publication, or visit the DOI to the publisher's website.

- The final author version and the galley proof are versions of the publication after peer review.

- The final published version features the final layout of the paper including the volume, issue and page numbers.

Link to publication

\footnotetext{
General rights rights.

- You may freely distribute the URL identifying the publication in the public portal. please follow below link for the End User Agreement:

www.umlib.nl/taverne-license

Take down policy

If you believe that this document breaches copyright please contact us at:

repository@maastrichtuniversity.nl

providing details and we will investigate your claim.
}

Copyright and moral rights for the publications made accessible in the public portal are retained by the authors and/or other copyright owners and it is a condition of accessing publications that users recognise and abide by the legal requirements associated with these

- Users may download and print one copy of any publication from the public portal for the purpose of private study or research.

- You may not further distribute the material or use it for any profit-making activity or commercial gain

If the publication is distributed under the terms of Article $25 \mathrm{fa}$ of the Dutch Copyright Act, indicated by the "Taverne" license above, 


\section{Exercise capacity, muscle strength and fatigue in sarcoidosis}

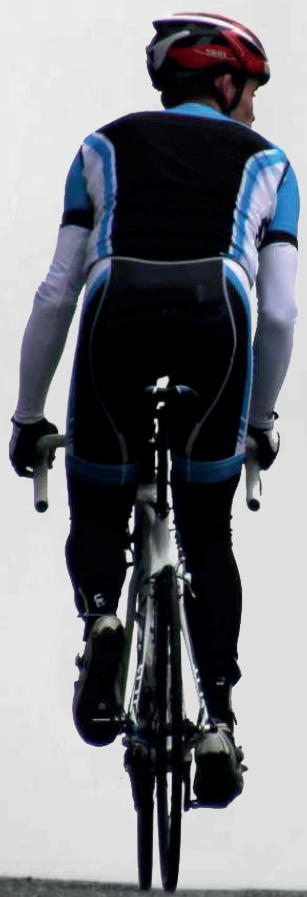

Rik G.J. Marcellis 
C Rik Gerardus Josef Marcellis, Maastricht 2015

Cover photography: Petal Wijnen

Cover illustration: Datawyse, Universitaire Pers Maastricht

Layout: Tiny Wouters

Production: Datawyse, Universitaire Pers Maastricht

ISBN: 978-90-78076-09-4

The research published in this thesis was financially supported by the ild care foundation, Department of Physical Therapy MUMC and the Sarcoïdose Belangenvereniging Nederland.

The printing of this thesis was financially supported by the Department of Physical Therapy MUMC, ild care foundation, Boehringer Ingelheim B.V., Takeda Nederland B.V., Longfonds, Sarcoïdose Belangenvereniging Nederland and the Longfibrose Patiëntenvereniging Nederland. 


\title{
Exercise capacity, muscle strength and fatigue in sarcoidosis
}

\author{
PROEFSCHRIFT
}

ter verkrijging van de graad van doctor

aan de Universiteit Maastricht, op gezag van de Rector Magnificus, Prof. dr. L.L.G. Soete,

volgens het besluit van het College van Decanen,

in het openbaar te verdedigen op

vrijdag 26 juni 2015 om 12.00 uur

door

Rik Gerardus Josef Marcellis 


\section{Promotor}

Prof. dr. M. Drent

\section{Copromotor}

Dr. A.F. Lenssen

\section{Beoordelingscommissie}

Prof. dr. F.J.W.M. Smeenk (voorzitter)

Prof. dr. R. Gosselink (Katholieke Universiteit Leuven, België)

Prof. dr. H. Kuipers

Prof. dr. M.W.G. Nijhuis-van der Sanden (Radboud Universitair Medisch

Centrum Nijmegen)

Prof. dr. R.J.E.M. Smeets 


\section{Contents}

$\begin{array}{lll}\text { Chapter } 1 & \text { General introduction } & 7\end{array}$

Chapter 2 Reduced muscle strength, exercise intolerance and disabling 19 symptoms in sarcoidosis

Chapter 3 Exercise capacity, muscle strength and fatigue in sarcoidosis 33

Chapter 4 Exercise capacity, muscle strength, and fatigue in sarcoidosis: $\quad 47$ a follow-up study

Chapter 5 Is there an added value of cardiopulmonary exercise testing in sarcoidosis patients?

Chapter 6 Association between physical functions and quality of life in sarcoidosis

Chapter 7 Does physical training reduce fatigue in sarcoidosis?

Chapter 8 Summary, general discussion and directions for future research

Valorisatie

Dankwoord (acknowledgements)

Curriculum vitae

List of publications 



\section{Chapter 1}

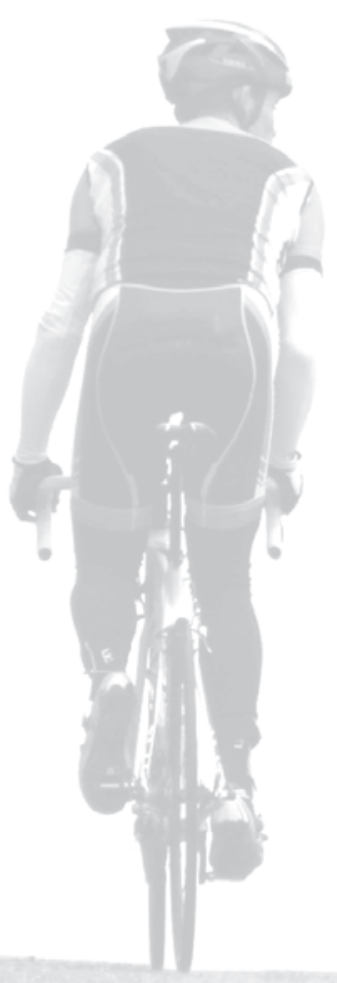

General introduction 


\section{Sarcoidosis}

Sarcoidosis is a systemic granulomatous disease of unknown cause, characterized by the formation of noncaseating epithelioid cell granulomas, consisting of mononuclear phago- and lymphocytes, in various organ systems. ${ }^{1-3}$ The diagnosis sarcoidosis is established according to the World Association of Sarcoidosis and Other Granulomatous Disorders (WASOG) guideline by excluding other granulomas provoking disorders supported by a compatible clinicoradiologic presentation together with histological evidence of granulomas (Figure 1.1). ${ }^{1,4}$ However, in patients presenting with Löfgren's syndrome, characterized by fever, erythema nodosum, bilateral hilar adenopathy, and polyarthralgias, a biopsy will not be necessary to establish the disease because of the specific disease presentation. ${ }^{5}$ Generally, chest radiographs are graded according to the radiographic staging proposed by DeRemee: stage 0 (no visible intrathoracic abnormalities), stage I (bilateral hilar lymphadenopathy), stage II (bilateral hilar lymphadenopathy and parenchymal infiltration), stage III (parenchymal infiltration without bilateral hilar lymphadenopathy), and stage IV (advanced lung fibrosis)., ${ }^{1,6}$

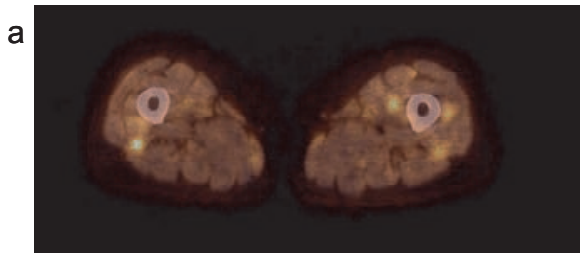

b

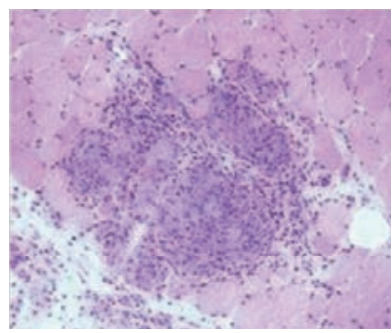

Figure 1.1 a. PET/CT image of a sarcoidosis patient showing multiple foci with increased fluorodeoxyglucose (FDG) uptake in the muscles of the lower extremities. b. Noncaseating granuloma present in a biopsy obtained from the left quadriceps muscle of a patient with sarcoidosis. 


\section{Epidemiology}

The disease occurs throughout the world, affecting both men and women of all races and ages. ${ }^{1}$ However, sarcoidosis shows a predilection for young adults in their working age (25-45 years). ${ }^{2}$ In general, the disease is more severe in black compared to white patients. ${ }^{7}$ African-Americans also had about a three-fold higher age-adjusted annual incidence rate $(35.5$ cases per 100,000$)$ compared with Caucasians $\left(10.9\right.$ per 100,000). ${ }^{8}$ The incidence in the Netherlands is thought to be 20 per 100,000 and the prevalence 50 per $100,000 .^{9}$ Scandinavian countries showed the highest prevalence rates. ${ }^{1,10}$

\section{Etiology}

Although the etiology of sarcoidosis is still unknown, it is assumed that sarcoidosis is the result of an exaggerated granulomatous reaction after exposure of genetically predisposed persons to specific environmental and occupational agents, such as viruses, metal dusts, insecticides and moldy environments. ${ }^{1,2,4}$

For example, after the World Trade Center disaster, the incidence of sarcoidosis among rescue workers of the Fire Department of New York was increased. ${ }^{11}$ Even evidence exists that dental material with silicates might be a factor in the onset of sarcoidosis in dental surgeons. ${ }^{12}$ Sarcoidal granulomas have also been reported in tattoos, since the tattoo pigment is foreign body material. ${ }^{13}$

\section{Clinical presentation}

The clinical course of sarcoidosis is unpredictable and clinical manifestations are variable, depending on the specific site and extent of the organ involvement, disease activity of the granulomatous process, duration of the illness and severity. Patients may suffer from a wide spectrum of organ-specific symptoms, since every organ can be involved. Most commonly the lungs are affected in approximately $90 \%$ of the sarcoidosis patients, resulting in symptoms such as cough, breathlessness and dyspnea on exertion. Besides the lungs, the skin, eyes, heart, lymphatic, nervous and musculoskeletal system are often involved. ${ }^{1,14,15}$ In $50-80 \%$ of patients with sarcoidosis asymptomatic sarcoid muscle involvement will be detected by muscle biopsy. Symptomatic muscle involvement is rare. ${ }^{16}$ Fluorine18-fluoro-deoxyglucose positron emission tomography/computed tomography $\left({ }^{18} \mathrm{~F}-\mathrm{FDG} \mathrm{PET} / \mathrm{CT}\right)$ is a sensitive method to detect inflammatory activity in extrathoracic organs, including muscle involvement (Figure 1.1a). ${ }^{17,18}$ Patients also frequently visit their physician with non-specific health complaints, such as pain, arthralgia, cognitive failure ${ }^{19}$, anxiety, depressive symptoms $^{20,21}$, fatigue ${ }^{22,23}$, muscle weakness and exercise intolerance. ${ }^{24-28}$ Although physical impairments are common problems in sarcoidosis, the number of studies on 
this topic are limited. Muscle atrophy is a substantial problem in sarcoidosis with a prevalence of $25 \%$ and is associated with impaired exercise capacity. ${ }^{29}$ In a previous study, $50 \%$ of the sarcoidosis patients reported reduced exercise capacity and $22 \%$ general weakness by completing a questionnaire. ${ }^{24}$ Besides muscle atrophy various other causes of physical impairments exist, for example inefficient ventilation, oxygen diffusing impairments, physical inactivity and use of corticosteroids. ${ }^{30}$ Studies concerning muscle weakness included small study populations or sarcoidosis patients with specific health complaints. Previous studies reported reduced mean values of exercise capacity and muscle strength in sarcoidosis. ${ }^{25,28,31,32}$ However, studies about the prevalence of muscle weakness and exercise intolerance in sarcoidosis are scarce.

Fatigue is a clear hallmark of sarcoidosis patients affecting quality of life (QoL) negatively. The etiology of fatigue is still unknown and is most probably multifactorial. Possible factors involved in the etiology of fatigue in sarcoidosis are inflammatory activity $^{33}$, sleep disturbances (obstructive sleep apnea syndrome) ${ }^{34}$, psychological disorders (depression, anxiety and stress) ${ }^{21,35}$, cognitive failures ${ }^{19}$ and side effects of drug use. ${ }^{22}$ Small fiber neuropathy (SFN) is common in sarcoidosis and linked to fatigue. Symptoms in SFN, like pain and paraesthesias, may also interfere with physical functions and functioning. ${ }^{36,37}$

However, fatigued patients with physical impairments may reduce their daily physical activities, causing more perceived physical problems. This mechanism is also called the negative vicious circle of physical deconditioning. ${ }^{25}$ Therefore, muscle weakness or exercise intolerance may explain fatigue complaints partially. Although the influence of physical functions on fatigue and QoL not has been studied extensively, it is likely that improvement of physical functioning has a positive effect on patients QoL.

\section{Course of the disease}

In generally, the acute form of sarcoidosis, i.e. Löfgren's syndrome, has a good prognosis. ${ }^{9}$ More than $50 \%$ of the patients shows a spontaneous remission within two years of the diagnosis, and within a decade for two-thirds with few or no consequences. ${ }^{2,5}$ However, the disease shows a progressive or chronic course in $10-30 \%{ }^{1}$ Therefore, sarcoidosis is often classified into acute ( $<2$ years) and chronic (3-5 years) phenotypes. ${ }^{2,38}$ A worse prognosis is associated with patient and disease characteristics, like black race, extrapulmonary (neurological and cardiac) involvement, and advanced pulmonary disease. ${ }^{1,9}$ The mortality rates in sarcoidosis range from $1-8 \%$ also as a result of neurological and cardiac involvement or progressive pulmonary insufficiency, mainly due to pulmonary fibrosis or pulmonary hypertension. ${ }^{39}$

Mostly, sarcoidosis-related symptoms are disabling, especially when they are progressive or chronic, and can have a substantial impact on the patients' daily activities and families resulting in a reduced QoL. ${ }^{40,41}$ So far, studies using a longitudinal study design to examine changes in physical functions over time in sarcoidosis are 
missing. Therefore, no conclusions can be drawn with regard to the course of these physical impairments. This point is of clinical interest in the management of sarcoidosis, since a physiotherapeutic intervention, for instance a rehabilitation program, could offer added value in patients with persistent physical impairments.

\section{Assessment of physical functions and functioning}

The management of sarcoidosis patients suffering from physical impairments, requires clinically useful tools to objectify the severity of these impairments. Commonly used physiological tests in current clinical practice to assess disease activity and severity in sarcoidosis include chest radiography, lung function testing and serological parameters. ${ }^{1}$ These parameters are only weakly related with fatigue and do not reliably reflect the patients' QoL. ${ }^{42,43}$ So, patients without signs of inflammatory activity may suffer from unexplained disabling symptoms, such as fatigue and dyspnea, resulting in a reduced QoL. Frequently used questionnaires to assess fatigue complaints and QoL in sarcoidosis are the Fatigue Assessment Scale (FAS) and World Health Organization Quality of Life-BREF assessment instrument (WHOQOL-BREF).

In other chronic disorders exercise and/or muscle strength testing appeared to be of additional value in the management of the disease. ${ }^{44}$ Therefore, it is important to study the added value of physical testing in sarcoidosis patients with unexplained disabling symptoms, especially when a discrepancy exists between clinical findings and routinely used physiological tests. The six-minute walk test (submaximal functional exercise test) and cardiopulmonary exercise testing (maximal exercise test) are commonly used exercise tests in the management of sarcoidosis. ${ }^{25,45,46}$ Peripheral muscle weakness can be assessed using the Biodex System 3 Pro $^{47}, \operatorname{Jamar}^{48}$ or a handheld dynamometer (Figure 1.2). ${ }^{49}$
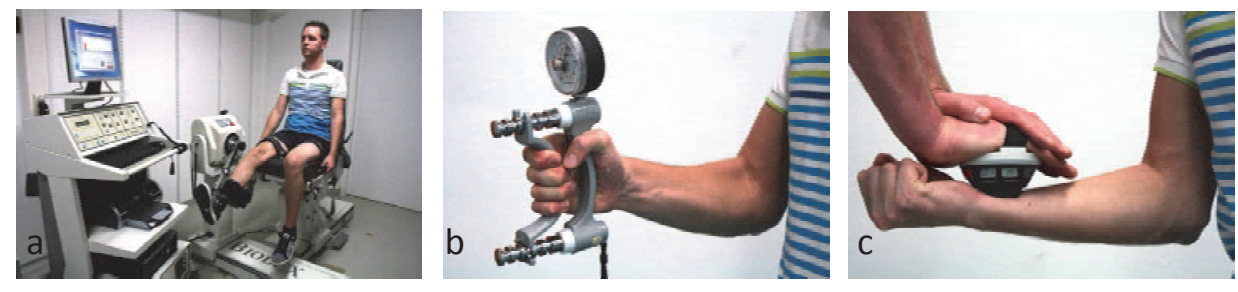

Figure 1.2 Peripheral muscle strength testing in patients with sarcoidosis: a. Biodex System 3 pro dynamometer b. Jamar dynamometer c. Hand-held dynamometer. 


\section{Therapeutic options}

Pharmaceutical treatment often fails to eradicate persistent fatigue and physical impairments in sarcoidosis. ${ }^{22}$ However, exercise training appeared beneficial in improving exercise capacity, dyspnea and QoL and belongs to the standard of care in the treatment of patients with chronic obstructive pulmonary diseases (COPD). ${ }^{44}$ Similar improvements were reported in patients with interstitial lung diseases (ild). ${ }^{50,51}$ Regrettably, studies reporting about the benefits of exercise training in ild only include ild patients other than sarcoidosis or do not perform a subgroup analysis of the sarcoidosis patients. Obviously, exercise training can fulfil an important role in the treatment of these persistent disabling symptoms. However, studies to support the benefits of exercise training in sarcoidosis are scarce.

\section{Scope and aims of the study}

The aims of the studies presented in this thesis were to assess the prevalence of muscle weakness and exercise intolerance in sarcoidosis and the usefulness of exercise and/or muscle strength testing in the management of sarcoidosis. Additionally, the predictive value of physical functions for fatigue and QoL were assessed. And finally, the impact of physical training on physical functions and QoL were studied. The studies included patients with sarcoidosis who were referred to a tertiary ild care center in the Netherlands.

Chapter 2 provides an overview of the current literature regarding prevalence, assessment and treatment of muscle weakness and exercise intolerance in sarcoidosis and the association between these physical parameters and fatigue, dyspnea and QoL.

Chapter 3 presents a case-control study performed between November 2008 and September 2009, which reported on the prevalence of exercise intolerance, muscle weakness and fatigue measured with the six-minute walk test, microFET, Biodex System 3 pro and Jamar dynamometer, maximal inspiratory mouth pressures and the FAS in 124 symptomatic Dutch sarcoidosis patients and 62 healthy controls. Also the predictive value of exercise capacity, muscle strength and other clinical characteristics for fatigue was evaluated. Chapter 4 describes the changes in the prevalence of exercise intolerance, muscle weakness, and fatigue in 90 sarcoidosis patients of the 2008/9 study (chapter 3) and the changes in these parameters in individual patients during a 2-year follow-up study. Chapter $\mathbf{5}$ evaluates the additional value of cardiopulmonary exercise testing, performing a symptom-limited incremental exercise test with blood gas analysis on a bicycle ergometer, compared to the measurement of the diffusing capacity of the lung for carbon monoxide (DLCO) in detecting pulmonary gas exchange impairment in 160 sarcoidosis patients with unexplained disabling symptoms. Secondly, the predictive value of physical testing and clinical characteristics for impaired gas exchange was reported. Chapter 6 assesses the associations between 
QoL measured with the WHOQOL-BREF and both physical functions (six-minute walking distance, peripheral and maximal inspiratory muscle strength) and clinical characteristics in 88 symptomatic Dutch sarcoidosis patients and evaluates whether these associations change over a 2-year period. Chapter 7 shows the impact of a 13-week physical training program (including peripheral muscle and endurance training) for one hour, thrice a week, on fatigue, physical functions and QoL in 18 fatigued sarcoidosis patients and/or patients with exercise intolerance. Finally, chapter 8 provides a summary of the findings presented in this thesis and a general discussion. Additionally, the implications of the study outcomes for clinical practice are argued and recommendations for future research are briefly discussed. 


\section{References}

1. Statement on sarcoidosis. Joint Statement of the American Thoracic Society (ATS), the European Respiratory Society (ERS) and the World Association of Sarcoidosis and Other Granulomatous Disorders (WASOG) adopted by the ATS Board of Directors and by the ERS Executive Committee, February 1999. Am J Respir Crit Care Med 1999;160:736-755.

2. Valeyre D, Prasse A, Nunes H, Uzunhan Y, Brillet PY, Muller-Quernheim J. Sarcoidosis. Lancet 2014; 383:1155-1167.

3. Morgenthau AS, lannuzzi MC. Recent advances in sarcoidosis. Chest 2011;139:174-182.

4. Baughman RP, Culver DA, Judson MA. A concise review of pulmonary sarcoidosis. Am J Respir Crit Care Med 2011;183:573-581.

5. Iannuzzi MC, Fontana JR. Sarcoidosis: clinical presentation, immunopathogenesis, and therapeutics. JAMA 2011;305:391-399.

6. DeRemee RA. The roentgenographic staging of sarcoidosis. Historic and contemporary perspectives. Chest 1983;83:128-133.

7. Baughman RP, Teirstein AS, Judson MA, Rossman MD, Yeager H, Jr., Bresnitz EA, DePalo L, Hunninghake G, lannuzzi MC, Johns CJ, McLennan G, Moller DR, Newman LS, Rabin DL, Rose C, Rybicki B, Weinberger SE, Terrin ML, Knatterud GL, Cherniak R, Case Control Etiologic Study of Sarcoidosis research group. Clinical characteristics of patients in a case control study of sarcoidosis. Am J Respir Crit Care Med 2001;164:1885-1889.

8. Rybicki BA, Major M, Popovich J, Jr., Maliarik MJ, lannuzzi MC. Racial differences in sarcoidosis incidence: a 5-year study in a health maintenance organization. Am J Epidemiol 1997;145:234-241.

9. Drent M. Sarcoïdose: stand van zaken. FarmacotherapieOnline. 2012:1-25. www.farmacotherapie.org.

10. Pietinalho A, Hiraga $Y$, Hosoda $Y$, Lofroos AB, Yamaguchi $M$, Selroos O. The frequency of sarcoidosis in Finland and Hokkaido, Japan. A comparative epidemiological study. Sarcoidosis 1995;12:61-67.

11. Izbicki G, Chavko R, Banauch GI, Weiden MD, Berger KI, Aldrich TK, Hall C, Kelly KJ, Prezant DJ. World Trade Center "sarcoid-like" granulomatous pulmonary disease in New York City Fire Department rescue workers. Chest 2007;131:1414-1423.

12. Checchi L, Nucci MC, Gatti AM, Mattia D, Violante FS. Sarcoidosis in a dental surgeon: a case report. J Med Case Rep 2010;4:259.

13. Sheu J, Saavedra AP, Mostaghimi A. Rapid response of tattoo-associated cutaneous sarcoidosis to minocycline: case report and review of the literature. Dermatol Online J 2014;20.

14. Baughman RP, Lower EE, Gibson K. Pulmonary manifestations of sarcoidosis. Presse Med 2012;41: e289-302.

15. Valeyre D, Nunes H, Bernaudin JF. Advanced pulmonary sarcoidosis. Curr Opin Pulm Med 2014;20: 488-495.

16. Fayad F, Liote F, Berenbaum F, Orcel P, Bardin T. Muscle involvement in sarcoidosis: a retrospective and followup studies. J Rheumatol 2006;33:98-103.

17. Mostard RL, Voo S, Van Kroonenburgh MJ, Verschakelen JA, Wijnen PA, Nelemans PJ, Erckens RJ, Drent M. Inflammatory activity assessment by F18 FDG-PET/CT in persistent symptomatic sarcoidosis. Respir Med 2011;105:1917-1924.

18. Cremers JP, Van Kroonenburgh MJ, Mostard RL, Voo SA, Wijnen PA, Koek GH, Drent M. Extent of disease activity assessed by 18F-FDG PET/CT in a Dutch sarcoidosis population. Sarcoidosis Vasc Diffuse Lung Dis 2014;31:37-45.

19. Elfferich MD, Nelemans PJ, Ponds RW, De Vries J, Wijnen PA, Drent M. Everyday cognitive failure in sarcoidosis: the prevalence and the effect of anti-TNF-alpha treatment. Respiration 2010;80:212-219.

20. Elfferich MD, De Vries J, Drent M. Type D or 'distressed' personality in sarcoidosis and idiopathic pulmonary fibrosis. Sarcoidosis Vasc Diffuse Lung Dis 2011;28:65-71.

21. Chang B, Steimel J, Moller DR, Baughman RP, Judson MA, Yeager H, Jr., Teirstein AS, Rossman MD, Rand CS. Depression in sarcoidosis. Am J Respir Crit Care Med 2001;163:329-334.

22. Drent M, Lower EE, De Vries J. Sarcoidosis-associated fatigue. Eur Respir J 2012;40:255-263.

23. De Kleijn WP, De Vries J, Lower EE, Elfferich MD, Baughman RP, Drent M. Fatigue in sarcoidosis: a systematic review. Curr Opin Pulm Med 2009;15:499-506.

24. Wirnsberger RM, De Vries J, Wouters EF, Drent M. Clinical presentation of sarcoidosis in the Netherlands an epidemiological study. Neth J Med 1998;53:53-60. 
25. Spruit MA, Thomeer MJ, Gosselink R, Troosters T, Kasran A, Debrock AJ, Demedts MG, Decramer M. Skeletal muscle weakness in patients with sarcoidosis and its relationship with exercise intolerance and reduced health status. Thorax 2005;60:32-38.

26. Alhamad EH. The six-minute walk test in patients with pulmonary sarcoidosis. Ann Thorac Med 2009; 4:60-64.

27. Wilsher ML. Psychological stress in sarcoidosis. Curr Opin Pulm Med 2012;18:524-527.

28. Wirnsberger RM, Drent M, Hekelaar N, Breteler MH, Drent S, Wouters EF, Dekhuijzen PN. Relationship between respiratory muscle function and quality of life in sarcoidosis. Eur Respir J 1997;10:1450-1455.

29. Cremers JP, Drent M, Elfferich MD, Nelemans PJ, Wijnen PA, Witteman BJ, Schols AM. Body composition profiling in a Dutch sarcoidosis population. Sarcoidosis Vasc Diffuse Lung Dis 2013;30: 289-299.

30. Spruit MA, Wouters EFM, Gosselink R. Rehabilitation programmes in sarcoidosis: a multidisciplinary approach. Eur Respir J 2005;32:316-326.

31. Bourbonnais JM, Malaisamy S, Dalal BD, Samarakoon PC, Parikh SR, Samavati L. Distance saturation product predicts health-related quality of life among sarcoidosis patients. Health Qual Life Outcomes 2012;10:67.

32. Baughman RP, Sparkman BK, Lower EE. Six-minute walk test and health status assessment in sarcoidosis. Chest 2007;132:207-213.

33. Drent M, Wirnsberger RM, De Vries J, Van Dieijen-Visser MP, Wouters EF, Schols AM. Association of fatigue with an acute phase response in sarcoidosis. Eur Respir J 1999;13:718-722.

34. Verbraecken J, Hoitsma E, Van der Grinten CP, Cobben NA, Wouters EF, Drent M. Sleep disturbances associated with periodic leg movements in chronic sarcoidosis. Sarcoidosis Vasc Diffuse Lung Dis 2004;21:137-146.

35. Goracci A, Fagiolini A, Martinucci M, Calossi S, Rossi S, Santomauro T, Mazzi A, Penza F, Fossi A, Bargagli E, Pieroni MG, Rottoli P, Castrogiovanni P. Quality of life, anxiety and depression in sarcoidosis. Gen Hosp Psychiatry 2008;30:441-445.

36. Hoitsma E, Drent M, Verstraete E, Faber CG, Troost J, Spaans F, Reulen JP. Abnormal warm and cold sensation thresholds suggestive of small-fibre neuropathy in sarcoidosis. Clin Neurophysiol 2003;114:2326-2333.

37. Hoitsma E, Marziniak M, Faber CG, Reulen JP, Sommer C, De Baets M, Drent M. Small fibre neuropathy in sarcoidosis. Lancet 2002;359:2085-2086.

38. Pereira CA, Dornfeld MC, Baughman R, Judson MA. Clinical phenotypes in sarcoidosis. Curr Opin Pulm Med 2014;20:496-502.

39. Baughman RP, Lower EE. Who dies from sarcoidosis and why? Am J Respir Crit Care Med 2011;183: 1446-1447.

40. Korenromp IH, Laar MA. Health-related quality of life in sarcoidosis. Curr Opin Pulm Med 2014;20: 503-507.

41. Michielsen HJ, Peros-Golubicic T, Drent M, De Vries J. Relationship between symptoms and quality of life in a sarcoidosis population. Respiration 2007;74:401-405.

42. De Vries J, Rothkrantz-Kos S, Van Dieijen-Visser MP, Drent M. The relationship between fatigue and clinical parameters in pulmonary sarcoidosis. Sarcoidosis Vasc Diffuse Lung Dis 2004;21:127-136.

43. Wirnsberger RM, De Vries J, Breteler MH, Van Heck GL, Wouters EF, Drent M. Evaluation of quality of life in sarcoidosis patients. Respir Med 1998;92:750-756.

44. Spruit MA, Singh SJ, Garvey C, ZuWallack R, Nici L, Rochester C, Hill K, Holland AE, Lareau SC, Man WD, Pitta F, Sewell L, Raskin J, Bourbeau J, Crouch R, Franssen FM, Casaburi R, Vercoulen JH, Vogiatzis I, Gosselink R, Clini EM, Effing TW, Maltais F, Van der Palen J, Troosters T, Janssen DJ, Collins E, GarciaAymerich J, Brooks D, Fahy BF, Puhan MA, Hoogendoorn M, Garrod R, Schols AM, Carlin B, Benzo R, Meek P, Morgan M, Rutten-van Molken MP, Ries AL, Make B, Goldstein RS, Dowson CA, Brozek JL, Donner CF, Wouters EF. An official American Thoracic Society/European Respiratory Society statement: key concepts and advances in pulmonary rehabilitation. Am J Respir Crit Care Med 2013;188:e13-64.

45. Kabitz HJ, Lang F, Walterspacher S, Sorichter S, Muller-Quernheim J, Windisch W. Impact of impaired inspiratory muscle strength on dyspnea and walking capacity in sarcoidosis. Chest 2006;130:1496-1502.

46. Miller A, Brown LK, Sloane MF, Bhuptani A, Teirstein AS. Cardiorespiratory responses to incremental exercise in sarcoidosis patients with normal spirometry. Chest 1995;107:323-329. 
47. Drouin JM, Valovich-mcLeod TC, Shultz SJ, Gansneder BM, Perrin DH. Reliability and validity of the Biodex system 3 pro isokinetic dynamometer velocity, torque and position measurements. Eur J Appl Physiol 2004;91:22-29.

48. Werle S, Goldhahn J, Drerup S, Simmen BR, Sprott H, Herren DB. Age- and gender-specific normative data of grip and pinch strength in a healthy adult Swiss population. J Hand Surg Eur Vol 2009;34:76-84.

49. Bohannon RW. Make tests and break tests of elbow flexor muscle strength. Phys Ther 1988;68:193-194.

50. Holland A, Hill C. Physical training for interstitial lung disease. Cochrane Database Syst Rev 2008: CD006322.

51. Huppmann P, Sczepanski B, Boensch M, Winterkamp S, Schonheit-Kenn U, Neurohr C, Behr J, Kenn K. Effects of in-patient pulmonary rehabilitation in patients with interstitial lung disease. Eur Respir J 2013;42:444-453. 


\section{Chapter 2}

Reduced muscle strength, exercise intolerance and disabling symptoms in sarcoidosis

RGJ Marcellis, AF Lenssen, J De Vries, M Drent

Curr Opin Pulm Med 2013;19:524-530 


\section{Abstract}

\section{Purpose of review}

This review focuses on innovations in the field of assessment and treatment of muscle weakness and exercise intolerance in sarcoidosis and the association between these and fatigue, dyspnea and quality of life (QoL).

\section{Recent findings}

Muscle strength and exercise intolerance are prevalent in patients with sarcoidosis. Exercise testing can be used to identify the presence of strength deficits and exercise intolerance. Routinely performed clinical tests, including lung function tests and imaging methods, are only weakly related to these nonspecific health complaints. Assessment of exercise capacity might also be useful for the early detection of parenchymal involvement and diagnosis of sarcoidosisassociated pulmonary hypertension. Both muscle weakness and exercise intolerance have been suggested as underlying causes of fatigue and dyspnea complaints, resulting in reduced QoL. Research is required to find out whether a multidisciplinary rehabilitation program is of clinical benefit in the management of sarcoidosis patients.

\section{Summary}

This review underlines the added value of physical testing in the management of sarcoidosis patients, especially in those with unexplained physical complaints. 


\section{Introduction}

Sarcoidosis is a multisystem disorder of unknown origin, which is characterized by noncaseating epithelioid cell granulomas. ${ }^{1-3}$ The course of sarcoidosis is unpredictable and clinical manifestations are variable, depending on the organs involved, disease activity and severity. Patients often suffer from a wide spectrum of organ-specific symptoms. In addition to the lungs (>90\%), the lymphatic system and the eyes are often affected. $^{2,4}$ Patients may also consult their physician with nonspecific health complaints, such as exercise intolerance, muscle weakness and fatigue. ${ }^{5^{* *}-10}$ These sarcoidosis-related symptoms may be disabling for patients. The presence of disabling symptoms is defined as having more than one symptom that substantially influences a patient's daily activities and quality of life (QoL), and that cannot be explained from the results of routine investigations including lung function tests or chest radiographs. ${ }^{11}$ The influence of muscle weakness and exercise intolerance on QoL has not been studied extensively.

Several studies have demonstrated that exercise intolerance, muscle weakness, fatigue and dyspnea are frequent problems in sarcoidosis..$^{* *, 6,9}$ Possible factors involved in the development of such physical impairments are sarcoid muscle involvement, corticosteroid-induced myopathy, decreased pulmonary function and inflammatory processes. Moreover, inactivation because of the disabling symptoms may cause physical deconditioning as well. ${ }^{6,12}$ Nevertheless, the primary cause of the physical impairments remains unclear.

Fatigue is the most frequently reported symptom in sarcoidosis (prevalence $50-80 \%)$, and is a clear hallmark of the disease. ${ }^{5^{* *}, 10,13}$ The cause of fatigue remains unknown and is most probably multifactorial. Reported cofactors are corticosteroid therapy, small fiber neuropathy, mood disorders like depression, cognitive failure ${ }^{14}$, stress and anxiety ${ }^{15}$, inflammatory activity and altered sleep patterns. ${ }^{16,17}$ Physical impairment has been suggested to be associated with fatigue. ${ }^{6,10}$ Another frequently reported symptom in sarcoidosis is dyspnea. Although pulmonary symptoms are the most common reason for treatment in sarcoidosis, the impact of dyspnea in relation to physical parameters has not been studied extensively. ${ }^{6,7,9,10}$

Physicians treating patients with sarcoidosis generally rely on conventional tests at rest, including lung function tests and imaging methods, and on indicators of disease activity during the follow-up and evaluation of a therapeutic response. ${ }^{3}$ However, several studies have reported that these tests are only weakly related to nonspecific health complaints, including muscle weakness and exercise intolerance. ${ }^{5^{* *}, 10,13,18^{*}}$ A physical assessment may be helpful in the management of exercise-related symptoms in sarcoidosis, especially in patients with unexplained disabling symptoms, to guide appropriate treatment. ${ }^{19^{*}}$

This review focuses on the prevalence, assessment and treatment of muscle weakness and exercise intolerance in sarcoidosis and the association between these and fatigue, dyspnea and QoL. 


\section{Selection of studies}

A computerized literature search was performed from 1997 up to 2013 using the search terms sarcoidosis and muscle strength, exercise capacity, fatigue, dyspnea and QoL. PubMed, Cinahl, Embase and the Cochrane Library were searched. Titles of interest were further reviewed by abstract. Reference lists of relevant studies were handsearched for additional studies.

Studies included in this review met the following criteria: their objectives were to describe muscle weakness and exercise intolerance in sarcoidosis; their study samples included sarcoidosis patients; the articles were full reports; the studies were published in English.

\section{Assessment of muscle weakness}

Although peripheral muscle weakness is a frequently reported symptom in sarcoidosis, the number of studies on this topic is limited..$^{5^{* *}-7,19^{*}, 20}$ Marcellis et al. . $^{{ }^{* *}}$ found peripheral muscle weakness in sarcoidosis patients $(n=124)$ compared with healthy controls. Handgrip force, elbow flexor muscle strength, isokinetic quadriceps and hamstrings peak torque were reduced in $12-27 \%$ of the population studied. Similarly, Spruit et $a l^{6}{ }^{6}$ found reduced handgrip force and quadriceps strength in fatigued sarcoidosis patients compared with healthy controls.

In line with previous studies, a retrospective study by Marcellis et al. ${ }^{1{ }^{*}}$ found reduced handgrip force in symptomatic sarcoidosis patients. Korenromp et al. ${ }^{20}$ also found reduced peripheral muscle strength in patients with sarcoidosis in clinical remission.

Involvement of the diaphragm and intercostal muscles may result in respiratory muscle failure, and inspiratory (maximal inspiratory mouth pressure (PImax)) and expiratory (maximal expiratory mouth pressure (PEmax)) muscle weakness are indeed rather common in sarcoidosis. ${ }^{7}$ Marcellis et al. ${ }^{5^{* *}, 19^{*}}$ showed that PImax, assessed by measuring maximal respiratory mouth pressures, was reduced in more than $40 \%$ of the sarcoidosis patients studied. Several studies showed reduced mean respiratory endurance time, PImax and PEmax values in patients with sarcoidosis compared with healthy controls ${ }^{6,8,21-23}$ and in fatigued compared with nonfatigued sarcoidosis patients in an acute phase of the disease and in clinical remission. ${ }^{10,20}$ In contrast to Baydur et al. ${ }^{22}$, Brancaleone et al. ${ }^{23}$ did not find a correlation between PImax and lung function test results. Reduction of inspiratory muscle endurance has also been reported, even in patients with normal lung function test results, which may indicate inspiratory muscle fatigue. ${ }^{8,23}$

So far, only cross-sectional study designs have been used to assess the prevalence of muscle weakness and exercise intolerance in sarcoidosis. As a result, no conclusions 
can be drawn with regard to disease progression. Recently, a 2-year follow-up study by Marcellis et al. ${ }^{24}$ showed that these impairments had a persistent character.

\section{Assessment of exercise intolerance}

Maximal exercise testing (cardiopulmonary exercise testing (CPET)) and submaximal exercise testing (6-minute walk test $(6 \mathrm{MWT})$ and 6-minute stepper test (6MST)) appeared to be useful in detecting exercise limitations and deciphering exercise-related symptoms. ${ }^{19^{*}, 25-27^{*}}$

CPET on a cycle ergometer or treadmill provides an overall measure of integrated exercise responses, which are not adequately reflected by measurements of individual organ system function. ${ }^{26}$ Several studies reported reduced maximal oxygen uptake $\left(\mathrm{VO}_{2} \mathrm{max}\right)$ in sarcoidosis patients, with a prevalence between $50 \%$ and $88 \%$. ${ }^{6,19^{*}, 23,28-30,31^{*}, 32}$ A reduction in $\mathrm{VO}_{2}$ max can be accounted for by muscle weakness, pulmonary and cardiovascular function impairments. Quadriceps peak torque was positively correlated with peak external work rates $(r=0.47)$ assessed by a maximal incremental cycle exercise test. In addition, sarcoidosis patients reported higher Borg scores for leg fatigue after the peak exercise test. ${ }^{6}$ A study by Miller et al. ${ }^{33}$ also found that $67 \%$ of the sarcoidosis patients terminated their peak exercise test because of 'leg complaints', which was considered an indication of skeletal muscle weakness.

CPET is useful in the early detection of parenchymal involvements, including pulmonary gas exchange impairments (PGEI), in sarcoidosis patients with normal lung function test results and chest radiographs without signs of parenchymal involvement. ${ }^{19 *}, 34,35$ Physical impairments such as PGEI, which are not yet recognizable at rest, often become apparent during exercise. In contrast to the resting situation, in which the apical regions of the lung contribute relatively little to ventilation and gas exchange, these regions normally contribute to meeting the increasing demands of ventilation and gas exchange during exercise. As sarcoidosis lesions favor the apical regions of the lung, CPET may be a sensitive tool to detect the presence and progression of parenchymal disease. ${ }^{28,35}$ An abnormally increased alveolar-arterial oxygen pressure gradient at maximal exercise $\left(\mathrm{P}(\mathrm{A}-\mathrm{a}) \mathrm{O}_{2} \mathrm{max}\right)$ in sarcoidosis may reflect impairment of the gas exchange area, barrier thickness, ventilation-perfusion-diffusion mismatching of the lung or a decline in mixed venous partial oxygen pressure..$^{19^{*}, 28,31^{*}, 36}$

Lopes et al. $^{31^{*}}$ demonstrated that the outcome measures of CPET, P(A-a) $\mathrm{O}_{2}$ max and breathing reserve are predictors of a decline in pulmonary function in patients with rather severe thoracic sarcoidosis.

The 6MWT is a submaximal exercise test which is a widely used alternative to CPET to assess exercise and functional capacity. The test is easy to use, inexpensive, reproducible and more patient-friendly. ${ }^{37,38}$ Marcellis et al..$^{5^{* *}}$ showed reduced 6 -minute walking distance (6MWD) in $45 \%$ of a sample of sarcoidosis patients. In line with this, Kabitz et al. ${ }^{21}$ also found reduced mean 6MWD in male patients and 
Spruit et al. ${ }^{6}$ found the same in fatigued sarcoidosis patients compared with healthy individuals. Alhamad ${ }^{39}$ and Baughman et al. ${ }^{40}$ found that $73 \%$ and $51 \%$ of their respective sarcoidosis samples had a $6 \mathrm{MWD}$ of less than $400 \mathrm{~m}$. In addition to the $6 \mathrm{MWD}$, the distance-saturation product (DSP), defined as the product of 6MWD and the lowest oxygen saturation during the 6MWT, as well as the Borg dyspnea score, may be useful indicators of functional status and $\mathrm{QoL}$ in patients with sarcoidosis. ${ }^{18^{*}, 41}$ Integration of the 6MWT in the work-up of sarcoidosis patients may also be useful for the diagnosis of sarcoidosis-associated pulmonary hypertension. ${ }^{38,40,41}$

Lack of space can prevent the performance of a 6MWT. A study of patients with various diffuse interstitial lung diseases (ilds), including sarcoidosis, found that the 6MST appeared a suitable alternative to the 6MWT. The number of steps achieved in the 6MST was strongly correlated with the 6MWD. ${ }^{27^{*}}$ The sensitivity and reproducibility of this test were demonstrated for several patient groups, including ild. ${ }^{42,43}$

\section{Relation of muscle weakness and exercise intolerance with fatigue, dyspnea and quality of life}

Muscle weakness and exercise intolerance have been suggested as underlying causes of fatigue. Several studies reported that 6MWD, respiratory muscle weakness (PImax and PEmax) and peripheral muscle weakness (handgrip force and quadriceps peak torque) are positively related to fatigue..$^{6,8,20,40}$ Using a symptom inventory questionnaire, Drent et $a .^{10}$ showed that fatigued sarcoidosis patients are more likely to report exercise intolerance, muscle pain and dyspnea than nonfatigued patients. They also showed a more pronounced reduction in fat-free mass, as an expression of muscle wasting and loss of muscle bulk, in fatigued compared with nonfatigued patients. This may explain the reduced respiratory muscle strength in fatigued patients. ${ }^{10}$ In contrast to previous studies, however, Marcellis et $a .^{5^{* *}}$ showed that fatigue was predicted neither by muscle strength nor by exercise capacity. Both fatigued and nonfatigued patients had to cope with these physical impairments. These studies underline the complexity of fatigue in sarcoidosis. Although the impact of muscle weakness and exercise intolerance on fatigue remains unclear, physicians should be aware that all patients might have these physical impairments.

Although the majority of patients with sarcoidosis have pulmonary manifestations, and although related symptoms are the most common reason for treatment, the impact of dyspnea on muscle strength and exercise capacity has not been studied extensively. ${ }^{3}$ The Borg dyspnea scale has been applied to assess perceived dyspnea during exercise and is often administered before and after an exercise test. ${ }^{44}$ Lung function test results did not correlate with the severity of perceived dyspnea measured with the British Medical Research Council scale. ${ }^{22}$ However, reduced respiratory mouth pressures, in particular measured as twitch mouth pressure, were related to levels of dyspnea. $^{21,22}$ Thus, reduced respiratory muscle strength may affect the degree of 
dyspnea. ${ }^{21}$ Patients with inspiratory muscle weakness require greater utilization and effort of the available muscles to overcome an external workload during breathing. As a consequence, these patients may experience exertional dyspnea, resulting in reduced 6 MWDs. ${ }^{8,21}$ This underlines that respiratory muscle testing may provide additional information when the cause of dyspnea is unclear. ${ }^{22}$ Several studies also showed that dyspnea may contribute to reduced 6MWD. ${ }^{39-41}$ Hinz et al. ${ }^{45^{*}}$ found that dyspnea was an important symptom predicting anxiety and depression. Moreover, other comorbidities such as physical deconditioning, sleep apnea and pulmonary hypertension may also explain dyspnea sensations. ${ }^{6,17,46}$

QoL and health status are reduced in patients with sarcoidosis compared with healthy controls, and this reduction involves various clinical parameters. ${ }^{6,47}$ General health status, measured by the King's Sarcoidosis Questionnaire, proved to be associated with forced vital capacity, sex, number of organs involved and immunosuppressant medication. ${ }^{48^{*}}$ Spruit et al. ${ }^{6}$ showed that quadriceps peak torque was related to health status (with correlation coefficients of 0.44-0.70) as measured with the Medical Outcomes Study 36-item Short-Form Health Survey (SF-36). Marcellis et al. $^{5^{* *}}$ also showed reduced $\mathrm{QoL}$ in patients with peripheral muscle weakness. Brancaleone et $a l^{23}$ and Wirnsberger et al. ${ }^{8}$ found a relation between respiratory muscle endurance and health status, although no such relationship was found between peripheral or inspiratory muscle strength and health status. The 6MWD proved to be associated with QoL and may serve as a potential target for interventions to improve QoL. ${ }^{18^{*}, 40}$ Unlike exercise intolerance, fatigue appeared to be the most important predictor of QoL. In terms of improving patients' QoL, it has therefore been recommended to focus not only on objective but also on subjective health parameters. ${ }^{9}$

\section{Treatment options}

Too few intervention studies have examined the contribution of pharmaceutical treatment to the reduction of fatigue and exercise intolerance in sarcoidosis patients. Successful treatment of active sarcoidosis frequently fails to eradicate the disabling symptoms of persistent fatigue. This persistent malady, sarcoidosis-associated fatigue and exercise limitations may require nontargeted generalized fatigue strategies. To date, the most frequently employed pharmacologic strategies for fatigue have focused on the use of neurostimulants, neurostimulant-like drugs and tumor necrosis factor- $\alpha$ inhibitors. ${ }^{16}$ Recently, Heij et al. ${ }^{49}$ demonstrated that ARA reduced symptoms related to small fiber neuropathy, including fatigue and pain. They also found a significant improvement from baseline in the pain and physical functioning dimensions of the SF-36 QoL questionnaire. In addition to pharmaceutical treatments, rehabilitation and cognitive behavioral therapy should also be considered as treatment strategies. ${ }^{16}$

The development of physical impairments may involve physical deconditioning. For instance, patients suffering from fatigue, muscle weakness, exercise intolerance, 
anxiety or depression may reduce their daily physical activities, resulting in general deconditioning. In turn, this may cause more perceived fatigue, exercise intolerance, muscle weakness and a further reduction in daily activities. This is called the negative vicious circle of physical deconditioning (Figure 2.1). ${ }^{6,12,50}$

Exercise training could be considered for those patients with persistent or progressive physical complaints. Huppmann et $a l^{51}$ demonstrated that pulmonary rehabilitation had a positive impact on the functional status of patients with ild, including their 6MWD, and on their QoL. Several studies have found exercise training to be effective in treating exercise intolerance, muscle weakness, fatigue and dyspnea and to improve QoL in chronic pulmonary diseases. ${ }^{52-55}$ Although physical impairments are frequently mentioned symptoms of sarcoidosis and exercise training could be beneficial in reducing symptoms, the effects of exercise training have never been studied in a representative sarcoidosis population.

Additionally, cognitive therapy can be offered to patients with physical deconditioning because of psychological problems, such as anxiety and depression, to treat coping problems or stress perception with psychosocial counseling. ${ }^{56}$ Patients may also benefit from other therapeutic options, such as dietary interventions and supplemental oxygen. ${ }^{12}$

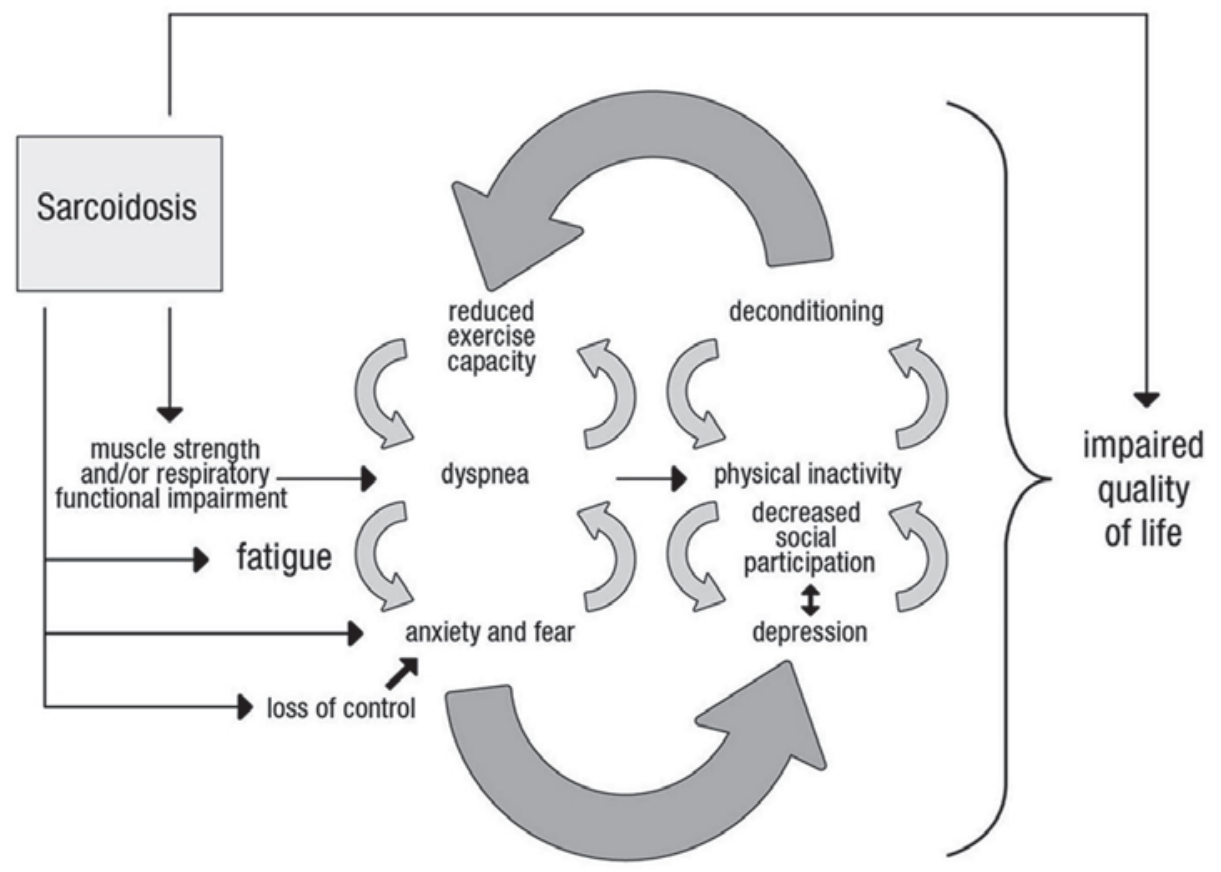

Figure 2.1 Negative vicious circle of physical deconditioning: disabling symptoms in sarcoidosis can reduce daily physical activities, resulting in general deconditioning and a reduced quality of life (adapted from ${ }^{50}$ ). 


\section{Clinical implications}

The nature of sarcoidosis underlines the need for a multidisciplinary approach. As the management of sarcoidosis has not been standardized, guidelines and recommendations are essential to further optimize the management of these patients. In clinical practice, routinely performed tests during the evaluation and follow-up of sarcoidosis include laboratory and pulmonary function testing at rest and chest radiographic imaging. However, these tests appear to be unreliable predictors of exercise capacity, functional capacity and health status. As this review has highlighted, muscle weakness and exercise intolerance appear to be a substantial problem in sarcoidosis, so we recommend the inclusion of tests to assess muscle strength and exercise capacity in the management of sarcoidosis (Table 2.1). In addition to a 6MWT and/or peripheral muscle weakness, respiratory muscle strength testing should be considered for patients with dyspnea complaints, by measuring maximal respiratory mouth pressures. Additionally, patients should complete the Fatigue Assessment Scale and a dyspnea scale. These tests are inexpensive and easy to perform. If the cause of exercise-related symptoms still remains unclear, a CPET with blood gas analyses could be useful.

Table 2.1 Recommended muscle strength and exercise tests to be included in the regular work-up of sarcoidosis patients.

\begin{tabular}{|c|c|c|}
\hline & Physical test & Optional \\
\hline \multicolumn{3}{|l|}{ Muscle strength } \\
\hline \multirow[t]{2}{*}{ Upper extremity } & $\begin{array}{l}\text { Musculus biceps (hand-held dynamometer) } \\
\text { or }\end{array}$ & \\
\hline & Handgrip strength (Jamar dynamometer) & \\
\hline Lower extremity & $\begin{array}{l}\text { Musculus quadriceps (hand-held } \\
\text { dynamometer) }\end{array}$ & Biodex \\
\hline Respiratory & $\begin{array}{l}\text { Respiratory mouth pressures } \\
\text { (pressure transducer) }\end{array}$ & \\
\hline \multicolumn{3}{|l|}{ Exercise capacity } \\
\hline Submaximal & 6-minute walk test & \\
\hline Maximal & & $\begin{array}{l}\text { Cardiopulmonary exercise testing with } \\
\text { blood gas analysis (for patients with } \\
\text { unexplained exercise-related symptoms) }\end{array}$ \\
\hline
\end{tabular}

\section{Conclusion}

Muscle weakness and exercise intolerance are frequent problems in sarcoidosis, with a persistent character. More research is needed to standardize the assessment of these symptoms. This review underlines the value of physical testing in the screening and follow-up of sarcoidosis patients, especially those patients with unexplained physical complaints. We therefore recommend including physical testing in the multidisciplinary management of sarcoidosis. Although the impact of muscle weakness and exercise 
intolerance on fatigue and dyspnea remains unclear, physicians should be aware that fatigued and dyspneic patients can also have these physical impairments, resulting in reduced QoL. Although exercise training has proved beneficial in several chronic diseases, research as to whether a multidisciplinary rehabilitation program would be of clinical benefit in the management of sarcoidosis patients is urgently needed. 


\section{References and recommended reading}

Papers of particular interest, published within the annual period of review, have been highlighted as:

* of special interest

** of outstanding interest

1. Morgenthau AS, lannuzzi MC. Recent advances in sarcoidosis. Chest 2011;139:174-182.

2. Iannuzzi MC, Fontana JR. Sarcoidosis: clinical presentation, immunopathogenesis, and therapeutics. JAMA 2011;305:391-399.

3. Baughman RP, Culver DA, Judson MA. A concise review of pulmonary sarcoidosis. Am J Respir Crit Care Med 2011;183:573-581.

4. Baughman RP, Lower EE, Gibson K. Pulmonary manifestations of sarcoidosis. Presse Med 2012;41: e289-302.

5.** Marcellis RG, Lenssen AF, Elfferich MD, De Vries J, Kassim S, Foerster K, Drent M. Exercise capacity, muscle strength and fatigue in sarcoidosis. Eur Respir J 2011;38:628-634.

This study showed that exercise intolerance, muscle weakness and fatigue are frequent problems in both fatigued and nonfatigued sarcoidosis patients. Fatigue was predicted neither by exercise capacity, nor by muscle strength.

6. Spruit MA, Thomeer MJ, Gosselink R, Troosters T, Kasran A, Debrock AJ, Demedts MG, Decramer M. Skeletal muscle weakness in patients with sarcoidosis and its relationship with exercise intolerance and reduced health status. Thorax 2005;60:32-38.

7. Wirnsberger RM, De Vries J, Wouters EF, Drent M. Clinical presentation of sarcoidosis in the Netherlands an epidemiological study. Neth J Med 1998;53:53-60.

8. Wirnsberger RM, Drent M, Hekelaar N, Breteler MH, Drent S, Wouters EF, Dekhuijzen PN. Relationship between respiratory muscle function and quality of life in sarcoidosis. Eur Respir J 1997;10:1450-1455.

9. Michielsen HJ, Peros-Golubicic T, Drent M, De Vries J. Relationship between symptoms and quality of life in a sarcoidosis population. Respiration 2007;74:401-405.

10. Drent M, Wirnsberger RM, De Vries J, Van Dieijen-Visser MP, Wouters EF, Schols AM. Association of fatigue with an acute phase response in sarcoidosis. Eur Respir J 1999;13:718-722.

11. Mostard RL, Voo S, Van Kroonenburgh MJ, Verschakelen JA, Wijnen PA, Nelemans PJ, Erckens RJ, Drent M. Inflammatory activity assessment by F18 FDG-PET/CT in persistent symptomatic sarcoidosis. Respir Med 2011;105:1917-1924.

12. Spruit MA, Wouters EFM, Gosselink R. Rehabilitation programmes in sarcoidosis: a multidisciplinary approach. Eur Respir J 2005;32:316-326.

13. Michielsen HJ, Drent M, Peros-Golubicic T, De Vries J. Fatigue is associated with quality of life in sarcoidosis patients. Chest 2006;130:989-994.

14. Elfferich MD, Nelemans PJ, Ponds RW, De Vries J, Wijnen PA, Drent M. Everyday cognitive failure in sarcoidosis: the prevalence and the effect of anti-TNF-alpha treatment. Respiration 2010;80:212-219.

15. De Vries J, Drent M. Relationship between perceived stress and sarcoidosis in a Dutch patient population. Sarcoidosis Vasc Diffuse Lung Dis 2004;21:57-63.

16. Drent M, Lower EE, De Vries J. Sarcoidosis-associated fatigue. Eur Respir J 2012;40:255-263.

17. Verbraecken J, Hoitsma E, Van der Grinten CP, Cobben NA, Wouters EF, Drent M. Sleep disturbances associated with periodic leg movements in chronic sarcoidosis. Sarcoidosis Vasc Diffuse Lung Dis 2004;21:137-146.

18.* Bourbonnais JM, Malaisamy S, Dalal BD, Samarakoon PC, Parikh SR, Samavati L. Distance saturation product predicts health-related quality of life among sarcoidosis patients. Health Qual Life Outcomes 2012;10:67.

This study demonstrated that the DSP, defined as the product of 6MWD and the lowest oxygen saturation during the 6MWT, and the Borg dyspnea score, may be more useful indicators of QoL in patients with sarcoidosis than the 6MWD alone. 
19.* Marcellis RG, Lenssen AF, De Vries GJ, Baughman RP, Van der Grinten CP, Verschakelen JA, De Vries J, Drent M. Is There an Added Value of Cardiopulmonary Exercise Testing in Sarcoidosis Patients? Lung 2013;191:43-52.

This study emphasized that normal lung function test results or chest radiographs showing no parenchymal involvement did not rule out abnormalities of pulmonary gas exchange at maximal exercise in symptomatic sarcoidosis patients.

20. Korenromp IH, Heijnen CJ, Vogels OJ, Van den Bosch JM, Grutters JC. Characterization of chronic fatigue in patients with sarcoidosis in clinical remission. Chest 2011;140:441-447.

21. Kabitz HJ, Lang F, Walterspacher S, Sorichter S, Muller-Quernheim J, Windisch W. Impact of impaired inspiratory muscle strength on dyspnea and walking capacity in sarcoidosis. Chest 2006;130:1496-1502.

22. Baydur A, Alsalek M, Louie SG, Sharma OP. Respiratory muscle strength, lung function, and dyspnea in patients with sarcoidosis. Chest 2001;120:102-108.

23. Brancaleone $\mathrm{P}$, Perez $\mathrm{T}$, Robin $\mathrm{S}$, Neviere R, Wallaert B. Clinical impact of inspiratory muscle impairment in sarcoidosis. Sarcoidosis Vasc Diffuse Lung Dis 2004;21:219-227.

24. Marcellis RGJ, Lenssen AF, Kleynen S, De Vries J, Drent M. Exercise capacity, muscle strength and fatigue in sarcoidosis: a follow-up study. Lung 2013;191:247-256.

25. Arena R, Sietsema KE. Cardiopulmonary exercise testing in the clinical evaluation of patients with heart and lung disease. Circulation 2011;123:668-680.

26. ATS/ACCP Statement on cardiopulmonary exercise testing. Joint Statement of the American Thoracic Society (ATS) and the American College of Chest Physicians (ACCP) was adopted by the ATS Board of Directors and by the ACCP Health Science Policy Committee, November 1, 2001. Am J Respir Crit Care Med 2003;167:211-277.

27.* Delourme J, Stervinou-Wemeau L, Salleron J, Grosbois JM, Wallaert B. Six-minute stepper test to assess effort intolerance in interstitial lung diseases. Sarcoidosis Vasc Diffuse Lung Dis 2012;29:107-112.

This study found that the 6MST appeared to be a suitable alternative to the 6MWT.

28. Lopes AJ, De Menezes SL, Dias CM, De Oliveira JF, Mainenti MR, Guimaraes FS. Comparison between cardiopulmonary exercise testing parameters and computed tomography findings in patients with thoracic sarcoidosis. Lung 2011;189:425-431.

29. Baydur A, Alavy B, Nawathe A, Liu S, Louie S, Sharma OP. Fatigue and plasma cytokine concentrations at rest and during exercise in patients with sarcoidosis. Clin Respir J 2011;5:156-164.

30. Wallaert B, Talleu C, Wemeau-Stervinou L, Duhamel A, Robin S, Aguilaniu B. Reduction of maximal oxygen uptake in sarcoidosis: relationship with disease severity. Respiration 2011;82:501-508.

31.* Lopes AJ, Menezes SL, Dias CM, Oliveira JF, Mainenti MR, Guimaraes FS. Cardiopulmonary exercise testing variables as predictors of long-term outcome in thoracic sarcoidosis. Braz J Med Biol Res 2012;45:256-263.

This study demonstrated that outcome measures of CPET are predictive of a decline in pulmonary function in patients with rather severe thoracic sarcoidosis.

32. Delobbe A, Perrault H, Maitre J, Robin S, Hossein-Foucher C, Wallaert B, Aguilaniu B. Impaired exercise response in sarcoid patients with normal pulmonary function. Sarcoidosis Vasc Diffuse Lung Dis 2002; 19:148-153.

33. Miller A, Brown LK, Sloane MF, Bhuptani A, Teirstein AS. Cardiorespiratory responses to incremental exercise in sarcoidosis patients with normal spirometry. Chest 1995;107:323-329.

34. Kollert F, Geck B, Suchy R, Jorres RA, Arzt M, Heidinger D, Hamer OW, Prasse A, Muller-Quernheim J, Pfeifer M, Budweiser S. The impact of gas exchange measurement during exercise in pulmonary sarcoidosis. Respir Med 2011;105:122-129.

35. Medinger AE, Khouri S, Rohatgi PK. Sarcoidosis: the value of exercise testing. Chest 2001;120:93-101.

36. Barros WG, Neder JA, Pereira CA, Nery LE. Clinical, radiographic and functional predictors of pulmonary gas exchange impairment at moderate exercise in patients with sarcoidosis. Respiration 2004;71: 367-373.

37. ATS committee on proficiency standards for clinical pulmonary function laboratories. ATS statement: guidelines for the six-minute walk test. Am J Respir Crit Care Med 2002;166:111-117.

38. Bourbonnais JM, Samavati L. Clinical predictors of pulmonary hypertension in sarcoidosis. Eur Respir J 2008;32:296-302.

39. Alhamad EH. The six-minute walk test in patients with pulmonary sarcoidosis. Ann Thorac Med 2009;4: 60-64. 
40. Baughman RP, Sparkman BK, Lower EE. Six-minute walk test and health status assessment in sarcoidosis. Chest 2007;132:207-213.

41. Alhamad EH, Shaik SA, Idrees MM, Alanezi MO, Isnani AC. Outcome measures of the 6 minute walk test: relationships with physiologic and computed tomography findings in patients with sarcoidosis. BMC Pulm Med 2010;10:42.

42. Borel B, Fabre C, Saison S, Bart F, Grosbois JM. An original field evaluation test for chronic obstructive pulmonary disease population: the six-minute stepper test. Clin Rehabil 2010;24:82-93.

43. Dal Corso S, Duarte SR, Neder JA, Malaguti C, De Fuccio MB, De Castro Pereira CA, Nery LE. A step test to assess exercise-related oxygen desaturation in interstitial lung disease. Eur Respir J 2007;29:330-336.

44. Baughman RP, Lower EE. Six-minute walk test in managing and monitoring sarcoidosis patients. Curr Opin Pulm Med 2007;13:439-444.

45.* Hinz A, Brähler E, Möde R, Wirtz H, Bosse-Henck A. Anxiety and depression in sarcoidosis: the influence of age, gender, affected organs, concomitant diseases and dyspnea. Sarcoidosis Vasc Diffuse Lung Dis 2012;29:139-146.

This study found that dyspnea is an important symptom in the prediction of anxiety and depression.

46. Corte TJ, Wells AU, Nicholson AG, Hansell DM, Wort SJ. Pulmonary hypertension in sarcoidosis: a review. Respirology 2011;16:69-77.

47. De Vries J, Drent M. Quality of life and health status in sarcoidosis: a review. Semin Respir Crit Care Med 2007;28:121-127.

48.* Patel AS, Siegert RJ, Creamer D, Larkin G, Maher TM, Renzoni EA, Wells AU, Higginson IJ, Birring SS. The development and validation of the King's Sarcoidosis Questionnaire for the assessment of health status. Thorax 2013;68:57-65.

This study presented the King's Sarcoidosis Questionnaire, a brief, valid and easy to administer health status measure in sarcoidosis.

49. Heij L, Niesters M, Swartjes M, Hoitsma E, Drent M, Dunne A, Grutters JC, Vogels O, Brines M, Cerami A, Dahan A. Safety and efficacy of ARA 290 in sarcoidosis patients with symptoms of small fiber neuropathy: a randomized, double-blind pilot study. Mol Med 2013;18:1430-1436.

50. Swigris JJ, Brown KK, Make BJ, Wamboldt FS. Pulmonary rehabilitation in idiopathic pulmonary fibrosis: a call for continued investigation. Respir Med 2008;102:1675-1680.

51. Huppmann P, Sczepanski B, Boensch M, Winterkamp S, Schonheit-Kenn U, Neurohr C, Behr J, Kenn K. Effects of in-patient pulmonary rehabilitation in patients with interstitial lung disease. Eur Respir J 2013; 42:444-453.

52. Kozu R, Senjyu H, Jenkins SC, Mukae H, Sakamoto N, Kohno S. Differences in response to pulmonary rehabilitation in idiopathic pulmonary fibrosis and chronic obstructive pulmonary disease. Respiration 2011;81:196-205.

53. Salhi B, Troosters T, Behaegel M, Joos G, Derom E. Effects of pulmonary rehabilitation in patients with restrictive lung diseases. Chest 2010;137:273-279.

54. Kozu R, Jenkins S, Senjyu H. Effect of disability level on response to pulmonary rehabilitation in patients with idiopathic pulmonary fibrosis. Respirology 2011;16:1196-1202.

55. Langer D, Hendriks E, Burtin C, Probst V, Van der Schans C, Paterson W, Verhoef-de Wijk M, Straver R, Klaassen M, Troosters T, Decramer M, Ninane V, Delguste P, Muris J, Gosselink R. A clinical practice guideline for physiotherapists treating patients with chronic obstructive pulmonary disease based on a systematic review of available evidence. Clin Rehabil 2009;23:445-462.

56. De Vries J, Wirnsberger RM. Fatigue, quality of life and health status in sarcoidosis. Eur Respir Mon 2005;32:92-104. 


\section{Chapter 3}

Exercise capacity, muscle strength and fatigue in sarcoidosis

RGJ Marcellis, AF Lenssen, MDP Elfferich, J De Vries, S Kassim, K Foerster, M Drent

Eur Respir J 2011;38:628-634 


\section{Abstract}

Aims

The aim of this case-control study was to investigate the prevalence of exercise intolerance, muscle weakness and fatigue in sarcoidosis patients. Additionally, we evaluated whether fatigue can be explained by exercise capacity, muscle strength or other clinical characteristics (lung function tests, radiographic stages, prednisone usage and inflammatory markers).

\section{Methods}

One hundred twenty-four sarcoidosis patients ( 80 males) referred to the Maastricht University Medical Centre (Maastricht, the Netherlands) were included (mean age $46.6 \pm 10.2 \mathrm{yrs}$ ). Patients performed a 6-minute walk test (6MWT) and handgrip force (HGF), elbow flexor muscle strength (EFMS), quadriceps peak torque (QPT) and hamstring peak torque (HPT) tests. Maximal inspiratory pressure (PImax) was recorded. All patients completed the Fatigue Assessment Scale (FAS) questionnaire.

\section{Results}

The 6MWT was reduced in $45 \%$ of the population, while HGF, EFMS, QPT and HPT muscle strength were reduced in $15 \%, 12 \%, 27 \%$ and $18 \%$, respectively. PImax was reduced in $43 \%$ of the population. The majority of the patients $(81 \%)$ reported fatigue (FAS $\geq 22)$. Patients with reduced peripheral muscle strength of the upper and/or lower extremities were more fatigued and demonstrated impaired lung functions, fat-free mass, PImax, 6MWT and quality of life. Fatigue was neither predicted by exercise capacity, nor by muscle strength.

\section{Conclusion}

Besides fatigue, exercise intolerance and muscle weakness are frequent problems in sarcoidosis. We therefore recommend physical tests in the multidisciplinary management of sarcoidosis patients, even in nonfatigued patients. 


\section{Introduction}

Sarcoidosis is a multisystem disorder of unknown origin, which is characterised by noncaseating epithelioid cell granulomas. The clinical course of sarcoidosis is highly variable, and virtually every organ can be involved. The lungs are affected in $>90 \%$ of sarcoidosis patients, but muscles are also frequently involved. Patients often present with nonspecific symptoms, such as general weakness, arthralgia, reduced exercise capacity and fatigue. ${ }^{1}$

Despite the fact that fatigue is a common disabling problem (with a reported prevalence of $30-90 \%$ ) and a clear hallmark of sarcoidosis patients that affects quality of life (QoL), it still remains underestimated and poorly understood. ${ }^{2}$ The aetiology of fatigue in sarcoidosis is still unclear, and is most probably multifactoral. Moreover, fatigue is difficult to objectify. Possible factors related to fatigue are general inflammation, sleeping disorders, depression and small-fibre neuropathy. ${ }^{3}$ However, fatigue does not correlate with lung function test results. ${ }^{2,4}$ Fatigue may be explained by peripheral muscle weakness and exercise intolerance, and both may be caused by multiple factors, such as sarcoidosis located in the skeletal muscle, decreased pulmonary function, negative vicious circle of physical deconditioning and corticosteroid-induced myopathy. ${ }^{5}$

The influence of exercise capacity and muscle strength on fatigue has not been studied extensively in sarcoidosis, although reduced exercise capacity and general weakness are frequently reported symptoms. Patients with fatigue complaints are more likely to report problems of exercise intolerance compared with nonfatigued patients. ${ }^{4}$ The 6 -minute walk test (6MWT) is widely used to assess exercise capacity. ${ }^{6}$ Previous research found that the 6-minute walking distance (6MWD) was reduced in sarcoidosis patients compared with healthy subjects. ${ }^{7,8}$ Impairment of inspiratory muscle strength has been suggested as an important factor reducing 6MWD. ${ }^{9}$ Alhamad $^{7}$ and Baughman et al. $^{8}$ found that $73 \%$ and $51 \%$ of their respective sarcoidosis populations had a 6MWD of $<400 \mathrm{~m}$.

In a study by Miller et al. ${ }^{10}, 67 \%$ of the sarcoidosis patients terminated their peak exercise test because of "leg complaints", which was considered an indication of skeletal muscle weakness. Similarly, Spruit et al. ${ }^{5}$ reported diminished peripheral muscle strength in patients with sarcoidosis suffering from fatigue, and reduced peripheral muscle strength correlated with exercise intolerance and fatigue. In line with this, Wirnsberger et al. ${ }^{11}$ found reduced respiratory muscle strength and endurance time. However, the study populations were rather small or only included sarcoidosis patients with specific health complaints.

The primary aim of our study was to assess the prevalence of exercise intolerance, peripheral muscle weakness and fatigue in sarcoidosis patients. Additionally, the predictive value of exercise capacity, muscle strength and other clinical characteristics, including lung function test results, radiographic stages, prednisone usage and inflammatory markers, were studied. 


\section{Methods}

\section{Subjects}

Between November 2008 and September 2009, symptomatic sarcoidosis patients referred to the interstitial lung disease care team of the Department of Respiratory Medicine at Maastricht University Medical Centre (MUMC; Maastricht, the Netherlands) were included in this study. Patients were diagnosed based on consistent clinical features and bronchoalveolar lavage fluid analysis, and/or biopsy-proven noncaseating epithelioid cell granulomas, according to the World Association of Sarcoidosis and Other Granulomatous Disorders (WASOG) guidelines. ${ }^{1}$ Clinical data were obtained from medical records. A healthy control group matched for age and sex (one control for two patients) was recruited from hospital employees and the surrounding community. These healthy subjects did not use any medication. The data were used as reference for exercise capacity and peripheral muscle strength. Written informed consent was obtained from all subjects. This case-control study was approved by the local Medical Ethics Committee of the MUMC.

\section{Clinical data}

At inclusion, forced vital capacity (FVC) and forced expiratory volume in one second $\left(\mathrm{FEV}_{1}\right)$ were measured with a pneumotachograph (Masterlab; Jaeger, Würzburg, Germany). The diffusing capacity of the lung for carbon monoxide (DLCO) was measured by the single-breath method (Masterlab; Jaeger). Values were expressed as percentage of predicted value. ${ }^{12}$

Chest radiographs were graded according to the radiographic staging proposed by DeRemee (0 to III), adding stage IV, for patients showing signs of pulmonary fibrosis, loss of lung volume, hilar retraction and bullae. ${ }^{1}$

Body composition was measured by single-frequency bioelectrical impedance analysis (RJL Systems Inc., Clinton Township, MI, USA) in the supine position on the right side. Fat-free mass (FFM) was calculated from height $\left(\mathrm{m}^{2}\right) /$ resistance and body weight using the Lukaski formula. In order to assess the degree of functional tissue depletion, FFM was adjusted for body size by calculating the FFM-index: FFM $(\mathrm{kg}) /$ height $\left(\mathrm{m}^{2}\right){ }^{4}$

The C-reactive protein (CRP) concentration was measured by a turbidimetric method on the SYNCHRON LX (Beckman Coulter Inc., Fullerton, CA, USA). The normal value for CRP is $<10 \mathrm{mg} / \mathrm{l}$. The serum levels of soluble interleukin-2 receptor (sIL-2R) were analysed using commercially available Diaclone ELISA kits (Sanquin, Amsterdam, the Netherlands). Normal values are between $240-3,154 \mathrm{pg} / \mathrm{ml}$. 


\section{Muscle strength and exercise capacity}

The 6MWT was used to assess exercise capacity, and was performed according to the American Thoracic Society guideline. ${ }^{13}$

The Biodex System 3 Pro dynamometer (Biodex Medical Systems, Shirley, NY, USA) was used to measure isokinetic peak torques (in $\mathrm{Nm}$ ) of the hamstrings and quadriceps of the dominant leg, with a velocity of $180^{\circ}$ per second, as described previously. ${ }^{14}$ The Biodex is a reliable and valid isokinetic dynamometer. ${ }^{15}$

The maximal isometric grip strength of the dominant hand (Ibs) was measured with the Jamar dynamometer (Fabrication Enterprises Inc., Irvington, NY, USA), which is also a valid and reliable instrument. ${ }^{16}$

Maximal isometric strength of the elbow flexors was measured with the microFET (Biometrics, Almere, the Netherlands), an electronic, hand-held dynamometer, with the subject sitting in a chair. The "break" method was used to measure the maximal peak force of the dominant arm in Newtons (N). ${ }^{17}$ This hand-held dynamometer is a reliable measurement. $^{17}$

Maximal inspiratory pressure (PImax) was assessed by measuring maximal respiratory mouth pressures using the method of Black and Hyatt. ${ }^{18}$ Maximal inspiratory mouth pressure was measured at residual volume with a pressure transducer (model MP 45-30; Validyne Engineering Corp., Northridge, CA, USA). ${ }^{4}$ Data from the study by Harik-Khan et al. ${ }^{19}$ ( $n=267$ healthy subjects) were used as reference values.

\section{Questionnaires}

Fatigue was measured with the 10-item Fatigue Assessment Scale (FAS), which indicates both physical and psychological fatigue. Each item has a five-point rating scale and FAS scores range from 10 to 50 . FAS scores $<22$ indicate nonfatigued persons, scores of 22-34 indicate fatigued persons and scores of $\geq 35$ indicate extremely fatigued persons. ${ }^{20}$ The psychometric properties of the FAS are also good in sarcoidosis. ${ }^{20}$

The World Health Organization Quality of Life assessment instrument-BREF (WHOQOL-BREF) is a generic, cross-culturally developed comprehensive measure of QoL. It consists of 24 questions within four domains (physical health, psychological health, social relationships and environment) and two questions that compose the facet of overall QoL and general health. The psychometric properties of the WHOQOLBREF appeared to be good. ${ }^{21,22}$

\section{Statistical analysis}

Demographic and clinical data are expressed as mean \pm standard deviation (SD) and, if appropriate, in absolute numbers. To detect statistically significant differences between the patient and control groups, continuous data were analysed with independentsample unpaired t-tests and nominal data were tested using Chi-squared tests. 
Physical test results below the mean results of the control group minus 2SD (95\% confidence interval) were assumed to indicate exercise intolerance or muscle strength impairment. The cut-off value for PImax, FVC, FEV 1 and DLCO was $<80 \%$ of the predicted value. ${ }^{12,19}$ Frequency distributions were used to determine the prevalence of exercise intolerance, reduced muscle strength and fatigue.

Associations between exercise capacity, muscle strength, fatigue and other clinical characteristics were calculated using Pearson's correlations. Differences in FAS scores in relation to sex, prednisone use and radiographic stages were explored by means of t-tests and one-way ANOVA. Variables with a significant association with fatigue were used for multiple regression analysis. A backward multiple regression analysis was used to develop a model to predict fatigue. A p-value $<0.05$ was considered to be statistically significant.

Differences between sarcoidosis patients with (group 4: combination of patients in group 2 (reduced muscle strength of arms) and group 3 (reduced muscle strength of legs)) and without (group 1: normal muscle strength of both arms and legs) peripheral muscle strength impairment with regard to physical and clinical characteristics were examined using independent-sample t-tests. Differences in nominal data were tested using Chi-squared tests. All analyses were performed using SPSS 15.0 for Windows (SPSS Inc.,Chicago, IL, USA).

\section{Results}

\section{Patient and healthy control characteristics}

During the study period, 145 sarcoidosis patients were referred to the outpatient clinic of the MUMC. Twenty one of the patients were not able to participate because they visited the hospital in a week when the maximum inclusion capacity of five subjects had

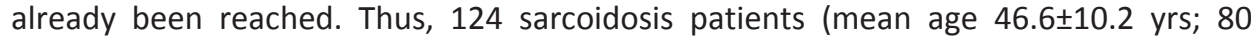
males and 44 females) were included. Clinical data are summarised in Table 3.1. FAS scores $>21$ points, indicating fatigue complaints, were reported in 101 (81\%) patients, and $26 \%$ of these fatigued patients reported extreme fatigue (FAS $\geq 35$ ). The mean body mass index (BMI) was $28.0 \pm 4.7 \mathrm{~kg} / \mathrm{m}^{2}$, which indicated some excess weight (BMI between $25-30 \mathrm{~kg} / \mathrm{m}^{2}$ indicates overweight). The pulmonary function tests showed that $\mathrm{FEV}_{1}$ and DLCO, as a percentage of predicted values, were slightly reduced in this population. The clinical data of the healthy control group are also presented in Table 3.1. Sarcoidosis patients were significantly more fatigued compared with the healthy controls $(p<0.001)$. 
Table 3.1 Summary of demographic and clinical characteristics of the sarcoidosis patients and the healthy controls studied.

\begin{tabular}{|c|c|c|}
\hline & Sarcoidosis patients & Healthy controls \\
\hline \multicolumn{3}{|l|}{ Demographics } \\
\hline Subjects & 124 & 62 \\
\hline Females/males & $44 / 80$ & $22 / 40$ \\
\hline Age (yrs) & $46.6 \pm 10.2$ & $46.4 \pm 9.9$ \\
\hline Time since diagnosis (yrs) & $6.1 \pm 6.2$ & NA \\
\hline $\mathrm{BMI}\left(\mathrm{kg} / \mathrm{m}^{2}\right)$ & $28.0 \pm 4.7^{c}$ & $24.7 \pm 1.8$ \\
\hline Nonsmoker/smoker/stopped <1 yr & $106 / 11 / 7$ & $56 / 6 / 0$ \\
\hline Arthralgia (yes/no) & $93 / 29^{c}$ & $0 / 62$ \\
\hline \multicolumn{3}{|l|}{ Medication } \\
\hline Prednisone use (yes/no) & $48 / 76^{c}$ & $0 / 62$ \\
\hline Prednisone dosage (mg) & $13.2 \pm 7.4$ & 0 \\
\hline Methotrexate use (yes/no) & $39 / 85^{c}$ & $0 / 62$ \\
\hline Methotrexate dosage (mg) & $10.8 \pm 3.1$ & 0 \\
\hline \multicolumn{3}{|l|}{ Lung function tests } \\
\hline DLCO (\% pred) & $75.7 \pm 17.6$ & NA \\
\hline FVC (\% pred) & $98.3 \pm 20.8$ & NA \\
\hline $\mathrm{FEV}_{1}(\%$ pred $)$ & $84.2 \pm 22.6$ & NA \\
\hline \multicolumn{3}{|l|}{ Chest radiographic stages } \\
\hline 0/I/II/III/IV & 28 / 18 / 32 / 14 / 32 & NA \\
\hline \multicolumn{3}{|l|}{ Inflammatory markers } \\
\hline $\mathrm{CRP}^{\mathrm{a}}$ & $8.6 \pm 15.4$ & NA \\
\hline SIL-2R $R^{b}$ & $3,282 \pm 2,331$ & NA \\
\hline \multicolumn{3}{|l|}{ Fatigue measure } \\
\hline FAS score & $28.3 \pm 7.7^{c}$ & $15.6 \pm 4.0$ \\
\hline \multicolumn{3}{|l|}{ WHOQOL-BREF } \\
\hline Facet overall QoL & $5.9 \pm 1.6^{c}$ & $8.7 \pm 1.0$ \\
\hline Physical health domain & $12.3 \pm 2.8^{c}$ & $17.9 \pm 1.5$ \\
\hline
\end{tabular}

Data are expressed as absolute numbers $(n)$ or mean \pm standard deviation (SD). BMI: body mass index; DLCO: diffusing capacity of the lung for carbon monoxide; \% pred: \% predicted; FVC: forced vital capacity; FEV ${ }_{1}$ : forced expiratory volume in one second; CRP: C-reactive protein; sIL-2R: soluble interleukin-2 receptor; FAS: Fatigue Assessment Scale; WHOQOL-BREF: World Health Organization Quality of Life assessment instrumentBREF; QoL: quality of life; NA: not applicable. ${ }^{a}$ normal range $<10 \mathrm{mg} / \mathrm{l} ;{ }^{b}$ normal range $240-3,154 \mathrm{pg} / \mathrm{ml}$; ${ }^{\mathrm{C}} \mathrm{p}<0.001$.

\section{Exercise capacity}

Sarcoidosis patients demonstrated a significantly shorter 6MWD compared with healthy controls (Table 3.2). The sarcoidosis population showed a mean reduction in exercise capacity of $20 \%$ (Table 3.2 ), $>45 \%$ of the sarcoidosis patients demonstrated a reduction in exercise capacity.

Exercise capacity was reduced in $49 \%$ of the fatigued and in $30 \%$ of the nonfatigued patients $(p=0.116)$. Patients with peripheral muscle strength impairment demonstrated a reduced $6 \mathrm{MWD}$ compared with patients without reduced peripheral muscle strength $(p<0.001)$ (Table 3.3). 
Table 3.2 Summary of the physical characteristics of the sarcoidosis patients and healthy controls studied.

\begin{tabular}{|c|c|c|c|c|c|c|}
\hline & \multicolumn{2}{|c|}{ Total } & \multicolumn{2}{|c|}{ Males } & \multicolumn{2}{|c|}{ Females } \\
\hline & Sarcoidosis & Healthy & Sarcoidosis & Healthy & Sarcoidosis & Healthy \\
\hline \multicolumn{7}{|l|}{ Exercise capacity } \\
\hline 6MWD (m) & $576 \pm 124^{c}$ & $723 \pm 80$ & $607 \pm 118^{c}$ & $747 \pm 74$ & $518 \pm 115^{c}$ & $679 \pm 73$ \\
\hline 6MWD (\% pred) & $79.5 \pm 16.3$ & & $81.3 \pm 15.8$ & & $76.3 \pm 16.9$ & \\
\hline Reduced $6 \mathrm{MWD}^{\mathrm{a}}$ & 45.2 & 3.2 & 41.3 & 2.5 & 52.3 & 4.5 \\
\hline \multicolumn{7}{|l|}{ Muscle force } \\
\hline HGF (lbs) & $94.4 \pm 33.3$ & $97.9 \pm 27.8$ & $110.7 \pm 25.9$ & $115.5 \pm 15.1$ & $64.1 \pm 22.4$ & $65.9 \pm 12.5$ \\
\hline HGF (\% pred) & $96.3 \pm 27.0$ & & $95.8 \pm 22.5$ & & $97.1 \pm 34.0$ & \\
\hline Reduced $\mathrm{HGF}^{\mathrm{a}}$ & 15.4 & 3.2 & 16.3 & 2.5 & 14.0 & 4.5 \\
\hline EFMS (N) & $219.5 \pm 72.2^{b}$ & $242.8 \pm 72.4$ & $255.8 \pm 58.8^{b}$ & $287.0 \pm 47.9$ & $150.4 \pm 35.8$ & $162.6 \pm 22.9$ \\
\hline EFMS (\% pred) & $90.3 \pm 21.0$ & & $89.1 \pm 20.5$ & & $92.5 \pm 22.0$ & \\
\hline Reduced EFMS ${ }^{a}$ & 12.3 & 3.2 & 10.0 & 2.5 & 16.7 & 4.5 \\
\hline QPT (Nm) & $80.9 \pm 36.1^{c}$ & $101.3 \pm 30.6$ & $95.6 \pm 34.0^{c}$ & $118.4 \pm 23.0$ & $53.9 \pm 21.1^{c}$ & $70.2 \pm 13.3$ \\
\hline QPT (\% pred) & $79.3 \pm 29.1$ & & $80.8 \pm 28.7$ & & $76.7 \pm 30.0$ & \\
\hline Reduced QPT ${ }^{a}$ & 27.0 & 6.5 & 22.8 & 5.0 & 34.9 & 9.1 \\
\hline $\mathrm{HPT}(\mathrm{Nm})$ & $61.5 \pm 26.6^{c}$ & $75.3 \pm 23.0$ & $71.4 \pm 26.0^{c}$ & $86.3 \pm 18.7$ & $43.2 \pm 16.2^{b}$ & $55.3 \pm 15.3$ \\
\hline HPT (\% pred) & $81.3 \pm 29.7$ & & $82.9 \pm 30.1$ & & $78.3 \pm 29.1$ & \\
\hline Reduced $\mathrm{HPT}^{\mathrm{a}}$ & 18.0 & 0 & 20.3 & 0 & 14.0 & 0 \\
\hline PImax $\left(\mathrm{cmH}_{2} \mathrm{O}\right)$ & $-82.5 \pm 29.5$ & NA & $-90.7 \pm 30.7$ & NA & $-67.7 \pm 20.1$ & NA \\
\hline PImax (\% pred) & $82.5 \pm 28.5$ & & $80.2 \pm 25.9$ & & $86.6 \pm 32.8$ & \\
\hline Reduced PImax & 43.1 & & 44.3 & & 41.0 & \\
\hline
\end{tabular}

Data are expressed as mean \pm standard deviation (SD) or percentages (\%). 6MWD: 6-minute walking distance; $\%$ pred: \% predicted; HGF: handgrip force; EFMS: elbow flexor muscle strength; QPT: quadriceps peak torque; HPT: hamstrings peak torque; PImax: maximal inspiratory pressure; NA: not applicable. ${ }^{a}$ : percentage of subjects below the mean results minus 2 SD of the control group; ${ }^{b} p<0.05 ;{ }^{c} p<0.001$.

\section{Muscle strength}

Peripheral muscle strength, i.e. elbow flexor muscle strength, and quadriceps and hamstrings peak torque, was significantly lower in the sarcoidosis patients compared to the control subjects (Table 3.2). No differences were found in handgrip force between both groups.

Handgrip force, elbow flexor muscle strength, quadriceps peak torque, hamstrings peak torque and PImax were reduced in 15\%, 12\%, 27\%, 18\% and $43 \%$ of the population, respectively (Table 3.2 ).

A substantial proportion of the fatigued and nonfatigued patients showed a reduction in handgrip force ( $18 \%$ and $4 \%$, respectively; $p=0.102)$, elbow flexor muscle strength ( $12 \%$ and $13 \%$, respectively; $p=0.903)$, quadriceps peak torque $(27 \%$ and $26 \%$, respectively; $p=0.908)$, hamstrings peak torque $(19 \%$ and $13 \%$, respectively; $p=0.490)$ and PImax (47\% and $26 \%$, respectively; $p=0.083$ ).

Patients with reduced peripheral muscle strength of the upper limbs (group 2: $n=24$ ), lower limbs (group 3: $n=37$ ) or both (group 4: $n=45$ ) differed from patients without peripheral muscle strength impairment (group 1: $n=79$ ) with regard to fatigue (Table 3.3). The overall QoL and the QoL domain physical health, as well as the lung function test results, FFM, PImax and 6MWD, were found to be impaired in the 
subgroup with reduced peripheral muscle strength compared to patients without muscle strength impairment (Table 3.3). Neither peripheral muscle strength nor PImax was found to be related to prednisone dose.

Table 3.3 Summary of clinical characteristics of the sarcoidosis patients studied stratified by upper- and lower-extremity muscle strength.

\begin{tabular}{|c|c|c|c|c|c|}
\hline & $\begin{array}{c}\text { Group 1: } \\
\text { normal muscle } \\
\text { strength }\end{array}$ & $\begin{array}{l}\text { Group 2: } \\
\text { reduced HGF } \\
\text { and/or EFMS }\end{array}$ & $\begin{array}{c}\text { Group 3: } \\
\text { reduced QPT } \\
\text { and/or HPT }\end{array}$ & $\begin{array}{c}\text { Group 4: } \\
\text { reduced muscle } \\
\text { strength of } \\
\text { arms and/or } \\
\text { legs }\end{array}$ & $p$-value ${ }^{a}$ \\
\hline \multicolumn{6}{|l|}{ Demographics } \\
\hline Subjects & 79 & 24 & 37 & 45 & \\
\hline Prednisone use (yes/no) & $29 / 50$ & $11 / 13$ & $16 / 21$ & $19 / 26$ & 0.544 \\
\hline Prednisone dosage (mg) & $14.2 \pm 7.8$ & $12.0 \pm 5.6$ & $12.5 \pm 6.9$ & $11.7 \pm 6.7$ & 0.267 \\
\hline Methotrexate use (yes/no) & $25 / 54$ & $7 / 17$ & $12 / 25$ & 14 / 31 & 0.951 \\
\hline Methotrexate dosage (mg) & $11.6 \pm 2.2$ & $10.0 \pm 5.0$ & $9.0 \pm 4.1$ & $9.3 \pm 4.1$ & 0.065 \\
\hline \multicolumn{6}{|l|}{ Lung function tests } \\
\hline DLCO (\% pred) & $79.6 \pm 17.2$ & $68.8 \pm 16.6$ & $66.9 \pm 15.9$ & $68.7 \pm 16.3$ & 0.001 \\
\hline FVC (\% pred) & $101.5 \pm 21.6$ & $89.0 \pm 17.4$ & $91.7 \pm 18.8$ & $92.7 \pm 18.3$ & 0.023 \\
\hline $\mathrm{FEV}_{1}(\%$ pred $)$ & $87.4 \pm 21.7$ & $78.0 \pm 23.6$ & $76.2 \pm 23.6$ & $78.6 \pm 23.2$ & 0.037 \\
\hline \multicolumn{6}{|l|}{ Inspiratory muscle strength } \\
\hline PImax (\% pred) & $88.3 \pm 25.7$ & $67.4 \pm 32.0$ & $78.6 \pm 30.7$ & $72.1 \pm 30.7$ & 0.004 \\
\hline \multicolumn{6}{|l|}{ Exercise capacity } \\
\hline 6MWD (\% pred) $)^{\mathrm{b}}$ & $86.7 \pm 12.5$ & $63.3 \pm 16.3$ & $68.3 \pm 14.2$ & $67.1 \pm 14.6$ & $<0.001$ \\
\hline Chest radiographic stage & $2.1 \pm 1.4$ & $1.9 \pm 1.7$ & $2.1 \pm 1.7$ & $2.0 \pm 1.7$ & 0.864 \\
\hline \multicolumn{6}{|l|}{ Inflammatory markers } \\
\hline $\mathrm{CRP}^{\mathrm{C}}$ & $7.2 \pm 14.1$ & $8.6 \pm 12.7$ & $11.1 \pm 17.4$ & $11.0 \pm 17.3$ & 0.193 \\
\hline SIL-2R $R^{d}$ & $3,452 \pm 2,472$ & $2,897 \pm 2,028$ & $3,159 \pm 2,121$ & $2,958 \pm 2,028$ & 0.281 \\
\hline \multicolumn{6}{|l|}{ Body composition } \\
\hline $\mathrm{BMI}\left(\mathrm{kg} / \mathrm{m}^{2}\right)$ & $28.2 \pm 4.4$ & $28.3 \pm 4.9$ & $27.7 \pm 5.2$ & $28.0 \pm 5.2$ & 0.783 \\
\hline FFM (kg) & $57.1 \pm 10.3$ & $54.1 \pm 10.7$ & $50.5 \pm 9.8$ & $52.2 \pm 10.0$ & 0.016 \\
\hline FFM index $\left(\mathrm{kg} / \mathrm{m}^{2}\right)$ & $18.2 \pm 2.4$ & $17.9 \pm 2.7$ & $17.0 \pm 2.9$ & $17.4 \pm 2.8$ & 0.095 \\
\hline \multicolumn{6}{|l|}{ Fatigue } \\
\hline FAS score & $27.1 \pm 7.4$ & $32.0 \pm 8.2$ & $30.3 \pm 8.3$ & $30.4 \pm 7.8$ & 0.023 \\
\hline \multicolumn{6}{|l|}{ WHOQOL-BREF } \\
\hline Facet overall QoL & $6.2 \pm 1.4$ & $5.2 \pm 1.6$ & $5.2 \pm 1.8$ & $5.4 \pm 1.7$ & 0.004 \\
\hline Physical health domain & $13.1 \pm 2.7$ & $10.7 \pm 2.4$ & $11.0 \pm 2.8$ & $11.0 \pm 2.7$ & $<0.001$ \\
\hline
\end{tabular}

Data are expressed as absolute numbers $(n)$ or mean \pm standard deviation (SD), unless otherwise stated. HGF: handgrip force; EFMS: elbow flexor muscle strength; QPT: quadriceps peak torque; HPT: hamstrings peak torque; DLCO: diffusing capacity of the lung for carbon monoxide; \% pred: \% predicted; FVC: forced vital capacity; $\mathrm{FEV}_{1}$ : forced expiratory volume in one second; PImax: maximal inspiratory pressure; 6MWD: 6minute walking distance; CRP: C-reactive protein; sIL-2R: soluble interleukin-2 receptor; BMI: body mass index; FFM: fat-free mass; FAS: Fatigue Assessment Scale; WHOQOL-BREF: World Health Organization Quality of Life assessment instrument-BREF; QoL: quality of life. ${ }^{a}$ group 1 compared to group $4 ;^{b} \%$ of mean results of the control group; ${ }^{\mathrm{c}}$ normal range $<10 \mathrm{mg} / \mathrm{l} ;{ }^{\mathrm{d}}$ normal range $240-3,154 \mathrm{pg} / \mathrm{ml}$.

\section{Relationship between fatigue and clinical parameters}

Fatigue showed weak correlations with exercise capacity and muscle strength parameters in male patients but not in female patients (Table 3.4). In the female 
patients only, BMI ( $r=0.329, p=0.029)$ showed a significant positive correlation with fatigue. In both sexes, fatigue was unrelated to demographic characteristics (age, FFM and time since diagnosis), lung function test results (FVC\% pred and $\mathrm{FEV}_{1} \%$ pred) and levels of inflammatory markers (CRP and sIL-2R). FAS scores did not differ regarding sex $(t=0.426, p=0.671)$, oral prednisone use $(t=-1.011, p=0.314)$ or radiographic stages (F-score 0.507 (df regression 4, df residual 119), $p=0.730$ ).

In multiple regression analyses, only hamstrings peak torque was a significant predictor of fatigue in male patients, predicting $14.3 \%$ of the FAS score $(p=0.001$; $ß=0.114)$.

Table 3.4 Correlations between Fatigue Assessment Scale (FAS) scores and the absolute values of the physical characteristics of the 80 male and 44 female sarcoidosis patients studied.

$\begin{array}{lllllll}\text { FAS scores } & \text { 6MWD } & \text { HGF } & \text { EFMS } & \text { QPT } & \text { HPT } & \text { PImax } \\ \text { Males } & -0.25(0.024) & -0.25(0.023) & -0.29(0.010) & -0.17(0.131) & -0.36(0.001) & 0.24(0.047) \\ \text { Females } & -0.12(0.425) & -0.21(0.171) & -0.30(0.055) & -0.04(0.824) & -0.043(0.783) & 0.051(0.756)\end{array}$

Data are expressed as Pearson correlation (p-value). 6MWD: 6-minute walking distance; HGF: handgrip force; EFMS: elbow flexor muscle strength; QPT: quadriceps peak torque; HPT: hamstrings peak torque; PImax: maximal inspiratory pressure.

\section{Discussion}

The main finding of this study is that a substantial number of patients with symptomatic sarcoidosis display exercise intolerance (45\%), as well as muscle weakness (prevalence rates of $12-27 \%$ ) and fatigue (81\%). Exercise intolerance and reduced muscle strength occurred in both fatigued and nonfatigued sarcoidosis patients. Patients with impaired peripheral muscle strength were more fatigued and demonstrated impaired lung function test results, FFM, PImax, 6MWD and QoL compared with patients without reduced peripheral muscle strength. Fatigue was neither predicted by exercise capacity, nor by muscle strength. Hamstrings peak torque accounted for only $14 \%$ of the variance of the FAS score in male patients.

Exercise intolerance was present in a substantial number of the studied sarcoidosis patients, especially in those with reduced peripheral muscle strength. In line with this, Kabitz et al. ${ }^{9}$ also found reduced 6MWD in male sarcoidosis patients compared to healthy males. Similarly, Spruit et al. $^{5}$ found reduced 6MWD in sarcoidosis patients complaining of fatigue compared with healthy subjects, and Alhamad ${ }^{7}$ and Baughman et $a l^{8}{ }^{8}$ reported even lower 6MWD. The differences in 6MWD between studies were not explained by clinical characteristics. A factor that might explain differences in 6MWD in different sarcoidosis populations may be ethnicity. The study by Alhamad et al. ${ }^{7}$ involved Saudi Arabian sarcoidosis patients. Al-Nozha et al. $^{23}$ reported a high prevalence of physical inactivity (96.1\%) in general among Saudi Arabian adults. 
In the present study, muscle weakness was found in a substantial proportion of our study population, even in the absence of fatigue. Measurement of muscle strength of either the upper or lower body provided complementary information even when patients were not fatigued. The mean handgrip force and PImax were comparable with the results reported by Spruit et al. ${ }^{5}$, who found peripheral and PImax impairment in sarcoidosis patients complaining of fatigue. However, the quadriceps peak torques found in the study by Spruit et al. ${ }^{5}$ cannot be compared to those in the present study, as they measured isometric quadriceps forces, while the present study measured isokinetic quadriceps forces. Although Wirnsberger et al. ${ }^{11}$ did not find peripheral muscle weakness in sarcoidosis patients, they did find a tendency towards reduced peripheral muscle strength. The sample size of their study population was rather small. Drent et al. ${ }^{4}$ demonstrated that fatigued patients were more likely to suffer from exercise intolerance than nonfatigued patients. Nevertheless, our study found fatigue to be only weakly related to both exercise capacity and muscle strength. Both fatigued and nonfatigued sarcoidosis patients have to cope with the complaints of reduced muscle strength and exercise intolerance. Drent et al. ${ }^{4}$ also found reduced FFM in their studied fatigued patients. In the present study, the FFM was found to be decreased in patients with reduced peripheral muscle strength. Reduction of FFM is an expression of muscle wasting. ${ }^{24}$ Although not directly measured in the present study, it is assumed that muscle wasting, i.e. loss of muscle bulk, might be a determinant of strength as in other chronic disorders.

Fatigue is a prominent problem in sarcoidosis and is frequently related to an impaired QoL. Previous studies have shown a wide range of fatigue rates $(30-90 \%)$ in sarcoidosis patients. ${ }^{2}$ Nevertheless, the majority of studies show fatigue prevalence rates between $70 \%$ and $90 \%{ }^{2}$ The prevalence of fatigue in the present study was $81 \%$. It is important to consider that most of the patients we studied were suffering from severe sarcoidosis, as this was the main reason why they were referred to a tertiary referral centre in the Netherlands.

Despite the complex and multifaceted aetiology of fatigue, several investigators have attempted to elucidate the potential causes of fatigue in sarcoidosis. Most of these studies evaluated clinical parameters, with only a few studies postulating psychological factors, such as underlying mechanisms of fatigue. ${ }^{25}$ De Vries et al. ${ }^{2}$ found no relationship between fatigue in sarcoidosis patients and a number of clinical variables, including pulmonary function, metabolic variables, laboratory parameters of inflammation and T-cell activation and granuloma formation. The present study investigated a multifactorial explanation of fatigue. In line with De Vries et al. ${ }^{2}$, we did not find a relationship between fatigue and parameters commonly used to assess fatigue in sarcoidosis (demographic patient characteristics, lung function tests, radiographic stages and corticosteroid use). The aetiology of fatigue may involve general inflammation, and Drent et al. ${ }^{4}$ found that an acute phase response (CRP levels) was associated with fatigue complaints in sarcoidosis. In the present study, however, 
CRP levels were unrelated to fatigue, which is in line with De Vries et $a l^{2}{ }^{2}$ In the present study, fatigue showed only a weak relationship with peripheral muscle strength.

Reduced exercise capacity, muscle weakness, loss of FFM and fatigue have been described in association with various chronic inflammatory diseases, such as Crohn's disease and rheumatoid arthritis. ${ }^{26,27}$ Sarcoidosis patients also often present with exercise intolerance, general weakness and fatigue. The number of studies on this topic among sarcoidosis patients is limited, and most studies only included small study populations or sarcoidosis patients with specific health complaints. ${ }^{5,11}$ Nevertheless, the primary causes of these physical disabilities and their interrelations remain unclear for sarcoidosis too.

\section{Study limitations}

The present study was a cross-sectional study and, therefore, no conclusions could be drawn with regard to causality. This study only included refractory sarcoidosis patients suffering from severe physical complaints who were referred to a tertiary hospital, which may have caused selection bias. This selection might have resulted in an overestimation of the prevalence of reduced exercise capacity, muscle weakness and fatigue.

Both the 6MWT and the muscle strength tests are volitional tests. The results of these tests partially depend on the patient's motivation and cooperation during the test. Nonvolitional testing would probably yield more valid results. However, these tests used are generally accepted in clinical studies $5,6,28$ and, to our knowledge, sarcoidosis patients are very cooperative and motivated to participate in research projects.

In the literature, normative values for the $6 \mathrm{MWT}^{29}$, handgrip force ${ }^{16}$, elbow flexor muscle strength ${ }^{30}$, and quadriceps and hamstrings peak torque ${ }^{14}$ do exist. Our control group data are comparable with the normative values.

In conclusion, the present study showed exercise intolerance, muscle weakness and fatigue to be frequent problems in sarcoidosis. Although the majority of the patients in our study suffered from fatigue, exercise intolerance and muscle weakness occurred in both fatigued and nonfatigued patients. Patients with peripheral muscle strength impairment of the upper or lower body or both were more fatigued and demonstrated impaired lung function test results, FFM, PImax, 6MWD and QoL. Fatigue was not predicted by clinical parameters. More research is needed to standardise the assessment of exercise intolerance, muscle strength and fatigue in sarcoidosis. Research as to whether a multidisciplinary rehabilitation programme is of clinical benefit in the management of sarcoidosis patients is extremely necessary. 


\section{References}

1. Statement on sarcoidosis. Joint Statement of the American Thoracic Society (ATS), the European Respiratory Society (ERS) and the World Association of Sarcoidosis and Other Granulomatous Disorders (WASOG) adopted by the ATS Board of Directors and by the ERS Executive Committee, February 1999. Am J Respir Crit Care Med 1999;160:736-755.

2. De Vries J, Rothkrantz-Kos S, Van Dieijen-Visser MP, Drent M. The relationship between fatigue and clinical parameters in pulmonary sarcoidosis. Sarcoidosis Vasc Diffuse Lung Dis 2004;21:127-136.

3. De Vries J, Wirnsberger RM. Fatigue, quality of life and health status in sarcoidosis. Eur Respir Mon 2005;32:92-104.

4. Drent M, Wirnsberger RM, De Vries J, Van Dieijen-Visser MP, Wouters EF, Schols AM. Association of fatigue with an acute phase response in sarcoidosis. Eur Respir J 1999;13:718-722.

5. Spruit MA, Thomeer MJ, Gosselink R, Troosters T, Kasran A, Debrock AJ, Demedts MG, Decramer M. Skeletal muscle weakness in patients with sarcoidosis and its relationship with exercise intolerance and reduced health status. Thorax 2005;60:32-38.

6. Bourbonnais JM, Samavati L. Clinical predictors of pulmonary hypertension in sarcoidosis. Eur Respir J 2008;32:296-302.

7. Alhamad EH. The six-minute walk test in patients with pulmonary sarcoidosis. Ann Thorac Med 2009;4:60-64.

8. Baughman RP, Sparkman BK, Lower EE. Six-minute walk test and health status assessment in sarcoidosis. Chest 2007;132:207-213.

9. Kabitz HJ, Lang F, Walterspacher S, Sorichter S, Muller-Quernheim J, Windisch W. Impact of impaired inspiratory muscle strength on dyspnea and walking capacity in sarcoidosis. Chest 2006;130:1496-1502.

10. Miller A, Brown LK, Sloane MF, Bhuptani A, Teirstein AS. Cardiorespiratory responses to incremental exercise in sarcoidosis patients with normal spirometry. Chest 1995;107:323-329.

11. Wirnsberger RM, Drent M, Hekelaar N, Breteler MH, Drent S, Wouters EF, Dekhuijzen PN. Relationship between respiratory muscle function and quality of life in sarcoidosis. Eur Respir J 1997;10:1450-1455.

12. Quanjer PH, Tammeling GJ, Cotes JE, Pedersen OF, Peslin R, Yernault JC. Lung volumes and forced ventilatory flows. Report working party standardization of lung function tests, European community for steel and coal. Official statement of the European Respiratory Society. Eur Respir J Suppl 1993;16:5-40.

13. ATS committee on proficiency standards for clinical pulmonary function laboratories. ATS statement: guidelines for the six-minute walk test. Am J Respir Crit Care Med 2002;166:111-117.

14. Freedson PS, Gilliam TB, Mahoney T, Maliszewski MA, Kastango K. Industrial torque levels by age group and gender. Isokinet Exerc Sci 1993;3:34-42.

15. Drouin JM, Valovich-mcLeod TC, Shultz SJ, Gansneder BM, Perrin DH. Reliability and validity of the Biodex system 3 pro isokinetic dynamometer velocity, torque and position measurements. Eur J Appl Physiol 2004;91:22-29.

16. Werle S, Goldhahn J, Drerup S, Simmen BR, Sprott H, Herren DB. Age- and gender-specific normative data of grip and pinch strength in a healthy adult Swiss population. J Hand Surg Eur Vol 2009;34:76-84.

17. Bohannon RW. Make tests and break tests of elbow flexor muscle strength. Phys Ther 1988;68:193-194.

18. Black LF, Hyatt RE. Maximal respiratory pressures: normal values and relationship to age and sex. Am Rev Respir Dis 1969;99:696-702.

19. Harik-Khan RI, Wise RA, Fozard JL. Determinants of maximal inspiratory pressure. The Baltimore longitudinal study of aging. Am J Respir Crit Care Med 1998;158:1459-1464.

20. Michielsen HJ, De Vries J, Van Heck GL, Van de Vijver FJR, Sijtsma K. Examination of the dimensionality of fatigue: The construction of the Fatigue Assessment Scale (FAS). EJPA 2004;20:39-48.

21. WHO. Development of the World Health Organization WHOQOL-BREF quality of life assessment. The WHOQOL Group. Psychol Med 1998;28:551-558.

22. Trompenaars FJ, Masthoff ED, Van Heck GL, Hodiamont PP, De Vries J. Content validity, construct validity, and reliability of the WHOQOL-BREF in a population of Dutch adult psychiatric outpatients. Qual Life Res 2005;14:151-160.

23. Al-Nozha MM, Al-Hazzaa HM, Arafah MR, Al-Khadra A, Al-Mazrou YY, Al-Maatouq MA, Khan NB, AlMarzouki K, Al-Harthi SS, Abdullah M, Al-Shahid MS. Prevalence of physical activity and inactivity among Saudis aged 30-70 years. A population-based cross-sectional study. Saudi Med J 2007;28: 559-568. 
24. Seymour JM, Spruit MA, Hopkinson NS, Natanek SA, Man WD, Jackson A, Gosker HR, Schols AM, Moxham J, Polkey MI, Wouters EF. The prevalence of quadriceps weakness in COPD and the relationship with disease severity. Eur Respir J 2010;36:81-88.

25. De Kleijn WP, De Vries J, Lower EE, Elfferich MD, Baughman RP, Drent M. Fatigue in sarcoidosis: a systematic review. Curr Opin Pulm Med 2009;15:499-506.

26. Wiroth JB, Filippi J, Schneider SM, Al-Jaouni R, Horvais N, Gavarry O, Bermon S, Hébuterne X. Muscle performance in patients with Crohn's disease in clinical remission. Inflamm Bowel Dis 2005;11:296-303.

27. Ho LY, Mok CC, To CH, Anselm M, Cheung MY, Yu KL. Rituximab for refractory rheumatoid arthritis: a 24-week open-label prospective study. Open Rheumatol J 2007;1:1-4.

28. Baughman RP, Lower EE. Six-minute walk test in managing and monitoring sarcoidosis patients. Curr Opin Pulm Med 2007;13:439-444.

29. Gibbons WJ, Fruchter N, Sloan S, Levy RD. Reference values for a multiple repetition 6-minute walk test in healthy adults older than 20 years. J Cardiopulm Rehabil 2001;21:87-93.

30. Bohannon RW. Reference values for extremity muscle strength obtained by hand-held dynamometry from adults aged 20 to 79 years. Arch Phys Med Rehabil 1997;78:26-32. 


\section{Chapter 4}

Exercise capacity, muscle strength, and fatigue in sarcoidosis: a follow-up study

RGJ Marcellis, AF Lenssen, S Kleynen, J De Vries, M Drent

Lung 2013;191:247-256 


\section{Abstract}

Purpose

The purpose of this study was to examine changes in the prevalence of exercise intolerance, reduced muscle strength, and fatigue and the changes in these parameters in individual patients during a 2-year follow-up study.

\section{Methods}

Ninety sarcoidosis patients (62 males and 28 females; mean age: $46.0 \pm 10.2$ years) participated in a 2-year follow-up study. At the baseline and follow-up measurements, patients performed a 6-minute walk test and elbow flexor muscle strength, quadriceps peak torque, and hamstrings peak torque tests. Maximal inspiratory pressure was recorded. All patients completed the Fatigue Assessment Scale.

\section{Results}

Both at baseline and follow-up, a substantial proportion of the patients showed a reduced 6-minute walk test $(41.6 \%$ and $34.8 \%$, respectively), elbow flexor muscle strength $(6.7 \%$ and $14.6 \%)$, quadriceps peak torque (21.3\% and $18.0 \%)$, hamstrings peak torque ( $13.5 \%$ and $12.4 \%)$, and maximal inspiratory pressure (45.9\% and $48.6 \%)$. The majority of the patients reported fatigue ( $86 \%$ and $77 \%)$. These physical impairments remained stable during the follow-up period. The prevalence of these physical impairments in patients diagnosed with sarcoidosis $<2$ years before inclusion in this study was similar to that in patients with a longer history of the disease.

\section{Conclusions}

Exercise intolerance, muscle weakness, and fatigue are frequent problems in symptomatic sarcoidosis patients with a stable and persistent character. This study highlights that beyond medical treatment a rehabilitation program should be considered as adjunct therapy in the multidisciplinary management of sarcoidosis patients even though the achieved benefit needs future studies. 


\section{Introduction}

The course of sarcoidosis is unpredictable and clinical manifestations are variable, depending on the organs involved. ${ }^{1-3}$ Patients consult their physician not only with organ-specific symptoms, but also with nonspecific health complaints, such as fatigue, exercise intolerance, and muscle weakness. ${ }^{4}$ These physical impairments in sarcoidosis are disabling, especially when they become chronic. ${ }^{5,6}$ Nearly two-thirds of sarcoidosis patients may show spontaneous remission in the first two years after diagnosis. Nevertheless, sarcoidosis is reported to become chronic (>2 years) or progressive in $10-30 \%{ }^{1,2}$ There are currently no data about the course of physical complaints and fatigue in these subgroups of sarcoidosis patients.

Fatigue is the most frequently reported symptom in sarcoidosis, with a prevalence of $60-90 \% .{ }^{5,7,8}$ In the study by Marcellis et $a l .{ }^{9}, 81 \%$ of the sarcoidosis patients in the sample reported fatigue and $26 \%$ of the fatigued patients reported extreme fatigue. This study ${ }^{9}$ also found exercise intolerance and muscle weakness to be frequent problems in sarcoidosis, both in fatigued and nonfatigued patients. Previous studies also found reduced 6-minute walking distances (6MWDs) and/or muscle weakness in sarcoidosis. $^{10-15}$

So far, only cross-sectional designs have been used to study the prevalence of exercise intolerance, muscle weakness, and fatigue in sarcoidosis, and studies using a longitudinal design are lacking. No conclusions therefore can be drawn with regard to changes in these physical parameters over time in sarcoidosis.

Another question is whether patients diagnosed with sarcoidosis $<2$ years ago show remission of the physical complaints in the first two years after diagnosis and whether it is true that $10-30 \%$ develop chronic physical complaints. These points are obviously of clinical interest in the management of sarcoidosis patients, as a rehabilitation program could offer added value in patients with persistent physical complaints. ${ }^{13,16}$

The purpose of the current study was to examine changes in the prevalence of exercise intolerance, reduced muscle strength, and fatigue and to assess the changes in these parameters in individual patients during a 2-year follow-up study.

\section{Methods}

\section{Subjects}

Between November 2008 and September 2009, 124 symptomatic sarcoidosis patients referred to the interstitial lung disease (ild) care team of the Department of Respiratory Medicine of the Maastricht University Medical Centre (MUMC; the Netherlands) were included in a cross-sectional study. ${ }^{9}$ Patients were diagnosed with sarcoidosis according to the World Association of Sarcoidosis and Other Granulomatous Disorders (WASOG) guidelines. ${ }^{1}$ Between July 2010 and September 2011, all participants of the 2008/9 
study ${ }^{9}$ living in the southern part of the Netherlands $(n=104)$ were invited to participate in the follow-up measurement.

\section{Measurements}

All measurements in this study have been described previously. ${ }^{9}$ Both at baseline and follow-up, the data were collected between 10:30 and 14:00. The physical test results and fatigue scores of the 2008/9 cross-sectional study were used as baseline values. ${ }^{9}$ During the $2008 / 9$ cross-sectional study a healthy control group $(n=62)$ matched for age and sex was recruited from hospital employees and the surrounding community (Table 4.1).

Table 4.1 Summary of the demographic and clinical characteristics of the sarcoidosis patients studied at baseline and follow-up and the healthy controls.

\begin{tabular}{|c|c|c|c|c|c|}
\hline & $\begin{array}{l}\text { Total sarcoidosis } \\
\text { sample 2008- } \\
2009\end{array}$ & $\begin{array}{l}\text { Sarcoidosis } \\
\text { patients } \\
\text { at baseline }\end{array}$ & $\begin{array}{l}\text { Sarcoidosis } \\
\text { patients } \\
\text { at follow-up }\end{array}$ & Dropouts & $\begin{array}{l}\text { Healthy } \\
\text { controls }\end{array}$ \\
\hline \multicolumn{6}{|l|}{ Demographics } \\
\hline Subjects & 124 & 90 & 90 & 34 & 62 \\
\hline Females/males & $44 / 80$ & $28 / 62$ & $28 / 62$ & $16 / 18$ & 22 / 40 \\
\hline Age (yrs) & $46.6 \pm 10.2$ & $46.0 \pm 10.2$ & $47.8 \pm 10.2$ & $48.5 \pm 10.2$ & $46.4 \pm 9.9$ \\
\hline Time since diagnosis (yrs) & $6.1 \pm 6.2$ & $5.9 \pm 5.8$ & & $6.6 \pm 7.0$ & NA \\
\hline $\mathrm{BMI}\left(\mathrm{kg} / \mathrm{m}^{2}\right)$ & $28.0 \pm 4.7$ & $28.5 \pm 4.6$ & $28.4 \pm 4.6$ & $26.7 \pm 4.5$ & $24.7 \pm 1.8$ \\
\hline Nonsmokers/smokers & 113 / 11 & $83 / 7$ & $83 / 7$ & $30 / 4$ & $56 / 6$ \\
\hline \multicolumn{6}{|l|}{ Medication } \\
\hline No medication & 76 & 54 & 57 & 22 & 62 \\
\hline Prednisone use (yes/no) & $48 / 76$ & $36 / 54$ & $32 / 58$ & $12 / 22$ & $0 / 62$ \\
\hline Prednisone dosage (mg) & $13.2 \pm 7.4$ & $11.8 \pm 5.6$ & $8.3 \pm 3.5^{c}$ & $14.6 \pm 8.9$ & 0 \\
\hline Methotrexate use (yes/no) & 39 / 85 & $29 / 61$ & 33 / 57 & $10 / 24$ & $0 / 62$ \\
\hline Methotrexate dosage (mg) & $10.8 \pm 3.1$ & $10.1 \pm 2.8$ & $9.6 \pm 3.3$ & $10.8 \pm 4.3$ & 0 \\
\hline Anti-TNF- $\alpha$ use (yes/no) & 14 / 110 & $13 / 77$ & $21 / 69^{c}$ & $1 / 33$ & $0 / 62$ \\
\hline \multicolumn{6}{|l|}{ Lung function tests } \\
\hline DLCO (\% pred) & $75.7 \pm 17.6$ & $76.6 \pm 17.4$ & $77.0 \pm 17.9$ & $71.1 \pm 19.3$ & NA \\
\hline FVC (\% pred) & $98.3 \pm 20.8$ & $98.5 \pm 19.6$ & $99.0 \pm 17.9$ & $95.7 \pm 23.9$ & NA \\
\hline $\mathrm{FEV}_{1}(\%$ pred) & $84.2 \pm 22.6$ & $84.6 \pm 21.7$ & $85.4 \pm 22.0$ & $78.0 \pm 25.1$ & NA \\
\hline \multicolumn{6}{|l|}{ Chest radiograph stages } \\
\hline $0+\mathrm{I} / \mathrm{II}+\mathrm{III} / \mathrm{IV}(\%)$ & 37 / 37 / 26 & $39 / 38 / 23$ & $41 / 36 / 23$ & $31 / 38$ / 31 & NA \\
\hline \multicolumn{6}{|l|}{ Inflammatory markers } \\
\hline $\mathrm{CRP}^{\mathrm{a}}$ & $8.6 \pm 15.4$ & $8.0 \pm 12.6$ & $3.8 \pm 3.6^{c}$ & $9.4 \pm 16.9$ & NA \\
\hline SIL-2R & $3,282 \pm 2,331$ & $2,995 \pm 1,501$ & $2,366 \pm 1,505^{c}$ & $3,578 \pm 2,440$ & NA \\
\hline \multicolumn{6}{|l|}{ Fatigue measure } \\
\hline FAS score & $28.3 \pm 7.7$ & $28.6 \pm 7.2$ & $26.5 \pm 7.2^{c}$ & $27.4 \pm 8.8$ & $15.6 \pm 4.0$ \\
\hline \multicolumn{6}{|l|}{ WHOQOL-BREF } \\
\hline Overall QoL facet & $5.9 \pm 1.6$ & $5.9 \pm 1.5$ & $6.3 \pm 1.6^{\mathrm{c}}$ & $6.0 \pm 1.8$ & $8.7 \pm 1.0$ \\
\hline Physical health domain & $12.3 \pm 2.8$ & $12.4 \pm 2.8$ & $13.3 \pm 2.8^{\mathrm{c}}$ & $12.1 \pm 3.0$ & $17.9 \pm 1.5$ \\
\hline
\end{tabular}

Data are expressed as mean \pm standard deviation (SD) or absolute numbers (n). BMI: body mass index; TNF: tumor necrosis factor; DLCO: diffusing capacity of the lung for carbon monoxide; \% pred: \% of predicted value; FVC: forced vital capacity; FEV $_{1}$ : forced expiratory volume in one second; CRP: C-reactive protein; sIL2R: soluble interleukin-2 receptor; FAS: Fatigue Assessment Scale; WHOQOL-BREF: World Health Organization Quality of Life-BREF assessment instrument; QoL: quality of life; NA: not applicable. ${ }^{a}$ Normal range $<10 \mathrm{mg} / \mathrm{l}$; ${ }^{b}$ Normal range $240-3,154 \mathrm{pg} / \mathrm{ml}$; Sarcoidosis patients $(n=90)$ at baseline versus follow-up: ${ }^{c} p<0.05$. 
These data were used as reference values for exercise capacity and peripheral muscle strength results for both the baseline and follow-up measurements (Tables 4.2, 4.3). ${ }^{9}$

This study was approved by the local Medical Ethics Committee of the MUMC. Written, informed consent was obtained from all participants.

Table 4.2 Summary of the physical characteristics of the male sarcoidosis patients studied at baseline (t0) and follow-up (t1) and the male healthy controls.

\begin{tabular}{|c|c|c|c|c|c|c|}
\hline Males $(n=62)$ & $\begin{array}{l}\text { Sarcoidosis } \\
\text { patients t0 }\end{array}$ & $\begin{array}{l}\text { Sarcoidosis } \\
\text { patients t1 }\end{array}$ & $\begin{array}{l}\text { Controls } \\
(n=40)\end{array}$ & $\begin{array}{l}\text { Mean difference } \\
\text { sarcoidosis } \\
\text { t1 vs. t0 } \\
(95 \% \mathrm{Cl})\end{array}$ & $\begin{array}{l}\text { Mean difference } \\
\text { controls vs. } \\
\text { sarcoidosis to } \\
(95 \% \mathrm{Cl})\end{array}$ & $\begin{array}{l}\text { Mean difference } \\
\text { controls vs. } \\
\text { sarcoidosis t1 } \\
(95 \% \mathrm{Cl})\end{array}$ \\
\hline \multicolumn{7}{|l|}{ Exercise capacity } \\
\hline 6MWD (m) & $609 \pm 93$ & $627 \pm 98$ & $747 \pm 74$ & $\begin{array}{c}18.4 \\
(4.6 \text { to } 32.2)^{a}\end{array}$ & $\begin{array}{c}138.8 \\
(104.2 \text { to } 173.4)^{b}\end{array}$ & $\begin{array}{c}120.4 \\
(86.5 \text { to } 154.3)^{b}\end{array}$ \\
\hline 6MWD (\% pred) & $81.4 \pm 12.4$ & $83.9 \pm 13$ & & $\begin{array}{c}2.5 \\
(0.6 \text { to } 4.3)^{a}\end{array}$ & & \\
\hline \multicolumn{7}{|l|}{ Muscle force } \\
\hline EFMS (N) & $257.4 \pm 54.8$ & $247.0 \pm 67.0$ & $287.0 \pm 47.9$ & $\begin{array}{c}-10.4 \\
(-21.7 \text { to } 0.9)\end{array}$ & $\begin{array}{c}29.6 \\
(8.6 \text { to } 50.6)^{a}\end{array}$ & $\begin{array}{c}40.0 \\
(15.7 \text { to } 64.3)^{a}\end{array}$ \\
\hline EFMS (\% pred) & $89.7 \pm 19.1$ & $86.1 \pm 23.4$ & & $\begin{array}{c}-3.6 \\
(-7.5 \text { to } 0.3)\end{array}$ & & \\
\hline QPT (Nm) & $96.6 \pm 30.5$ & $99.2 \pm 31.1$ & $118.4 \pm 23.0$ & $\begin{array}{c}2.7 \\
(-3.0 \text { to } 8.3)\end{array}$ & $\begin{array}{c}21.9 \\
(10.7 \text { to } 33.1)^{b}\end{array}$ & $\begin{array}{c}18.8 \\
(8.1 \text { to } 29.4)^{\mathrm{a}}\end{array}$ \\
\hline QPT (\% pred) & $81.6 \pm 25.7$ & $83.8 \pm 26.3$ & & $\begin{array}{c}2.2 \\
(-2.5 \text { to } 7.0)\end{array}$ & & \\
\hline HPT (Nm) & $70.7 \pm 23.2$ & $72.1 \pm 23.1$ & $86.3 \pm 18.7$ & $\begin{array}{c}1.4 \\
(-2.3 \text { to } 5.1)\end{array}$ & $\begin{array}{c}15.6 \\
(6.9 \text { to } 24.3)^{a}\end{array}$ & $\begin{array}{c}13.8 \\
(5.2 \text { to } 22.5)^{a}\end{array}$ \\
\hline HPT (\% pred) & $82.0 \pm 26.9$ & $83.6 \pm 26.7$ & & $\begin{array}{c}1.6 \\
(-2.7 \text { to } 5.9)\end{array}$ & & \\
\hline PImax (\% pred) & $79.3 \pm 25.8$ & $83.3 \pm 24.4$ & NA & $\begin{array}{c}4.0 \\
(-0.4 \text { to } 8.4)\end{array}$ & NA & NA \\
\hline
\end{tabular}

Data are expressed as mean \pm standard deviation (SD). 6MWD: 6-minute walking distance; \% pred: \% of predicted value; EFMS: elbow flexor muscle strength; QPT and HPT: isokinetic quadriceps and hamstrings peak torques at $180^{\circ}$ per second; PImax: maximal inspiratory pressure, NA: not applicable. ${ }^{a} p<0.05$; ${ }^{\mathrm{b}} \mathrm{p}<0.001$.

\section{Clinical data}

Forced vital capacity (FVC), forced expiratory volume in one second $\left(F E V_{1}\right)$, and the diffusing capacity of the lung for carbon monoxide (DLCO) were measured. ${ }^{17}$ Chest radiographs were graded according to the radiographic staging proposed by DeRemee. ${ }^{1}$

The C-reactive protein (CRP) concentration and the serum levels of soluble interleukin-2 receptor (sIL-2R) were analyzed. ${ }^{18}$ According to performed validations and the manufactory's instructions the repeatability coefficient of variation (CV) and the intermediate precision CV for CRP measurements are $3 \%$ and $4 \%$, respectively, and for sIL-2R measurements $8 \%$ and $5 \%$ respectively. 
Table 4.3 Summary of the physical characteristics of the female sarcoidosis patients studied at baseline (t0) and follow-up (t1) and the female healthy controls.

\begin{tabular}{|c|c|c|c|c|c|c|}
\hline Females $(n=28)$ & $\begin{array}{l}\text { Sarcoidosis } \\
\text { patients t0 }\end{array}$ & $\begin{array}{l}\text { Sarcoidosis } \\
\text { patients t1 }\end{array}$ & $\begin{array}{l}\text { Controls } \\
(n=22)\end{array}$ & $\begin{array}{c}\text { Mean } \\
\text { difference } \\
\text { sarcoidosis } \\
\text { t1 vs. t0 } \\
(95 \% \mathrm{Cl})\end{array}$ & $\begin{array}{c}\text { Mean } \\
\text { difference } \\
\text { controls vs. } \\
\text { sarcoidosis t0 } \\
(95 \% \mathrm{Cl})\end{array}$ & $\begin{array}{l}\text { Mean difference } \\
\text { controls vs. } \\
\text { sarcoidosis t1 } \\
(95 \% \mathrm{Cl})\end{array}$ \\
\hline \multicolumn{7}{|l|}{ Exercise capacity } \\
\hline 6MWD (m) & $553 \pm 87$ & $572 \pm 85$ & $679 \pm 73$ & $\begin{array}{c}18.3 \\
(-2.3 \text { to } 39.0)\end{array}$ & $\begin{array}{c}128.8 \\
(82.2 \text { to } 175.5)^{b}\end{array}$ & $\begin{array}{c}107.3 \\
(61.2 \text { to } 153.3)^{b}\end{array}$ \\
\hline 6MWD (\% pred) & $81.5 \pm 12.8$ & $84.2 \pm 12.4$ & & $\begin{array}{c}2.7 \\
(-0.4 \text { to } 5.8)\end{array}$ & & \\
\hline \multicolumn{7}{|l|}{ Muscle force } \\
\hline EFMS (N) & $160.0 \pm 27.1$ & $162.6 \pm 34.3$ & $162.6 \pm 22.9$ & $\begin{array}{c}2.6 \\
(-6.6 \text { to } 11.8)\end{array}$ & $\begin{array}{c}2.6 \\
(-12.0 \text { to } 17.2)\end{array}$ & $\begin{array}{c}1.9 \\
(-15.5 \text { to } 19.3)\end{array}$ \\
\hline EFMS (\% pred) & $98.4 \pm 16.7$ & $100.0 \pm 21.1$ & & $\begin{array}{c}1.6 \\
(-4.1 \text { to } 7.3)\end{array}$ & & \\
\hline $\mathrm{QPT}(\mathrm{Nm})$ & $60.0 \pm 19.9$ & $65.7 \pm 19.9$ & $70.2 \pm 13.3$ & $\begin{array}{c}5.7 \\
(2.1 \text { to } 9.2)^{\mathrm{a}}\end{array}$ & $\begin{array}{c}10.2 \\
(0.3 \text { to } 20.1)^{a}\end{array}$ & $\begin{array}{c}4.5 \\
(-4.9 \text { to } 14.0)\end{array}$ \\
\hline QPT (\% pred) & $85.5 \pm 28.4$ & $93.6 \pm 28.3$ & & $\begin{array}{c}8.1 \\
(3.0 \text { to } 13.1)^{a}\end{array}$ & & \\
\hline HPT (Nm) & $48.2 \pm 16.2$ & $48.5 \pm 12.8$ & $55.3 \pm 15.3$ & $\begin{array}{c}0.2 \\
(-3.9 \text { to } 4.3)\end{array}$ & $\begin{array}{c}7.1 \\
(-2.0 \text { to } 16.1)\end{array}$ & $\begin{array}{c}6.9 \\
(-1.1 \text { to } 14.9)\end{array}$ \\
\hline HPT (\% pred) & $87.2 \pm 29.3$ & $87.6 \pm 23.2$ & & $\begin{array}{c}0.4 \\
(-7.0 \text { to } 7.8)\end{array}$ & & \\
\hline PImax (\% pred) & $87.1 \pm 33.4$ & $85.2 \pm 28.8$ & NA & $\begin{array}{c}-1.9 \\
(-13.0 \text { to } 9.1)\end{array}$ & NA & NA \\
\hline
\end{tabular}

Data are expressed as mean \pm standard deviation (SD). 6MWD: 6-minute walking distance; \% pred: \% of predicted value; EFMS: elbow flexor muscle strength; QPT and HPT: isokinetic quadriceps and hamstrings peak torques at $180^{\circ}$ per second; PImax: maximal inspiratory pressure; NA: not applicable. ${ }^{a} p<0.05$; ${ }^{\mathrm{b}} \mathrm{p}<0.001$.

\section{Exercise capacity and muscle strength}

The 6-minute walk test (6MWT) was used to assess exercise capacity and performed according to the American Thoracic Society guidelines. ${ }^{19}$ The 6MWT is a reliable measure of exercise capacity in patients with pulmonary and cardiac diseases. ${ }^{20,21}$

The Biodex System 3 Pro dynamometer was used to measure isokinetic peak torques (in Nm) of the hamstrings and quadriceps, with a velocity of $180 \%$ second. ${ }^{22}$ The Biodex is a reliable and valid isokinetic dynamometer. ${ }^{23,24}$

Maximal isometric strength (in Newton) of the elbow flexors was measured with the microFET. ${ }^{25}$ This hand-held dynamometer is a reliable instrument. ${ }^{25,26}$ Maximal inspiratory pressure (PImax) was assessed by measuring maximal respiratory mouth pressures. ${ }^{27}$

\section{Questionnaires}

Fatigue was measured with the Fatigue Assessment Scale (FAS). ${ }^{28}$ FAS scores $<22$ indicate no fatigue. The minimal clinically important difference (MCID) of the FAS in 
sarcoidosis patients is a 4-point or $10 \%$ change in FAS score. ${ }^{28,29}$ The psychometric properties of the FAS also are good in sarcoidosis. ${ }^{30}$

The World Health Organization Quality of Life-BREF assessment instrument (WHOQOL-BREF) is a measure of quality of life (QoL). It consists of 24 questions in four domains (physical health, psychological health, social relationships, and environment) and two questions that compose the overall QoL and general health facets. ${ }^{31}$

\section{Statistical analysis}

Data are expressed as mean \pm standard deviation (SD) and, if appropriate, in absolute numbers or percentages. Paired sample t-tests were used to test mean differences in continuous data of the patient group at baseline, and follow-up and nominal data were analyzed using Chi-square. To detect differences between the patient and control groups, continuous data were analyzed with independent sample t-tests and nominal data were tested using Chi-square tests.

Physical test results below the mean values of the control group minus two times SD (95\% confidence interval) were assumed to indicate exercise intolerance or muscle strength impairment. The cutoff value for PImax, FVC, FEV ${ }_{1}$, and DLCO was $<80 \%$ of the predicted value. ${ }^{17,32}$ Frequency distributions were used to determine the prevalence of exercise intolerance, reduced muscle strength, and fatigue. Symmetry and changes in prevalence rates between the baseline and follow-up physical tests were analyzed by means of crosstabs and Chi-square tests.

P-values $<0.05$ were considered statistically significant. All analyses were performed using SPSS 18.0 for Windows (SPSS Inc., Chicago, IL, USA).

\section{Results}

\section{Patient characteristics}

In total, 104 participants of the 2008/9 study were invited to participate in the follow-up study. Fourteen of these patients were unable to participate, for the following reasons: death $(n=2)$, exacerbations of sarcoidosis $(n=2)$, health problems other than sarcoidosis $(n=4)$, and change of address without notice $(n=6)$. Finally, 90 patients (mean follow-up: $1.9 \pm 0.4$ years) participated. The clinical data of the patients at baseline and follow-up are summarized in Table 4.1. Most patients $(n=75)$ did not participate in a rehabilitation program during this study. Only six patients started, three stopped, and six patients continued their rehabilitation program during the follow-up period.

No differences in demographic, clinical, or physical characteristics were found between the patients who dropped out and those remaining in the study. We therefore regarded the patients who participated in the follow-up study as a randomly selected group of the patients studied in 2008-9 (Table 4.1). 


\section{Exercise capacity}

Sarcoidosis patients showed a significantly lower 6MWD (Tables 4.2, 4.3) and a higher prevalence of reduced exercise capacity compared with healthy controls both at baseline and follow-up.

Virtually no difference in mean 6MWD was found between the baseline and follow-up measurements (Tables 4.2, 4.3). Exercise capacity was reduced (relative to the control group) in $41.6 \%$ and $34.8 \%$ of the total population at the baseline and follow-up measurements, respectively. The prevalence of reduced exercise capacity at follow-up was higher in male sarcoidosis patients. The measurements at baseline and follow-up were highly related (Tables 4.4, 4.5). Figure 4.1 also shows this high level of agreement $(r=0.83 ; p<0.001)$ in 6MWD between the baseline and follow-up measurement.

Table 4.4 Prevalence of reduced (i.e., lower than predicted) physical test values at baseline and follow-up of the sarcoidosis patients studied.

\begin{tabular}{|c|c|c|c|}
\hline & $\begin{array}{c}\text { Prevalence of reduced } \\
\text { physical test values at } \\
\text { baseline (\%) }\end{array}$ & $\begin{array}{c}\text { Prevalence of reduced } \\
\text { physical test values at } \\
\text { follow-up (\%) }\end{array}$ & $\begin{array}{c}\text { Chi-square test } \\
\text { (p-value) }\end{array}$ \\
\hline \multicolumn{4}{|l|}{ Total sarcoidosis sample } \\
\hline 6MWD (\% reduced) & 41.6 & 34.8 & $<0.001$ \\
\hline EFMS (\% reduced) & 6.7 & 14.6 & 0.011 \\
\hline QPT (\% reduced) & 21.3 & 18.0 & $<0.001$ \\
\hline HPT (\% reduced) & 13.5 & 12.4 & 0.018 \\
\hline PImax (\% reduced) & 45.9 & 48.6 & $<0.001$ \\
\hline \multicolumn{4}{|c|}{ Male sarcoidosis patients } \\
\hline 6MWD (\% reduced) & 41.9 & 38.7 & $<0.001$ \\
\hline EFMS (\% reduced) & 4.8 & 19.4 & 0.033 \\
\hline QPT (\% reduced) & 19.7 & 21.3 & $<0.001$ \\
\hline HPT (\% reduced) & 16.4 & 16.4 & 0.027 \\
\hline PImax (\% reduced) & 45.1 & 49.0 & $<0.001$ \\
\hline \multicolumn{4}{|c|}{ Female sarcoidosis patients } \\
\hline 6MWD (\% reduced) & 40.7 & 25.9 & 0.005 \\
\hline EFMS (\% reduced) & 11.1 & 3.7 & 0.004 \\
\hline QPT (\% reduced) & 25.0 & 10.7 & 0.001 \\
\hline HPT (\% reduced) & 7.1 & 3.6 & 0.778 \\
\hline PImax (\% reduced) & 47.8 & 47.8 & 0.022 \\
\hline
\end{tabular}

Data are expressed as percentages (\%). 6MWD: 6-minute walking distance; EFMS: elbow flexor muscle strength; QPT and HPT: isokinetic quadriceps and hamstrings peak torques at $180^{\circ}$ per second; PImax: maximal inspiratory pressure.

\section{Muscle strength}

All mean peripheral muscle strength test results were significantly lower in male sarcoidosis patients compared with the control subjects (Table 4.2). In contrast to these findings, hardly any differences in mean test results were found between female sarcoidosis patients and healthy controls (Table 4.3). 
Table 4.5 Crosstab showing the numbers of sarcoidosis patients with a normal and reduced 6-minute walking distance at the baseline and follow-up measurements.

\begin{tabular}{|lcccc|} 
& \multicolumn{4}{c}{ Follow-up measurement } \\
\cline { 3 - 5 } & & Reduced 6MWD & Normal 6MWD \\
Baseline measurement & Reduced 6MWD & 27 & 10 & 37 \\
& Normal 6MWD & 4 & 48 & 52 \\
& & 31 & 58 & 89
\end{tabular}

Data are expressed as absolute numbers. 6MWD: 6-minute walking distance.

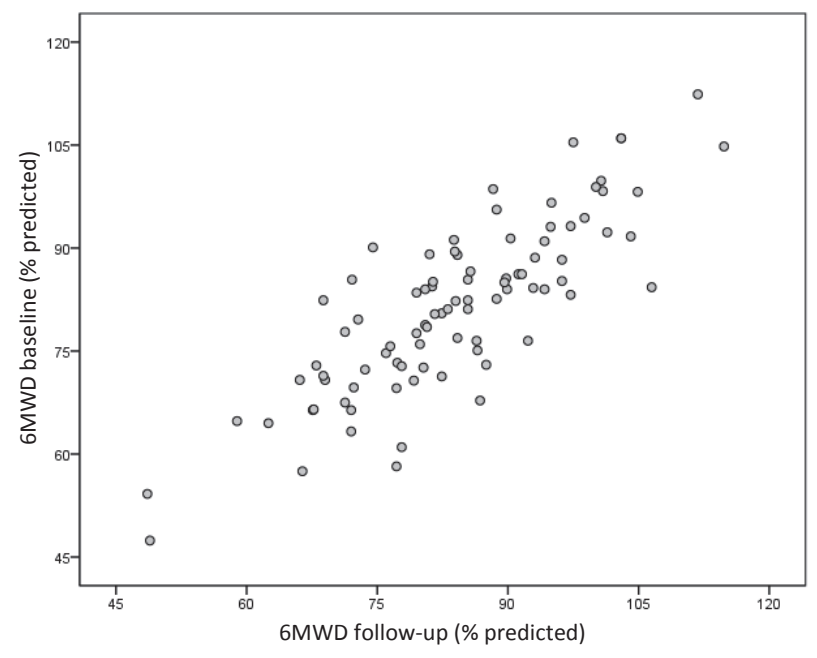

Figure 4.1 Correlation between the 6-minute walking distance (6MWD) as a percentage of the predicted value measured at baseline and the $6 \mathrm{MWD}$ as a percentage of the predicted value measured at follow-up in patients with sarcoidosis $(r=0.830 ; p<0.001)$.

Although female sarcoidosis patients showed a small, yet statistically significant improvement of the quadriceps peak torques at the follow-up measurement compared with the baseline measurement $(p=0.003)$, none of the other mean peripheral muscle strength test results appeared to be changed neither for men nor for women (Tables $4.2,4.3)$. Both at baseline and follow-up, a substantial proportion of the sarcoidosis patients showed reduced elbow flexor muscle strength $(6.7 \%$ and $14.6 \%$, respectively), quadriceps (21.3\% and 18.0\%, respectively; Table 4.6; Figure 4.2) and hamstrings (13.5\% and $12.4 \%$, respectively) peak torques, and PImax (45.9\% and $48.6 \%$, respectively; Table 4.4). In general, male sarcoidosis patients showed higher prevalences of reduced muscle strength. Table 4.4 also shows a high level of agreement in test results between the baseline and follow-up measurements of the peripheral muscle strength tests.

During the follow-up period in four cases the prednisone was stopped, and in 20 cases the dose was tapered. In four cases methotrexate (MTX) was started. 
However, in most cases the treatment at inclusion was continued with only a small dose adaption due to the chronicity of the disease. In this study, eight patients started anti-TNF- $\alpha$ treatment during the follow-up period (Table 4.1). Neither exercise capacity nor muscle strength was found to be related to medication use (prednisone, methotrexate, and anti-TNF- $\alpha$ ) and participation in a rehabilitation program.

Table 4.6 Crosstab showing the numbers of sarcoidosis patients with normal and reduced isokinetic peak torques of the quadriceps at the baseline and follow-up measurements.

\begin{tabular}{lcccc} 
& \multicolumn{3}{c}{ Follow-up measurement } \\
\cline { 3 - 4 } Baseline measurement & Reduced QPT & Normal QPT \\
& Reduced QPT & 10 & 9 & 19 \\
& Normal QPT & 6 & 64 & 70 \\
& & 16 & 73 & 89
\end{tabular}

Data are expressed as absolute numbers. QPT: isokinetic quadriceps peak torques at $180^{\circ}$ per second.

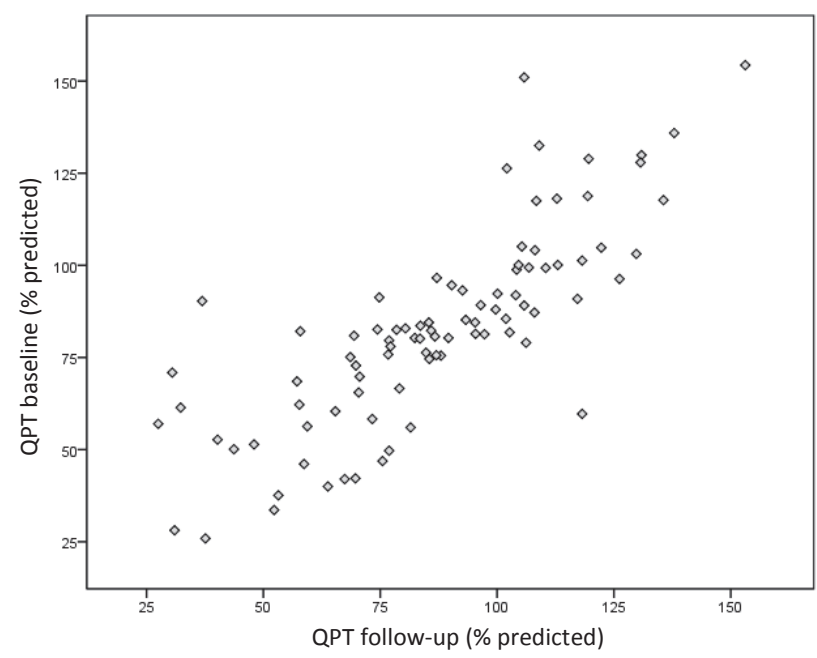

Figure 4.2 Correlation between the quadriceps peak torque (QPT) as a percentage of the predicted value measured at baseline and the QPT as a percentage of the predicted value measured at followup $(r=0.794 ; p<0.001)$ in patients with sarcoidosis.

\section{Fatigue}

Although the difference in mean FAS score was small between baseline and follow-up measurements in our sarcoidosis patients, it was statistically significant (Table 4.1). The prevalences of fatigue in sarcoidosis at baseline and follow-up were $86 \%$ and $77 \%$, respectively. Of these fatigued patients, $23 \%$ reported extreme fatigue at baseline and $14 \%$ at follow-up (Chi-square test: $p=0.048$ ). There was a significant relationship between these paired measurements (Chi-square test: $p=0.012$ ). The mean FAS score 
$(15.6 \pm 4.0)$ and the prevalence of fatigue $(4.8 \%)$ were significantly lower in the control group than among the sarcoidosis patients $(p<0.001)$.

Based on the MCID of the FAS (4 points difference), fatigue complaints were reduced, increased, or stable at the follow-up measurement in 31, 10, and 49 patients, respectively. When we used a $10 \%$ change in FAS score as MCID, fatigue complaints were reduced, increased, or stable at the follow-up measurement in 36, 16, and 38 patients, respectively. Analysis of these subgroups showed no differences between them regarding demographic characteristics (age, sex, time since diagnosis), lung function test results (DLCO\% pred, FVC\% pred, and $\mathrm{FEV}_{1} \%$ pred), levels of inflammatory markers (CRP and SIL-2R), radiographic stages, medication use (prednisone, methotrexate, and anti-TNF- $\alpha$ ), exercise capacity (Figure 4.3 ) or muscle strength. The only difference was that the subgroup that reported a reduction in fatigue included more patients started anti-TNF- $\alpha$ treatment than the other subgroups.

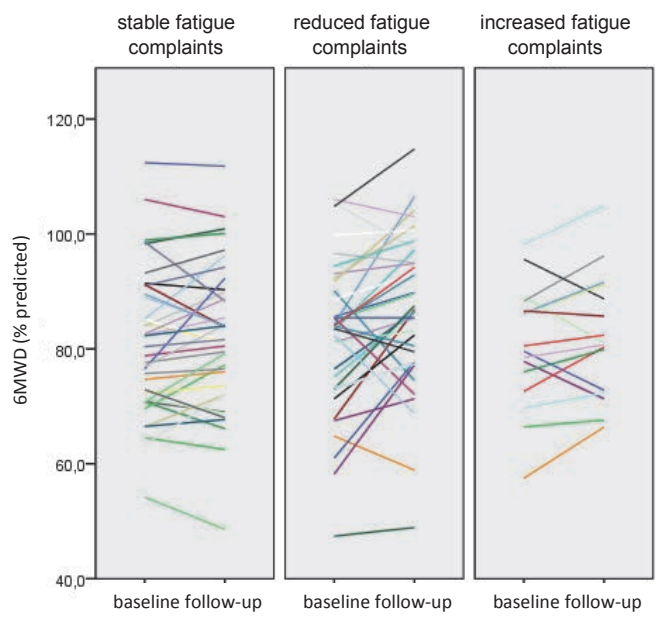

Figure 4.3 Individual changes in 6-minute walking distance (6MWD) as a percentage of the predicted value of the sarcoidosis patients studied, stratified by stable $(n=38)$, reduced $(n=36)$, or increased ( $n=16)$ fatigue complaints (MCID: 10\% difference on the Fatigue Assessment Scale (FAS)).

\section{Time since diagnosis}

Our evaluation of the total population revealed no differences in physical test results or FAS scores between the baseline and follow-up measurements. Evaluation of two subgroups, i.e., patients who were diagnosed with sarcoidosis $<2$ years before inclusion in this study and those with a history of sarcoidosis of more than two years did not reveal any differences. This subgroup analysis showed no differences in physical test results or FAS scores between the baseline and follow-up measurements. 


\section{Discussion}

To the best of our knowledge, this is the first longitudinal study in sarcoidosis to examine changes in exercise capacity, muscle strength, and fatigue at group and individual level over a 2-year period. So far, only cross-sectional study designs had been used to assess the prevalence of these physical impairments in sarcoidosis, which meant that no conclusions could be drawn with regard to the progression of the disease severity. This longitudinal study demonstrated that exercise intolerance, muscle weakness, and fatigue are frequent problems in sarcoidosis patients and that these physical impairments persisted over a 2-year follow-up period. These physical impairments appeared to be similar for patients diagnosed with sarcoidosis < 2 years before inclusion in this study and those with a longer disease history.

\section{Exercise capacity}

In the present study, exercise capacity was reduced in $41.6 \%$ of the patients at baseline and in $34.8 \%$ at follow-up. Exercise intolerance in sarcoidosis has been reported in several cross-sectional studies. In line with the present study, Spruit et al. ${ }^{13}$ found reduced 6MWD in fatigued sarcoidosis patients and Kabitz et al. ${ }^{12}$ in male sarcoidosis patients. Alhamad et al. ${ }^{10}$ and Baughman et al. ${ }^{11}$ even reported a $6 \mathrm{MWD}$ of $<400 \mathrm{~m}$ in $73 \%$ and $51 \%$ of their respective sarcoidosis populations. The differences in 6MWD findings between these studies might be explained by gender and ethnicity. Several studies found that female gender was associated with a reduced 6MWD. ${ }^{9-11}$ Al-Nozha et al. $^{33}$ reported a high prevalence of inactivity among Saudi adults, leading to physical deconditioning. In contrast to the findings reported in the literature ${ }^{1,2}$, our subgroup analysis showed that physical impairments in patients diagnosed with sarcoidosis $<2$ years before inclusion in this study mostly remained unchanged during the 2-year follow-up period.

\section{Muscle strength}

In the present study, a substantial proportion of the sarcoidosis patients showed reduced peripheral muscle strength, i.e., elbow flexor muscle strength $(6.7 \%$ and $14.6 \%)$, quadriceps (21.3\% and $18.0 \%)$, and hamstrings ( $13.5 \%$ and $12.4 \%$ ) peak torques and PImax (45.9\% and 48.6\%) at the baseline and follow-up measurements, respectively. Reduced quadriceps peak torques in sarcoidosis patients also were reported by Spruit et al. ${ }^{13}$ Inspiratory muscle weakness in sarcoidosis also has been reported in several studies. ${ }^{12-15}$

Although the sample size of female sarcoidosis patients in the present study was rather small, we found a tendency toward more physical impairments in male compared with female sarcoidosis patients. In general, male sarcoidosis patients showed more reduced lung function values ( $F E V_{1}$ and $F V C$ ) and suffered from more severe pulmonary sarcoidosis according to the chest $\mathrm{X}$-ray stages. 
In line with other studies, we found a relationship between exercise capacity and both the quadriceps and hamstrings muscle strength in sarcoidosis patients. ${ }^{13}$ In a study by Miller et al. ${ }^{34}, 67 \%$ of the sarcoidosis patients terminated their peak exercise test because of "leg complaints", which was considered an indication of skeletal muscle weakness. There are several reasons why muscle weakness develops in sarcoidosis, including sarcoid granuloma infiltration in the muscles, steroid-induced myopathy, increased circulating inflammatory markers, and physical deconditioning. Sarcoid muscle involvement is mostly asymptomatic and therefore an underdetected problem. Symptomatic muscle involvement is rare in sarcoidosis. Corticosteroid treatment is indicated in this latter group, often resulting in improved muscle functions. ${ }^{35}$ However, no muscle biopsies were performed in the present study. Quadriceps muscle strength has been found to be inversely related to the daily dose of corticosteroids in fatigued sarcoidosis patients. ${ }^{13}$ Although corticosteroids are known to cause a myopathy, Spruit et al. $^{13}$ found no differences in muscle strength between patients using corticosteroids and those who did not. In line with this, the present study and a previous study by Marcellis et al. ${ }^{9}$ did not find an association between muscle strength and prednisone dosage either. The effects of corticosteroid treatment on muscle strength in sarcoidosis thus remain unclear.

Sarcoidosis patients have been found to exhibit higher plasma TNF- $\alpha$ concentrations than control subjects. ${ }^{28}$ Elevated TNF- $\alpha$ levels may cause muscle dysfunction in chronic diseases. Although the median circulating level of TNF- $\alpha$ was higher in sarcoidosis patients compared with healthy controls, TNF- $\alpha$ did not correlate with muscle strength. ${ }^{13}$

According to the present study, fatigue, exercise intolerance, and muscle weakness are frequent reported symptoms in sarcoidosis. These disabling symptoms may cause physical inactivity in sarcoidosis, resulting in general deconditioning. In turn, general deconditioning may cause more perceived fatigue, physical impairments, and a reduction in daily activities. This is called the negative vicious circle of physical deconditioning. ${ }^{13}$ However, the degree of physical inactivity was not measured in the present study, because this was beyond the scope of this study.

\section{Fatigue}

The etiology of fatigue seems to be multifactorial but remains unclear. ${ }^{4,9,28}$ In the present study, the prevalence of fatigue at baseline was $86 \%$ and at follow-up $77 \%$, which is in line with previous studies..$^{5,9,11,36}$ Sarcoidosis mostly affects young adults. Fatigue and physical impairments can obviously have a major influence on the daily activities, social, and working lives of these patients, resulting in a reduced QoL. ${ }^{5}$

Although the differences we found in fatigue complaints and QoL were statistically significant, they may be (clinically) irrelevant from the patients' point of view. A study by de Kleijn et al. ${ }^{29}$ showed that a change in FAS score over time of at least four points represents the MCID. Recently, Drent et al. ${ }^{28}$ established a percentage-based MCID in the FAS score of $10 \%$. Regardless of whether we used a four-point or a $10 \% \mathrm{MCID}^{28,29}$, 
our subgroup analysis showed no differences in demographic, clinical, or physical characteristics between patients with stable, reduced, or increased fatigue complaints. The only difference was that the subgroup of patients who demonstrated a clinically relevant improvement in terms of fatigue included more patients who had started antiTNF- $\alpha$ treatment during the follow-up period.

In general, physicians assess disease severity and progression in sarcoidosis on the basis of clinical test results, such as pulmonary function tests, chest radiographs, and serological tests. However, these objective clinical parameters correlate poorly with the patients' subjective feeling of well-being. ${ }^{7}$ For example, fatigue and general weakness may persist even if routine clinical tests results have returned to normal. ${ }^{5,7}$ Assessment of the presence of physical impairments provides additional information about the patient's functional status, disease severity, and progression. ${ }^{6,37}$ Therefore, we recommend physical tests in the multidisciplinary management of sarcoidosis. Huppmann et al. $^{38}$ demonstrated in a large cohort of patients with ild, including sarcoidosis patients $(n=50)$, that pulmonary rehabilitation $(P R)$ had a positive impact on functional status and QoL. They concluded that PR appears to be a valuable adjunct therapy in patients with ild, including sarcoidosis. Therefore, a rehabilitation program should be considered in those patients with persistent or progressive physical impairment.

\section{Study limitations}

At baseline, this study included refractory sarcoidosis patients suffering from severe physical complaints referred to a tertiary clinic, which may have caused selection bias. Because this selection may have resulted in an overestimation of the prevalence of reduced exercise capacity, muscle weakness, and fatigue, these results may not be valid for all sarcoidosis patients.

The physical tests performed in this study are volitional tests, and the results partially depend on the patient's motivation and cooperation. Nonvolitional testing would possibly yield more valid results. However, the used tests are generally accepted in clinical studies ${ }^{13}$, and in our experience, sarcoidosis patients are very cooperative and motivated to participate in research projects.

\section{Future research}

This study was not designed to answer the question why some patients show improvements in terms of physical impairments while others report progression of disease severity. Future research should include prospective intervention studies to explore the relationship between physical impairments and different treatment strategies in sarcoidosis. In addition to medication, exercise training in patients with sarcoidosis should be considered, because it has been shown to be effective in treating exercise intolerance, muscle weakness, and fatigue in several chronic diseases, including sarcoidosis. $^{38,39}$ 
We conclude that exercise intolerance, muscle weakness, and fatigue are frequent problems in sarcoidosis patients and that these complaints may last for considerable periods of time. In patients with a physical impairment a rehabilitation program should be considered as adjunct therapy, even though the achieved benefit needs future studies. 


\section{References}

1. Statement on sarcoidosis. Joint Statement of the American Thoracic Society (ATS), the European Respiratory Society (ERS) and the World Association of Sarcoidosis and Other Granulomatous Disorders (WASOG) adopted by the ATS Board of Directors and by the ERS Executive Committee, February 1999. Am J Respir Crit Care Med 1999;160:736-755.

2. Iannuzzi MC, Fontana JR. Sarcoidosis: clinical presentation, immunopathogenesis, and therapeutics. JAMA 2011;305:391-399.

3. Baughman RP, Culver DA, Judson MA. A concise review of pulmonary sarcoidosis. Am J Respir Crit Care Med 2011;183:573-581.

4. Sharma OP. Fatigue in sarcoidosis: incompletely understood, inadequately treated. Curr Opin Pulm Med 2012;18:470-471.

5. Michielsen HJ, Drent M, Peros-Golubicic T, De Vries J. Fatigue is associated with quality of life in sarcoidosis patients. Chest 2006;130:989-994.

6. Baydur A. Recent developments in the physiological assessment of sarcoidosis: clinical implications. Curr Opin Pulm Med 2012;18:499-505.

7. Drent M, Wirnsberger RM, De Vries J, Van Dieijen-Visser MP, Wouters EF, Schols AM. Association of fatigue with an acute phase response in sarcoidosis. Eur Respir J 1999;13:718-722.

8. Hinz A, Fleischer M, Brahler E, Wirtz H, Bosse-Henck A. Fatigue in patients with sarcoidosis, compared with the general population. Gen Hosp Psychiatry 2011;33:462-468.

9. Marcellis RG, Lenssen AF, Elfferich MD, De Vries J, Kassim S, Foerster K, Drent M. Exercise capacity, muscle strength and fatigue in sarcoidosis. Eur Respir J 2011;38:628-634.

10. Alhamad EH. The six-minute walk test in patients with pulmonary sarcoidosis. Ann Thorac Med 2009; 4:60-64.

11. Baughman RP, Sparkman BK, Lower EE. Six-minute walk test and health status assessment in sarcoidosis. Chest 2007;132:207-213.

12. Kabitz HJ, Lang F, Walterspacher S, Sorichter S, Muller-Quernheim J, Windisch W. Impact of impaired inspiratory muscle strength on dyspnea and walking capacity in sarcoidosis. Chest 2006;130:1496-1502.

13. Spruit MA, Thomeer MJ, Gosselink R, Troosters T, Kasran A, Debrock AJ, Demedts MG, Decramer M. Skeletal muscle weakness in patients with sarcoidosis and its relationship with exercise intolerance and reduced health status. Thorax 2005;60:32-38.

14. Baydur A, Alsalek M, Louie SG, Sharma OP. Respiratory muscle strength, lung function, and dyspnea in patients with sarcoidosis. Chest 2001;120:102-108.

15. Wirnsberger RM, Drent M, Hekelaar N, Breteler MH, Drent S, Wouters EF, Dekhuijzen PN. Relationship between respiratory muscle function and quality of life in sarcoidosis. Eur Respir J 1997;10:1450-1455.

16. Spruit MA, Wouters EFM, Gosselink R. Rehabilitation programmes in sarcoidosis: a multidisciplinary approach. Eur Respir J 2005;32:316-326.

17. Quanjer PH, Tammeling GJ, Cotes JE, Pedersen OF, Peslin R, Yernault JC. Lung volumes and forced ventilatory flows. Report working party standardization of lung function tests, European community for steel and coal. Official statement of the European Respiratory Society. Eur Respir J Suppl 1993;16:5-40.

18. Rothkrantz-Kos S, Van Dieijen-Visser MP, Mulder PG, Drent M. Potential usefulness of inflammatory markers to monitor respiratory functional impairment in sarcoidosis. Clin Chem 2003;49:1510-1517.

19. ATS committee on proficiency standards for clinical pulmonary function laboratories. ATS statement: guidelines for the six-minute walk test. Am J Respir Crit Care Med 2002;166:111-117.

20. Du Bois RM, Weycker D, Albera C, Bradford WZ, Costabel U, Kartashov A, Lancaster L, Noble PW, Sahn SA, Szwarcberg J, Thomeer M, Valeyre D, King TE, Jr. Six-minute-walk test in idiopathic pulmonary fibrosis: test validation and minimal clinically important difference. Am J Respir Crit Care Med 2011; 183:1231-1237.

21. Demers C, McKelvie RS, Negassa A, Yusuf S, Investigators RPS. Reliability, validity, and responsiveness of the six-minute walk test in patients with heart failure. Am Heart J 2001;142:698-703.

22. Freedson PS, Gilliam TB, Mahoney T, Maliszewski MA, Kastango K. Industrial torque levels by age group and gender. Isokinet Exerc Sci 1993;3:34-42.

23. Drouin JM, Valovich-mcLeod TC, Shultz SJ, Gansneder BM, Perrin DH. Reliability and validity of the Biodex system 3 pro isokinetic dynamometer velocity, torque and position measurements. Eur J Appl Physiol 2004;91:22-29. 
24. McCleary RW, Andersen JC. Test-retest reliability of reciprocal isokinetic knee extension and flexion peak torque measurements. J Athl Train 1992;27:362-365.

25. Bohannon RW. Make tests and break tests of elbow flexor muscle strength. Phys Ther 1988;68:193-194.

26. Bohannon RW, Andrews AW. Interrater reliability of hand-held dynamometry. Phys Ther 1987;67: 931-933.

27. Black LF, Hyatt RE. Maximal respiratory pressures: normal values and relationship to age and sex. Am Rev Respir Dis 1969;99:696-702.

28. Drent M, Lower EE, De Vries J. Sarcoidosis-associated fatigue. Eur Respir J 2012;40:255-263.

29. De Kleijn WP, De Vries J, Wijnen PA, Drent M. Minimal (clinically) important differences for the Fatigue Assessment Scale in sarcoidosis. Respir Med 2011;105:1388-1395.

30. Michielsen HJ, De Vries J, Van Heck GL, Van de Vijver FJR, Sijtsma K. Examination of the dimensionality of fatigue: The construction of the Fatigue Assessment Scale (FAS). EJPA 2004;20:39-48.

31. Trompenaars FJ, Masthoff ED, Van Heck GL, Hodiamont PP, De Vries J. Content validity, construct validity, and reliability of the WHOQOL-BREF in a population of Dutch adult psychiatric outpatients. Qual Life Res 2005;14:151-160.

32. Harik-Khan RI, Wise RA, Fozard JL. Determinants of maximal inspiratory pressure. The Baltimore Longitudinal Study of Aging. Am J Respir Crit Care Med 1998;158:1459-1464.

33. Al-Nozha MM, Al-Hazzaa HM, Arafah MR, Al-Khadra A, Al-Mazrou YY, Al-Maatouq MA, Khan NB, AlMarzouki K, Al-Harthi SS, Abdullah M, Al-Shahid MS. Prevalence of physical activity and inactivity among Saudis aged 30-70 years. A population-based cross-sectional study. Saudi Med J 2007;28: 559-568.

34. Miller A, Brown LK, Sloane MF, Bhuptani A, Teirstein AS. Cardiorespiratory responses to incremental exercise in sarcoidosis patients with normal spirometry. Chest 1995;107:323-329.

35. Fayad F, Liote F, Berenbaum F, Orcel P, Bardin T. Muscle involvement in sarcoidosis: a retrospective and followup studies. J Rheumatol 2006;33:98-103.

36. De Kleijn WP, Elfferich MD, De Vries J, Jonker GJ, Lower EE, Baughman RP, King TE, Jr., Drent M. Fatigue in sarcoidosis: American versus Dutch patients. Sarcoidosis Vasc Diffuse Lung Dis 2009;26:92-97.

37. Marcellis RG, Lenssen AF, De Vries GJ, Baughman RP, Van der Grinten CP, Verschakelen JA, De Vries J, Drent M. Is There an Added Value of Cardiopulmonary Exercise Testing in Sarcoidosis Patients? Lung 2013;191:43-52.

38. Huppmann P, Sczepanski B, Boensch M, Winterkamp S, Schonheit-Kenn U, Neurohr C, Behr J, Kenn K. Effects of in-patient pulmonary rehabilitation in patients with interstitial lung disease. Eur Respir $J$ 2013;42:444-453.

39. Kozu R, Senjyu H, Jenkins SC, Mukae H, Sakamoto N, Kohno S. Differences in response to pulmonary rehabilitation in idiopathic pulmonary fibrosis and chronic obstructive pulmonary disease. Respiration 2011;81:196-205. 


\section{Chapter 5}

Is there an added value of cardiopulmonary exercise testing in sarcoidosis patients?

RGJ Marcellis, AF Lenssen, GJ de Vries, RP Baughman, CP van der Grinten, JA Verschakelen, J De Vries, M Drent 


\section{Abstract}

\section{Background}

Cardiopulmonary exercise testing (CPET) with blood gas analysis may be helpful when there is a discrepancy between clinical findings and physiologic tests at rest. The aim of this study was to examine the added value of CPET compared to the measurement of the diffusing capacity of the lung for carbon monoxide (DLCO) in detecting impaired pulmonary gas exchange in sarcoidosis patients.

\section{Methods}

The clinical records of 160 (age $=41.3 \pm 10.0$ years; number of females $=63$ ) sarcoidosis patients referred to the former Maastricht University Medical Centre (MUMC) ild care center were retrospectively reviewed. Patients performed a symptom-limited incremental exercise test with blood gas analysis on a bicycle ergometer. DLCO was measured by the single-breath method.

\section{Results}

DLCO (mean $=83.2 \pm 18.0 \%$ ) below $80 \%$ of predicted was demonstrated by $38 \%$ of the sarcoidosis patients in our sample. Of the patients with normal DLCO $(n=99,61.9 \%)$, the $\mathrm{P}(\mathrm{A}-\mathrm{a}) \mathrm{O}_{2}$ at maximal exercise $\left(\mathrm{P}(\mathrm{A}-\mathrm{a}) \mathrm{O}_{2} \mathrm{max}\right)$ was moderately increased $(>2.5 \mathrm{kPa})$ in $69.7 \%$ and excessively increased $(>4.7 \mathrm{kPa}$ ) in $18.2 \%$. Pulmonary gas exchange impairment (PGEI) was more obvious in patients with lower DLCO values. A DLCO value below $60 \%$ of predicted indicated substantial gas exchange impairment. $\mathrm{PaO}_{2}$ at rest, $\mathrm{DLCO}$, and $\mathrm{FVC}$ as a percentage of predicted and radiographic staging predicted $40 \%$ of the PGEI at maximal exercise.

\section{Conclusion}

A substantial number of the symptomatic sarcoidosis patients with normal DLCO appeared to have PGEI at maximal exercise, suggesting that normal DLCO at rest is an inappropriate predictor of abnormal pulmonary gas exchange during exercise. CPET appeared to offer added value in detecting impaired gas exchange during exercise in sarcoidosis patients with unexplained disabling symptoms. 


\section{Introduction}

Pulmonary disease is the most common manifestation of sarcoidosis and pulmonary symptoms are the most common reason for treatment. ${ }^{1-3}$ Pulmonary sarcoidosis is the second-most common respiratory disease in young adults ( $<40$ years) after asthma. ${ }^{1,4,5}$ Apart from lung-related symptoms (e.g., coughing, breathlessness, and dyspnea on exertion), patients may suffer from a wide spectrum of rather nonspecific disabling symptoms like arthralgia, muscle pain, general weakness, muscle weakness, exercise limitations, fatigue, and cognitive failure. ${ }^{6-10}$ Sarcoidosis-related symptoms may be disabling, become chronic, and affect the patients' quality of life (QoL). ${ }^{7,11,12}$

Surveillance of sarcoidosis has not been standardized. In pulmonary sarcoidosis, lung function tests and imaging methods are the most used exams during the follow-up and evaluation of the therapeutic response. ${ }^{1,12-16}$ A treatment philosophy of sarcoidosis is that asymptomatic patients and patients with subtle abnormalities should probably be observed rather than treated so unnecessary side effects of treatment (e.g., corticosteroid side effects) can be avoided. ${ }^{1}$ Tools currently accepted in clinical practice to detect and follow-up respiratory functional impairment (RFI) and pulmonary gas exchange impairment (PGEI) in sarcoidosis include lung function tests at rest, including spirometry and measurement of the diffusing capacity of the lung for carbon monoxide (DLCO), and chest radiographic staging. ${ }^{1,17-19}$ Although these conventional tests at rest appear to be associated with an abnormal exercise test, normal spirometry and/or DLCO measurements do not exclude impaired gas exchange and exercise limitations

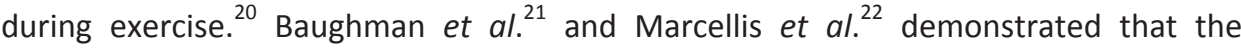
6-minute walking distance (6MWD) is useful to detect exercise limitations in sarcoidosis. However, in the Netherlands physical therapy reimbursement by health insurance companies depends on lung function test results at rest.

According to Miller et al. ${ }^{17}$, PGEI in sarcoidosis patients with normal spirometry and DLCO is extremely rare. However, both Miller et al. $^{17}$ and Medinger et al. ${ }^{23}$ reported that exercise testing might be a more sensitive way to detect impairment of oxygen transfer than DLCO in the early radiographic stages of sarcoidosis. Several other studies also discussed the value of cardiopulmonary exercise testing (CPET) for the detection of PGEI in early radiographic stages. ${ }^{18,19}$

It has also been suggested that CPET with blood gas analysis may be helpful, especially when there is a discrepancy between clinical findings and physiologic tests at rest. $^{24,25}$ Recently, Lopes et al. ${ }^{26}$ found significant reductions in forced vital capacity (FVC) and DLCO in patients with thoracic sarcoidosis at the 5-year follow-up. Additionally, they demonstrated that the outcome measures of the CPET $\left(P(A-a) O_{2}\right.$ and breathing reserve) are predictors of a decline in pulmonary function. Although mild defects in PGEI could easily be explained by parenchymal lesions associated with sarcoidosis, the presence of persistent or progressive RFI and PGEI may indicate an increased risk of developing pulmonary hypertension or a cor pulmonale. This knowledge might influence the frequency of follow-up and treatment strategies in the management of these patients. ${ }^{23,27,28}$ 
Therefore, the aim of the present study was to examine the possible added role of CPET compared to DLCO measurements to detect impaired pulmonary gas exchange in sarcoidosis patients with disabling symptoms. Additionally, we studied the predictive value of physical testing and other clinical characteristics, including lung function test results, radiographic stages, fatigue, dyspnea, prednisone use, and inflammatory markers, for the independent variable of impaired gas exchange.

\section{Methods}

\section{Subjects}

This retrospective study involved a review of the clinical records of 160 consecutive chronic refractory sarcoidosis patients suffering from disabling symptoms who were referred to the former ild (interstitial lung disease) care team, a tertiary referral center of the Department of Respiratory Medicine of the Maastricht University Medical Centre (MUMC), over a 4-year period, and who performed an exercise test with arterial blood gas analysis. The diagnosis of sarcoidosis was based on consistent clinical features and bronchoalveolar lavage fluid analysis, according to the World Association of Sarcoidosis and Other Granulomatous Disorders (WASOG) guidelines ${ }^{29}$, with biopsy-proven noncaseating epithelioid cell granulomas confirming sarcoidosis in $75 \%$. None of these patients was suffering from anemia or had another relevant medical history or comorbidity. Informed consent was obtained from all participants.

The reason for performing a CPET was unexplained disabling fatigue, complaints of dyspnea, exercise limitations, and other disabling symptoms. Disabling symptoms are defined as the presence of more than one symptom that had substantial influence on QoL and that could not be explained by the results of routine investigations, including lung function tests or chest radiographs. ${ }^{12}$ At that time, this test was an integral part of the diagnostic workup protocol for the patients with disabling symptoms who were referred for a second opinion. The questionnaires were completed the same day that the CPET was performed. The lung function test and chest radiographs were performed on the same day or within a week. The relevant clinical data were obtained from the medical records. This study was approved by the local Medical Ethics Committee of the MUMC.

\section{Clinical evaluation}

Forced expiratory volume in one second $\left(\mathrm{FEV}_{1}\right)$ and forced vital capacity (FVC) were measured with a pneumotachograph (Masterlab, Jaeger, Würzburg, Germany). DLCO was measured using the single-breath method (Masterlab). ${ }^{30}$ Pulmonary function tests were performed according to the standards of the European Community of Coal and Steel. $^{30}$ 
The serum levels of soluble interleukin-2 receptor (sIL-2R) were determined using an IMMULITE Automated Analyzer. ${ }^{31}$ The C-reactive protein (CRP) concentration was measured by a turbidimetric method on a SYNCHRON LX (Beckman Coulter Inc., Fullerton, CA, USA). ${ }^{31}$

The chest radiographs ${ }^{29}$ were scored by an experienced thoracic radiologist (JV), blinded to the patient's clinical history. Chest radiographs were graded according to DeRemee (0-III), adding stage IV. ${ }^{1}$

\section{Maximal exercise capacity and peripheral muscle strength}

Patients performed a symptom-limited incremental exercise test $(10 \mathrm{~W} / \mathrm{min})$ on an electronically braked cycle ergometer (Cornival 400, Lode, Groningen, the Netherlands) from which peak work rate (in watts $(\mathrm{W})$ ) and maximal oxygen uptake $\left(\mathrm{VO}_{2}\right.$ max) were determined. These exercise tests were performed according to the American Thoracic Society's standards. ${ }^{32}$ The CPETs were interpreted by a trained and experienced physiologist (CvdG), blinded to the patient's clinical history. Pedaling frequency of between 60 and $70 \mathrm{cpm}$ was chosen by the subjects and kept constant throughout the test. Breath-by-breath gas exchange was measured throughout the test using a face mask (Oxyconbeta, Jaeger, Würzburg, Germany). Arterial blood samples were taken at rest and during maximal exercise and analyzed immediately. The alveolar-arterial oxygen pressure difference (in $\mathrm{kPa}$ ) at rest $\left(\mathrm{P}(\mathrm{A}-\mathrm{a}) \mathrm{O}_{2}\right.$ rest) and at maximal exercise $\left(\mathrm{P}(\mathrm{A}-\mathrm{a}) \mathrm{O}_{2}\right.$ max $)$ and the difference in $\mathrm{P}(\mathrm{A}-\mathrm{a}) \mathrm{O}_{2}$ between rest and maximal exercise $\left(\triangle \mathrm{P}(\mathrm{A}-\mathrm{a}) \mathrm{O}_{2}\right)$ were calculated. $\mathrm{P}(\mathrm{A}-\mathrm{a}) \mathrm{O}_{2}$ max values above $2.5 \mathrm{kPa}$ were assumed to indicate moderately impaired gas exchange and values above $4.7 \mathrm{kPa}$ indicated excessively impaired gas exchange. ${ }^{33,34}$ The arterial oxygen pressure and carbon dioxide pressure were also determined at rest $\left(\mathrm{PaO}_{2}\right.$ rest and $\mathrm{PaCO}_{2}$ rest $)$ and during maximal exercise $\left(\mathrm{PaO}_{2}\right.$ max and $\left.\mathrm{PaCO}_{2} \mathrm{max}\right)$. $\mathrm{PaO}_{2}$ max below $10.6 \mathrm{kPa}$ and $\mathrm{PaCO}_{2}$ above $5.6 \mathrm{kPa}$ indicated impairment. ${ }^{34}$ Lactic acid was determined at rest and at the end of the test using the Chiron 800 series blood gas analyzer (Siemens/Chiron Diagnostics, Erlangen, Germany), which uses an electrochemical measuring chamber based on the principle of amperometry (normal value=0.6-2.4 $\mathrm{mmol} / \mathrm{l}$ ). Heart rate (HR) was monitored continuously throughout the test using a 12-lead ECG. The predicted peak heart rate was calculated as 220-age. ${ }^{34}$ Peak heart rate as a percentage of the predicted value was calculated as peak heart rate/220-age (normal value $\geq 85 \%$ of the predicted value). At the end of the test, the Borg scale was used to measure perceived dyspnea (range=1-10). CPETs were considered to be performed maximally if the lactate concentration was $>4 \mathrm{mmol} / \mathrm{l}$ and/or the peak heart rate was $>85 \%$ of the predicted value at the end of the test.

Inspiratory muscle strength (PImax) was assessed by measuring maximal inspiratory mouth pressures at residual volume using a handheld pressure transducer (MicroMPM, Micro Medical Ltd, Rochester, UK) with a small leak. ${ }^{35,36}$ The maximal isometric handgrip force (HGF) of the dominant hand (in $\mathrm{kg}$ ) was measured with a Jamar dynamometer (Sammons Preston, Chicago, IL, USA). ${ }^{37}$ 


\section{Questionnaire}

Fatigue was measured using the 10-item Fatigue Assessment Scale (FAS) questionnaire. Each item has a 5-point rating scale so FAS scores range from 10 to 50. FAS scores below 22 indicate nonfatigued persons, scores of 22-34 indicate fatigued persons, and scores of 35 or more indicate extremely fatigued persons. ${ }^{38}$ The psychometric properties of the FAS are good, including for sarcoidosis. ${ }^{38}$

\section{Statistical analysis}

Demographic and clinical data are expressed as mean \pm standard deviation (SD) and, where appropriate, in absolute numbers or percentages. Frequency distributions were used to determine the prevalence of impaired lung functions, exercise intolerance, reduced muscle strength, and fatigue. The normal distribution of the variables was evaluated with the Kolmogorov-Smirnov analysis. Lung function and physical test results (peak work rate, handgrip force, and maximal inspiratory pressure) below $80 \%$ of the predicted values were assumed to indicate physical impairment. ${ }^{30,32,36,37} \mathrm{VO}_{2} \mathrm{max}$ below $83 \%$ of the predicted value indicated impaired exercise intolerance. ${ }^{32}$

Patients were subdivided into three groups according to DLCO: group A (DLCO $<60 \%$ of the predicted value), group B (DLCO $60-80 \%$ of the predicted value), and group C (DLCO $\geq 80 \%$ of the predicted value). Statistically significant differences between these groups with regard to demographic, clinical, and physical characteristics were investigated by analyzing continuous data with a one-way ANOVA and examining nominal data using $\chi^{2}$ tests.

Bivariate associations between $\mathrm{P}(\mathrm{A}-\mathrm{a}) \mathrm{O}_{2}$ max and continuous demographic and physical characteristics were calculated using Pearson's correlations. Differences in $\mathrm{P}(\mathrm{A}-\mathrm{a}) \mathrm{O}_{2}$ max values with respect to gender, oral prednisone use, and chest radiographic stages (0-I vs. II-IV) were explored by means of t-tests. Variables with a significant bivariate association with $\mathrm{P}(\mathrm{A}-\mathrm{a}) \mathrm{O}_{2}$ max were used for multiple regression analysis. A backward multiple regression analysis was used to develop a model to predict $\mathrm{P}(\mathrm{A}-\mathrm{a}) \mathrm{O}_{2}$ max. $\mathrm{p}<0.05$ was considered statistically significant. Analyses were performed using SPSS 18.0 for Windows (SPSS Inc., Chicago, IL, USA).

\section{Results}

\section{Patient characteristics}

The study included 160 symptomatic sarcoidosis patients (mean age $=41.3 \pm 10.0$ years). The demographic and clinical data, subdivided according to DLCO, are summarized in Table 5.1. The majority of the study sample were men $(n=97,60.6 \%)$.

There was a high prevalence of reduced DLCO (38.1\%) and reduced $\mathrm{FEV}_{1}(35.6 \%)$. Respiratory functional impairment (RFI; DLCO or FVC or $\mathrm{FEV}_{1}<80 \%$ of predicted) was 
found in $47.5 \%$ of the sample. Patients with reduced DLCO values had more severely reduced lung function test results as well as more impaired chest radiographs compared to patients with normal DLCO values.

Table 5.1 Demographic and clinical characteristics of the sarcoidosis sample $(n=160)$ studied, subdivided according to DLCO.

\begin{tabular}{|c|c|c|c|c|}
\hline & $\begin{array}{l}\text { Total sarcoidosis } \\
\text { sample }\end{array}$ & DLCO $<60 \%$ & DLCO $60-80 \%$ & $\mathrm{DLCO} \geq 80 \%$ \\
\hline \multicolumn{5}{|l|}{ Demographics } \\
\hline No. of patients (female/male) & $160(63 / 97)$ & $14(3 / 11)$ & $47(20 / 27)$ & 99 (40 / 59) \\
\hline Age (yrs) & $41.3 \pm 10.0$ & $43.9 \pm 7.2$ & $39.8 \pm 9.4$ & $41.7 \pm 10.6$ \\
\hline Time since diagnosis (yrs) & $4.1 \pm 5.1$ & $5.9 \pm 4.9$ & $4.7 \pm 6.0$ & $3.5 \pm 4.5$ \\
\hline $\begin{array}{l}\text { Nonsmoker/smoker/given up } \\
<1 \text { year }(\mathrm{n})\end{array}$ & $140 / 17 / 3$ & $13 / 1 / 0$ & $40 / 6 / 1$ & $87 / 10 / 2$ \\
\hline \multicolumn{5}{|l|}{ Medication } \\
\hline Prednisone use (yes/no) (n (\%)) & $81(50.6)$ / $79(49.4)$ & $10(71.4) / 4(28.6)$ & $31(66.0) / 16(34.0)$ & $40(40.4) / 59(59.6)$ \\
\hline \multicolumn{5}{|l|}{ Lung function tests } \\
\hline DLCO (\% pred) & $83.2 \pm 18.0$ & $47.7 \pm 6.3$ & $70.7 \pm 5.9$ & $94.2 \pm 11.3$ \\
\hline \% Reduced DLCO & 38.1 & 100 & 100 & 0 \\
\hline FVC (\% pred $)^{a, b, c}$ & $93.9 \pm 21.2$ & $62.3 \pm 11.4$ & $83.6 \pm 17.6$ & $103.2 \pm 16.8$ \\
\hline$\%$ Reduced FVC ${ }^{a, b, c}$ & 23.1 & 85.7 & 40.4 & 6.1 \\
\hline $\mathrm{FEV}_{1}(\% \text { pred })^{\mathrm{a}, \mathrm{b}}$ & $84.7 \pm 23.6$ & $56.6 \pm 10.4$ & $69.9 \pm 21.0$ & $95.8 \pm 18.4$ \\
\hline$\%$ Reduced FEV ${ }_{1}^{\mathrm{a}, \mathrm{b}, \mathrm{c}}$ & 35.6 & 100 & 61.7 & 14.1 \\
\hline $\operatorname{RFI}(n(\%))^{a, b}$ & $76(47.5)$ & $14(100)$ & $47(100)$ & $15(15.2)$ \\
\hline \multicolumn{5}{|l|}{ Chest radiographic stages } \\
\hline $0+I$ versus $I I+I I I+I V(n(\%))^{a, b}$ & $46(28.8) / 114(71.2)$ & $0(0) / 14(100.0)$ & 5 (10.6) / 42 (89.4) & $41(41.4) / 58(58.6)$ \\
\hline \multicolumn{5}{|l|}{ Inflammatory markers } \\
\hline $\mathrm{CRP}<10 \mathrm{mg} / \mathrm{l}$ & $13.1 \pm 22.3$ & $13.3 \pm 9.4$ & $14.5 \pm 30.6$ & $12.3 \pm 18.8$ \\
\hline sIL-2R, 214-846 kU/I & $882 \pm 683$ & $1,194 \pm 770$ & $1,000 \pm 641$ & $792 \pm 682$ \\
\hline \multicolumn{5}{|l|}{ Body composition } \\
\hline Body mass index $\left(\mathrm{kg} / \mathrm{m}^{2}\right)^{\mathrm{b}}$ & $26.2 \pm 4.8$ & $23.5 \pm 4.7$ & $5.2 \pm 4.6$ & $27.0 \pm 4.7$ \\
\hline \multicolumn{5}{|l|}{ Fatigue measure } \\
\hline FAS score & $29.5 \pm 8.2$ & $32.1 \pm 6.8$ & $28.8 \pm 7.8$ & $29.4 \pm 8.5$ \\
\hline Fatigued (FAS $\geq 22$ ) (\%) & 81.6 & 100 & 80.0 & 79.6 \\
\hline Extremely fatigued (FAS $\geq 35$ ) (\%) & 30.6 & 42.9 & 25.0 & 31.2 \\
\hline
\end{tabular}

Data are expressed as mean \pm standard deviation (SD), absolute numbers $(n)$, or percentages (\%). DLCO: diffusing capacity of the lung for carbon monoxide; \% pred: \% of predicted value; FVC: forced vital capacity; $\mathrm{FEV}_{1}$ : forced expiratory volume in one second; RFI: respiratory functional impairment (DLCO or FVC or FEV $<80 \%$ of predicted value); CRP: C-reactive protein; sIL-2R: soluble interleukin-2 receptor; FAS: Fatigue Assessment Scale. $p<0.05$ : ${ }^{a}$ DLCO $\geq 80$ versus $60-80 \%$; ${ }^{b}$ DLCO $\geq 80$ versus $<60 \%$; ${ }^{\text {DLCO }} 60-80$ versus $<60 \%$.

\section{Exercise intolerance}

The physical characteristics of the sarcoidosis population, subdivided according to DLCO, are summarized in Table 5.2. Peak HR $\geq 85 \%$ of the predicted value was achieved by $68 \%$ of the patients. The peak HR was achieved by $50 \%, 57 \%$, and $74 \%$ in patients with a DLCO $<60 \%, 60-80 \%$, and $\geq 80 \%$ of the predicted value, respectively. According to the lactate concentration and/or the peak HR at the end of the test, $83 \%$ of the patients performed a maximal CPET. In this study, $59 \%$ of the patients failed to reach at least $83 \%$ of their predicted maximal $\mathrm{VO}_{2}$. There was a high prevalence of reduced peak work 
rate and $\mathrm{VO}_{2}$ max in patients with normal as well as reduced DLCO values. Patients with reduced DLCO values showed significantly poorer peak work rates and $\mathrm{VO}_{2}$ max values and more reduced peak heart rate values compared to those with normal DLCO values. $\mathrm{PaO}_{2}, \mathrm{PaCO}_{2}$, and $\mathrm{P}(\mathrm{A}-\mathrm{a}) \mathrm{O}_{2}$ at rest were normal compared to the reference values and did not differ between patients with normal and reduced DLCO values. Also, the difference in lactate concentrations between exercise and rest did not differ between subgroups. The mean $\mathrm{P}(\mathrm{A}-\mathrm{a}) \mathrm{O}_{2}$ at maximal exercise was increased in the total population. However, patients with reduced DLCO values showed significantly poorer $\mathrm{P}(\mathrm{A}-\mathrm{a}) \mathrm{O}_{2}$ and $\mathrm{PaO}_{2}$ values at maximal exercise compared to those with normal DLCO values.

Peak heart rate showed weak correlations with $\mathrm{VO}_{2}$ max values $(r=0.189 ; p=0.018)$. Fatigue (FAS score) was unrelated to the differences in lactate concentrations between rest and exercise and peak heart rate.

\section{Gas exchange impairment at maximal exercise}

$\mathrm{P}(\mathrm{A}-\mathrm{a}) \mathrm{O}_{2}$ max was above $2.5 \mathrm{kPa}$ in 125 patients (78.1\%) and above $4.7 \mathrm{kPa}$ in 51 patients (31.9\%; Tables 5.2 and 5.3). Slight and excessive gas exchange impairments at maximal exercise were found in $42(89.4 \%)$ and 20 (42.6\%) patients with a DLCO between $60 \%$ and $80 \%$ of predicted $(n=47 ; 29.4 \%)$, respectively, and in $69(69.7 \%)$ and $18(18.2 \%)$ patients with a normal DLCO ( $n=99 ; 61.9 \%$; Tables 5.2 and 5.3), respectively. None of the patients with DLCO $<60 \%$ of the predicted value had a $\mathrm{P}(\mathrm{A}-\mathrm{a}) \mathrm{O}_{2}$ max below $2.5 \mathrm{kPa}$, and only one patient had a $\mathrm{P}(\mathrm{A}-\mathrm{a}) \mathrm{O}_{2}$ max below $4.7 \mathrm{kPa}$ (Tables 5.2 and 5.3).

Ten of 21 (47.6\%) patients with radiographic stage 0 had a $P(A-a) \mathrm{O}_{2}$ max above $2.5 \mathrm{kPa}$, and 1 of 21 (4.8\%) had a $\mathrm{P}(\mathrm{A}-\mathrm{a}) \mathrm{O}_{2}$ max above $4.7 \mathrm{kPa}$. Seventeen of 25 (68.0\%) patients with radiographic stage I had a $\mathrm{P}(\mathrm{A}-\mathrm{a}) \mathrm{O}_{2}$ max above $2.5 \mathrm{kPa}$, and 1 of $25(4.0 \%)$ had a $\mathrm{P}(\mathrm{A}-\mathrm{a}) \mathrm{O}_{2}$ max above $4.7 \mathrm{kPa}$.

Of the patients $(n=41)$ with a normal DLCO value and a chest radiograph without parenchymal involvement (stages 0 and I), 23 (56.1\%) had a $\mathrm{P}(\mathrm{A}-\mathrm{a}) \mathrm{O}_{2}$ max above $2.5 \mathrm{kPa}$ and $2(4.9 \%)$ had a $\mathrm{P}(\mathrm{A}-\mathrm{a}) \mathrm{O}_{2}$ max above $4.7 \mathrm{kPa}$. 
Table 5.2 Physical characteristics of the sarcoidosis patients $(n=160)$ studied, subdivided according to DLCO.

\begin{tabular}{|c|c|c|c|c|}
\hline & $\begin{array}{c}\text { Total sarcoidosis } \\
\text { sample }\end{array}$ & DLCO $<60 \%$ & DLCO $60-80 \%$ & $\mathrm{DLCO} \geq 80 \%$ \\
\hline \multicolumn{5}{|l|}{ Maximal exercise capacity } \\
\hline $\mathrm{PaO}_{2}$ rest $(\mathrm{kPa})$ & $11.2 \pm 1.6$ & $10.7 \pm 1.4$ & $11.3 \pm 1.8$ & $11.2 \pm 1.6$ \\
\hline $\mathrm{PaO}_{2} \max (\mathrm{kPa})(>10.6 \mathrm{kPa})^{\mathrm{a}, \mathrm{b}, \mathrm{c}}$ & $11.1 \pm 2.0$ & $8.2 \pm 0.6$ & $10.6 \pm 2.0$ & $11.7 \pm 1.7$ \\
\hline$\Delta \mathrm{PaO}_{2}(\mathrm{kPa})^{\mathrm{a}, \mathrm{b}, \mathrm{c}}$ & $-0.06 \pm 2.1$ & $-2.6 \pm 1.6$ & $-0.7 \pm 2.1$ & $0.6 \pm 1.9$ \\
\hline $\mathrm{PaCO}_{2}$ rest $(\mathrm{kPa})(<5.6 \mathrm{kPa})$ & $5.2 \pm 0.5$ & $5.1 \pm 0.5$ & $5.2 \pm 0.5$ & $5.2 \pm 0.5$ \\
\hline $\mathrm{PaCO}_{2} \max (\mathrm{kPa})^{\mathrm{a}}$ & $4.9 \pm 0.7$ & $5.2 \pm 0.7$ & $5.1 \pm 0.8$ & $4.8 \pm 0.6$ \\
\hline$\Delta \mathrm{PaCO}_{2}(\mathrm{kPa})^{\mathrm{a}, \mathrm{b}}$ & $-0.3 \pm 0.7$ & $0.1 \pm 0.6$ & $-0.1 \pm 0.6$ & $-0.4 \pm 0.7$ \\
\hline $\mathrm{P}(\mathrm{A}-\mathrm{a}) \mathrm{O}_{2}$ rest $(\mathrm{kPa})$ & $2.3 \pm 1.7$ & $2.6 \pm 1.5$ & $2.3 \pm 2.1$ & $2.2 \pm 1.6$ \\
\hline $\mathrm{P}(\mathrm{A}-\mathrm{a}) \mathrm{O}_{2} \max (\mathrm{kPa})^{\mathrm{a}, \mathrm{b}, \mathrm{c}}$ & $4.1 \pm 1.8$ & $6.4 \pm 1.2$ & $4.6 \pm 1.7$ & $3.5 \pm 1.5$ \\
\hline Above $2.5 \mathrm{kPa}^{\mathrm{a}, \mathrm{b}}(\%)$ & 78.1 & 100.0 & 89.4 & 69.7 \\
\hline Above $4.7 \mathrm{kPa}^{\mathrm{a}, \mathrm{b}, \mathrm{c}}(\%)$ & 31.9 & 92.9 & 42.6 & 18.2 \\
\hline$\Delta \mathrm{P}(\mathrm{A}-\mathrm{a}) \mathrm{O}_{2}(\mathrm{kPa})^{\mathrm{a}, \mathrm{b}, \mathrm{c}}$ & $1.8 \pm 2.0$ & $4.0 \pm 1.6$ & $2.2 \pm 2.0$ & $1.2 \pm 1.8$ \\
\hline \multicolumn{5}{|l|}{ Peak power $(\mathrm{W})$} \\
\hline Women & $116.2 \pm 30.8$ & $87.5 \pm 10.6$ & $105.8 \pm 21.3$ & $122.9 \pm 33.5$ \\
\hline Men $^{a, b}$ & $152.6 \pm 51.5$ & $100.9 \pm 27.8$ & $131.9 \pm 44.9$ & $171.8 \pm 47.7$ \\
\hline Peak power (\% pred) $)^{a, b, c}$ & $75.6 \pm 24.8$ & $48.8 \pm 15.7$ & $69.1 \pm 24.6$ & $82.2 \pm 22.8$ \\
\hline$\%$ Reduced power ${ }^{a, b}$ & 60.4 & 92.3 & 70.2 & 51.5 \\
\hline $\mathrm{VO}_{2} \max (\% \text { pred })^{\mathrm{a}, \mathrm{b}, \mathrm{c}}$ & $78.5 \pm 23.9$ & $52.4 \pm 14.6$ & $72.5 \pm 23.4$ & $85.0 \pm 21.9$ \\
\hline$\%$ Reduced $\mathrm{VO}_{2} \max ^{\mathrm{a}, \mathrm{b}, \mathrm{c}}$ & 59.0 & 100.0 & 68.8 & 48.5 \\
\hline Peak heart rate (beats/min) & $159.1 \pm 21.0$ & $150.4 \pm 20.3$ & $154.1 \pm 21.7$ & $162.7 \pm 20.0$ \\
\hline Peak heart rate $(\% \text { pred })^{a}$ & $89.0 \pm 10.9$ & $85.6 \pm 12.8$ & $85.2 \pm 11.1$ & $91.3 \pm 10.1$ \\
\hline Lactate at rest $(\mathrm{mmol} / \mathrm{l})$ & $1.2 \pm 0.5$ & $1.3 \pm 0.6$ & $1.2 \pm 0.5$ & $1.1 \pm 0.5$ \\
\hline Lactate at exercise $(\mathrm{mmol} /)$ & $5.5 \pm 2.0$ & $5.1 \pm 1.7$ & $5.1 \pm 1.9$ & $5.7 \pm 2.0$ \\
\hline$\Delta$ Lactate $(\mathrm{mmol} / \mathrm{l})$ & $4.3 \pm 1.9$ & $3.8 \pm 1.8$ & $3.9 \pm 1.9$ & $4.6 \pm 1.9$ \\
\hline Borg scale & $4.6 \pm 2.9$ & $6.6 \pm 2.7$ & $4.8 \pm 3.2$ & $4.2 \pm 2.6$ \\
\hline \multicolumn{5}{|l|}{ Muscle force } \\
\hline \multicolumn{5}{|l|}{ HGF (kg) } \\
\hline Women & $26.9 \pm 6.4$ & $27.3 \pm 4.2$ & $27.4 \pm 7.1$ & $26.6 \pm 6.3$ \\
\hline Men & $45.3 \pm 9.8$ & $42.4 \pm 7.1$ & $46.3 \pm 9.1$ & $45.3 \pm 10.4$ \\
\hline HGF (\% pred) & $86.3 \pm 18.8$ & $84.8 \pm 14.9$ & $88.5 \pm 18.5$ & $85.5 \pm 19.4$ \\
\hline$\%$ Reduced HGF & 37.9 & 50.0 & 33.3 & 38.5 \\
\hline \multicolumn{5}{|l|}{ PImax $\left(\mathrm{cmH}_{2} \mathrm{O}\right)$} \\
\hline Women & $-76.2 \pm 23.9$ & $-87.3 \pm 15.3$ & $-79.0 \pm 24.5$ & $-74.0 \pm 24.2$ \\
\hline Men & $-92.9 \pm 28.3$ & $-92.2 \pm 33.7$ & $-96.4 \pm 31.2$ & $-91.5 \pm 26.2$ \\
\hline PImax (\% pred) & $87.2 \pm 30.1$ & $92.8 \pm 30.5$ & $90.6 \pm 33.9$ & $84.8 \pm 28.1$ \\
\hline \% Reduced PImax & 43.9 & 35.7 & 44.4 & 44.8 \\
\hline
\end{tabular}

Data are expressed as mean \pm standard deviation (SD) or percentages (\%). Reference values are in parenthesis. $\mathrm{PaO}_{2}$ : arterial oxygen pressure; $\Delta$ : change in oxygen or carbon dioxide pressure or lactate concentration between rest and maximal exercise; $\mathrm{PaCO}_{2}$ : arterial carbon dioxide pressure; $\mathrm{P}(\mathrm{A}-\mathrm{a}) \mathrm{O}_{2}$ : alveolar-arterial oxygen pressure difference; \% pred: \% of predicted value; HGF: handgrip force; PImax: maximal inspiratory pressure. $\mathrm{p}<0.05$ : ${ }^{a}$ DLCO $\geq 80 \%$ versus $60-80 \%$; ${ }^{b}$ DLCO $\geq 80 \%$ versus $<60 \%$; ${ }^{c}$ DLCO $60-80 \%$ versus $<60 \%$.

\section{Muscle weakness}

Although the mean muscle strength results were normal, the prevalence of reduced handgrip force (38\%) and PImax (44\%) was high (Table 5.2). There were no significant differences in muscle strength between patients with normal and reduced DLCO values. 
Table 5.3 Frequency distribution of the alveolar-arterial oxygen pressure difference at maximal exercise (cutoff values: $2.5 \mathrm{kPa}$ and $4.7 \mathrm{kPa}$ ) for each of the three DLCO groups.

\begin{tabular}{|c|c|c|c|c|}
\hline & DLCO $<60 \%$ & DLCO $60-80 \%$ & DLCO $\geq 80 \%$ & Total sarcoidosis sample \\
\hline $\mathrm{P}(\mathrm{A}-\mathrm{a}) \mathrm{O}_{2} \max \leq 2.5 \mathrm{kPa}$ & 0 & 5 & 30 & 35 \\
\hline $\mathrm{P}(\mathrm{A}-\mathrm{a}) \mathrm{O}_{2} \max >2.5-4.7 \mathrm{kPa}$ & 1 & 22 & 51 & 74 \\
\hline \multirow[t]{2}{*}{$\mathrm{P}(\mathrm{A}-\mathrm{a}) \mathrm{O}_{2} \max >4.7 \mathrm{kPa}$} & 13 & 20 & 18 & 51 \\
\hline & 14 & 47 & 99 & 160 \\
\hline
\end{tabular}

Data are expressed as absolute numbers. DLCO: diffusing capacity of the lung for carbon monoxide; $\mathrm{P}(\mathrm{A}-\mathrm{a}) \mathrm{O}_{2}$ max: alveolar-arterial oxygen pressure difference at maximal exercise.

\section{Relationship between $\mathrm{P}(\mathrm{A}-\mathrm{a}) \mathrm{O}_{2}$ max and clinical parameters}

$\mathrm{P}(\mathrm{A}-\mathrm{a}) \mathrm{O}_{2}$ max showed a moderate bivariate correlation with DLCO\% (Figure 5.1), FVC\%, and $\mathrm{FEV}_{1} \%$, and a weak correlation with the Borg scale and $\mathrm{PaO}_{2}$ rest (Table 5.4).

$\mathrm{P}(\mathrm{A}-\mathrm{a}) \mathrm{O}_{2}$ max also differed with sex $(\mathrm{t}=2.545, \mathrm{p}=0.012)$, oral prednisone use $(\mathrm{t}=-2.699$, $\mathrm{p}=0.008$ ), and parenchymal involvement on chest radiograph (stages 0 -I vs. II-IV) $(t=-7.197, p<0.001) . P(A-a) O_{2}$ max was not correlated with demographic characteristics (age and time since diagnosis), peak heart rate, lactate concentrations, peripheral and inspiratory muscle strength, fatigue scores, and levels of inflammatory markers (CRP and SIL-2R).

Multiple regression analysis showed $\mathrm{PaO}_{2}$ rest, $\mathrm{DLCO} \%, \mathrm{FVC} \%$, and radiographic staging to be significantly independent predictors of $\mathrm{P}(\mathrm{A}-\mathrm{a}) \mathrm{O}_{2}$ max in these patients, predicting $39.6 \%$ of $\mathrm{P}(\mathrm{A}-\mathrm{a}) \mathrm{O}_{2} \max$ (Table 5.5 ).

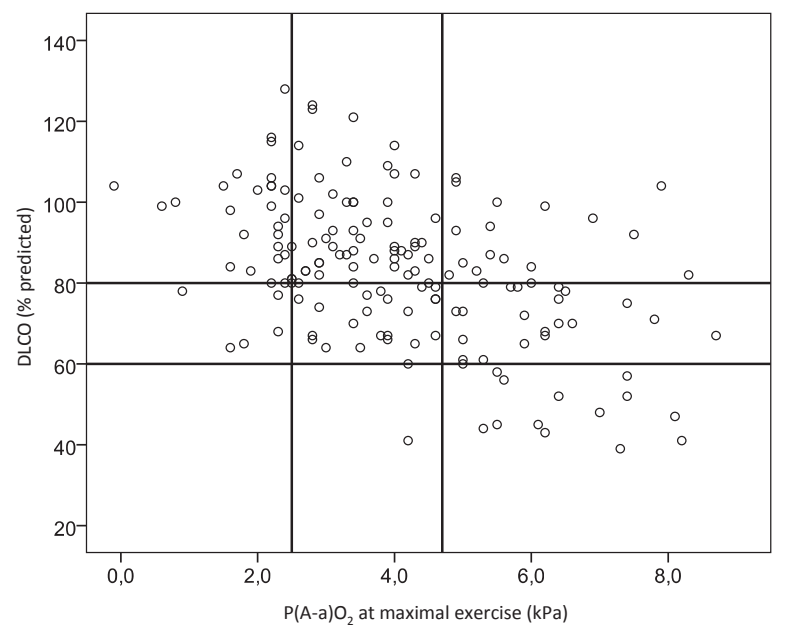

Figure 5.1 Correlation of the resting single-breath DLCO expressed as percentage of the predicted value and the alveolar-arterial oxygen pressure difference $\left(P(A-a) O_{2}\right)$ at maximal exercise $(r=-0.48$, $p<0.001)$. The figure includes cutoff values for both DLCO $(60 \%$ and $80 \%$, respectively) and $\mathrm{P}(\mathrm{A}-\mathrm{a}) \mathrm{O}_{2}$ at maximal exercise $(2.5 \mathrm{kPa}$ and $4.7 \mathrm{kPa}$, respectively). 
Table 5.4 Correlations between alveolar-arterial oxygen pressure difference at maximal exercise $\left(\mathrm{P}(\mathrm{A}-\mathrm{a}) \mathrm{O}_{2} \mathrm{max}\right)$ and patients' pulmonary and physical characteristics.

$\begin{array}{lcc}\text { Variables } & \text { Pearson's correlation coefficient }(r) & p \text {-value } \\ \text { DLCO (\% pred) } & -0.475 & <0.001 \\ \text { FVC (\% pred) } & -0.468 & <0.001 \\ \text { FEV }_{1} \text { (\% pred) } & -0.465 & <0.001 \\ \text { FAS score } & -0.060 & 0.474 \\ \text { Modified Borg scale } & 0.271 & 0.001 \\ \mathrm{PaO}_{2} \text { rest }(\mathrm{kPa}) & -0.315 & <0.001\end{array}$

DLCO: diffusing capacity of the lung for carbon monoxide; \% pred: \% of predicted value; FVC: forced vital capacity; $\mathrm{FEV}_{1}$ : forced expiratory volume in one second; $\mathrm{FAS}$ : fatigue assessment scale; $\mathrm{PaO}_{2}$ : arterial oxygen pressure.

Table 5.5 Multiple regression analysis: relationship between the alveolar-arterial oxygen pressure difference at maximal exercise and clinical variables.

\begin{tabular}{|c|c|c|c|c|c|}
\hline \multirow[t]{2}{*}{ Outcome variable } & \multirow[t]{2}{*}{ Independent variables } & \multicolumn{2}{|c|}{$\begin{array}{l}\text { Unstandardized } \\
\text { coefficient }\end{array}$} & \multirow{2}{*}{$\begin{array}{c}\text { Standardized } \\
\text { coefficients } \\
\text { Beta }\end{array}$} & \multirow[t]{2}{*}{$\mathrm{p}$-value } \\
\hline & & B & Std error & & \\
\hline \multirow[t]{5}{*}{$\mathrm{P}(\mathrm{A}-\mathrm{a}) \mathrm{O}_{2} \max (\mathrm{kPa})$} & (constant) & 10.42 & 1.091 & & $<0.001$ \\
\hline & DLCO (\% pred) & -0.028 & 0.008 & -0.291 & 0.001 \\
\hline & FVC (\% pred) & -0.016 & 0.007 & -0.194 & 0.029 \\
\hline & $\mathrm{PaO}_{2}$ rest $(\mathrm{kPa})$ & -0.274 & 0.072 & -0.255 & $<0.001$ \\
\hline & $\begin{array}{l}\text { Chest radiographic } \\
\text { stages (0-I vs. II-IV) }\end{array}$ & 0.700 & 0.278 & 0.181 & 0.013 \\
\hline
\end{tabular}

$\mathrm{P}(\mathrm{A}-\mathrm{a}) \mathrm{O}_{2}$ max: alveolar-arterial oxygen pressure difference at maximal exercise; DLCO: diffusing capacity of the lung for carbon monoxide; \% pred: \% of predicted value; FVC: forced vital capacity; $\mathrm{PaO}_{2}$ : arterial oxygen pressure.

\section{Discussion}

The aim of the present study was to evaluate the added value of CPET compared to DLCO measurements in detecting impaired pulmonary gas exchange in symptomatic sarcoidosis patients. Although $62 \%$ of the sarcoidosis patients in our sample had normal DLCO ( $280 \%$ of predicted), a substantial number of these patients had moderately (70\%) or even excessively (18\%) impaired pulmonary gas exchange during exercise. Chest radiographic stages without parenchymal involvement (stages 0 and I) or the absence of RFI did not exclude PGEI during exercise.

$\mathrm{P}(\mathrm{A}-\mathrm{a}) \mathrm{O}_{2}$ max was not correlated with demographic characteristics, peak heart rate, lactate concentrations, peripheral and inspiratory muscle strength, fatigue scores, and levels of inflammatory markers (CRP and sIL-2R). $\mathrm{PaO}_{2}$ at rest, DLCO\%, FVC\%, and radiographic staging predicted only $40 \%$ of $\mathrm{P}(\mathrm{A}-\mathrm{a}) \mathrm{O}_{2}$ max, so a normal DLCO as well as normal spirometry or a chest radiograph stage without signs of parenchymal involvement appeared to be inappropriate predictors of PGEI during exercise and did not rule out abnormalities in pulmonary gas exchange. 
Sarcoidosis patients often present with nonspecific health complaints. Chronic fatigue related to exercise intolerance is a common symptom of patients with sarcoidosis. $^{39}$ In agreement with other research findings, Marcellis et al. ${ }^{22}$ recently showed that exercise intolerance assessed by the 6-minute walk test and muscle weakness are rather common in sarcoidosis patients. ${ }^{40,41}$ Those with decreased limb muscle strength exhibited impaired pulmonary functions, peak inspiratory mouth pressures, and 6MWD. ${ }^{22}$ The results of the present study are in agreement with those of previous studies, demonstrating a reduction in $\mathrm{VO}_{2} \mathrm{max}$ in sarcoidosis. ${ }^{42}$ Exercise intolerance in sarcoidosis is most often multifactorial, involving, for instance, lungmechanical, musculoskeletal, and gas exchange abnormalities. ${ }^{43}$ Several studies have reported that neither lung function test results nor chest radiographs correlate with these nonspecific health complaints, nor with QoL. ${ }^{21,22,41,44}$ Our study results are in agreement with those of Wallaert et $a l^{42}$, who showed pulmonary function test results at rest to be poor predictors of exercise capacity. In contrast to our study, Wallaert et al. ${ }^{42}$ showed a moderate correlation between $\mathrm{VO}_{2}$ max and peak HR. In line with Ingram et $a l^{45}$, the present study also found that both DLCO and chest radiographs at rest appeared to be insensitive predictors of PGEI during exercise. Moreover, five of $47(11 \%)$ patients with a DLCO below $80 \%$ of predicted had a chest radiographic stage 0 or 1 .

Exercise testing is a useful tool that provides valuable diagnostic and prognostic information about patients with pulmonary diseases. ${ }^{46}$ The importance of exercise testing in evaluating PGEI in sarcoidosis and various other diffuse lung diseases has been demonstrated, as pulmonary gas exchange problems that are not obvious at rest often become apparent during exercise. ${ }^{20,24,25}$ In line with the present study, Lopes et al. ${ }^{26}$ demonstrated that the outcome measure $\mathrm{P}(\mathrm{A}-\mathrm{a}) \mathrm{O}_{2}$ of the CPET was a predictor of a decline in pulmonary function in a sarcoidosis population with rather severe thoracic sarcoidosis. They concluded that determining the CPET measures may be helpful in predicting the outcomes of patients with thoracic sarcoidosis. Obviously, in the study by Lopes et al. ${ }^{26}$ mainly patients with severe pulmonary involvement were included. This might explain the higher correlation between $\mathrm{P}(\mathrm{A}-\mathrm{a}) \mathrm{O}_{2}$ and the pulmonary functions compared with the results of our study (Table 5.4).

The present study also showed PGEI in patients with normal spirometry, as had also been observed by Kollert et al. ${ }^{47}$ Although abnormal gas exchange during exercise was rare in patients with normal spirometry and normal DLCO in the study by Miller et al. ${ }^{17}$, they stressed that exercise testing could play a role in demonstrating occult PGEI. Medinger et al. $^{23}$ and Athos et al. ${ }^{19}$ also demonstrated that CPET with blood gas analysis was useful in detecting abnormal gas exchange in early radiographic stages of sarcoidosis.

In contrast to the present study, Barros et al. ${ }^{18}$ did not find PGEI in patients with radiographic stages 0 and I during moderate exercise. Their research found a $27 \%$ prevalence of PGEI in sarcoidosis patients with radiographic stages II-IV. In our study, the prevalence of PGEI was higher in the more advanced radiographic stages II-IV. 
However, these studies used different criteria to define PGEI. Lopes et al. ${ }^{13}$ also showed an abnormally increased PGEI in the more advanced HRCT stages.

In accordance with the findings of Barros et al. ${ }^{18}$, a DLCO below $60 \%$ of predicted was indicative of PGEI in our study. Although we did find that a low DLCO predicted PGEI, we found a significant number of patients with a normal DLCO who still had PGEI. A DLCO below $60 \%$ of predicted is also a predictor of sarcoidosis-associated pulmonary hypertension $(\mathrm{SAPH})^{27}$, which is associated with increased mortality. ${ }^{48}$ However, DLCO was not as sensitive or specific as the 6-minute walk test results. ${ }^{27} \mathrm{~A}$ significant proportion of dyspneic sarcoidosis patients will have pulmonary hypertension, and CPET may also show impaired gas exchange in $\mathrm{SAPH} .{ }^{48}$ Exercise testing may prove more sensitive in screening for pulmonary hypertension. Our cross-sectional study design made it impossible to determine which patients went on to develop pulmonary hypertension. We do know that some patients with PGEI had a lung transplant or died a few years later. A prospective study with baseline and follow-up data is needed to identify more severe consequences of sarcoidosis and those who might be at risk of developing SAPH, and to evaluate the added value of CPET compared with the usefulness of the 6-minute walk test in this regard.

A symptom-limited incremental exercise test is a volitional test and can be influenced by the patient's motivation and will power. This has also been observed in studies using the 6MWD. ${ }^{21}$ However, the test we used is generally accepted in clinical studies. In our experience, sarcoidosis patients are highly motivated and are willing to participate in all kinds of studies, including an exercise test.

In conclusion, normal DLCO and spirometry and a chest radiograph without parenchymal involvement did not rule out abnormalities in pulmonary gas exchange at maximal exercise in symptomatic sarcoidosis patients. Surveillance of sarcoidosis has still not been standardized, as no single measurement appeared to be sufficient to assess pulmonary disease severity. CPET could offer added value in detecting PGEI during exercise for symptomatic patients with normal spirometry and chest radiography without parenchymal involvement. CPET might also be useful for detecting early parenchymal involvement in sarcoidosis. Hence, CPET with blood gas analysis should be considered an integral part of the multidisciplinary management of sarcoidosis patients with unexplained disabling symptoms aimed to guide appropriate treatment including physical therapy. 


\section{References}

1. Statement on sarcoidosis. Joint Statement of the American Thoracic Society (ATS), the European Respiratory Society (ERS) and the World Association of Sarcoidosis and Other Granulomatous Disorders (WASOG) adopted by the ATS Board of Directors and by the ERS Executive Committee, February 1999. Am J Respir Crit Care Med 1999;160:736-755.

2. Baughman RP, Culver DA, Judson MA. A concise review of pulmonary sarcoidosis. Am J Respir Crit Care Med 2011;183:573-581.

3. Baughman RP, Nunes H. Therapy for sarcoidosis: evidence-based recommendations. Expert Rev Clin Immunol 2012;8:95-103.

4. Morgenthau AS, lannuzzi MC. Recent advances in sarcoidosis. Chest 2011;139:174-182.

5. Iannuzzi MC, Rybicki BA, Teirstein AS. Sarcoidosis. N Engl J Med 2007;357:2153-2165.

6. Wirnsberger RM, De Vries J, Wouters EF, Drent M. Clinical presentation of sarcoidosis in the Netherlands an epidemiological study. Neth J Med 1998;53:53-60.

7. Michielsen HJ, Drent M, Peros-Golubicic T, De Vries J. Fatigue is associated with quality of life in sarcoidosis patients. Chest 2006;130:989-994.

8. Elfferich MD, Nelemans PJ, Ponds RW, De Vries J, Wijnen PA, Drent M. Everyday cognitive failure in sarcoidosis: the prevalence and the effect of anti-TNF-alpha treatment. Respiration 2010;80:212-219.

9. Korenromp IH, Heijnen CJ, Vogels OJ, Van den Bosch JM, Grutters JC. Characterization of chronic fatigue in patients with sarcoidosis in clinical remission. Chest 2011;140:441-447.

10. Baydur A, Alavy B, Nawathe A, Liu S, Louie S, Sharma OP. Fatigue and plasma cytokine concentrations at rest and during exercise in patients with sarcoidosis. Clin Respir J 2011;5:156-164.

11. Drent M, Lower EE, De Vries J. Sarcoidosis-associated fatigue. Eur Respir J 2012;40:255-263.

12. Mostard RL, Voo S, Van Kroonenburgh MJ, Verschakelen JA, Wijnen PA, Nelemans PJ, Erckens RJ, Drent M. Inflammatory activity assessment by F18 FDG-PET/CT in persistent symptomatic sarcoidosis. Respir Med 2011;105:1917-1924.

13. Lopes AJ, de Menezes SL, Dias CM, De Oliveira JF, Mainenti MR, Guimaraes FS. Comparison between cardiopulmonary exercise testing parameters and computed tomography findings in patients with thoracic sarcoidosis. Lung 2011;189:425-431.

14. Gafa G, Sverzellati N, Bonati E, Chetta A, Franco F, Rabaiotti E, De Filippo M, Marangio E, Figoli D, Meschi T, Zompatori M, Rossi C. Follow-up in pulmonary sarcoidosis: comparison between HRCT and pulmonary function tests. Radiol Med 2012;117:968-978.

15. Erdal BS, Crouser ED, Yildiz V, King MA, Patterson AT, Knopp MV, Clymer BD. Quantitative computerized two-point correlation analysis of lung CT scans correlates with pulmonary function in pulmonary sarcoidosis. Chest 2012;142:1589-1597.

16. Nunes H, Uzunhan Y, Gille T, Lamberto C, Valeyre D, Brillet PY. Imaging of sarcoidosis of the airways and lung parenchyma with correlation with lung function. Eur Respir J 2012;40:750-765.

17. Miller A, Brown LK, Sloane MF, Bhuptani A, Teirstein AS. Cardiorespiratory responses to incremental exercise in sarcoidosis patients with normal spirometry. Chest 1995;107:323-329.

18. Barros WG, Neder JA, Pereira CA, Nery LE. Clinical, radiographic and functional predictors of pulmonary gas exchange impairment at moderate exercise in patients with sarcoidosis. Respiration 2004;71: 367-373.

19. Athos L, Mohler JG, Sharma OP. Exercise testing in the physiologic assessment of sarcoidosis. Ann $N$ Y Acad Sci 1986;465:491-501.

20. Karetzky M, McDonough M. Exercise and resting pulmonary function in sarcoidosis. Sarcoidosis Vasc Diffuse Lung Dis 1996;13:43-49.

21. Baughman RP, Lower EE. Six-minute walk test in managing and monitoring sarcoidosis patients. Curr Opin Pulm Med 2007;13:439-444.

22. Marcellis RG, Lenssen AF, Elfferich MD, De Vries J, Kassim S, Foerster K, Drent M. Exercise capacity, muscle strength and fatigue in sarcoidosis. Eur Respir J 2011;38:628-634.

23. Medinger AE, Khouri S, Rohatgi PK. Sarcoidosis: the value of exercise testing. Chest 2001;120:93-101.

24. Risk C, Epler GR, Gaensler EA. Exercise alveolar-arterial oxygen pressure difference in interstitial lung disease. Chest 1984;85:69-74.

25. Bradvik I, Wollmer P, Blom-Bulow B, Albrechtsson U, Jonson B. Lung mechanics and gas exchange during exercise in pulmonary sarcoidosis. Chest 1991;99:572-578. 
26. Lopes AJ, Menezes SL, Dias CM, Oliveira JF, Mainenti MR, Guimaraes FS. Cardiopulmonary exercise testing variables as predictors of long-term outcome in thoracic sarcoidosis. Braz J Med Biol Res 2012; 45:256-263.

27. Bourbonnais JM, Samavati L. Clinical predictors of pulmonary hypertension in sarcoidosis. Eur Respir J 2008;32:296-302.

28. Corte TJ, Wells AU, Nicholson AG, Hansell DM, Wort SJ. Pulmonary hypertension in sarcoidosis: a review. Respirology 2011;16:69-77.

29. Hunninghake GW, Costabel U, Ando M, Baughman R, Cordier JF, Du Bois R, Eklund A, Kitaichi M, Lynch J, Rizzato G, Rose C, Selroos O, Semenzato G, Sharma OP. ATS/ERS/WASOG statement on sarcoidosis. American Thoracic Society/European Respiratory Society/World Association of Sarcoidosis and other Granulomatous Disorders. Sarcoidosis Vasc Diffuse Lung Dis 1999;16:149-173.

30. Quanjer PH, Tammeling GJ, Cotes JE, Pedersen OF, Peslin R, Yernault JC. Lung volumes and forced ventilatory flows. Report working party standardization of lung function tests, European community for steel and coal. Official statement of the European Respiratory Society. Eur Respir J Suppl 1993;16:5-40.

31. Rothkrantz-Kos S, Van Dieijen-Visser MP, Mulder PG, Drent M. Potential usefulness of inflammatory markers to monitor respiratory functional impairment in sarcoidosis. Clin Chem 2003;49:1510-1517.

32. ATS/ACCP Statement on cardiopulmonary exercise testing. Joint Statement of the American Thoracic Society (ATS) and the American College of Chest Physicians (ACCP) was adopted by the ATS Board of Directors and by the ACCP Health Science Policy Committee, November 1, 2001. Am J Respir Crit Care Med 2003;167:211-277.

33. Warrell DA, Cox TM, Firth JD, Benz EJ. Oxford Textbook of Medicine. 4th ed. Oxford, New York: Oxford University Press Inc., 2005; 1308

34. Wasserman K, Hansen JE, Sue DY, Stringer WW, Whipp BJ. Principles of exercise testing and interpretation. 4th ed. Philadelphia: Lippincott Williams \& Wilkens, 2005.

35. Black LF, Hyatt RE. Maximal respiratory pressures: normal values and relationship to age and sex. Am Rev Respir Dis 1969;99:696-702.

36. Harik-Khan RI, Wise RA, Fozard JL. Determinants of maximal inspiratory pressure. The Baltimore Longitudinal Study of Aging. Am J Respir Crit Care Med 1998;158:1459-1464.

37. Mathiowetz V, Kashman N, Volland G, Weber K, Dowe M, Rogers S. Grip and pinch strength: normative data for adults. Arch Phys Med Rehabil 1985;66:69-74.

38. Michielsen HJ, De Vries J, Van Heck GL, Van de Vijver FJR, Sijtsma K. Examination of the dimensionality of fatigue: the construction of the Fatigue Assessment Scale (FAS). EJPA 2004;20:39-48.

39. Baydur A. Recent developments in the physiological assessment of sarcoidosis: clinical implications. Curr Opin Pulm Med 2012;18:499-505.

40. Spruit MA, Thomeer MJ, Gosselink R, Troosters T, Kasran A, Debrock AJ, Demedts MG, Decramer M. Skeletal muscle weakness in patients with sarcoidosis and its relationship with exercise intolerance and reduced health status. Thorax 2005;60:32-38.

41. Wirnsberger RM, Drent M, Hekelaar N, Breteler MH, Drent S, Wouters EF, Dekhuijzen PN. Relationship between respiratory muscle function and quality of life in sarcoidosis. Eur Respir J 1997;10:1450-1455.

42. Wallaert B, Talleu C, Wemeau-Stervinou L, Duhamel A, Robin S, Aguilaniu B. Reduction of maximal oxygen uptake in sarcoidosis: relationship with disease severity. Respiration 2011;82:501-508.

43. Sietsema KE, Kraft M, Ginzton L, Sharma OP. Abnormal oxygen uptake responses to exercise in patients with mild pulmonary sarcoidosis. Chest 1992;102:838-845.

44. De Vries J, Rothkrantz-Kos S, Van Dieijen-Visser MP, Drent M. The relationship between fatigue and clinical parameters in pulmonary sarcoidosis. Sarcoidosis Vasc Diffuse Lung Dis 2004;21:127-136.

45. Ingram CG, Reid PC, Johnston RN. Exercise testing in pulmonary sarcoidosis. Thorax 1982;37:129-132.

46. Arena R, Sietsema KE. Cardiopulmonary exercise testing in the clinical evaluation of patients with heart and lung disease. Circulation 2011;123:668-680.

47. Kollert F, Geck B, Suchy R, Jorres RA, Arzt M, Heidinger D, Hamer OW, Prasse A, Muller-Quernheim J, Pfeifer M, Budweiser S. The impact of gas exchange measurement during exercise in pulmonary sarcoidosis. Respir Med 2011;105:122-129.

48. Palmero V, Sulica R. Sarcoidosis-associated pulmonary hypertension: assessment and management. Semin Respir Crit Care Med 2010;31:494-500. 


\section{Chapter 6}

Association between physical functions and quality of life in sarcoidosis

RGJ Marcellis, AF Lenssen, M Drent, J De Vries Sarcoidosis Vasc Diffuse Lung Dis 2014;31:117-128 


\section{Abstract}

\section{Background}

Quality of life (QoL) is often reduced in patients with sarcoidosis. Studies of the associations between physical functions and QoL are lacking.

\section{Objectives}

So the aims of this study were (i) to evaluate the associations between QoL and physical functions, including muscle strength and exercise capacity, and other clinical characteristics, and (ii) to evaluate whether these associations change over a two-year period.

\section{Methods}

Eighty-eight sarcoidosis patients (61 men; mean age: $46.1 \pm 10.2$ years) participated in a two-year follow-up to cross-sectional study. All patients completed the short World Health Organization Quality of Life assessment instrument (WHOQOL-BREF) and Fatigue Assessment Scale (FAS) at the baseline and follow-up assessments. Patients also performed a six-minute walk test (6MWT) and elbow flexor muscle strength, quadriceps and hamstrings peak torque tests. Maximal inspiratory pressure was recorded.

\section{Results}

QoL in sarcoidosis remained stable over a two-year course of the disease, and was reduced compared with healthy controls, particularly regarding the physical health domain. Fatigue and the six-minute walking distance showed strong associations with QoL at both baseline and followup. Fatigue and exercise capacity predicted the scores for the WHOQOL-BREF physical health domain at baseline (59\%) and follow-up (64\%). QoL at baseline was the best predictor of QoL at follow-up.

\section{Conclusions}

QoL is reduced in sarcoidosis. Fatigue and exercise capacity showed important stable associations with QoL, especially in the physical health domain. FAS and 6MWT should therefore be included in the management of sarcoidosis. 


\section{Introduction}

Sarcoidosis is a multisystem granulomatous disorder of unknown origin. The course and impact of the disease are variable, depending on the organs involved and the intensity of the inflammation. Although virtually every organ can be involved, the lungs, lymphatic system, skin and eyes are frequently affected. Apart from organ-specific symptoms patients also have to deal with side-effects of medical treatments and nonspecific health complaints, such as fatigue and physical impairments. ${ }^{1-4}$ These sarcoidosis-related disabling symptoms can significantly reduce a person's quality of life (QoL), especially in chronic sarcoidosis. ${ }^{5-7}$

Health care professionals mostly rely on improvements of clinical parameters to determine treatment outcomes in sarcoidosis, and give less attention to subjective feelings of well-being, such as QoL. ${ }^{1,2}$ Nowadays, however, QoL is regarded as an important aspect of disease management in general. ${ }^{8}$ QoL refers to patients' perception or evaluation of their overall functioning in daily life. In other words, it reflects how satisfied patients are about their functioning in daily life. ${ }^{9}$ QoL measurements are essential in patient-centered care to identify patients' needs, and should be one of the major therapeutic outcome measures used to individualize the management of sarcoidosis. Since QoL is an abstraction, a key to improving it is understanding the association between QoL and functional impairments. For instance, physical impairments and fatigue complaints due to sarcoidosis can induce patients to reduce their daily activities, resulting in general deconditioning and possibly a reduced QoL. For these patients, exercise training might be considered as an adjunct therapy to improve QoL indirectly by improving exercise capacity and muscle strength. Thus, knowledge about aspects that influence QoL in sarcoidosis is of great clinical relevance. $^{10,11}$

Clinical parameters, such as lung function test results and chest radiographs, correlate only weakly with QoL. ${ }^{5,7,12,13}$ Moreover, it is well-known that fatigue, one of the major problems in sarcoidosis, substantially affects QoL. ${ }^{6,12,13}$ Recently, Marcellis et $a l^{3}{ }^{3}$ reported muscle weakness and exercise intolerance to be frequent problems in sarcoidosis. Nevertheless, studies about the influence of physical functions on QoL are lacking, as most studies have assessed the relationship between physical functions and health status instead of QoL. ${ }^{11,14-17}$ Health status, which is often reduced in sarcoidosis, refers to the impact of health-related factors, such as disease (for example sarcoidosis) and its treatment, on patients' functioning. Using health status measures to assess QoL can thus be misleading. ${ }^{9,11,18,19}$ A few studies found that peripheral muscle strength ${ }^{11}$ and inspiratory muscle endurance ${ }^{16,17}$ correlated with health status in sarcoidosis. However, the study populations were rather small ${ }^{11,16,17}$ or only included sarcoidosis patients with specific health complaints. ${ }^{11}$ And the associations between physical impairments and health status were calculated using bivariate correlations rather than multiple regression analyses, so without correction for the influence of possible confounding variables. Exercise capacity has also proved to be associated with health status. $^{14,15}$ 
The aims of this study were therefore to evaluate the associations between QoL and physical functions, including muscle strength and exercise capacity, and other clinical characteristics, and to evaluate whether these associations change over a twoyear period.

\section{Methods}

\section{Subjects}

Between November 2008 and September 2009, 124 symptomatic sarcoidosis patients referred to the interstitial lung disease (ild) care team of the Department of Respiratory Medicine of the Maastricht University Medical Centre (MUMC; Maastricht, the Netherlands) were included in a cross-sectional study. ${ }^{20}$ Patients were diagnosed based on consistent clinical features and bronchoalveolar lavage fluid analysis and/or biopsyproven noncaseating epithelioid cell granulomas, according to the World Association of Sarcoidosis and Other Granulomatous Disorders (WASOG) guidelines. ${ }^{1}$ Between July 2010 and September 2011, all participants of the 2008/9 study ${ }^{20}$ living in the southern part of the Netherlands $(n=104)$ were invited to participate in a follow-up measurement.

\section{Measurements}

All measurements in this study have been described previously. ${ }^{20}$ The QoL and fatigue scores and the physical test results of the 2008/9 cross-sectional study were used as baseline values. ${ }^{20}$ During the $2008 / 9$ study, a healthy control group $(n=62)$ matched for age and sex was recruited from hospital employees and the surrounding community (Table $6.1 ;^{20}$ ). These data were used as reference values for QoL scores, fatigue scores and physical test results for both the baseline and follow-up measurements.

This study was approved by the local Medical Ethics Committee of the MUMC (MEC 09-4-007). Written informed consent was obtained from all participants.

\section{Clinical data}

Forced vital capacity (FVC) and forced expiratory volume in one second (FEV 1 ) were measured with a pneumotachograph (Masterlab, Jaeger, Würzburg, Germany). The diffusing capacity of the lung for carbon monoxide (DLCO) was measured using the single-breath method (Masterlab, Jaeger, Würzburg, Germany). Values were expressed as percentage of the predicted value. ${ }^{21}$

The C-reactive protein (CRP) concentration was measured by a turbidimetric method on the SYNCHRON LX (Beckman Coulter Inc., Fullerton, CA, USA). The normal value for CRP is $<10 \mathrm{mg} / \mathrm{l}$. The serum levels of soluble interleukin-2 receptor (sIL-2R) were analyzed using commercially available Diaclone ELISA kits (Sanquin, Amsterdam, the Netherlands). Normal values are between 240 and 3,154 pg/ml. ${ }^{22}$ 
Table 6.1 Summary of the demographic, clinical and physical characteristics of the sarcoidosis patients studied at baseline and follow-up and the healthy controls.

\begin{tabular}{|c|c|c|c|}
\hline & $\begin{array}{c}\text { Sarcoidosis patients at } \\
\text { baseline }\end{array}$ & $\begin{array}{l}\text { Sarcoidosis patients at } \\
\text { follow-up }\end{array}$ & Healthy controls \\
\hline \multicolumn{4}{|l|}{ Demographics } \\
\hline Subjects (n) & 88 & & 62 \\
\hline Women/men (n) & $7 / 61$ & & $22 / 40$ \\
\hline Age (yrs) & $46.1 \pm 10.2$ & & $46.4 \pm 9.9$ \\
\hline Time since diagnosis (yrs) & $5.9 \pm 5.8$ & & NA \\
\hline $\mathrm{BMI}\left(\mathrm{kg} / \mathrm{m}^{2}\right)$ & $28.4 \pm 4.6$ & $28.3 \pm 4.6$ & $24.7 \pm 1.8$ \\
\hline Nonsmokers/smokers (n) & $81 / 7$ & $81 / 7$ & $56 / 6$ \\
\hline \multicolumn{4}{|l|}{ Medication } \\
\hline Prednisone use yes/no (n) & $35 / 53$ & $31 / 57$ & $0 / 62$ \\
\hline Prednisone dosage $(\mathrm{mg})$ & $12.5 \pm 6.9$ & $7.5 \pm 3.2^{\mathrm{a}}$ & 0 \\
\hline Methotrexate use yes/no (n) & $29 / 59$ & $33 / 55$ & $0 / 62$ \\
\hline Methotrexate dosage (mg) & $10.8 \pm 2.8$ & $10.0 \pm 3.5$ & 0 \\
\hline Anti-TNF- $\alpha$ use yes/no (n) & $14 / 74$ & $22 / 66^{a}$ & $0 / 62$ \\
\hline \multicolumn{4}{|l|}{ Lung function tests } \\
\hline DLCO (\% pred) & $76.4 \pm 17.4$ & $77.0 \pm 18.0$ & NA \\
\hline FVC (\% pred) & $98.2 \pm 19.5$ & $98.9 \pm 18.0$ & NA \\
\hline $\mathrm{FEV}_{1}(\%$ pred $)$ & $84.1 \pm 21.3$ & $85.1 \pm 22.0$ & NA \\
\hline \multicolumn{4}{|l|}{ Chest radiograph stages } \\
\hline $0+1 / I I+I I I / I V(n)$ & 34 / 33 / 21 & 34 / 33 / 21 & NA \\
\hline \multicolumn{4}{|l|}{ Inflammatory markers } \\
\hline $\mathrm{CRP}^{\mathrm{b}}$ & $8.1 \pm 12.7$ & $3.8 \pm 3.7^{\mathrm{a}}$ & NA \\
\hline$S I L-2 R^{c}$ & $2,995 \pm 1,501$ & $2,366 \pm 1,505^{a}$ & NA \\
\hline \multicolumn{4}{|l|}{ Fatigue measure } \\
\hline FAS score & $28.6 \pm 7.2$ & $26.6 \pm 7.1^{\mathrm{a}}$ & $15.6 \pm 4.0$ \\
\hline \multicolumn{4}{|l|}{ Physical functions (women/men) } \\
\hline 6MWD (m) & $551 \pm 88 / 606 \pm 90$ & $572 \pm 86 / 625 \pm 97^{\mathrm{a}}$ & $679 \pm 73 / 747 \pm 74$ \\
\hline 6MWD (\% pred) & $81.2 \pm 13.0 / 81.0 \pm 12.1$ & $84.2 \pm 12.7 / 83.7 \pm 13.0^{a}$ & NA \\
\hline EFMS (N) & $158.9 \pm 26.9 / 258.1 \pm 55.0$ & $159.0 \pm 29.1 / 247.4 \pm 67.5$ & $162.6 \pm 22.9 / 287.0 \pm 47.9$ \\
\hline EFMS (\% pred) & $97.7 \pm 16.6 / 89.9 \pm 19.2$ & $97.8 \pm 17.9 / 86.2 \pm 23.5$ & NA \\
\hline $\mathrm{QPT}(\mathrm{Nm})$ & $59.6 \pm 20.1 / 96.4 \pm 30.7$ & $64.8 \pm 19.6^{a} / 98.9 \pm 31.3$ & $70.2 \pm 13.3 / 118.4 \pm 23.0$ \\
\hline QPT (\% pred) & $84.9 \pm 28.7 / 81.4 \pm 25.9$ & $92.3 \pm 27.9^{\mathrm{a}} / 83.5 \pm 26.4$ & NA \\
\hline HPT (Nm) & $47.8 \pm 16.3 / 70.7 \pm 23.4$ & $47.5 \pm 12.1 / 72.0 \pm 23.2$ & $55.3 \pm 15.3 / 86.3 \pm 18.7$ \\
\hline HPT (\% pred) & $86.4 \pm 29.5 / 81.9 \pm 27.2$ & $85.9 \pm 21.8 / 83.4 \pm 26.9$ & NA \\
\hline PImax (\% pred) & $87.1 \pm 33.4 / 79.3 \pm 25.8$ & $85.2 \pm 28.8 / 83.3 \pm 24.4$ & NA \\
\hline
\end{tabular}

Data are expressed as mean \pm standard deviation (SD) or absolute numbers (n). BMI: body mass index; TNF: tumor necrosis factor; DLCO: diffusing capacity of the lung for carbon monoxide; \% pred: \% of predicted value; FVC: forced vital capacity; $\mathrm{FEV}_{1}$ : forced expiratory volume in one second; CRP: C-reactive protein; sIL-2R: soluble interleukin-2 receptor; FAS: Fatigue Assessment Scale; 6MWD: six-minute walking distance; EFMS: elbow flexor muscle strength; QPT and HPT: isokinetic quadriceps and hamstrings peak torques at $180^{\circ}$ per second; PImax: maximal inspiratory pressure; NA: not applicable. Sarcoidosis patients $(n=88)$ at baseline versus follow-up: ${ }^{a} \mathrm{p}<0.05 .{ }^{b}$ normal range $<10 \mathrm{mg} / \mathrm{l} ;{ }^{c}$ normal range $240-3,154 \mathrm{pg} / \mathrm{ml}$.

\section{Questionnaires}

The World Health Organization Quality of Life-BREF assessment instrument (WHOQOLBREF), an abbreviated version of the WHOQOL-100, is a generic, cross-culturally developed comprehensive measure of QoL. It consists of 24 questions in four domains (physical health, psychological health, social relationships and environment) related to QoL and two questions that assess the facet of overall QoL and general health. Each 
question uses a 5-point Likert scale. The psychometric properties of the WHOQOL-BREF have been found to be good, including for sarcoidosis patients. ${ }^{23-25}$

Fatigue was measured with the 10-item Fatigue Assessment Scale (FAS). Each item uses a 5-point rating scale, so FAS scores range from 10 to 50 . FAS scores below 22 indicate nonfatigued persons, scores of 22-34 indicate fatigued persons, and scores of 35 or more indicate extremely fatigued persons. The psychometric properties of the FAS in sarcoidosis patients are good. ${ }^{26}$

\section{Exercise capacity and muscle strength}

The six-minute walk test (6MWT) was used to assess exercise capacity, and was performed according to the American Thoracic Society guidelines. ${ }^{27}$

The Biodex System 3 Pro dynamometer (Biodex Medical Systems, Shirley, New York, USA) was used to measure isokinetic peak torques (in $\mathrm{Nm}$ ) of the hamstrings and quadriceps of the dominant leg, with a velocity of $180^{\circ} /$ second as described previously. ${ }^{28}$ The Biodex is a reliable and valid isokinetic dynamometer. ${ }^{29,30}$

Maximal isometric strength (in $\mathrm{N}$ ) of the elbow flexors was measured with the microFET (Biometrics, Almere, the Netherlands). ${ }^{31}$ This hand-held dynamometer is a reliable measurement instrument. ${ }^{31,32}$

Maximal inspiratory pressure (PImax) was assessed by measuring maximal respiratory mouth pressures. ${ }^{33}$ Data from the study by Harik-Khan et al. ( $n=267$ healthy subjects) were used as reference values. ${ }^{34}$

\section{Statistical analysis}

Demographic, clinical, and physical data are expressed as mean \pm standard deviation (SD) and, where appropriate, in absolute numbers. Paired sample t-tests were used to test mean differences in continuous data of the patient group between baseline and follow-up, while nominal data were analyzed using McNemar's test. To detect statistically significant differences between the patient and control groups, continuous data were analyzed with independent sample t-tests, while nominal data were tested using Chi-square tests. ${ }^{35}$

Associations between the domains of the WHOQOL-BREF and the continuous demographic, clinical, and physical characteristics of the patient group were calculated using Pearson's correlations. Differences in WHOQOL-BREF domain scores in relation to sex, prednisone and methotrexate use, and radiographic stages were explored by means of independent sample t-tests and one-way ANOVA. Variables with a significant association ( $p$-value $<0.05$ ) with the domains of the WHOQOL-BREF were selected for the multiple regression analysis (backward method). Multiple regression analyses were used to assess the association between QoL and both clinical and physical parameters and also to assess the predictive value of these parameters at baseline for the QoL measured at follow-up. P-values $<0.05$ were considered statistically significant. 
All analyses were performed using SPSS 18.0 for Windows (SPSS Inc., Chicago, IL, USA).

\section{Results}

\section{Patient characteristics}

In total, 104 participants of the 2008/9 study were invited to participate in the follow-up study. Fourteen of these patients were unable to participate for the following reasons: death $(n=2)$, exacerbations of sarcoidosis $(n=2)$, health problems other than sarcoidosis $(n=4)$, and change of address without notice $(n=6)$. Two patients did not complete the WHOQOL-BREF, the primary outcome measure of this study. In the end, 88 patients (mean follow-up $1.9 \pm 0.4$ years) participated. The demographic, clinical, and physical data of the patients at baseline and follow-up are summarized in Table 6.1. During the two years of follow-up, more patients had started to use methotrexate and anti-TNF- $\alpha$ medication, resulting in a reduced prednisone usage.

Since no differences in demographic, clinical, or physical characteristics were found between the patients who dropped out and those remaining in the study, those participating in the follow-up study were regarded as a representative sample of the patients studied in 2008/9. ${ }^{3}$

The sarcoidosis patients showed significantly lower mean scores on the general evaluative facet and all domains of the WHOQOL-BREF compared with healthy controls, both at baseline and follow-up. The largest difference between the patient group and healthy controls emerged for the physical health domain (Table 6.2). The sarcoidosis group showed no differences in mean scores between the baseline and follow-up measurements for the social relationships and environment domains. Although the changes in mean scores on the general evaluative facet and the physical and psychological health domains between baseline and follow-up measurements were very small, the scores showed a statistically significant improvement at the follow-up measurement compared with the baseline measurement (Figure 6.1). 
Table 6.2 Summary of the quality of life characteristics, measured with the WHOQOL-BREF, of the sarcoidosis patients studied at baseline (t0) and follow-up (t1) and the healthy controls.

\begin{tabular}{|c|c|c|c|c|c|c|}
\hline & $\begin{array}{l}\text { Sarcoidosis } \\
\text { patients t0 }\end{array}$ & $\begin{array}{l}\text { Sarcoidosis } \\
\text { patients t1 }\end{array}$ & $\begin{array}{l}\text { Controls } \\
(n=62)\end{array}$ & $\begin{array}{c}\text { Mean difference } \\
\text { sarcoidosis t1 } \\
\text { vs. t0 }(95 \% \mathrm{Cl})\end{array}$ & $\begin{array}{c}\text { Mean } \\
\text { difference } \\
\text { controls vs. } \\
\text { sarcoidosis to } \\
(95 \% \mathrm{Cl})\end{array}$ & $\begin{array}{c}\text { Mean } \\
\text { difference } \\
\text { controls vs. } \\
\text { sarcoidosis t1 } \\
(95 \% \mathrm{Cl})\end{array}$ \\
\hline \multicolumn{7}{|l|}{ WHOQOL-BREF } \\
\hline Overall QoL facet & $5.9 \pm 1.5$ & $6.3 \pm 1.6$ & $8.7 \pm 1.0$ & $0.4(0.2 \text { to } 0.7)^{\mathrm{a}}$ & $2.9(2.5 \text { to } 3.3)^{b}$ & $2.4(2.0 \text { to } 2.8)^{b}$ \\
\hline Physical health & $12.4 \pm 2.8$ & $13.3 \pm 2.8$ & $17.9 \pm 1.5$ & $0.8(0.4 \text { to } 1.3)^{a}$ & $5.5(4.8 \text { to } 6.2)^{b}$ & $4.7(4.0 \text { to } 5.4)^{b}$ \\
\hline $\begin{array}{l}\text { Psychological } \\
\text { health }\end{array}$ & $13.8 \pm 2.4$ & $14.3 \pm 2.4$ & $17.0 \pm 1.9$ & $0.5(0.1 \text { to } 0.9)^{\mathrm{a}}$ & $3.2(2.5 \text { to } 3.9)^{b}$ & $2.7(2.0 \text { to } 3.4)^{\mathrm{b}}$ \\
\hline $\begin{array}{l}\text { Social } \\
\text { relationships }\end{array}$ & $15.2 \pm 3.1$ & $15.4 \pm 2.5$ & $17.3 \pm 2.4$ & $0.3(-0.2$ to 0.8$)$ & $2.2(1.2 \text { to } 3.1)^{b}$ & $1.9(1.1 \text { to } 2.7)^{b}$ \\
\hline Environment & $15.8 \pm 2.4$ & $15.8 \pm 2.1$ & $18.0 \pm 1.6$ & $0.0(-0.4$ to 0.4$)$ & $2.2(1.6 \text { to } 2.9)^{b}$ & $2.2(1.6 \text { to } 2.8)^{b}$ \\
\hline
\end{tabular}

Data are expressed as mean \pm standard deviation (SD). WHOQOL-BREF: World Health Organization Quality of Life-BREF assessment instrument; QoL: quality of life. ${ }^{a} p<0.05 ;{ }^{b} p<0.001$.

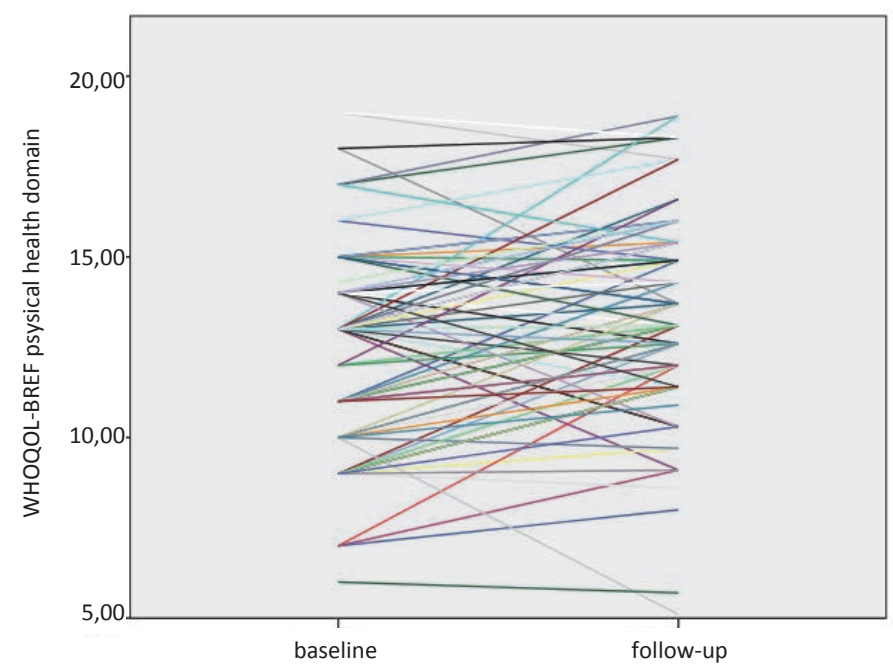

Figure 6.1 Individual changes in WHOQOL-BREF scores, physical health domain, of the sarcoidosis patients studied.

\section{Associations with quality of life}

In general, the FAS scores at baseline showed medium to high correlations with all domains of the WHOQOL-BREF (Table 6.3). The FAS score showed the best correlation with the physical health domain. Besides the FAS scores, the following clinical and physical variables were included in the multiple regression analyses for the overall QoL facet (six-minute walking distances (6MWDs), elbow flexor muscle strength (EFMS) and hamstrings peak torque (HPT)) and the physical health (6MWDs, EFMS, and HPT) and environment (DLCO, 6MWDs, HPT, and PImax) domains of the WHOQOL-BREF. Multiple 
regression analyses demonstrated that fatigue had strong associations with all domains of the WHOQOL-BREF at baseline, while the 6MWD was strongly associated with the overall QoL facet and the physical health and environment domains, predicting $8 \%$ to 59\% (Table 6.4).

At the follow-up measurement, the FAS scores showed moderate to high and the 6MWDs low to moderate correlations with all domains of the WHOQOL-BREF (Table 6.3). The following variables were also included in the multiple regression analyses for the overall QoL facet (EFMS, quadriceps peak torque (QPT), HPT, and prednisone use) and the physical health (DLCO, EFMS, and HPT) and social relationships (QPT, HPT, PImax, and prednisone use) domains of the WHOQOL-BREF. The multiple regression analyses at follow-up also showed that fatigue had strong associations with all domains of the WHOQOL-BREF, while the GMWD was strongly associated with the overall QoL facet and the physical health and environment domains, predicting $34 \%$ to $64 \%$ (Table 6.4).

Both at baseline and follow-up, the physical health domain was best predicted by FAS scores and 6MWDs (59\% and 64\%, respectively; Table 6.4). The correlations between FAS scores and 6MWDs were weak, so there was no multicollinearity between these variables.

Table 6.3 Correlations between the physical and clinical characteristics of the sarcoidosis patients studied and their WHOQOL-BREF scores.

\begin{tabular}{|c|c|c|c|c|c|}
\hline & \multicolumn{5}{|c|}{ WHOQOL-BREF } \\
\hline & $\begin{array}{c}\text { Overall } \\
\text { QoL facet }\end{array}$ & $\begin{array}{c}\text { Physical } \\
\text { health }\end{array}$ & $\begin{array}{l}\text { Psychological } \\
\text { health }\end{array}$ & $\begin{array}{c}\text { Social } \\
\text { relationships }\end{array}$ & Environment \\
\hline \multicolumn{6}{|l|}{ Baseline } \\
\hline FAS score & $-0.45^{b}$ & $-0.74^{b}$ & $-0.60^{b}$ & $-0.28^{a}$ & $-0.40^{b}$ \\
\hline 6MWD (\% pred) & $0.27^{\mathrm{a}}$ & $0.34^{\mathrm{a}}$ & & & $0.33^{\mathrm{a}}$ \\
\hline EFMS (\% pred) & $0.23^{a}$ & $0.31^{a}$ & & & \\
\hline HPT (\% pred) & $0.23^{\mathrm{a}}$ & $0.25^{\mathrm{a}}$ & & & $0.23^{\mathrm{a}}$ \\
\hline PImax (\% pred) & & & & & $0.28^{a}$ \\
\hline DLCO (\% pred) & & & & & $0.25^{a}$ \\
\hline \multicolumn{6}{|l|}{ Follow-up } \\
\hline FAS score & $-0.67^{b}$ & $-0.76^{b}$ & $-0.75^{b}$ & $-0.40^{b}$ & $-0.56^{b}$ \\
\hline 6MWD (\% pred) & $0.39^{b}$ & $0.43^{b}$ & $0.29^{a}$ & $0.26^{\mathrm{a}}$ & $0.38^{b}$ \\
\hline EFMS (\% pred) & $0.24^{a}$ & $0.25^{a}$ & & & \\
\hline HPT (\% pred) & $0.31^{a}$ & $0.26^{\mathrm{a}}$ & & $0.23^{a}$ & \\
\hline QPT (\% pred) & $0.25^{\mathrm{a}}$ & & & $0.23^{a}$ & \\
\hline PImax (\% pred) & & & & $0.28^{a}$ & \\
\hline DLCO (\% pred) & & $0.28^{a}$ & & & \\
\hline
\end{tabular}

Data are expressed as Pearson correlation. WHOQOL-BREF: World Health Organization Quality of Life-BREF assessment instrument; FAS: Fatigue Assessment Scale; 6MWD: six-minute walking distance; \% pred: \% of predicted value; EFMS: elbow flexor muscle strength; HPT and QPT: isokinetic hamstrings and quadriceps peak torques at $180^{\circ}$ per second; PImax: maximal inspiratory pressure; DLCO: diffusing capacity of the lung for carbon monoxide. ${ }^{a} p<0.05 ;{ }^{b} p<0.001$. 
Table 6.4 Clinical and physical predictors of the WHOQOL-BREF measured at baseline and follow-up.

\begin{tabular}{|c|c|c|c|c|c|}
\hline & \multicolumn{5}{|c|}{ WHOQOL-BREF } \\
\hline & $\begin{array}{c}\text { Overall QoL facet } \\
B(S E B) \beta\end{array}$ & $\begin{array}{c}\text { Physical health } \\
\text { B (SE B) } \beta\end{array}$ & $\begin{array}{c}\text { Psychological health } \\
\text { B (SE B) } \beta\end{array}$ & $\begin{array}{c}\text { Social relationships } \\
\text { B (SE B) } \beta\end{array}$ & $\begin{array}{l}\text { Environment } \\
\text { B (SE B) } \beta\end{array}$ \\
\hline \multicolumn{6}{|l|}{ Baseline } \\
\hline Constant & $6.45(1.23)-$ & $16.39(1.68)$ - & $19.48(0.84)-$ & $18.54(1.32)-$ & $14.92(2.13)$ - \\
\hline FAS score & $-0.08(0.02)-0.41^{b}$ & $-0.27(0.03)-0.70^{b}$ & $-0.20(0.03)-0.60^{b}$ & $-0.12(0.05)-0.28^{a}$ & $-0.11(0.04)-0.32^{a}$ \\
\hline 6MWD (\% pred) & $0.02(0.01) 0.18$ & $0.05(0.02) 0.20^{a}$ & & & $0.05(0.02) 0.25^{\mathrm{a}}$ \\
\hline $\mathrm{R}^{2}$ & 0.23 & 0.59 & 0.36 & 0.08 & 0.20 \\
\hline \multicolumn{6}{|l|}{ Follow-up } \\
\hline Constant & $7.72(1.10)-$ & $16.39(1.76)-$ & $21.06(0.67)-$ & $20.03(0.85)-$ & $16.38(1.65)-$ \\
\hline FAS score & $-0.13(0.18)-0.60^{b}$ & $-0.28(0.03)-0.70^{b}$ & $-0.25(0.03)-0.75^{b}$ & $-0.15(0.03)-0.45^{b}$ & $-0.14(0.03)-0.48^{b}$ \\
\hline 6MWD (\% pred) & $0.03(0.01) 0.21^{a}$ & $0.05(0.02) 0.23^{a}$ & & & $0.04(0.02) 0.23^{\mathrm{a}}$ \\
\hline Prednisone use & & & & $-1.55(0.48)-0.31^{a}$ & \\
\hline $\mathrm{R}^{2}$ & 0.47 & 0.64 & 0.56 & 0.34 & 0.35 \\
\hline
\end{tabular}

WHOQOL-BREF: World Health Organization Quality of Life-BREF assessment instrument; QoL: quality of life; FAS: Fatigue Assessment Scale; 6MWD: six-minute walking distance; $\%$ pred: $\%$ of predicted value. ${ }^{a} p<0.05$; ${ }^{\mathrm{b}} \mathrm{p}<0.001$.

\section{Predictive value of baseline variables for QoL measured at follow-up}

Table 6.5 shows the correlations between the baseline physical and clinical characteristics and follow-up WHOQOL-BREF scores of the sarcoidosis patients. Multiple regression analyses showed that WHOQOL-BREF scores measured at baseline were the most predictive variables ( $\beta$ between 0.46 and 0.71 ; all $p$-values $<0.001$ ) for QoL at follow-up (Table 6.6).

Table 6.5 Correlations between baseline physical and clinical characteristics of the sarcoidosis patients studied and their follow-up WHOQOL-BREF scores.

\begin{tabular}{|c|c|c|c|c|c|}
\hline & \multicolumn{5}{|c|}{$\begin{array}{l}\text { WHOQOL-BREF } \\
\text { Follow-up }\end{array}$} \\
\hline & $\begin{array}{l}\text { Overall } \\
\text { QoL facet }\end{array}$ & $\begin{array}{l}\text { Physical } \\
\text { health }\end{array}$ & $\begin{array}{l}\text { Psychological } \\
\text { health }\end{array}$ & $\begin{array}{l}\text { Social } \\
\text { relationships }\end{array}$ & Environment \\
\hline \multicolumn{6}{|l|}{ Baseline } \\
\hline FAS score & $-0.34^{a}$ & $-0.44^{b}$ & $-0.46^{b}$ & $-0.23^{a}$ & $-0.35^{a}$ \\
\hline 6MWD (\% pred) & $0.32^{a}$ & $0.34^{a}$ & $0.32^{a}$ & $0.22^{a}$ & $0.31^{a}$ \\
\hline EFMS (\% pred) & $0.27^{a}$ & $0.28^{a}$ & & & \\
\hline QPT (\% pred) & $0.25^{a}$ & & & $0.23^{a}$ & \\
\hline HPT (\% pred) & $0.29^{a}$ & $0.23^{a}$ & $0.22^{a}$ & $0.25^{a}$ & \\
\hline DLCO (\% pred) & & $0.22^{a}$ & & & \\
\hline \multicolumn{6}{|l|}{ WHOQOL-BREF } \\
\hline Overall QoL facet & $0.65^{b}$ & $0.49^{b}$ & $0.54^{b}$ & $0.34^{a}$ & $0.36^{a}$ \\
\hline Physical health & $0.57^{b}$ & $0.71^{b}$ & $0.51^{b}$ & $0.37^{b}$ & $0.49^{b}$ \\
\hline Psychological health & $0.47^{b}$ & $0.37^{b}$ & $0.67^{b}$ & $0.41^{b}$ & $0.46^{b}$ \\
\hline Social relationships & $0.28^{a}$ & $0.24^{a}$ & $0.41^{b}$ & $0.69^{b}$ & $0.43^{b}$ \\
\hline Environment & $0.48^{b}$ & $0.47^{b}$ & $0.42^{b}$ & $0.47^{b}$ & $0.69^{b}$ \\
\hline
\end{tabular}

Data are expressed as Pearson correlation. WHOQOL-BREF: World Health Organization Quality of Life-BREF assessment instrument; QoL: quality of life; FAS: Fatigue Assessment Scale; 6MWD: six-minute walking distance; \% pred: \% of predicted value; EFMS: elbow flexor muscle strength; QPT and HPT: isokinetic hamstrings and quadriceps peak torques at $180^{\circ}$ per second; DLCO: diffusing capacity of the lung for carbon monoxide. ${ }^{a} p<0.05 ;{ }^{b} p<0.001$. 
The predictive value of the clinical and physical variables measured at baseline for QoL at follow-up was also analyzed. To this end, the baseline WHOQOL-BREF scores were excluded from the multiple regression analyses. The results of these analyses were similar to those mentioned under the previous heading. Fatigue measured at baseline ( $\beta$ between -0.29 and -0.41 ; all $p$-values $<0.001$ ) was an important negative predictor of the WHOQOL-BREF domains, followed by the 6MWD ( $\beta$ between 0.23 and 0.27 ; all p-values $<0.05$ ), predicting $10 \%$ to $27 \%$ (Table 6.6 ).

Table 6.6 Predictive value of clinical and physical variables measured at baseline and follow-up for the WHOQOL-BREF scores measured at follow-up.

\begin{tabular}{|c|c|c|c|c|c|}
\hline & \multicolumn{5}{|c|}{ WHOQOL-BREF measured at follow-up } \\
\hline & $\begin{array}{l}\text { Overall QoL } \\
\text { facet } \\
\text { B (SE B) } \beta\end{array}$ & $\begin{array}{l}\text { Physical health } \\
\text { B (SE B) } \beta\end{array}$ & $\begin{array}{l}\text { Psychological } \\
\text { health } \\
\text { B (SE B) } \beta\end{array}$ & $\begin{array}{c}\text { Social } \\
\text { relationships } \\
B(S E B) \beta\end{array}$ & $\begin{array}{l}\text { Environment } \\
\qquad \text { B (SE B) } \beta\end{array}$ \\
\hline $\begin{array}{l}\text { Baseline variables } \\
\text { (WHOQOL-BREF } \\
\text { included) }\end{array}$ & & & & & \\
\hline $\begin{array}{l}\text { Constant } \\
\text { WHOQOL-BREF }\end{array}$ & $0.86(0.67)-$ & $4.21(1.01)-$ & $2.19(1.50)-$ & $5.87(1.10)-$ & $6.22(1.08)-$ \\
\hline Overall QoL facet & $\begin{array}{c}0.48 \\
(0.11) 0.46^{b}\end{array}$ & & & & \\
\hline Physical health & $\begin{array}{c}0.15 \\
(0.06) 0.27^{a}\end{array}$ & $\begin{array}{c}0.73 \\
(0.08) 0.71^{b}\end{array}$ & $\begin{array}{c}0.15 \\
(0.08) 0.17\end{array}$ & & \\
\hline $\begin{array}{l}\text { Psychological } \\
\text { health }\end{array}$ & & & $\begin{array}{c}0.56 \\
(0.09) 0.56^{b}\end{array}$ & & \\
\hline $\begin{array}{l}\text { Social } \\
\text { relationships }\end{array}$ & & & & $\begin{array}{c}0.55 \\
(0.06) 0.68^{b}\end{array}$ & \\
\hline Environment & & & & & $\begin{array}{c}0.61 \\
(0.07) 0.69^{b}\end{array}$ \\
\hline QPT (\% pred) & $\begin{array}{c}0.01 \\
(0.01) 0.14\end{array}$ & & & $\begin{array}{c}0.02 \\
(0.01) 0.16^{a}\end{array}$ & \\
\hline 6MWD (\% pred) & & & $\begin{array}{c}0.03 \\
(0.02) 0.15\end{array}$ & & \\
\hline $\begin{array}{l}\mathrm{R}^{2} \\
\text { Baseline variables }\end{array}$ & 0.49 & 0.51 & 0.51 & 0.50 & 0.48 \\
\hline $\begin{array}{l}\text { (WHOQOL-BREF } \\
\text { not included) }\end{array}$ & & & & & \\
\hline Constant & $5.33(1.34)-$ & $13.10(2.36)-$ & $14.54(1.98)-$ & $15.66(1.48)-$ & $14.81(1.78)-$ \\
\hline FAS score & $\begin{array}{c}-0.06 \\
(0.02)-0.29^{a}\end{array}$ & $\begin{array}{c}-0.16 \\
(0.04)-0.40^{b}\end{array}$ & $\begin{array}{c}-0.14 \\
(0.03)-0.41^{b}\end{array}$ & $\begin{array}{c}-0.06 \\
(0.04)-0.19\end{array}$ & $\begin{array}{c}-0.09 \\
(0.03)-0.29^{a}\end{array}$ \\
\hline 6MWD (\% pred) & $\begin{array}{c}0.03 \\
(0.01) 0.27^{a}\end{array}$ & $\begin{array}{c}0.06 \\
(0.02) 0.25^{a}\end{array}$ & $\begin{array}{c}0.05 \\
(0.02) 0.23^{\mathrm{a}}\end{array}$ & & $\begin{array}{c}0.04 \\
(0.02) 0.25^{a}\end{array}$ \\
\hline HPT180 (\% pred) & & & & $\begin{array}{c}0.02 \\
(0.01) 0.21^{a}\end{array}$ & \\
\hline$R^{2}$ & 0.19 & 0.27 & 0.26 & 0.10 & 0.18 \\
\hline
\end{tabular}

WHOQOL-BREF: World Health Organization Quality of Life-BREF assessment instrument; QoL: quality of life; QPT and HPT: isokinetic quadriceps and hamstrings peak torques at $180^{\circ}$ per second; $\%$ pred: $\%$ of predicted value; 6MWD: six-minute walking distance; FAS: Fatigue Assessment Scale. ${ }^{a} p<0.05 ;{ }^{b} p<0.001$. 


\section{Discussion}

The aims of this study were to evaluate the associations between QoL, measured with the WHOQOL-BREF, and physical functions, including muscle strength and exercise capacity, and other clinical characteristics (fatigue, lung function test results, radiographic stages, medication use and inflammatory markers), and to evaluate whether these associations changed over a two-year course of the disease. In agreement with previous studies ${ }^{5,7}$, the present study found reduced QoL in patients with sarcoidosis compared with healthy controls. The main outcomes of this study were that fatigue and 6MWD were associated with QoL. In particular, the most affected domain, that of physical health, showed strong associations with fatigue and exercise capacity at baseline and follow-up. These associations remained stable during the twoyear course of sarcoidosis we investigated. When QoL at baseline was taken into account, these scores best predicted QoL at follow-up.

QoL is currently a major topic in the management of chronic diseases. QoL refers to patients' perception or evaluation of their overall functioning in daily life. ${ }^{9}$ Using QoL measures as intervention outcome measures is useful to determine the treatment benefits for patients. ${ }^{8}$ The World Health Organization Quality of Life-100 and BREF questionnaires are both good instruments to assess QoL in sarcoidosis. ${ }^{23-25}$ In line with previous studies, we found a reduced QoL in patients with sarcoidosis compared with healthy controls, especially in the physical health domain. ${ }^{5}$ This implies that patients felt physically less healthy than the healthy controls. In line with the results of the present study, Alilovic et al. ${ }^{7}$ also found reduced QoL in Croatian sarcoidosis patients, measured with the WHOQOL-BREF, in the domains of physical and psychological health, in comparison to healthy controls. In contrast to our study, Alilovic et al. ${ }^{7}$ found that sarcoidosis patients reported a better perceived QoL than healthy controls as regards the domains of social relationships and environment. Although the WHOQOL-BREF scores of the patients in the present study were largely similar to theirs, the scores of our healthy controls were higher.

In agreement with Michielsen et al. ${ }^{12,13}$, the present study found that fatigue is an important negative predictor of QoL. Fatigue is a clear hallmark of sarcoidosis, with a prevalence of $60-90 \% .^{3,36,37}$ The subjective FAS appeared to be a good measure to assess and evaluate fatigue complaints. The FAS is easy to complete and not time-consuming (1-2 minutes). The digital version can be completed at home or even during a visit to the patient's own physician (www.ildcare.nl/pages/artsen_informatie_fasnl.html). ${ }^{6,38-40}$

Several studies have reported that exercise intolerance and muscle weakness are frequent problems in sarcoidosis patients, and these impairments show a stable and persistent character. ${ }^{3,11,20,41}$ The present study found a positive association between QoL, particularly in the physical health domain, and exercise capacity measured with the 6MWT. Michielsen et al. ${ }^{13}$ did not report exercise capacity to be a predictor of QoL. However, their study measured exercise capacity with a symptom inventory questionnaire. Bourbonnais et $a .^{15}$ and Baughman et al. ${ }^{14}$ reported positive 
relationships between 6MWD and health status measures such as the Sarcoidosis Health Questionnaire (SHQ), 36-item Short-Form Health Survey (SF-36) and St. George's Respiratory Questionnaire (SGRQ).

The present study found no associations between QoL and either inspiratory or peripheral muscle strength. These results are in line with those reported by Wirnsberger et al. ${ }^{16}$ However, in a study by Wirnsberger et al. ${ }^{16}$, respiratory muscle endurance time did correlate with the Sickness Impact Profile (SIP) subscales for "mobility" and "body care and movement". Brancaleone et al. ${ }^{17}$ found correlations between inspiratory muscle endurance and SF-36 scores, especially the physical subscales. Spruit et al. ${ }^{11}$ also found positive correlations between quadriceps strength and SF-36 scores.

QoL measured at baseline appeared to be the best predictor of QoL measured at follow-up in our study. After the WHOQOL-BREF scores measured at baseline were excluded from the multiple regression analyses, fatigue and exercise capacity appeared to be good predictors of QoL at follow-up. These results are not surprising, since group mean WHOQOL-BREF scores did not show relevant changes between baseline and follow-up (Figure 6.1).

In patient-centered care/personalized medicine, in which the patient has a central role, physicians should be more aware of the impact of sarcoidosis on their patients' subjective feelings of well-being and needs. In the management of sarcoidosis, physicians should not only focus on objective, but also on subjective clinical parameters, including QoL. Since QoL is an abstraction, a key to improving it is understanding the association between QoL and functional impairments. For instance, physical therapists try to influence a patient's functions and activities, which in turn might improve QoL. Commonly used clinical parameters, such as lung function test results or chest radiographs, have been found to be not or only weakly associated with QoL. ${ }^{5,7,12}$ Studies about the impact of physical functions on QoL are lacking, since most studies have measured health status instead of QoL. Health status refers to the impact of health-related factors, such as disease (for example sarcoidosis) and its treatment, on patients' functioning. Generally used health status measures are the SF-36, SHQ, SIP, SGRQ and King's Sarcoidosis Questionnaire (KSQ). ${ }^{9,42}$ Since QoL and health status are two different concepts with different levels of differentiation, one may wonder whether it is possible for patients to differentiate between these concepts.

To our best knowledge, ours is the first longitudinal study in sarcoidosis to examine associations between QoL and physical functions. We found that the associations between QoL and both fatigue and exercise capacity remained stable over the two-year course of the disease we investigated. These results suggest that fatigue complaints and exercise intolerance have a significant impact on daily living and QoL. These impairments may therefore be important intervention targets to indirectly improve the QoL of patients with sarcoidosis. The present study found no multicollinearity between FAS scores and 6MWDs. Braam et al. ${ }^{43}$ also found that fatigue in sarcoidosis cannot be objectified by repeated exercise testing. Previous studies also concluded that both 
fatigue measures and exercise tests should be included in the management of sarcoidosis. ${ }^{20}$ Alilovic et al. ${ }^{7}$ stated that a fatigue measure should be used in addition to the WHOQOL-BREF to improve the QoL evaluation.

Successful treatment of sarcoidosis frequently fails to eradicate the symptoms of sarcoidosis-associated fatigue. Pharmacologic strategies for fatigue mostly focus on the use of neurostimulants, neurostimulant-like drugs and tumor necrosis factor- $\alpha$ inhibitors. ${ }^{38}$ Heij et al. ${ }^{44}$ showed that ARA290 reduced symptoms related to small fiber neuropathy in sarcoidosis, including fatigue. They also reported an improvement in the physical functioning dimensions of the SF-36 health status questionnaire.

Physical deconditioning may also be a cause of fatigue and exercise intolerance reducing QoL. Fatigue and physical impairments may induce patients to reduce their daily physical activities, resulting in general deconditioning. This in turn will increase the degree of fatigue and exercise intolerance, causing a further reduction of daily activities (negative vicious circle of physical deconditioning). ${ }^{11,45}$ Exercise training could therefore be considered for patients with physical impairments and/or fatigue complaints. Several studies have reported that exercise training in chronic diseases was effective in treating physical impairments and improving QoL. ${ }^{46-48}$ Unfortunately, the effects of exercise training have never been studied in a representative sarcoidosis population.

\section{Study limitations}

This study included refractory sarcoidosis patients referred to a tertiary clinic as they suffered from severe physical complaints, which may have caused selection bias. This selection may have resulted in an overestimation of the QoL reduction.

The physical tests performed in this study are volitional tests, and the results partially depend on the patient's motivation and cooperation. Nonvolitional testing would possibly yield more valid results. However, the tests we used are generally accepted in clinical studies ${ }^{11}$, and in our experience, sarcoidosis patients are very cooperative and motivated to participate in research projects.

\section{Future research}

Since fatigue and exercise intolerance appeared to be important parameters affecting QoL, especially in the physical health domain, a prospective intervention study focusing on the clinical benefit of exercise training in the management of sarcoidosis is warranted.

Although the differences in QoL between baseline and follow-up measurements were statistically significant, they may be clinically irrelevant from the patients' point of view. However, the minimal clinically important difference and the measurement error of the WHOQOL-BREF have not yet been studied.

We conclude that QoL is reduced in sarcoidosis. Fatigue and exercise capacity showed important associations with QoL, especially in the domain of physical health, 
and these associations remained stable over a two-year follow-up period. Hence, the FAS and 6MWT should be included in the management of sarcoidosis. Future studies should investigate whether exercise training might be useful. 


\section{References}

1. Statement on sarcoidosis. Joint Statement of the American Thoracic Society (ATS), the European Respiratory Society (ERS) and the World Association of Sarcoidosis and Other Granulomatous Disorders (WASOG) adopted by the ATS Board of Directors and by the ERS Executive Committee, February 1999. Am J Respir Crit Care Med 1999;160:736-755.

2. Valeyre D, Prasse A, Nunes H, Uzunhan Y, Brillet PY, Muller-Quernheim J. Sarcoidosis. Lancet 2014;383:1155-1167.

3. Marcellis RGJ, Lenssen AF, Kleynen S, De Vries J, Drent M. Exercise capacity, muscle strength and fatigue in sarcoidosis: a follow-up study. Lung 2013;191:247-256.

4. Cremers JP, Drent M, Elfferich MD, Nelemans PJ, Wijnen PA, Witteman BJ, Schols AM. Body composition profiling in a Dutch sarcoidosis population. Sarcoidosis Vasc Diffuse Lung Dis 2013;30: 289-299.

5. Wirnsberger RM, De Vries J, Breteler MH, Van Heck GL, Wouters EF, Drent M. Evaluation of quality of life in sarcoidosis patients. Respir Med 1998;92:750-756.

6. De Vries J, Michielsen H, Van Heck GL, Drent M. Measuring fatigue in sarcoidosis: the Fatigue Assessment Scale (FAS). Br J Health Psychol 2004;9:279-291.

7. Alilovic M, Peros-Golubicic T, Radosevic-Vidacek B, Koscec A, Tekavec-Trkanjec J, Solak M, Hecimovic A, Smojver-Jezek S. WHOQOL-BREF questionnaire as a measure of quality of life in sarcoidosis. Coll Antropol 2013;37:701-706.

8. Baughman RP, Drent M, Culver DA, Grutters JC, Handa T, Humbert M, Judson MA, Lower EE, Mana J, Pereira CA, Prasse A, Sulica R, Valyere D, Vucinic V, Wells AU. Endpoints for clinical trials of sarcoidosis. Sarcoidosis Vasc Diffuse Lung Dis 2012;29:90-98.

9. De Vries J, Wirnsberger RM. Fatigue, quality of life and health status in sarcoidosis. Eur Respir Mon 2005;32:92-104.

10. Steiner WA, Ryser L, Huber E, Uebelhart D, Aeschlimann A, Stucki G. Use of the ICF model as a clinical problem-solving tool in physical therapy and rehabilitation medicine. Phys Ther 2002;82:1098-1107.

11. Spruit MA, Thomeer MJ, Gosselink R, Troosters T, Kasran A, Debrock AJ, Demedts MG, Decramer M. Skeletal muscle weakness in patients with sarcoidosis and its relationship with exercise intolerance and reduced health status. Thorax 2005;60:32-38.

12. Michielsen HJ, Drent M, Peros-Golubicic T, De Vries J. Fatigue is associated with quality of life in sarcoidosis patients. Chest 2006;130:989-994.

13. Michielsen HJ, Peros-Golubicic T, Drent M, De Vries J. Relationship between symptoms and quality of life in a sarcoidosis population. Respiration 2007;74:401-405.

14. Baughman RP, Sparkman BK, Lower EE. Six-minute walk test and health status assessment in sarcoidosis. Chest 2007;132:207-213.

15. Bourbonnais JM, Malaisamy S, Dalal BD, Samarakoon PC, Parikh SR, Samavati L. Distance saturation product predicts health-related quality of life among sarcoidosis patients. Health Qual Life Outcomes 2012;10:67.

16. Wirnsberger RM, Drent M, Hekelaar N, Breteler MH, Drent S, Wouters EF, Dekhuijzen PN. Relationship between respiratory muscle function and quality of life in sarcoidosis. Eur Respir J 1997;10:1450-1455.

17. Brancaleone P, Perez T, Robin S, Neviere R, Wallaert B. Clinical impact of inspiratory muscle impairment in sarcoidosis. Sarcoidosis Vasc Diffuse Lung Dis 2004;21:219-227.

18. Cox CE, Donohue JF, Brown CD, Kataria YP, Judson MA. Health-related quality of life of persons with sarcoidosis. Chest 2004;125:997-1004.

19. De Vries J, Drent M. Quality of life and health status in sarcoidosis: a review of the literature. Clin Chest Med 2008;29:525-532.

20. Marcellis RG, Lenssen AF, Elfferich MD, De Vries J, Kassim S, Foerster K, Drent M. Exercise capacity, muscle strength and fatigue in sarcoidosis. Eur Respir J 2011;38:628-634.

21. Quanjer PH, Tammeling GJ, Cotes JE, Pedersen OF, Peslin R, Yernault JC. Lung volumes and forced ventilatory flows. Report working party standardization of lung function tests, European community for steel and coal. Official statement of the European Respiratory Society. Eur Respir J Suppl 1993;16:5-40.

22. Rothkrantz-Kos S, Van Dieijen-Visser MP, Mulder PG, Drent M. Potential usefulness of inflammatory markers to monitor respiratory functional impairment in sarcoidosis. Clin Chem 2003;49:1510-1517. 
23. WHO. Development of the World Health Organization WHOQOL-BREF quality of life assessment. The WHOQOL Group. Psychol Med 1998;28:551-558.

24. Trompenaars FJ, Masthoff ED, Van Heck GL, Hodiamont PP, De Vries J. Content validity, construct validity, and reliability of the WHOQOL-BREF in a population of Dutch adult psychiatric outpatients. Qual Life Res 2005;14:151-160.

25. O'Carroll RE, Smith K, Couston M, Cossar JA, Hayes PC. A comparison of the WHOQOL-100 and the WHOQOL-BREF in detecting change in quality of life following liver transplantation. Qual Life Res 2000;9:121-124.

26. Michielsen HJ, De Vries J, Van Heck GL, Van de Vijver FJR, Sijtsma K. Examination of the dimensionality of fatigue: The construction of the Fatigue Assessment Scale (FAS). EJPA 2004;20:39-48.

27. ATS committee on proficiency standards for clinical pulmonary function laboratories. ATS statement: guidelines for the six-minute walk test. Am J Respir Crit Care Med 2002;166:111-117.

28. Freedson PS, Gilliam TB, Mahoney T, Maliszewski MA, Kastango K. Industrial torque levels by age group and gender. Isokinet Exerc Sci 1993;3:34-42.

29. Drouin JM, Valovich-mcLeod TC, Shultz SJ, Gansneder BM, Perrin DH. Reliability and validity of the Biodex system 3 pro isokinetic dynamometer velocity, torque and position measurements. Eur J Appl Physiol 2004;91:22-29.

30. McCleary RW, Andersen JC. Test-retest reliability of reciprocal isokinetic knee extension and flexion peak torque measurements. J Athl Train 1992;27:362-365.

31. Bohannon RW. Make tests and break tests of elbow flexor muscle strength. Phys Ther 1988;68:193-194.

32. Bohannon RW, Andrews AW. Interrater reliability of hand-held dynamometry. Phys Ther 1987;67: 931-933.

33. Black LF, Hyatt RE. Maximal respiratory pressures: normal values and relationship to age and sex. Am Rev Respir Dis 1969;99:696-702.

34. Harik-Khan RI, Wise RA, Fozard JL. Determinants of maximal inspiratory pressure. The Baltimore longitudinal study of aging. Am J Respir Crit Care Med 1998;158:1459-1464.

35. McCrum-Gardner E. Which is the correct statistical test to use? Br J Oral Maxillofac Surg 2008;46:38-41.

36. Wirnsberger RM, De Vries J, Wouters EF, Drent M. Clinical presentation of sarcoidosis in The Netherlands an epidemiological study. Neth J Med 1998;53:53-60.

37. De Vries J, Rothkrantz-Kos S, Van Dieijen-Visser MP, Drent M. The relationship between fatigue and clinical parameters in pulmonary sarcoidosis. Sarcoidosis Vasc Diffuse Lung Dis 2004;21:127-136.

38. Drent M, Lower EE, De Vries J. Sarcoidosis-associated fatigue. Eur Respir J 2012;40:255-263.

39. De Kleijn WP, De Vries J, Lower EE, Elfferich MD, Baughman RP, Drent M. Fatigue in sarcoidosis: a systematic review. Curr Opin Pulm Med 2009;15:499-506.

40. De Kleijn WP, De Vries J, Wijnen PA, Drent M. Minimal (clinically) important differences for the Fatigue Assessment Scale in sarcoidosis. Respir Med 2011;105:1388-1395.

41. Kabitz HJ, Lang F, Walterspacher S, Sorichter S, Muller-Quernheim J, Windisch W. Impact of impaired inspiratory muscle strength on dyspnea and walking capacity in sarcoidosis. Chest 2006;130:1496-1502.

42. Patel AS, Siegert RJ, Creamer D, Larkin G, Maher TM, Renzoni EA, Wells AU, Higginson IJ, Birring SS. The development and validation of the King's Sarcoidosis Questionnaire for the assessment of health status. Thorax 2013;68:57-65.

43. Braam AW, De Haan SN, Vorselaars AD, Rijkers GT, Grutters JC, Van den Elshout FJ, Korenromp IH. Influence of repeated maximal exercise testing on biomarkers and fatigue in sarcoidosis. Brain Behav Immun 2013;33:57-64.

44. Heij L, Niesters M, Swartjes M, Hoitsma E, Drent M, Dunne A, Grutters JC, Vogels O, Brines M, Cerami A, Dahan A. Safety and efficacy of ARA 290 in sarcoidosis patients with symptoms of small fiber neuropathy: A randomized, double-blind pilot study. Mol Med 2013;18:1430-1436.

45. Spruit MA, Wouters EFM, Gosselink R. Rehabilitation programmes in sarcoidosis: a multidisciplinary approach. Eur Respir J 2005;32:316-326.

46. Huppmann P, Sczepanski B, Boensch M, Winterkamp S, Schonheit-Kenn U, Neurohr C, Behr J, Kenn K. Effects of in-patient pulmonary rehabilitation in patients with interstitial lung disease. Eur Respir $J$ 2013;42:444-453.

47. Salhi B, Troosters T, Behaegel M, Joos G, Derom E. Effects of pulmonary rehabilitation in patients with restrictive lung diseases. Chest 2010;137:273-279. 
48. Kozu R, Senjyu H, Jenkins SC, Mukae H, Sakamoto N, Kohno S. Differences in response to pulmonary rehabilitation in idiopathic pulmonary fibrosis and chronic obstructive pulmonary disease. Respiration 2011;81:196-205. 


\section{Chapter 7}

Does physical training reduce fatigue in sarcoidosis?

RGJ Marcellis, MAF van der Veeke, I Mesters, M Drent, RA de Bie, GJ de Vries,

AF Lenssen

Sarcoidosis Vasc Diffuse Lung Dis 2015; in press 


\section{Abstract}

\section{Background}

Sarcoidosis patients frequently experience fatigue, exercise intolerance and muscle weakness, resulting in reduced quality of life (QoL). Scientific studies on the benefits of physical training in sarcoidosis have been scarce, so the aim of this pilot study was to examine the impact of a 13-week physical training program on fatigue, physical functions and QoL in fatigued sarcoidosis patients and/or patients with exercise intolerance.

\section{Methods}

Eighteen sarcoidosis patients participated in a 13-week physical training program. The Fatigue Assessment Scale (FAS), World Health Organization Quality of Life-BREF assessment instrument (WHOQOL-BREF), Medical Research Council (MRC) dyspnea scale, Visual Analogue Scale (VAS), six-minute walk test (6MWT), submaximal bicycle test and muscle strength of the quadriceps and elbow flexors were assessed at baseline and after the program.

\section{Results}

FAS scores had decreased (mean difference -2.7 points, 95\% $\mathrm{Cl}-4.4$ to -1.1 ) after completion of the training program, along with improvements in WHOQOL-BREF psychological health domain (mean difference 0.9 points, $95 \% \mathrm{Cl} 0.2$ to 1.7 ) and MRC dyspnea score (mean difference -0.4 points, $95 \% \mathrm{Cl}-0.8$ to -0.1 ). Six-minute walking distance improved by $34.6 \mathrm{~m} \mathrm{(95 \%} \mathrm{Cl} 20.3$ to 49.0 ) and mean heart rate on the bicycle test improved (mean difference 8.4 beats/minute, $95 \% \mathrm{Cl}$ -13.8 to -3.0 ), as did quadriceps strength (mean difference $10.7 \mathrm{~kg}, 95 \% \mathrm{Cl} 5.5$ to 15.9 ).

\section{Conclusion}

Fatigue reduced after a period of physical training in sarcoidosis patients. Moreover, psychological health and physical functions improved. Future studies are warranted to assess the benefits of physical training in sarcoidosis. 


\section{Introduction}

Exercise training has an important role in chronic disease management. It has become the standard in pulmonary rehabilitation (PR) for patients with chronic obstructive pulmonary disease (COPD). ${ }^{1,2}$ Exercise training in COPD appears beneficial in improving functional exercise capacity, dyspnea, and quality of life (QoL). ${ }^{1}$

Training programs may benefit not only COPD patients but also other pulmonary disease patients, for example those with interstitial lung diseases (ilds), a heterogeneous group of diagnoses, including sarcoidosis. ${ }^{1}$ Studies found that patients with ilds showed improvements similar to those in patients with COPD. ${ }^{3-6}$

Sarcoidosis is an inflammatory disease of unknown etiology, characterized by noncaseating epithelioid cell granulomas, resulting in multiple organ system disorders. Sarcoidosis most commonly affects younger adults. Depending on the organs involved and the severity of the inflammation, patients suffer from a broad range of complaints. $^{7-10}$

Fatigue is the most frequently reported symptom in patients with sarcoidosis. ${ }^{11-14}$ Previous studies also showed that exercise intolerance and muscle weakness are frequent symptoms in sarcoidosis, with a persistent character. ${ }^{13,15-17}$ It is well-known that fatigue complaints in sarcoidosis affect QoL unfavorably. ${ }^{18,19}$ In addition, Marcellis et $a l^{20}{ }^{20}$ recently showed that exercise intolerance is also associated with reduced QoL, suggesting that QoL may be improved by reducing fatigue complaints and exercise intolerance. QoL is an important aspect of the management of chronic patients and refers to the patients' perception or evaluation of their overall functioning in daily life. $^{21,22}$

The etiology of physical impairments in sarcoidosis is multifactorial and the primary causes are still unknown. The disease can involve corticosteroid-induced myopathy, sarcoid muscle and lung involvement, inflammatory processes, and mood disorders. ${ }^{16,23}$ In addition, physical inactivity caused by perceived disabling symptoms can induce physical deconditioning, resulting in more perceived fatigue and increased physical inactivity. In the long term, this negative vicious circle of deconditioning may cause exercise intolerance and muscle weakness. ${ }^{23}$

Pharmaceutical treatment options for sarcoidosis to reduce physical impairments, including fatigue, are scarce and also often fail to eradicate these disabling symptoms. ${ }^{11,24,25}$ Physical symptoms may be partially reversible by following a structured physical training program. Scientific studies on the benefits of physical training in sarcoidosis have been scarce, as published studies only included patients with ilds other than sarcoidosis ${ }^{5}$ or did not perform a subgroup analysis of sarcoidosis patients. ${ }^{4}$ Recently, Strookappe et al. ${ }^{6}$ reported improvements in muscle strength, exercise capacity, and fatigue following a 12-week training program in a small population $(n=12)$ with end-stage refractory sarcoidosis. 
The aim of this pilot study was to examine the impact of a 13-week physical training program on fatigue, physical functions, and QoL in fatigued sarcoidosis patients and/or patients with exercise intolerance.

\section{Methods}

\section{Subjects}

We planned to include 34 sarcoidosis patients with fatigue complaints and/or exercise intolerance, referred for physical therapy by their pulmonologist between January 2013 and December 2013. This pilot study had a single-group pre-post measurement design. The sample size was calculated to detect a change of four points in the FAS score. ${ }^{26}$ The power calculation was based on the study by Marcellis et al. ${ }^{13}$ ((mean baseline FAS score $=28 \pm 8$ points) with a power (1-beta) of $80 \%$ and an alpha of 0.05 ).

Patients were eligible to participate if they (1) reported fatigue complaints (FAS score $\geq 22$ points) and/or a reduced six-minute walking distance (6MWD <predicted 6MWD-50 meters ${ }^{13}$ ); (2) were in a clinical stable condition with no exacerbation of complaints or changes in initiated therapeutic management during the preceding three months; (3) were between 18 and 70 years old, and (4) were able to participate in a physical training program.

Patients with cognitive impairments and/or unfamiliarity with the Dutch language making them unable to understand questionnaires and instructions were excluded. Other exclusion criteria were (1) severe oncological, cardiac, neurological, or orthopedic disorders making patients unable to participate in a training program and (2) participation in a training program during the six months prior to inclusion.

The diagnosis of sarcoidosis was based on consistent clinical features and bronchoalveolar lavage fluid analysis and/or biopsy-proven noncaseating epithelioid cell granulomas, according to the World Association of Sarcoidosis and Other Granulomatous Disorders (WASOG) guidelines. ${ }^{9}$

This study was approved by the local Medical Ethics Committee of the Maastricht University Medical Centre (MEC 12-3-032.7/ivb). Written informed consent was obtained from all participants.

\section{Demographics}

Relevant demographic characteristics and clinical data, including medication use, inflammatory markers, lung function test results, and chest radiographic stages, were obtained at baseline from the medical records. 


\section{Clinical data}

Forced vital capacity (FVC) and forced expiratory volume in one second $\left(\mathrm{FEV}_{1}\right)$ were measured with a pneumotachograph (ZAN 500 bodyplethysmograph, ZAN, Oberthulba, Germany) and the diffusing capacity of the lung for carbon monoxide (DLCO) was measured using the single-breath method with carbon monoxide and methane (ZAN 500 bodyplethysmograph, ZAN, Oberthulba, Germany). Values were expressed as percentage of the predicted value. ${ }^{27}$

C-reactive protein (CRP) concentration was measured by a turbidimetric method on the UniCel Dxc 800 (Beckman Coulter Nederland B.V., Woerden, the Netherlands). The normal value for CRP is $<10 \mathrm{mg} / \mathrm{l}$. Serum levels of soluble interleukin-2 receptor (sIL-2R) were analyzed using commercially available Diaclone ELISA kits (Sanquin, Amsterdam, the Netherlands). Normal values are between 240 and 3,154 pg/ml. Serum angiotensinconverting enzyme (ACE) was measured by a colorimetric method (Fujirebio Inc., Tokyo, Japan, cat. no. FU 116). Normal values are between 12 and $68 \mathrm{U} / \mathrm{l}$.

Chest radiographs were graded according to the radiographic staging proposed by DeRemee (0 to III), adding stage IV for patients showing signs of pulmonary fibrosis, loss of lung volume, hilar retraction, and bullae. ${ }^{9}$

\section{Outcome measurements}

Physical functions and functioning were measured at baseline and again after 13 weeks at the end of the training program, by a researcher not involved in the training.

\section{Questionnaires}

Fatigue was measured with the 10-item Fatigue Assessment Scale (FAS). Each item uses a 5-point rating scale, so FAS scores range from 10 to 50. FAS scores below 22 indicate nonfatigued persons while scores of 22 or higher indicate fatigued persons. ${ }^{28}$ The minimal clinically important difference (MCID) of the FAS in sarcoidosis patients is a 4-point or $10 \%$ change in FAS score. ${ }^{11,26}$

QoL was measured with the World Health Organization Quality of Life-BREF assessment instrument (WHOQOL-BREF). It consists of 24 questions in four domains (physical health, psychological health, social relationships, and environment) related to QoL and two questions assessing overall QoL and general health aspect. Each question uses a 5-point Likert scale. ${ }^{29-31}$

The Medical Research Council (MRC) dyspnea scale was used to assess the patient's level of perceived dyspnea ${ }^{32,33}$ and a Visual Analogue Scale (VAS) to assess the degree of arthralgia and muscle pain. ${ }^{33}$

\section{Exercise capacity and muscle strength}

The six-minute walk test (6MWT) was used to assess exercise capacity, and was performed according to the American Thoracic Society guidelines ${ }^{34}$, although a $25-\mathrm{m}$ 
walking course was used instead of a 30-m course. Before and after the 6MWT, heart rate was measured with a pulse oxymeter, and dyspnea and leg fatigue severity with the Modified Borg Scale. ${ }^{35}$ Although the MCID of the 6MWT in sarcoidosis is not known, in patients with COPD this value ranges from $29 \mathrm{~m}$ to $54 \mathrm{~m}$ and in patients with idiopathic pulmonary fibrosis (IPF) from $24 \mathrm{~m}$ to $45 \mathrm{~m}$. $^{36-40}$

Patients performed a submaximal bicycle test on a cycle ergometer. At baseline, the maximal workload (Wmax) was assessed, normal values being $3 \mathrm{Watt} / \mathrm{kg}$ for men and 2 Watt/kg for women. Next, submaximal workload was calculated as maximal workload $x \mathbf{8 0} \%$. This submaximal workload was achieved with a stepwise increase in workload every minute during ten minutes. At the end of the highest achieved workload, heart rate was monitored with a pulse oxymeter. The same test protocol was used at follow-up until the highest achieved step of the baseline measurement (isoworkload) was reached. Differences in heart rate at the end of the last step between baseline and follow-up measurements were calculated to show changes in exercise capacity.

The submaximal multiple-repetition (X-RM) test procedure on a leg extension machine (EN-Dynamic Leg Extension, Enraf Nonius, Rotterdam, the Netherlands) was used to estimate the maximal strength of the $\mathrm{m}$. quadriceps. ${ }^{41}$ Maximal muscle strength was calculated from the maximal number of repetitions at a certain set weight and the Holten diagram. ${ }^{42}$

Maximal isometric strength $(\mathrm{N})$ of the elbow flexors of the dominant arm was measured with the microFET (Biometrics, Almere, the Netherlands), which is a valid and reliable instrument. ${ }^{43-45}$ The 'break' method was used to measure the maximal peak force. $^{43}$

\section{Physical training program}

After having given written informed consent, the sarcoidosis patients started a 13-week physical training program for one hour, thrice a week. This training program included peripheral muscle training and endurance training.

Peripheral muscle training for both the upper (lateral pull-down, chest press, and triceps dips) and lower (leg press, leg extension, and leg curl) extremities was performed using three sets of eight to ten repetitions, starting at $40 \%$ of the calculated multiple-repetition maximum. Each week (three training sessions), the resistance was progressively increased by $3 \%$ of the multiple-repetition maximum.

Endurance training consisted of walking on a treadmill, starting at $60 \%$ of the maximal walking speed of the 6MWT or cycling on a ergometer starting at $50 \% \mathrm{Wmax}$, during 20-30 minutes. Each week (three training sessions), the walking speed or workload on the ergometer was progressively increased by $3 \%$ of the maximal assessed walking speed and workload.

The study included low-intensity resistance training and moderate-intensity endurance training, for the following reason. ${ }^{2}$ Sarcoidosis patients often suffer from severe physical impairments, such as fatigue, arthralgia and muscle pain, which might 
result in a reduced training capacity. ${ }^{12} \mathrm{~A}$ high-intensity training program may worsen these patients' physical complaints, resulting in high dropout rates.

\section{Statistical analysis}

Demographic, clinical, and physical data are expressed as mean \pm standard deviation (SD) and, where appropriate, in absolute numbers or percentages. Paired samples t-tests were used to test mean differences in continuous data between baseline and follow-up, and nominal data were analyzed using McNemar's test.

P-values $<0.05$ were considered statistically significant. All analyses were performed using SPSS 18.0 for Windows (SPSS Inc., Chicago, IL, USA).

\section{Results}

\section{Patient characteristics}

Twenty-four patients were included in this study. The training program was completed by 18 patients ( $75 \%$; mean age: $50.3 \pm 10.4$ years), while six patients dropped out for the following reasons: health problems other than sarcoidosis $(n=3)$, problems with their health insurance $(n=2)$ and stopped without giving a specific reason $(n=1)$. The demographic and clinical characteristics of these patients are summarized in Table 7.1.

At baseline, 16 (89\%) patients reported fatigue complaints, $16(89 \%)$ patients had reduced exercise capacity and 14 patients had both.

The mean number of training sessions attended was $29.0 \pm 6.8$ of the total potential number of 39. No adverse events were recorded during the program. After the training program, $13(72.2 \%)$ patients continued a training program comparable to that used in this study. 
Table 7.1 Summary of the demographic and clinical characteristics of the sarcoidosis patients at baseline.

\begin{tabular}{|c|c|c|c|}
\hline & $\begin{array}{l}\text { Total sarcoidosis sample } \\
\qquad(n=24)\end{array}$ & $\begin{array}{l}\text { Sarcoidosis participants } \\
\text { at baseline }(n=18)\end{array}$ & Dropouts $(n=6)$ \\
\hline \multicolumn{4}{|l|}{ Demographics } \\
\hline Females/males & $6 / 18$ & $4 / 14$ & $2 / 4$ \\
\hline Age (yrs) & $49.4 \pm 10.5$ & $50.3 \pm 10.4$ & $46.7 \pm 11.2$ \\
\hline Time since diagnosis (yrs) & $7.3 \pm 7.0$ & $8.1 \pm 7.5$ & $4.3 \pm 4.2$ \\
\hline $\mathrm{BMI}\left(\mathrm{kg} / \mathrm{m}^{2}\right)$ & $28.8 \pm 4.0$ & $29.3 \pm 3.9$ & $27.4 \pm 4.2$ \\
\hline \multicolumn{4}{|l|}{ Medication } \\
\hline No medication & 12 & 9 & 3 \\
\hline Prednisone use (yes/no) & 7 / 17 & $6 / 12$ & $1 / 5$ \\
\hline Prednisone dosage (mg) & $6.8 \pm 3.1$ & $6.3 \pm 3.1$ & $10.0 \pm 0$ \\
\hline Methotrexate use (yes/no) & $6 / 18$ & $4 / 14$ & $2 / 4$ \\
\hline Methotrexate dosage (mg) & $10.0 \pm 4.2$ & $8.8 \pm 4.8$ & $12.5 \pm 0$ \\
\hline Anti-TNF- $\alpha$ use (yes/no) & $3 / 21$ & $1 / 17$ & $2 / 4$ \\
\hline \multicolumn{4}{|l|}{ Lung function tests } \\
\hline DLCO (\% pred) & $88.7 \pm 17.9$ & $91.2 \pm 18.4$ & $79.4 \pm 13.7$ \\
\hline FVC (\% pred) & $100.3 \pm 17.5$ & $102.2 \pm 18.1$ & $94.7 \pm 15.6$ \\
\hline $\mathrm{FEV}_{1}(\%$ pred $)$ & $93.5 \pm 16.9$ & $93.6 \pm 17.0$ & $93.3 \pm 18.5$ \\
\hline \multicolumn{4}{|l|}{ Chest radiograph stages } \\
\hline $0+$ I / II + III / IV (\%) & 29.2 / 66.6 / 4.2 & $27.8 / 66.6 / 5.6$ & $33.3 / 66.7 / 0$ \\
\hline \multicolumn{4}{|l|}{ Inflammatory markers } \\
\hline $\mathrm{CRP}^{\mathrm{a}}$ & $5.5 \pm 6.2$ & $5.4 \pm 6.2$ & $6.0 \pm 7.0$ \\
\hline SIL-2R $R^{b}$ & $3,884 \pm 1,918$ & $4,316 \pm 1,948$ & $2,417 \pm 804$ \\
\hline $\mathrm{ACE}^{\mathrm{C}}$ & $30.0 \pm 11.7$ & $29.2 \pm 12.5$ & $32.8 \pm 9.4$ \\
\hline
\end{tabular}

Data are expressed as mean \pm standard deviation (SD) or absolute numbers $(n)$ or percentages (\%). BMI: body mass index; TNF: tumor necrosis factor; DLCO: diffusing capacity of the lung for carbon monoxide; \% pred: \% of predicted value; FVC: forced vital capacity; $\mathrm{FEV}_{1}$ : forced expiratory volume in one second; CRP: C-reactive protein; sIL-2R: soluble interleukin-2 receptor, ACE: angiotensin converting enzyme. ${ }^{\text {a }}$ Normal range $<10 \mathrm{mg} / \mathrm{l}$; ${ }^{\mathrm{b}}$ Normal range $240-3,154 \mathrm{pg} / \mathrm{ml} ;{ }^{\mathrm{C}}$ Normal range $12-68 \mathrm{U} / \mathrm{I}$.

\section{Health questionnaires}

The results of the health questionnaires are shown in Table 7.2. Patients reported fatigue complaints both at baseline $(16 ; 89 \%)$ and after the training program $(14 ; 78 \%)$ ( $p>0.05)$. The mean FAS score had decreased significantly (mean difference -2.7 points, $95 \% \mathrm{Cl}-4.4$ to -1.1 ) after the training program (27.0 \pm 7.3 points) in comparison with the baseline measurement (29.7 \pm 7.7 points). Based on an MCID of 4 points, 6 patients (33.3\%) reported reduced, one patient $(5.6 \%)$ increased and 11 patients $(61.1 \%)$ stable fatigue complaints after the training program. Based on a $10 \%$ change in FAS score, 9 patients (50\%) showed reduced, one patient (5.6\%) increased and 8 patients $(44.4 \%)$ stable fatigue complaints after the training program (Table 7.3). Figure 7.1 shows the individual changes in FAS scores between baseline and follow-up measurements.

In addition to the FAS score, the mean score on the psychological health domain of the WHOQOL-BREF and the MRC dyspnea score had improved significantly after the training program. Mean score on the psychological health domain of the WHOQOLBREF was $13.7 \pm 2.6$ points at baseline and $14.6 \pm 2.6$ at follow-up (mean difference 0.9 points, $95 \% \mathrm{Cl} 0.2$ to 1.7$)$. The mean $\mathrm{MRC}$ score showed a significant improvement 
at the follow-up measurement $(1.6 \pm 0.7$ points $)$ in comparison with the baseline measurement ( $2.0 \pm 0.7$ points; mean difference -0.4 points, $95 \% \mathrm{Cl}-0.8$ to -0.1 ).

No significant changes were found in the degree of arthralgia and muscle pain following the training program.

Table 7.2 Differences in questionnaire outcomes of the sarcoidosis patients $(n=18)$ studied before (t0) and after (t1) a training program.

\begin{tabular}{|c|c|c|c|c|}
\hline & $\begin{array}{c}\text { Sarcoidosis patients } \\
\text { t0 }\end{array}$ & $\begin{array}{c}\text { Sarcoidosis patients } \\
\text { t1 }\end{array}$ & $\begin{array}{l}\text { Mean difference in } \\
\text { sarcoidosis t1 vs. t0 } \\
(95 \% \mathrm{Cl})\end{array}$ & $\mathrm{p}$-value \\
\hline FAS & $29.7 \pm 7.7$ & $27.0 \pm 7.3$ & $-2.7(-4.4$ to -1.1$)$ & 0.003 \\
\hline \multicolumn{5}{|l|}{ WHOQOL-BREF } \\
\hline Overall QoL facet & $6.2 \pm 1.2$ & $6.4 \pm 1.8$ & $0.2(-0.4$ to 0.9$)$ & 0.48 \\
\hline Physical health & $12.7 \pm 2.7$ & $13.2 \pm 3.1$ & $0.5(-0.4$ to 1.3$)$ & 0.24 \\
\hline Psychological health & $13.7 \pm 2.6$ & $14.6 \pm 2.6$ & 0.9 (0.2 to 1.7$)$ & 0.02 \\
\hline Social relationships & $15.6 \pm 2.7$ & $15.5 \pm 2.5$ & $-0.1(-0.7$ to 0.4$)$ & 0.60 \\
\hline Environment & $15.8 \pm 2.6$ & $16.1 \pm 2.3$ & $0.3(-0.6$ to 1.3$)$ & 0.46 \\
\hline MRC & $2.0 \pm 0.7$ & $1.6 \pm 0.7$ & $-0.4(-0.8$ to -0.1$)$ & 0.02 \\
\hline \multicolumn{5}{|l|}{ VAS } \\
\hline Joint pain & $36.4 \pm 26.5$ & $42.2 \pm 29.6$ & $5.8(-3.2$ to 14.9$)$ & 0.19 \\
\hline Muscle pain & $26.8 \pm 26.6$ & $36.0 \pm 25.8$ & 9.1 (-3.7 to 21.9$)$ & 0.15 \\
\hline
\end{tabular}

Data are expressed as mean \pm standard deviation (SD). FAS: Fatigue Assessment Scale; WHOQOL-BREF: World Health Organization Quality of Life BREF assessment instrument; QOL: quality of life; MRC: Medical Research Council dyspnea scale; VAS: Visual Analogue Scale.

Table 7.3 Numbers of sarcoidosis patients with changes in FAS scores, 6MWD, and quadriceps muscle strength test results, as a percentage of the baseline value.

\begin{tabular}{lccccccc} 
& \multicolumn{3}{c}{ Improvement } & \multicolumn{3}{c}{ Deterioration } \\
& $0-5 \%$ & $5-10 \%$ & $\geq 10 \%$ & $0-5 \%$ & $5-10 \%$ & $\geq 10 \%$ \\
FAS & 2 & 5 & 9 & 1 & - & 1 \\
6MWD & 6 & 8 & 3 & - & 1 & - \\
Quadriceps muscle strength & 2 & 2 & 12 & - & 1 & 1
\end{tabular}

FAS: Fatigue Assessment Scale; 6MWD: six-minute walking distance.

\section{Physical parameters}

The physical test results, measured at baseline and after the training program, are

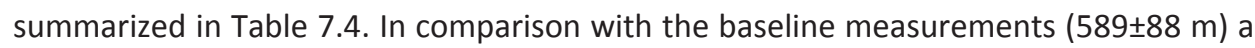
statistically significant increase in the mean 6MWD of $34.6 \mathrm{~m} \mathrm{(95 \%} \mathrm{Cl} 20.3$ to 49.0) was seen after completion of the training program $(624 \pm 92 \mathrm{~m})$. Figure 7.2 shows the individual changes in 6MWD between baseline and follow-up measurement. Seventeen patients showed an increase in 6MWD after the program $(<5 \%$ increase, $n=6 ; 5-10 \%$ increase, $n=8 ; \geq 10 \%$ increase, $n=3$; Table 7.3). Heart rate, dyspnea, and leg fatigue severity, measured before and after the 6MWD, had not changed after the training program. 


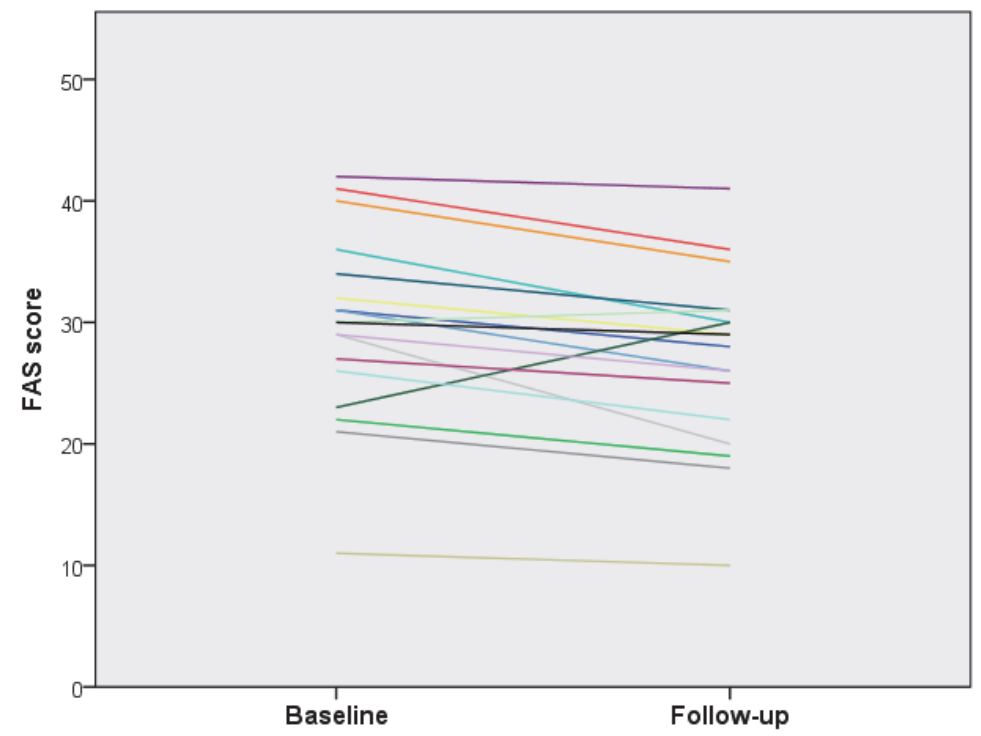

Figure 7.1 Individual changes in fatigue scores, measured with the Fatigue Assessment Scale, following a 13-week physical training program.

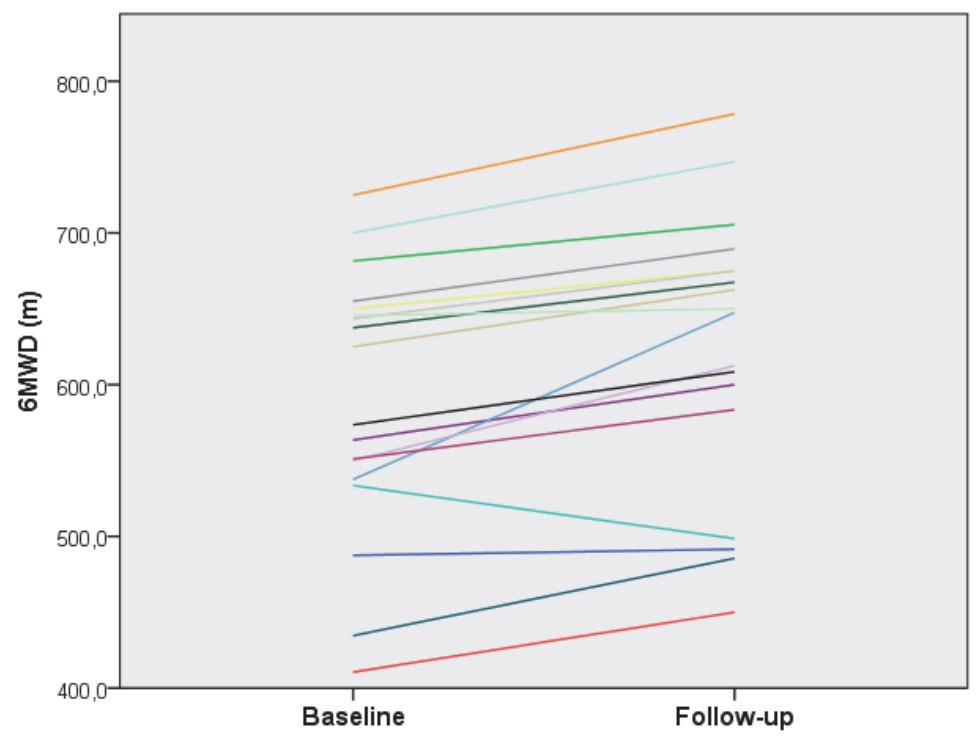

Figure 7.2 Individual changes in six-minute walking distances following a 13-week physical training program. 
The submaximal bicycle test was performed at a mean workload of 170.3 Watt (W; range $80-225 \mathrm{~W})$. After the training program, the mean heart rate had decreased significantly, by 8.4 beats per minute $(95 \% \mathrm{Cl}-13.8$ to -3.0$)$, going from $146.3 \pm 21.5$ at baseline to $137.9 \pm 19.9$ at follow-up.

In contrast to elbow flexor muscle strength, the strength of the quadriceps had improved significantly after the training program, from $48.0 \pm 12.5 \mathrm{~kg}$ at baseline to $58.7 \pm 15.0 \mathrm{~kg}$ at follow-up (mean difference $10.7 \mathrm{~kg}, 95 \% \mathrm{Cl} 5.5$ to 15.9 ). Sixteen patients showed an increase in quadriceps muscle strength after the program $(<5 \%$ increase, $n=2 ; 5-10 \%$ increase, $n=2 ; \geq 10 \%$ increase, $n=12$; Table 7.3).

Table 7.4 Differences in physical characteristics of the sarcoidosis patients $(n=18)$ studied before (t0) and after (t1) a training program.

\begin{tabular}{|c|c|c|c|c|}
\hline & $\begin{array}{l}\text { Sarcoidosis } \\
\text { patients t0 }\end{array}$ & $\begin{array}{l}\text { Sarcoidosis } \\
\text { patients t1 }\end{array}$ & $\begin{array}{l}\text { Mean difference in } \\
\text { sarcoidosis t1 vs. to } \\
(95 \% \mathrm{Cl})\end{array}$ & $\mathrm{p}$-value \\
\hline \multicolumn{5}{|l|}{ Exercise capacity } \\
\hline 6MWD (m) & $589 \pm 88$ & $624 \pm 92$ & $34.6(20.3$ to 49.0$)$ & $<0.001$ \\
\hline \multicolumn{5}{|l|}{ Dyspnea severity, MBS } \\
\hline Before the 6MWT & $0.9 \pm 1.2$ & $1.3 \pm 1.0$ & $0.3(-0.2$ to 0.9$)$ & 0.23 \\
\hline After the 6MWT & $2.4 \pm 2.0$ & $3.0 \pm 2.0$ & $0.6(-0.4$ to 1.6$)$ & 0.22 \\
\hline \multicolumn{5}{|l|}{ Leg fatigue severity, MBS } \\
\hline Before the 6MWT & $2.0 \pm 2.1$ & $1.8 \pm 1.4$ & $-0.2(-1.2$ to 0.8$)$ & 0.65 \\
\hline After the 6MWT & $3.4 \pm 2.3$ & $3.2 \pm 2.1$ & $-0.3(-1.0$ to 0.5$)$ & 0.48 \\
\hline \multicolumn{5}{|l|}{ Heart rate (beats per minute) } \\
\hline Before the 6MWT & $82.7 \pm 13.1$ & $77.1 \pm 12.8$ & $-5.6(-12.6$ to 1.4$)$ & 0.11 \\
\hline After the 6MWT & $117.6 \pm 19.3$ & $118.1 \pm 19.0$ & $0.5(-4.2$ to 5.2$)$ & 0.83 \\
\hline \multicolumn{5}{|l|}{ Bicycle test } \\
\hline Heart rate (beats per minute) & $146.3 \pm 21.5$ & $137.9 \pm 19.9$ & $-8.4(-13.8$ to -3.0$)$ & 0.005 \\
\hline \multicolumn{5}{|l|}{ Muscle strength } \\
\hline Elbow flexors (N) & $269.4 \pm 76.8$ & $269.9 \pm 80.6$ & 0.5 (-19.3 to 20.2$)$ & 0.96 \\
\hline Quadriceps (kg) & $48.0 \pm 12.5$ & $58.7 \pm 15.0$ & 10.7 (5.5 to 15.9 ) & $<0.001$ \\
\hline
\end{tabular}

Data are expressed as mean \pm standard deviation (SD). 6MWD: six-minute walking distance; MBS: modified Borg scale.

\section{Discussion}

This pilot study examined changes in fatigue, physical functions, and QoL in fatigued sarcoidosis patients and/or sarcoidosis patients with a reduced exercise capacity, following a 13-week physical training program. The results showed statistically significant improvements in fatigue, the psychological health domain of the WHOQOLBREF, dyspnea, exercise capacity, and quadriceps muscle strength. No adverse effects or events were reported by the participants during the training period. In general, patient compliance was high and most patients continued a physical training program.

International guidelines state that PR is beneficial for patients with chronic respiratory diseases, regardless of cause. ${ }^{1}$ Salhi $^{46}$ and Holland et al. ${ }^{47}$ showed 
improvements in fatigue following a training program in patients with restrictive lung diseases (RLD) and ild, respectively. In these studies fatigue was measured with the Chronic Respiratory Disease Questionnaire, whereas the present study used the FAS. The mean FAS score in the present study was significantly reduced, by 2.7 points, while $33.3 \%$ and $50.0 \%$ of the patients showed reduced fatigue complaints using an MCID of 4 points and $10 \%$ change in FAS score, respectively. These results are comparable with those reported by Strookappe et al. ${ }^{6}$ Furthermore it is conceivable that some patients experienced stable fatigue complaints even though their activity level improved. Unfortunately, the present study did not use an activity monitor (accelerometer) or activity questionnaire, so the activity level could not be related to the fatigue complaints.

The results on the psychological health domain of the WHOQOL-BREF showed a significant improvement of 0.9. Huppmann et al. ${ }^{4}$ found statistically and clinically significant improvements in health-related QoL in ild patients, including sarcoidosis patients, measured with the SF-36 questionnaire after completing a PR program (PRP), with both the physical and mental health scores of the SF-36 improving. Unfortunately, they did not perform a subgroup analysis for the sarcoidosis patients. Several studies have found significant and clinically relevant improvements in health-related QoL in patients with IPF and COPD after physical training. ${ }^{5,48-50}$ However, it is questionable whether these study results can be compared with ours, since the study populations, outcome measures, and training programs differed.

In line with the present study, Holland et $a{ }^{47}{ }^{47}$ showed reduced dyspnea as measured with the MRC in patients with ild following an 8-week exercise training program, and Ozalevli et al. ${ }^{48}$ showed reduced dyspnea complaints in patients with IPF. By contrast, Nishiyama et al. ${ }^{5}$ did not find significant effects of PR on dyspnea. In the present study, the mean perceived dyspnea severity at baseline was already low and therefore not clinically relevant.

Studies have shown that the MCID of the 6MWT for patients with IPF is 24-45 m and for COPD 29-54 m. ${ }^{36-40}$ The present study found an improvement in 6MWD of $35 \mathrm{~m}$, which is within the range of the MCID, although at the lower end. Strookappe et al. ${ }^{6}$ reported a mean improvement on the $6 \mathrm{MWT}$ of $51 \mathrm{~m}$ following training, and half of their sarcoidosis patients reported an increase of $>10 \%$. Holland et al. ${ }^{47}$ reported improvements in 6MWD (mean $35 \mathrm{~m}, 95 \% \mathrm{Cl}$ 6-64) in ild patients following an 8-week exercise training program, compared with controls. Huppmann ${ }^{4}$ and Nishiyama et al. ${ }^{5}$ demonstrated improvements in 6MWD of $46 \mathrm{~m}$ following a PRP in ild patients, including sarcoidosis patients, and IPF patients, respectively. Several studies have shown improvements in 6MWD in patients with IPF, and Salhi et al. ${ }^{46}$ even found improvements of $64 \mathrm{~m}$ in patients with RLD. ${ }^{48,49}$ Kozu et al. ${ }^{50}$ showed significant improvements in 6MWD in both IPF and COPD patients following an 8-week PRP. However, the magnitude of the improvements was less in patients with IPF.

In line with the present study, Huppmann ${ }^{4}$ and Strookappe et al. ${ }^{6}$ did not find an improvement in dyspnea scores after the 6MWT. However, Ozalevli et al. ${ }^{48}$ showed a 
decrease in perceived dyspnea and leg fatigue at the end of the 6MWT. In general, the mean heart rate and modified Borg score as a measure of dyspnea and leg fatigue severity in our study were low at the end of the 6MWT. The results of our study suggest that the perceived intensity of the 6MWT is acceptable for sarcoidosis patients.

We found a significant reduction in heart rate during the bicycle test, suggesting increased exercise capacity. Holland et al. ${ }^{47}$ also showed a reduction in heart rate (mean -6.6 beats/minute, $95 \% \mathrm{Cl}-11.7$ to -1.52 ) at maximal isoworkload measured during an incremental exercise test following training, indicating cardiovascular adaptation to training.

In contrast to the muscle strength of the elbow flexors, we found significant improvements in muscle strength of the $\mathrm{m}$. quadriceps. This may have been caused by the fact that our training program mainly concentrated on the lower extremity muscles. These results are in line with those reported by Strookappe et al. ${ }^{6}$ Recent studies have shown that quadriceps strength is correlated to exercise capacity. ${ }^{13,16,51} \mathrm{Kozu}^{49,50}$ and Salhi et al. $^{46}$ also showed improvements in quadriceps strength in patients with IPF, RLD, and COPD following PR.

Although patients seemed to improve during a 13-week physical training program, improvements were smaller than expected. The duration, frequency, and intensity of an exercise program are critical to achieve physical benefits. The training parameters, duration, and frequency we used are in agreement with international guidelines. ${ }^{2,52}$ Training intensity in our study was deliberately chosen to be low to moderate. With hindsight, training with a higher intensity might have yielded greater progression. However, sarcoidosis patients can suffer from various impairments, such as arthralgia, muscle pain, and fatigue, and high-intensity training could worsen these impairments, resulting in high training dropout rates. This is why we used a low to moderate training intensity.

The limited improvements found in this study can also be explained by the heterogeneity of the disease. Disease severity in sarcoidosis is variable, depending on the organs involved, and this variability may have limited the participants' potential to achieve improvements through training. ${ }^{50}$ Sarcoidosis patients in our study were physically less impaired than IPF or COPD patients. Perhaps patients with more severe impairments are more likely to show improvements. Ferreira et al. $^{53}$ showed smaller improvements in 6MWD after PR with increasing baseline 6MWDs.

\section{Study limitations}

Our study was subject to some limitations. First, the number of patients included $(n=24)$ was smaller than what was indicated by the sample size calculation $(n=34)$, implying that it was underpowered. Not all sarcoidosis patients with fatigue complaints and/or exercise intolerance who were invited by their pulmonologist to take part actually participated in this study, for various reasons: (1) lack of motivation, (2) participation in another training program, (3) long traveling distance to the training site, 
and (4) lack of coverage by their health insurance policy. The exact number of nonparticipants is unfortunately not known.

This pilot study did not incorporate a control group, so the results have to be interpreted with caution. They cannot show the additional benefits of a training program in comparison with no treatment or usual care. As mentioned in the study by Ferreira et $a .^{53}$, a pilot study like ours can provide important evidence and suggestions for future studies to stimulate supervised physical training, especially since we found in an earlier study that physical outcome values in sarcoidosis hardly changed during a two-year follow-up study. ${ }^{15}$

\section{Future research}

This pilot study showed short-term benefits of a low-intensity physical training program in a small population of sarcoidosis patients. Future research is required to study both the short- and long-term benefits of such a physical training program in a larger sarcoidosis population, preferably using a randomized clinical trial design. The longterm benefits of a physical training program in sarcoidosis are still unknown. Furthermore, the intensity of the training should be optimized; improvements may be more obvious following a high-intensity training. Finally, the additional benefits of multidisciplinary PR should also be studied. The present study examined changes in physical functions following a monodisciplinary physical training program supervised by a physical therapist. Besides physical training, a multidisciplinary PR may include education and behavior change to improve the physical and psychological condition of people with chronic respiratory disease and to promote disease management. ${ }^{1}$

In conclusion, fatigue reduced after a period of physical training in sarcoidosis patients. Moreover, psychological health and physical functions improved. This physical training was safe for patients with sarcoidosis. Future studies are warranted to assess the benefits of physical training in sarcoidosis. 


\section{References}

1. Spruit MA, Singh SJ, Garvey C, ZuWallack R, Nici L, Rochester C, Hill K, Holland AE, Lareau SC, Man WD, Pitta F, Sewell L, Raskin J, Bourbeau J, Crouch R, Franssen FM, Casaburi R, Vercoulen JH, Vogiatzis I, Gosselink R, Clini EM, Effing TW, Maltais F, Van der Palen J, Troosters T, Janssen DJ, Collins E, GarciaAymerich J, Brooks D, Fahy BF, Puhan MA, Hoogendoorn M, Garrod R, Schols AM, Carlin B, Benzo R, Meek P, Morgan M, Rutten-van Molken MP, Ries AL, Make B, Goldstein RS, Dowson CA, Brozek JL, Donner CF, Wouters EF. An official American Thoracic Society/European Respiratory Society statement: key concepts and advances in pulmonary rehabilitation. Am J Respir Crit Care Med 2013;188:e13-64.

2. Langer D, Hendriks E, Burtin C, Probst V, Van der Schans C, Paterson W, Verhoef-de Wijk M, Straver R, Klaassen M, Troosters T, Decramer M, Ninane V, Delguste P, Muris J, Gosselink R. A clinical practice guideline for physiotherapists treating patients with chronic obstructive pulmonary disease based on a systematic review of available evidence. Clin Rehabil 2009;23:445-462.

3. Holland A, Hill C. Physical training for interstitial lung disease. Cochrane Database Syst Rev 2008: CD006322.

4. Huppmann P, Sczepanski B, Boensch M, Winterkamp S, Schonheit-Kenn U, Neurohr C, Behr J, Kenn K. Effects of in-patient pulmonary rehabilitation in patients with interstitial lung disease. Eur Respir $J$ 2013;42:444-453.

5. Nishiyama O, Kondoh Y, Kimura T, Kato K, Kataoka K, Ogawa T, Watanabe F, Arizono S, Nishimura K, Taniguchi $\mathrm{H}$. Effects of pulmonary rehabilitation in patients with idiopathic pulmonary fibrosis. Respirology 2008;13:394-399.

6. Strookappe B, Elfferich MD, Swigris JJ, Verschoof A, Verschakelen JA, Knevel T, Drent M. Benefits of physical training in patients with idiopathic or end-stage sarcoidosis-related pulmonary fibrosis: a pilot study. Sarcoidosis Vasc Diffuse Lung Dis 2015; In press

7. Iannuzzi MC, Fontana JR. Sarcoidosis: clinical presentation, immunopathogenesis, and therapeutics. JAMA 2011;305:391-399.

8. Baughman RP, Lower EE, Gibson K. Pulmonary manifestations of sarcoidosis. Presse Med 2012;41: e289-302.

9. Statement on sarcoidosis. Joint Statement of the American Thoracic Society (ATS), the European Respiratory Society (ERS) and the World Association of Sarcoidosis and Other Granulomatous Disorders (WASOG) adopted by the ATS Board of Directors and by the ERS Executive Committee, February 1999. Am J Respir Crit Care Med 1999;160:736-755.

10. Valeyre D, Prasse A, Nunes H, Uzunhan Y, Brillet PY, Muller-Quernheim J. Sarcoidosis. Lancet 2014; 383:1155-1167.

11. Drent M, Lower EE, De Vries J. Sarcoidosis-associated fatigue. Eur Respir J 2012;40:255-263.

12. Wirnsberger RM, De Vries J, Wouters EF, Drent M. Clinical presentation of sarcoidosis in the Netherlands an epidemiological study. Neth J Med 1998;53:53-60.

13. Marcellis RG, Lenssen AF, Elfferich MD, De Vries J, Kassim S, Foerster K, Drent M. Exercise capacity, muscle strength and fatigue in sarcoidosis. Eur Respir J 2011;38:628-634.

14. De Kleijn WP, De Vries J, Lower EE, Elfferich MD, Baughman RP, Drent M. Fatigue in sarcoidosis: a systematic review. Curr Opin Pulm Med 2009;15:499-506.

15. Marcellis RGJ, Lenssen AF, Kleynen S, De Vries J, Drent M. Exercise capacity, muscle strength and fatigue in sarcoidosis: a follow-up study. Lung 2013;191:247-256.

16. Spruit MA, Thomeer MJ, Gosselink R, Troosters T, Kasran A, Debrock AJ, Demedts MG, Decramer M. Skeletal muscle weakness in patients with sarcoidosis and its relationship with exercise intolerance and reduced health status. Thorax 2005;60:32-38.

17. Alhamad EH. The six-minute walk test in patients with pulmonary sarcoidosis. Ann Thorac Med 2009;4:60-64.

18. Michielsen HJ, Drent M, Peros-Golubicic T, De Vries J. Fatigue is associated with quality of life in sarcoidosis patients. Chest 2006;130:989-994.

19. De Vries J, Michielsen H, Van Heck GL, Drent M. Measuring fatigue in sarcoidosis: the Fatigue Assessment Scale (FAS). Br J Health Psychol 2004;9:279-291.

20. Marcellis R, Lenssen A, Drent M, De Vries J. Association between physical functions and quality of life in sarcoidosis. Sarcoidosis Vasc Diffuse Lung Dis 2014;31:117-128. 
21. De Vries J, Wirnsberger RM. Fatigue, quality of life and health status in sarcoidosis. Eur Respir Mon 2005;32:92-104.

22. Baughman RP, Drent M, Culver DA, Grutters JC, Handa T, Humbert M, Judson MA, Lower EE, Mana J, Pereira CA, Prasse A, Sulica R, Valyere D, Vucinic V, Wells AU. Endpoints for clinical trials of sarcoidosis. Sarcoidosis Vasc Diffuse Lung Dis 2012;29:90-98.

23. Spruit MA, Wouters EFM, Gosselink R. Rehabilitation programmes in sarcoidosis: a multidisciplinary approach. Eur Respir J 2005;32:316-326.

24. Sharma OP. Fatigue in sarcoidosis: incompletely understood, inadequately treated. Curr Opin Pulm Med 2012;18:470-471.

25. Baughman RP, Culver DA, Judson MA. A concise review of pulmonary sarcoidosis. Am J Respir Crit Care Med 2011;183:573-581.

26. De Kleijn WP, De Vries J, Wijnen PA, Drent M. Minimal (clinically) important differences for the Fatigue Assessment Scale in sarcoidosis. Respir Med 2011;105:1388-1395.

27. Quanjer PH, Tammeling GJ, Cotes JE, Pedersen OF, Peslin R, Yernault JC. Lung volumes and forced ventilatory flows. Report working party standardization of lung function tests, European community for steel and coal. Official statement of the European Respiratory Society. Eur Respir J Suppl 1993;16:5-40.

28. Michielsen HJ, De Vries J, Van Heck GL, Van de Vijver FJR, Sijtsma K. Examination of the dimensionality of fatigue: The construction of the Fatigue Assessment Scale (FAS). EJPA 2004;20:39-48.

29. WHO. Development of the World Health Organization WHOQOL-BREF quality of life assessment. The WHOQOL Group. Psychol Med 1998;28:551-558.

30. Trompenaars FJ, Masthoff ED, Van Heck GL, Hodiamont PP, De Vries J. Content validity, construct validity, and reliability of the WHOQOL-BREF in a population of Dutch adult psychiatric outpatients. Qual Life Res 2005;14:151-160.

31. O'Carroll RE, Smith K, Couston M, Cossar JA, Hayes PC. A comparison of the WHOQOL-100 and the WHOQOL-BREF in detecting change in quality of life following liver transplantation. Qual Life Res 2000; 9:121-124.

32. Bestall JC, Paul EA, Garrod R, Garnham R, Jones PW, Wedzicha JA. Usefulness of the Medical Research Council (MRC) dyspnoea scale as a measure of disability in patients with chronic obstructive pulmonary disease. Thorax 1999;54:581-586.

33. Spruit MA, Janssen DJ, Franssen FM, Wouters EF. Rehabilitation and palliative care in lung fibrosis. Respirology 2009;14:781-787.

34. ATS committee on proficiency standards for clinical pulmonary function laboratories. ATS statement: guidelines for the six-minute walk test. Am J Respir Crit Care Med 2002;166:111-117.

35. Borg GA. Psychophysical bases of perceived exertion. Med Sci Sports Exerc 1982;14:377-381.

36. Puhan MA, Mador MJ, Held U, Goldstein R, Guyatt GH, Schunemann HJ. Interpretation of treatment changes in 6-minute walk distance in patients with COPD. Eur Respir J 2008;32:637-643.

37. Redelmeier DA, Bayoumi AM, Goldstein RS, Guyatt GH. Interpreting small differences in functional status: the six minute walk test in chronic lung disease patients. Am J Respir Crit Care Med 1997;155: 1278-1282.

38. Swigris JJ, Wamboldt FS, Behr J, Du Bois RM, King TE, Raghu G, Brown KK. The 6 minute walk in idiopathic pulmonary fibrosis: longitudinal changes and minimum important difference. Thorax 2010; 65:173-177.

39. Holland AE, Hill CJ, Conron M, Munro P, McDonald CF. Small changes in six-minute walk distance are important in diffuse parenchymal lung disease. Respir Med 2009;103:1430-1435.

40. Du Bois RM, Weycker D, Albera C, Bradford WZ, Costabel U, Kartashov A, Lancaster L, Noble PW, Sahn SA, Szwarcberg J, Thomeer M, Valeyre D, King TE, Jr. Six-minute-walk test in idiopathic pulmonary fibrosis: test validation and minimal clinically important difference. Am J Respir Crit Care Med 2011; 183:1231-1237.

41. Verdijk LB, Van Loon L, Meijer K, Savelberg HH. One-repetition maximum strength test represents a valid means to assess leg strength in vivo in humans. J Sports Sci 2009;27:59-68.

42. Enraf-Nonius BV. Gebruikershandleiding En-Track. Rotterdam: Enraf-Nonius B.V. , 2011; 1-68

43. Bohannon RW. Make tests and break tests of elbow flexor muscle strength. Phys Ther 1988;68:193-194.

44. Bohannon RW, Andrews AW. Interrater reliability of hand-held dynamometry. Phys Ther 1987;67: 931-933. 
45. Bohannon RW. Test-retest reliability of hand-held dynamometry during a single session of strength assessment. Phys Ther 1986;66:206-209.

46. Salhi B, Troosters T, Behaegel M, Joos G, Derom E. Effects of pulmonary rehabilitation in patients with restrictive lung diseases. Chest 2010;137:273-279.

47. Holland AE, Hill CJ, Conron M, Munro P, McDonald CF. Short term improvement in exercise capacity and symptoms following exercise training in interstitial lung disease. Thorax 2008;63:549-554.

48. Ozalevli S, Karaali HK, Ilgin D, Ucan ES. Effect of home-based pulmonary rehabilitation in patients with idiopathic pulmonary fibrosis. Multidiscip Respir Med 2010;5:31-37.

49. Kozu R, Jenkins S, Senjyu H. Effect of disability level on response to pulmonary rehabilitation in patients with idiopathic pulmonary fibrosis. Respirology 2011;16:1196-1202.

50. Kozu R, Senjyu H, Jenkins SC, Mukae H, Sakamoto N, Kohno S. Differences in response to pulmonary rehabilitation in idiopathic pulmonary fibrosis and chronic obstructive pulmonary disease. Respiration 2011;81:196-205.

51. Nishiyama O, Taniguchi H, Kondoh Y, Kimura T, Ogawa T, Watanabe F, Arizono S. Quadriceps weakness is related to exercise capacity in idiopathic pulmonary fibrosis. Chest 2005;127:2028-2033.

52. Spruit MA, Pitta F, Garvey C, ZuWallack RL, Roberts CM, Collins EG, Goldstein R, McNamara R, Surpas P, Atsuyoshi K, Lopez-Campos JL, Vogiatzis I, Williams JE, Lareau S, Brooks D, Troosters T, Singh SJ, Hartl S, Clini EM, Wouters EF. Differences in content and organisational aspects of pulmonary rehabilitation programmes. Eur Respir J 2014;43:1326-1337.

53. Ferreira A, Garvey C, Connors GL, Hilling L, Rigler J, Farrell S, Cayou C, Shariat C, Collard HR. Pulmonary rehabilitation in interstitial lung disease: benefits and predictors of response. Chest 2009;135:442-447. 


\section{Chapter 8}

Summary, general discussion and directions for future

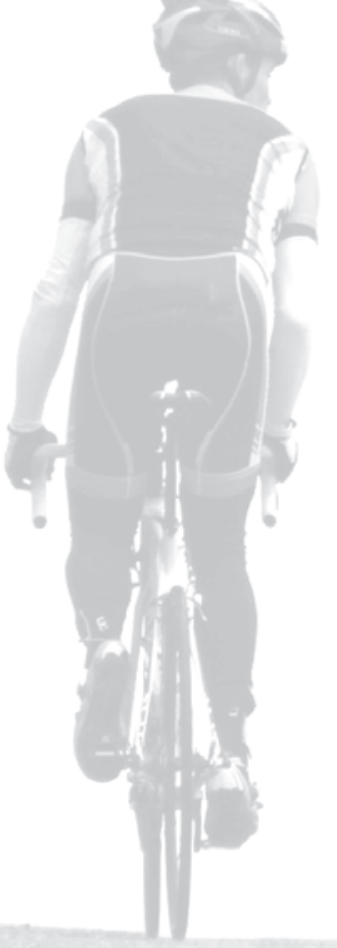

research 


\section{Summary}

The clinical presentation and course of sarcoidosis are highly variable, depending on various disease and patient characteristics. ${ }^{1}$ Besides respiratory and other organspecific problems, sarcoidosis patients frequently suffer from systemic symptoms, like general weakness, exercise intolerance, and fatigue. ${ }^{1,2}$ These sarcoidosis-related disabling symptoms can significantly reduce a patient's quality of life (QoL). ${ }^{3}$ Generally used medical assessments, including lung function tests or chest radiographs, often appear inappropriate to explain the physical impairments, and correlate weakly with QoL. ${ }^{3-5}$ Nevertheless, appropriate physical assessment is important in the management of sarcoidosis, to monitor the disease burden and the course of the disease, and possibly to guide therapeutic interventions. Understanding the associations between physical impairments and both subjective and clinical variables is essential to identify patients' needs. Physical testing can be helpful in assessing physical limitations due to sarcoidosis, in order to improve patient-centered care. However, standardized management strategies for the assessment and treatment of physical impairments in sarcoidosis are lacking. Although physical training of patients with chronic respiratory diseases has proven to be beneficial in improving physical functions and QoL, scientific evidence on the impact of training in sarcoidosis is scarce. ${ }^{6,7}$

The aims of the studies presented in this thesis were to assess whether patients with sarcoidosis suffer from physical impairments, and to determine the value of physical testing in the management of sarcoidosis. To this end, we measured the prevalence of muscle weakness, exercise intolerance, and fatigue among patients with sarcoidosis. In addition, we evaluated the predictive value of physical functions for fatigue and QoL. These studies included patients with sarcoidosis who were referred to the former ild (interstitial lung diseases) care team of the Maastricht University Medical Centre, a tertiary care center in the Netherlands. Finally, the impact of physical training on physical functions and QoL in sarcoidosis was studied in a pilot study with a single-group pre-post measurement design, among sarcoidosis patients referred for physical therapy by their pulmonologist at the Orbis Medical Center in the Netherlands.

\section{Overview of main findings}

Chapter 1, the general introduction, presents a summary of the pathogenesis, epidemiology, clinical features, and course of sarcoidosis. It also discusses the possible role of physical assessment and exercise training in the management of sarcoidosis and presents an outline of the thesis.

Chapter 2 provides an overview of the literature concerning the prevalence, assessment, and treatment of muscle weakness and exercise intolerance in sarcoidosis patients and the associations between these physical impairments and fatigue, dyspnea, and QoL. Muscle weakness and exercise intolerance appear to be frequent problems in sarcoidosis, with a persistent character. The results of routinely performed clinical tests, such as lung function tests and imaging methods, correlate only weakly 
with these nonspecific physical health complaints. Exercise testing can be used to identify the presence of strength deficits and exercise intolerance. Assessment of exercise capacity might also be useful for the early detection of parenchymal involvement and the diagnosis of sarcoidosis-associated pulmonary hypertension. Both muscle weakness and exercise intolerance have been suggested as underlying causes of fatigue and dyspnea complaints. Hence, physicians should be aware that fatigued and dyspneic patients may have physical impairments, resulting in reduced QoL. This chapter underlines the clinical relevance of physical testing in sarcoidosis patients, especially those with unexplained physical complaints. Although exercise training has proved beneficial in several chronic pulmonary diseases, the effects of exercise training have hardly been studied in a representative sarcoidosis population. Research as to whether a multidisciplinary rehabilitation program is of clinical benefit in the management of sarcoidosis patients is urgently required.

Chapter 3 reports on the prevalence of exercise intolerance, muscle weakness, and fatigue in 124 sarcoidosis patients and the predictive value for fatigue of exercise capacity, muscle strength, and other demographic (sex, age, body mass index, fat-free mass, and time since diagnosis) and clinical (lung function tests, radiographic staging, prednisone use, and inflammatory markers) characteristics. Patients performed a six-minute walk test (6MWT), and their handgrip force (HGF), elbow flexor muscle strength (EFMS), quadriceps (QPT), and hamstring peak torque (HPT) were measured. Maximal inspiratory pressure (PImax) was recorded and all patients completed the Fatigue Assessment Scale (FAS). The data of 62 healthy controls were used as a reference for the physical test results. The 6MWT was found to be reduced in $45 \%$ of the population, while HGF, EFMS, QPT, and HPT muscle strength were reduced in $15 \%$, $12 \%, 27 \%$, and $18 \%$, respectively. PImax was reduced in $43 \%$ of the population, and $81 \%$ of the patients reported fatigue. Exercise intolerance and muscle weakness occurred in both fatigued and nonfatigued patients. Patients with reduced peripheral muscle strength of the upper and/or lower extremities were more fatigued and had impaired lung functions, fat-free mass, PImax, 6MWT, and QoL compared to patients without muscle strength impairment. However, according to a multiple regression analysis, fatigue was predicted neither by exercise capacity nor by muscle strength. The results demonstrate that fatigue, exercise intolerance, and muscle weakness are frequent problems in sarcoidosis. Physical tests should be conducted in the multidisciplinary management of sarcoidosis patients, even in nonfatigued patients. More research is needed to standardize the assessment of physical impairments in sarcoidosis.

Chapter 4 presents the changes in the prevalence of exercise capacity, muscle weakness, and fatigue, and the changes in these parameters in individual sarcoidosis patients during a 2-year follow-up study. All participants of the 2008/9 study (chapter 3 ) living in the southern part of the Netherlands $(n=104)$ were invited to participate in the follow-up measurement. Fourteen of these patients were unable to participate. In the end, 90 sarcoidosis patients of the 2008/9 study participated in this 2-year follow-up 
study. At follow-up, patients performed the physical tests and completed the questionnaires mentioned in chapter 3 . Both at baseline and follow-up, a substantial proportion of the patients showed a reduced $6 \mathrm{MWT}(41.6 \%$ and $34.8 \%$, respectively), EFMS (6.7\% and 14.6\%), QPT (21.3\% and 18.0\%), HPT (13.5\% and $12.4 \%)$, and PImax (45.9\% and $48.6 \%)$. The majority of the patients reported fatigue ( $86 \%$ and $77 \%$ ). These physical impairments had remained stable during the follow-up period. The literature reports that nearly two-thirds of sarcoidosis patients may show spontaneous remission in the first two years after diagnosis, while sarcoidosis becomes chronic ( $>2$ years) or progressive in $10-30 \%$. However, the prevalence of physical impairments among patients diagnosed with sarcoidosis less than two years before inclusion in this study was similar to that among patients with a longer history of the disease. This study highlights that exercise intolerance, muscle weakness, and fatigue are frequent problems in symptomatic sarcoidosis patients, with a stable and persistent character.

Chapter 5 describes the added value of cardiopulmonary exercise testing (CPET) with blood gas analysis on a bicycle ergometer compared to the measurement of the diffusing capacity of the lung for carbon monoxide at rest (DLCO) in detecting impaired pulmonary gas exchange, based on a study in 160 symptomatic sarcoidosis patients. Of the patients with normal DLCO ( $n=99,61.9 \%)$, the alveolar-arterial oxygen pressure difference $\left(\mathrm{P}(\mathrm{A}-\mathrm{a}) \mathrm{O}_{2}\right)$ at maximal exercise was moderately increased $(>2.5 \mathrm{kPa})$ in $69.7 \%$ and excessively increased $(>4.7 \mathrm{kPa}$ ) in $18.2 \%$. Pulmonary gas exchange impairment (PGEI) was more obvious in patients with lower DLCO values. A DLCO value below $60 \%$ of predicted indicated substantial gas exchange impairment. Arterial oxygen pressure at rest, DLCO, and forced vital capacity as a percentage of predicted and radiographic staging predicted $40 \%$ of the PGEI at maximal exercise. We concluded that normal DLCO did not rule out abnormalities in pulmonary gas exchange at maximal exercise, suggesting that normal DLCO at rest is an inappropriate predictor of abnormal pulmonary gas exchange during exercise. CPET appeared to offer added value in detecting impaired gas exchange during exercise in sarcoidosis patients with unexplained disabling symptoms.

Chapter 6 assesses the associations between QoL and physical functions in sarcoidosis and evaluates whether these associations change over a 2-year period. Since two patients of the population reported on in chapter 4 did not complete the World Health Organization Quality of Life assessment instrument (WHOQOL-BREF), 88 sarcoidosis patients participated in this study. At baseline and follow-up, patients performed the physical tests discussed in chapter 3. Besides physical tests, patients completed the WHOQOL-BREF and the FAS. QoL of the sarcoidosis patients remained stable over a 2-year course of the disease, and was reduced compared with healthy controls, particularly regarding the physical health domain. Both at baseline and followup, fatigue and the six-minute walking distance showed strong associations with QoL. Fatigue and exercise capacity predicted the scores for the WHOQOL-BREF physical health domain at baseline (59\%) and follow-up (64\%). QoL at baseline was the best predictor of QoL at follow-up. Since fatigue and exercise capacity showed important 
stable associations with QoL, these measurements should therefore be included in the management of sarcoidosis. Future studies should investigate whether exercise training might be useful to treat physical impairments and improve QoL.

Whereas pulmonary rehabilitation has become standard care for patients with chronic obstructive pulmonary disease, scientific studies on the benefits of physical training in sarcoidosis are scarce. Chapter $\mathbf{7}$ shows the results of a pilot study examining the impact of a 13-week physical training program on fatigue, physical functions, and QoL in 18 fatigued sarcoidosis patients and/or patients with exercise intolerance. The FAS, WHOQOL-BREF, Medical Research Council (MRC) dyspnea scale, Visual Analogue Scale (VAS), 6MWT, submaximal bicycle test and muscle strength of the quadriceps and elbow flexors were assessed at baseline and after the program. This pilot study found that FAS scores had decreased (mean difference -2.7 points, $95 \% \mathrm{Cl}-4.4$ to -1.1 ) after completion of the training program, along with improvements in the WHOQOL-BREF psychological health domain (mean difference 0.9 points, $95 \% \mathrm{Cl} 0.2$ to 1.7 ) and $\mathrm{MRC}$ dyspnea score (mean difference -0.4 points, $95 \% \mathrm{Cl}-0.8$ to -0.1 ). $6 \mathrm{MWD}$ improved by $34.6 \mathrm{~m} \mathrm{(95 \%} \mathrm{Cl} 20.3$ to 49.0$)$ and mean heart rate on the bicycle test also improved (mean difference 8.4 beats/minute, $95 \% \mathrm{Cl}-13.8$ to -3.0 ), as did quadriceps strength (mean difference $10.7 \mathrm{~kg}, 95 \% \mathrm{Cl} 5.5$ to 15.9). No changes were observed in VAS score or elbow flexor muscle strength. Although the training effects were small, we concluded that fatigue seems to be reduced and both psychological health and physical functions seem to improve after a period of physical training for sarcoidosis patients. Future studies are warranted to assess the benefits of physical training in sarcoidosis.

\section{Highlights of this thesis}

In conclusion, this thesis presents several aspects of ways to optimize the assessment and treatment of physical impairments in sarcoidosis. Exercise intolerance, muscle weakness, and fatigue are shown to be frequent problems in symptomatic sarcoidosis patients, with a stable and persistent character. Exercise intolerance and muscle weakness occur in both fatigued and nonfatigued patients. CPET appears to offer added value in detecting impaired pulmonary gas exchange during exercise in sarcoidosis patients with unexplained disabling symptoms and with a normal DLCO and spirometry and chest radiography not showing parenchymal involvement. These findings indicate the importance of including physical testing in the multidisciplinary management of sarcoidosis, even in nonfatigued patients. Fatigue is predicted neither by physical nor by clinical parameters. We therefore recommend including a measure of fatigue in the follow-up of sarcoidosis patients. QoL is an important aspect of patient-centered care, and measurements of QoL are considered to be major therapeutic outcome measures. Since QoL is an abstraction, a key to improving it lies in understanding the association between QoL and functional impairments. Sarcoidosis has a major impact on patients' lives, and often reduces QoL. Fatigue and exercise capacity show important stable associations with QoL, suggesting that these physical parameters are important intervention targets to indirectly improve QoL. Finally, fatigue, psychological health and 
physical functions tend to improve after a period of physical training in sarcoidosis patients. However, future studies are warranted to assess the benefits of physical training in sarcoidosis.

\section{General discussion}

The population of sarcoidosis patients is a heterogeneous group, characterized by a broad range of specific and non-specific health complaints, depending on the organs involved. In addition to reporting primary complaints like shortness of breath due to pulmonary dysfunction, these patients often visit their physician with subjective physical health complaints, including muscle weakness and exercise intolerance. Although evidence regarding the effectiveness of physical training in sarcoidosis is scarce and generally of low quality, physicians do refer their patients with physical health complaints to physical therapy.

In line with evidence-based practice, scientific evidence in this field is necessary to support this treatment option. Research could start by examining whether physical complaints are secondary complaints in sarcoidosis patients in general. When we started our research project, the literature did not unequivocally show that sarcoidosis patients do suffer from physical impairments. ${ }^{8,9}$ In a case-control study, we found high prevalence rates of physical impairments in these patients (chapter 3 ). It is well-known that many sarcoidosis-related disabling symptoms are self-limiting in a few years. ${ }^{1}$ Knowing the natural course of a disease or symptoms is a key factor in the critical appraisal of therapeutic effectiveness/efficacy. The persistent character of physical impairments in sarcoidosis was objectively examined in a longitudinal study (chapter 4). To objectify physical impairments, valid and reliable test procedures are essential. Cardiopulmonary exercise testing appeared beneficial in detecting impaired pulmonary gas exchange during exercise in sarcoidosis patients with unexplained disabling symptoms (chapter 5). These studies show the importance of physical testing in the management of sarcoidosis to define disease phenotypes and burden, and to assess disease progression. Unfortunately, no standardized procedure to establish the presence of physical impairments in sarcoidosis is available.

Exercise training is a generally accepted treatment strategy in chronic lung diseases to reduce physical impairments. Our interventional pilot study (chapter 7) showed that physical training seemed feasible and safe in sarcoidosis patients. However, the training effects were small in terms of fatigue reduction and improvements of QoL and physical functions. The final chapter critically discusses the main findings and implications presented in this thesis.

\section{The review study}

The review presented in chapter 2 underlines the added value of physical testing in the management of sarcoidosis patients. Although this was a narrative review, we included 
as many as possible of the features of a systematic review. In general, a review is a cost-effective and efficient way to evaluate the available evidence on a particular topic, and provides health care professionals with an easy-to-read and up-to-date overview and summary of recent advances. A systematic review is based on a clearly formulated question, identifying relevant studies and assessing their quality, summarizing the evidence by methodological means, and finally interpreting the findings. ${ }^{10}$ Although the research question in our review was clearly formulated, a systematic review requires a more specific research question which is generally limited to one topic. ${ }^{10}$ Although an extensive computerized literature search was performed using various electronic libraries, and reference lists of relevant studies were hand-searched, this was done by only one author. Inclusion criteria were reported. Included studies were limited to those published in English, probably resulting in some selection bias. Despite a thorough literature search, we found only a limited number of studies in this field, so we chose to include studies regardless of the quality of their design, whereas a quality assessment is normally required to explore the heterogeneity of studies and determine whether a meta-analysis is suitable. ${ }^{10}$ Since our review thus has some qualitative limitations compared to a systematic review, the recommendations must be interpreted with caution. Finally, it is not common in a systematic review to give a subjective opinion about the topic, as we did.

\section{Prevalence and course of physical impairments in sarcoidosis}

As in other chronic diseases, muscle weakness and exercise intolerance were shown to be frequent problems in sarcoidosis, with a stable and persistent character (chapters 3 and 4). ${ }^{11,12}$ These physical impairments occur in both fatigued and nonfatigued patients.

In sarcoidosis, muscle strength of the quadriceps is related to exercise capacity. ${ }^{8}$ Just as in chronic obstructive pulmonary disease (COPD), peripheral and respiratory muscle weakness contributes to exercise limitations, and lower limb muscles are most often involved. ${ }^{13}$ Involvement of the upper limb muscles in daily activities may cause relative preservation of these muscles. ${ }^{12}$

These case-control studies included refractory sarcoidosis patients referred to a tertiary referral center. One could argue that these patients generally suffer from more severe physical health complaints than patients visiting secondary health care services, which may have caused selection bias, affecting the generalizability of these results. However, the studies included patients in all stages of the disease.

Our longitudinal study used a follow-up period of two years. Over such a period, many things in a patient's life may change. For example, substantial life events (change of job, becoming a parent or health problems other than sarcoidosis) or a change in pharmaceutical or non-pharmaceutical treatment strategies can influence study results. Remembering these events over the past two years can be very difficult and may result in loss of relevant details. Signaling these changes on a frequent basis is important for a better understanding of the course of a disease or physical impairments. A prospective assessment of life events and interventions is preferable, for example using a diary. 
During the follow-up period, several assessors participated in this study, which might have caused problems in terms of inter-rater reliability. To solve this problem as much as possible, assessors were trained to perform the measurements in an identical way.

\section{Physical assessment}

This thesis recommends incorporating physical assessment in the follow-up of sarcoidosis patients (Table 2.1; chapter 2). To date, however, no standardized physical assessment set is available.

Table 2.1 Recommended muscle strength and exercise tests to be included in the regular work-up of sarcoidosis patients.

\begin{tabular}{|c|c|c|}
\hline & Physical test & Optional \\
\hline \multicolumn{3}{|l|}{ Muscle strength } \\
\hline \multirow[t]{3}{*}{ Upper extremity } & Musculus biceps (hand-held dynamometer) & \\
\hline & or & \\
\hline & Handgrip strength (Jamar dynamometer) & \\
\hline Lower extremity & $\begin{array}{l}\text { Musculus quadriceps (hand-held } \\
\text { dynamometer) }\end{array}$ & Biodex \\
\hline Respiratory & $\begin{array}{l}\text { Respiratory mouth pressures } \\
\text { (pressure transducer) }\end{array}$ & \\
\hline \multicolumn{3}{|l|}{ Exercise capacity } \\
\hline Submaximal & 6-minute walk test & \\
\hline Maximal & & $\begin{array}{l}\text { Cardiopulmonary exercise testing with } \\
\text { blood gas analysis (for patients with } \\
\text { unexplained exercise-related symptoms) }\end{array}$ \\
\hline
\end{tabular}

A retrospective cohort study (chapter 5) showed the added value of cardiopulmonary exercise testing in the follow-up of sarcoidosis patients with unexplained disabling symptoms. Such a retrospective study design has both advantages and disadvantages. Compared to a prospective cohort study, a retrospective study is inexpensive and quick to carry out, since existing data are used for the analyses. Our study analyzed the data from a clinical database. An important disadvantage of this design is that the investigator depends on the availability and accuracy of the clinical records. ${ }^{14}$ Although the test procedures for the cardiopulmonary exercise test and lung function tests were specified in a protocol, it always remains questionable for the investigator whether the tests were performed in an identical way.

The Biodex System 3 Pro dynamometer (Biodex Medical Systems, Shirley, New York, USA), which is the gold standard in muscle strength testing, was used to assess muscle weakness of the quadriceps in sarcoidosis. However, this system is quite expensive and not portable, resulting in practical limitations for its daily use. The microFET (Biometrics, Almere, the Netherlands), a hand-held dynamometer, could offer a reliable alternative to measure peripheral muscle strength. ${ }^{15}$ Inspiratory mouth pressure was measured at the Department of Respiratory Medicine of the hospital by 
trained employees. Nowadays, reliable, easy-to-use and portable devices are available to measure respiratory mouth pressures. ${ }^{16}$ The six-minute walk test (6MWT) is a frequently used exercise test in sarcoidosis. According to the American Thoracic Society this test requires a straight line walking course of $30 \mathrm{~m}$, so lack of space can restrict the use of this test. ${ }^{17}$ The 6MWT over a $10 \mathrm{~m}$ walking course is a suitable alternative, since Beekman et al. $^{18}$ recently published reference equations for this test. A six-minute stepper test has also been suggested as an alternative, since the number of steps strongly correlates with the six-minute walking distance. ${ }^{19} \mathrm{CPET}$ with blood gas analysis may be helpful, especially when there is a discrepancy between clinical findings and physiological tests at rest (chapter 5). Although CPET is the gold standard in exercise testing, it is often not a first-choice measurement. This measurement is expensive, time-consuming, requires complex equipment and involves highly trained staff. The modified shuttle walk (MSWT) test and 6MWT may be good alternatives, since CPET results show good correlations with those of the MSWT and 6MWT. ${ }^{20,21}$

The physical tests mentioned in the above section are all volitional tests, so their results partially depend on patients' motivation and cooperation during the test. Nonvolitional testing would probably yield more valid results. For example, repetitive magnetic stimulation of the femoral nerve can be used to induce and quantify quadriceps endurance. $^{22,23}$ In general, however, sarcoidosis patients are very cooperative and motivated to participate in research projects.

\section{Training program}

A pilot study was conducted to examine the changes in fatigue, QoL, and physical functions in sarcoidosis patients following a 13-week physical training program (chapter 7). Scientific evidence regarding the trainability of sarcoidosis patients and the effectiveness of training programs in sarcoidosis is scarce. ${ }^{6,7}$ Since the potential study population in the Sittard-Geleen region of the Netherlands was limited, an uncontrolled interventional pilot study was chosen to examine the potential benefits of physical training in sarcoidosis.

Unfortunately, this study was underpowered, since the number of patients it included was smaller than had been indicated by the sample size calculation. Hence its results should be interpreted with caution.

Since the pilot study did not include a control group, it could not show the effectiveness of physical training in reducing physical impairments in sarcoidosis compared with no treatment or usual care.

In line with Strookappe et al. ${ }^{7}$, physical functions in our sarcoidosis patients seemed to improve following a 13-week physical training program designed for sarcoidosis patients (chapter 7), although the improvements were smaller than in their study. Some factors may have contributed to the smaller improvement. One could argue that higher intensity training, as advocated in international guidelines ${ }^{24,25}$, might have yielded greater impact. However, sarcoidosis patients often suffer from severe physical impairments, like arthralgia and muscle pain, and a high-intensity training 
program may worsen these complaints, resulting in high dropout rates. Therefore, we deliberately opted for a low- to moderate-intensity training program in this study. However, this intensity may be insufficient to induce a physiological adaptation of the cardiovascular and musculoskeletal system. ${ }^{26}$

The frequency and duration of the training program were in line with international guidelines $^{24,25}$, so these training parameters would seem to be sufficient. Physical training might also cause increased levels of inflammatory markers and cytokines, explaining sarcoidosis-associated symptoms. ${ }^{27,28} \mathrm{~A}$ training frequency of three times a week could affect the recovery period. Although Braam et al. ${ }^{28}$ showed higher levels of biochemical parameters in sarcoidosis patients compared to healthy controls before an exercise test, changes in these levels in response to exercise were similar in both groups. Hence, the biochemical response during exercise and the recuperative capacity after maximal exertion by sarcoidosis patients appear similar to those of healthy controls.

The physical training included peripheral muscle strength and endurance training. Since respiratory muscle weakness is also common in sarcoidosis, respiratory muscle training could be a valuable addition to general exercise training in sarcoidosis, especially for those with respiratory limitations during exercise. ${ }^{26}$ The additional benefits of multidisciplinary pulmonary rehabilitation (PR) should also be studied. Besides physical training, multidisciplinary PR includes education and behavior change to improve the physical and psychological condition of people with chronic respiratory disease and to promote disease management. ${ }^{26}$

\section{Cause of physical impairments}

The studies presented in this thesis show that physical impairments do occur in sarcoidosis. However, the primary cause of these impairments remains unknown. Several factors may contribute to the development of physical impairments. Exposure of a genetically predisposed person to antigens may cause an inflammatory response with granuloma formation in sarcoidosis. The most important characteristic of sarcoidosis is systemic inflammation with increased levels of cytokines and chemokines, such as tumor necrosis factor-alpha (TNF- $\alpha$ ) and interleukins (Figure 8.1). ${ }^{28-30}$ It is assumed that these inflammatory markers initiate protein breakdown in skeletal muscles. ${ }^{5,31}$ In addition, systemic inflammation can be a trigger for oxidative stress, which may contribute to muscle dysfunction in chronic diseases. ${ }^{32,33}$ The exaggerated immune response also causes granulomas in sarcoidosis. Sarcoid muscle involvement is commonly demonstrated, although it is mostly asymptomatic. ${ }^{34}$ Recently, Cremers et al. ${ }^{35}$ showed that ${ }^{18} \mathrm{~F}$-FDG-PET/CT was useful in detecting muscle involvement in sarcoidosis. Unfortunately, it remains unclear whether sarcoid muscle involvement is related to muscle weakness. In addition, corticosteroid-induced myopathy is a wellknown side-effect of corticosteroid treatment in sarcoidosis.

Another substantial problem in sarcoidosis appears to be muscle atrophy. ${ }^{36}$ Our sarcoidosis patients with reduced peripheral muscle strength demonstrated impaired 
lung functions and reduced fat-free mass (FFM) (chapter 3), which may be an expression of muscle wasting. Therefore, loss of muscle bulk might be a determinant of muscle strength. Unfortunately, muscle mass was not directly measured in our study. A recent study by Cremers et al. ${ }^{36}$ showed conflicting results. They found normal muscle strength but reduced exercise capacity in muscle atrophic patients compared to patients with normal muscle mass. Finally, physical inactivity caused by perceived disabling symptoms, like lung function impairments, fatigue, dyspnea, cognitive failure, and depression, can induce physical deconditioning, resulting in more perceived fatigue and physical inactivity. In the long term, this negative circle of deconditioning may cause exercise intolerance and muscle weakness. ${ }^{37}$ Unfortunately, generally used medical assessments cannot distinguish between these different causes, so future studies are necessary to demonstrate the primary cause of the physical impairments. Although knowledge about the etiology of physical impairments is essential to guide treatment strategies, this was beyond the scope of this thesis.

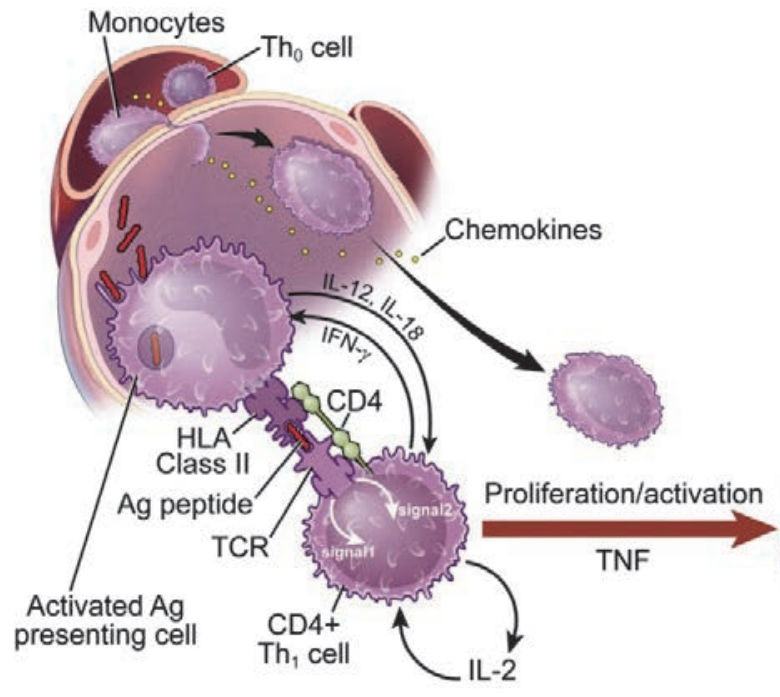

Figure 8.1 Schematic presentation of the inflammatory response with granuloma formation in sarcoidosis. An antigen induces antigen-specific Th1-mediated granulomatous inflammation with production of Th1 cytokines (IFN- $\gamma$, IL-2). Granuloma formation is set in motion by activated macrophages and T-cells, along with other effector cells (e.g. fibroblasts) under the regulatory influence of local cytokine production. Removal of the antigen allows downregulation of the immune response. Alveolar macrophages activated in the context of a predominant Th2 response appear to stimulate fibroblast proliferation and collagen production, leading to progressive fibrosis. ${ }^{38} \mathrm{Ag}$, antigen; HLA, human leukocyte antigen; IFN- $\nu$, interferon gamma; IL, interleukin; TCR, T-cell receptor; Th, T-helper; TNF, tumor necrosis factor. Adapted from Baughman et al. ${ }^{30}$ 


\section{Practical implications}

Since physical impairments are frequent problems in sarcoidosis, we recommend the use of physical tests in the diagnosis and evaluation of sarcoidosis patients, even in nonfatigued patients. Physical assessment should include submaximal exercise and peripheral muscle strength testing of the lower limbs and inspiratory muscle strength testing. In those patients with unexplained disabling symptoms, cardiopulmonary exercise testing can offer added value in detecting impaired gas exchange during exercise. Fatigue complaints cannot be predicted by physical or clinical test results. Therefore, a fatigue measure should also be included in the management of sarcoidosis. Although more research is necessary to assess the benefits of physical training in sarcoidosis, physical training might be considered in patients with physical complaints, to improve fatigue, physical functions, and QoL.

\section{Directions for future research}

Future research should focus on optimization of the physical assessment in sarcoidosis and the treatment options for physical impairments. This is necessary to avoid unnecessary exposure of patients to various clinical measurements and medical treatments because of inadequate management strategies.

Although it is clear that sarcoidosis patients frequently suffer from exercise intolerance and muscle weakness, the primary cause of these physical impairments remains unknown. As mentioned above, various hypotheses exist to explain the development of these impairments. A multidisciplinary research approach is necessary to identify the primary cause.

The study results presented in this thesis are a first step in the assessment of physical impairments in sarcoidosis. However, no standardized physical assessment battery is as yet available, so future studies should focus on the standardization and optimization of the physical assessment in sarcoidosis, incorporating the qualitative aspects, practical use, and costs of the measurements.

The Fatigue Assessment Scale (FAS) is a frequently used subjective fatigue measure in sarcoidosis with good psychometric properties. ${ }^{39}$ Unfortunately, the FAS does not include an activity monitor, such as an accelerometer or activity questionnaire. Hence, patients may experience stable fatigue complaints even though their activity level has improved, resulting in an underestimation of their physical activity level. Optimal patient monitoring requires knowledge of their activity level in relation to fatigue complaints.

The minimal clinically important difference (MCID) is the smallest change score on an outcome measure across time which patients perceive as relevant. ${ }^{40}$ This value is relevant for a clinician to interpret the clinical meaning of changes in outcome measures during the follow-up of individual sarcoidosis patients, since a statistically significant difference in outcome measure over time does not mean that this difference is relevant from the patients' point of view. An MCID value has been established for the 
$\mathrm{FAS}^{40,41}$ but not for other measures frequently used in sarcoidosis, like the WHOQOL-BREF and 6MWT. Prospective cohort studies are needed to establish the MCID for primary outcome measures used in the management of sarcoidosis.

This thesis has reported short-term changes in fatigue, psychological health, and physical functions following a low-intensity physical training program in a small population of sarcoidosis patients. Although this pilot study provided some important evidence with regard to physical training in sarcoidosis, further research is required. Both the short- and long-term benefits of a physical training program in a larger sarcoidosis population should be studied, preferably using a randomized controlled trial design. Another point of debate concerns the intensity of the training. At the same time, the additional benefits of a multidisciplinary pulmonary rehabilitation program in sarcoidosis and the use of ambulatory oxygen during training in patients with pulmonary impairments should be studied.

Besides participation in a physical training program, telephone- or internet-based health (telehealth) coaching services can support sarcoidosis patients in monitoring their health, enhanceing self-management of their disease, and promoting an active lifestyle. A review by Dennis et al. ${ }^{42}$ showed that telephone coaching is effective in chronically ill patients, including COPD patients, to improve health behavior, selfefficacy, and health status. It was especially in vulnerable patients or patients with limited access to health care that this service proved to offer added value in promoting better disease management. Tabak et al. $^{43}$ also showed that telehealth is effective in promoting better disease management and that patients' satisfaction with the program is good. Since studies of the effectiveness of telehealth in the management of sarcoidosis are lacking, prospective randomized controlled trials are necessary to examine whether telehealth programs are effective and provide added value in the management of sarcoidosis, and what kind of telehealth service would be most effective. 


\section{References}

1. Statement on sarcoidosis. Joint Statement of the American Thoracic Society (ATS), the European Respiratory Society (ERS) and the World Association of Sarcoidosis and Other Granulomatous Disorders (WASOG) adopted by the ATS Board of Directors and by the ERS Executive Committee, February 1999. Am J Respir Crit Care Med 1999;160:736-755.

2. Wirnsberger RM, De Vries J, Wouters EF, Drent M. Clinical presentation of sarcoidosis in the Netherlands an epidemiological study. Neth J Med 1998;53:53-60.

3. Wirnsberger RM, De Vries J, Breteler MH, Van Heck GL, Wouters EF, Drent M. Evaluation of quality of life in sarcoidosis patients. Respir Med 1998;92:750-756.

4. Alilovic M, Peros-Golubicic T, Radosevic-Vidacek B, Koscec A, Tekavec-Trkanjec J, Solak M, Hecimovic A, Smojver-Jezek S. WHOQOL-bREF questionnaire as a measure of quality of life in sarcoidosis. Coll Antropol 2013;37:701-706.

5. Drent M, Wirnsberger RM, De Vries J, Van Dieijen-Visser MP, Wouters EF, Schols AM. Association of fatigue with an acute phase response in sarcoidosis. Eur Respir J 1999;13:718-722.

6. Huppmann P, Sczepanski B, Boensch M, Winterkamp S, Schonheit-Kenn U, Neurohr C, Behr J, Kenn K. Effects of in-patient pulmonary rehabilitation in patients with interstitial lung disease. Eur Respir J 2013; 42:444-453.

7. Strookappe B, Elfferich MD, Swigris JJ, Verschoof A, Verschakelen JA, Knevel T, Drent M. Benefits of physical training in patients with idiopathic or end-stage sarcoidosis-related pulmonary fibrosis: a pilot study. Sarcoidosis Vasc Diffuse Lung Dis 2014; In press

8. Spruit MA, Thomeer MJ, Gosselink R, Troosters T, Kasran A, Debrock AJ, Demedts MG, Decramer M. Skeletal muscle weakness in patients with sarcoidosis and its relationship with exercise intolerance and reduced health status. Thorax 2005;60:32-38.

9. Wirnsberger RM, Drent M, Hekelaar N, Breteler MH, Drent S, Wouters EF, Dekhuijzen PN. Relationship between respiratory muscle function and quality of life in sarcoidosis. Eur Respir J 1997;10:1450-1455.

10. Khan KS, Kunz R, Kleijnen J, Antes G. Five steps to conducting a systematic review. J R Soc Med 2003;96: 118-121.

11. Barreiro E, Criner GJ. Update in chronic obstructive pulmonary disease 2013. Am J Respir Crit Care Med 2014;189:1337-1344.

12. Cielen N, Maes K, Gayan-Ramirez G. Musculoskeletal disorders in chronic obstructive pulmonary disease. Biomed Res Int 2014;2014:965764.

13. Gosselink R, Troosters T, Decramer M. Peripheral muscle weakness contributes to exercise limitation in COPD. Am J Respir Crit Care Med 1996;153:976-980.

14. Hess DR. Retrospective studies and chart reviews. Respir Care 2004;49:1171-1174.

15. Bohannon RW. Test-retest reliability of hand-held dynamometry during a single session of strength assessment. Phys Ther 1986;66:206-209.

16. Dimitriadis Z, Kapreli E, Konstantinidou I, Oldham J, Strimpakos N. Test/retest reliability of maximum mouth pressure measurements with the MicroRPM in healthy volunteers. Respir Care 2011;56: 776-782.

17. ATS Committee on proficiency standards for clinical pulmonary function laboratories. ATS statement: guidelines for the six-minute walk test. Am J Respir Crit Care Med 2002;166:111-117.

18. Beekman E, Mesters I, Gosselink R, Klaassen MP, Hendriks EJ, Van Schayck OC, De Bie RA. The first reference equations for the 6-minute walk distance over a 10 m course. Thorax 2014;69:867-868.

19. Delourme J, Stervinou-Wemeau L, Salleron J, Grosbois JM, Wallaert B. Six-minute stepper test to assess effort intolerance in interstitial lung diseases. Sarcoidosis Vasc Diffuse Lung Dis 2012;29:107-112.

20. Starobin D, Kramer MR, Yarmolovsky A, Bendayan D, Rosenberg I, Sulkes J, Fink G. Assessment of functional capacity in patients with chronic obstructive pulmonary disease: correlation between cardiopulmonary exercise, 6 minute walk and 15 step exercise oximetry test. Isr Med Assoc J 2006;8: 460-463.

21. De Boer S, Kolbe J, Wilsher ML. Comparison of the modified shuttle walk test and cardiopulmonary exercise test in sarcoidosis. Respirology 2014;19:604-607.

22. Natanek SA, Gosker HR, Slot IG, Marsh GS, Hopkinson NS, Moxham J, Kemp PR, Schols AM, Polkey MI. Pathways associated with reduced quadriceps oxidative fibres and endurance in COPD. Eur Respir J 2013;41:1275-1283. 
23. Swallow EB, Gosker HR, Ward KA, Moore AJ, Dayer MJ, Hopkinson NS, Schols AM, Moxham J, Polkey MI. A novel technique for nonvolitional assessment of quadriceps muscle endurance in humans. J Appl Physiol (1985) 2007;103:739-746.

24. Langer D, Hendriks E, Burtin C, Probst V, Van der Schans C, Paterson W, Verhoef-de Wijk M, Straver R, Klaassen M, Troosters T, Decramer M, Ninane V, Delguste P, Muris J, Gosselink R. A clinical practice guideline for physiotherapists treating patients with chronic obstructive pulmonary disease based on a systematic review of available evidence. Clin Rehabil 2009;23:445-462.

25. Spruit MA, Pitta F, Garvey C, ZuWallack RL, Roberts CM, Collins EG, Goldstein R, McNamara R, Surpas P, Atsuyoshi K, Lopez-Campos JL, Vogiatzis I, Williams JE, Lareau S, Brooks D, Troosters T, Singh SJ, Hartl S, Clini EM, Wouters EF. Differences in content and organisational aspects of pulmonary rehabilitation programmes. Eur Respir J 2014;43:1326-1337.

26. Spruit MA, Singh SJ, Garvey C, ZuWallack R, Nici L, Rochester C, Hill K, Holland AE, Lareau SC, Man WD, Pitta F, Sewell L, Raskin J, Bourbeau J, Crouch R, Franssen FM, Casaburi R, Vercoulen JH, Vogiatzis I, Gosselink R, Clini EM, Effing TW, Maltais F, van der Palen J, Troosters T, Janssen DJ, Collins E, GarciaAymerich J, Brooks D, Fahy BF, Puhan MA, Hoogendoorn M, Garrod R, Schols AM, Carlin B, Benzo R, Meek P, Morgan M, Rutten-van Molken MP, Ries AL, Make B, Goldstein RS, Dowson CA, Brozek JL, Donner CF, Wouters EF. An official American Thoracic Society/European Respiratory Society statement: key concepts and advances in pulmonary rehabilitation. Am J Respir Crit Care Med 2013;188:e13-64.

27. Baydur A, Alavy B, Nawathe A, Liu S, Louie S, Sharma OP. Fatigue and plasma cytokine concentrations at rest and during exercise in patients with sarcoidosis. Clin Respir J 2011;5:156-164.

28. Braam AW, De Haan SN, Vorselaars AD, Rijkers GT, Grutters JC, Van den Elshout FJ, Korenromp IH. Influence of repeated maximal exercise testing on biomarkers and fatigue in sarcoidosis. Brain Behav Immun 2013;33:57-64.

29. Valeyre D, Prasse A, Nunes H, Uzunhan Y, Brillet PY, Muller-Quernheim J. Sarcoidosis. Lancet 2014;383:1155-1167.

30. Baughman RP, Culver DA, Judson MA. A concise review of pulmonary sarcoidosis. Am J Respir Crit Care Med 2011;183:573-581.

31. Remels AH, Gosker HR, Schrauwen P, Hommelberg PP, Sliwinski P, Polkey M, Galdiz J, Wouters EF, Langen RC, Schols AM. TNF-alpha impairs regulation of muscle oxidative phenotype: implications for cachexia? FASEB J 2010;24:5052-5062.

32. Barreiro E, Peinado VI, Galdiz JB, Ferrer E, Marin-Corral J, Sanchez F, Gea J, Barbera JA, Project EiC. Cigarette smoke-induced oxidative stress: A role in chronic obstructive pulmonary disease skeletal muscle dysfunction. Am J Respir Crit Care Med 2010;182:477-488.

33. Lawler JM, Song W. Specificity of antioxidant enzyme inhibition in skeletal muscle to reactive nitrogen species donors. Biochem Biophys Res Commun 2002;294:1093-1100.

34. Fayad F, Liote F, Berenbaum F, Orcel P, Bardin T. Muscle involvement in sarcoidosis: a retrospective and followup studies. J Rheumatol 2006;33:98-103.

35. Cremers JP, Van Kroonenburgh MJ, Mostard RL, Voo SA, Wijnen PA, Koek GH, Drent M. Extent of disease activity assessed by 18F-FDG PET/CT in a Dutch sarcoidosis population. Sarcoidosis Vasc Diffuse Lung Dis 2014;31:37-45.

36. Cremers JP, Drent M, Elfferich MD, Nelemans PJ, Wijnen PA, Witteman BJ, Schols AM. Body composition profiling in a Dutch sarcoidosis population. Sarcoidosis Vasc Diffuse Lung Dis 2013;30: 289-299.

37. Spruit MA, Wouters EFM, Gosselink R. Rehabilitation programmes in sarcoidosis: a multidisciplinary approach. Eur Respir J 2005;32:316-326.

38. Iannuzzi MC, Rybicki BA, Teirstein AS. Sarcoidosis. N Engl J Med 2007;357:2153-2165.

39. Michielsen HJ, De Vries J, Van Heck GL, Van de Vijver FJR, Sijtsma K. Examination of the dimensionality of fatigue: The construction of the Fatigue Assessment Scale (FAS). EJPA 2004;20:39-48.

40. De Kleijn WP, De Vries J, Wijnen PA, Drent M. Minimal (clinically) important differences for the Fatigue Assessment Scale in sarcoidosis. Respir Med 2011;105:1388-1395.

41. Drent M, Lower EE, De Vries J. Sarcoidosis-associated fatigue. Eur Respir J 2012;40:255-263.

42. Dennis SM, Harris M, Lloyd J, Powell Davies G, Faruqi N, Zwar N. Do people with existing chronic conditions benefit from telephone coaching? A rapid review. Aust Health Rev 2013;37:381-388. 
43. Tabak M, Brusse-Keizer M, Van der Valk $P$, Hermens $H$, Vollenbroek-Hutten $M$. A telehealth program for self-management of COPD exacerbations and promotion of an active lifestyle: a pilot randomized controlled trial. Int J Chron Obstruct Pulmon Dis 2014;9:935-944. 
Samenvatting

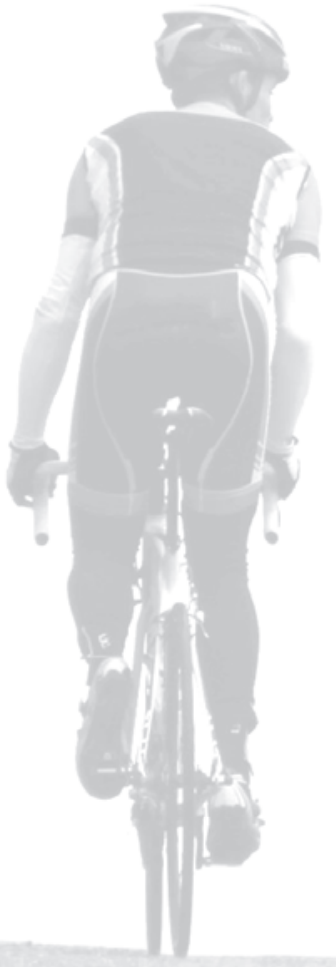




\section{Samenvatting}

Sarcoïdose is een multisysteemaandoening, welke gekenmerkt wordt door ontstekingsactiviteit met de vorming van niet-verkazende granulomen. Granulomen zijn ophopingen van afweercellen, die overal in het lichaam kunnen voorkomen en tot functievermindering van een orgaan kunnen leiden. Tot op heden is de oorzaak voor het ontstaan van sarcoïdose onbekend. Verondersteld wordt dat sarcoïdose het resultaat is van een buitensporige afweerreactie bij een genetisch vatbaar persoon, als gevolg van blootstelling aan specifieke prikkels uit de omgeving, zoals virussen, schimmels, bestrijdingsmiddelen, silica of metaaldeeltjes. Na de aanslag op het World Trade Center in New York bijvoorbeeld is de incidentie van sarcoïdose onder de betrokken brandweermannen toegenomen, waarschijnlijk doordat zij toen blootgesteld zijn aan grote hoeveelheden anorganische stoffen. Ook andere lichaamsvreemde stoffen, zoals de inkt in een tatoeage, kunnen aanleiding geven tot het ontstaan van sarcoïdose.

Sarcoïdose komt over de hele wereld voor bij alle rassen, bij zowel mannen als vrouwen. Het kan op alle leeftijden beginnen, maar met name bij jong volwassenen in de leeftijdscategorie van 25-45 jaar. Over het algemeen is de ernst van de ziekte en het beloop ernstiger bij mensen van het negroïde ras. De incidentie van sarcoïdose in Nederland wordt geschat op 20 per 100.000 inwoners en de prevalentie 50 per 100.000 inwoners.

Patiënten kunnen zich met een grote verscheidenheid aan klachten melden bij hun arts. Dit is mede afhankelijk van de betrokken organen en de activiteit, duur en ernst van de ziekte. Alle orgaansystemen van het menselijk lichaam kunnen betrokken zijn, maar bij de meeste patiënten zijn de longen aangedaan. De ogen, huid, het musculoskeletale en het lymfesysteem zijn ook veelvuldig bij de ziekte betrokken. Naast orgaan-specifieke symptomen hebben patiënten frequent last van niet-orgaan specifieke symptomen, zoals pijn, gewrichtsklachten, vermoeidheid, spierzwakte en inspanningsintolerantie. Deze sarcoïdose gerelateerde functiebeperkingen kunnen leiden tot problemen in het dagelijks functioneren en tot een verminderde kwaliteit van leven (KvL).

\section{Overzicht bevindingen}

Fysieke training is reeds effectief gebleken voor de behandeling van fysieke beperkingen bij meerdere chronische aandoeningen. Tot op heden is er weinig wetenschappelijk onderzoek gedaan op het gebied van de effectiviteit van training bij sarcoïdose. Desondanks worden sarcoïdosepatiënten met fysieke beperkingen veelvuldig door hun arts verwezen naar een fysiotherapeut. Vanuit het oogpunt van evidence-based practice is wetenschappelijk onderzoek noodzakelijk ter onderbouwing van deze behandeloptie. Hierbij dient allereerst onderzocht te worden in welke mate fysieke beperkingen voorkomen bij patiënten met sarcoïdose. 
De studies die beschreven worden in dit proefschrift hebben dan ook enerzijds tot doel het bepalen van de prevalentie van fysieke beperkingen bij sarcoïdose en anderzijds het onderzoeken van de meerwaarde van het gebruik van fysieke testen in de begeleiding van sarcoïdosepatiënten. Voor deze studies zijn sarcoïdosepatiënten geïncludeerd die verwezen waren naar het voormalig ild (interstitial lung disease) care team van het Maastricht Universitair Medisch Centrum. In de laatste studie wordt gekeken naar de invloed van fysieke training op de mate van vermoeidheid, fysieke beperkingen en KvL bij patiënten met sarcoïdose. In deze studie zijn sarcoïdosepatiënten geïncludeerd die door hun longarts van het Orbis Medisch Centrum werden verwezen naar de fysiotherapeut.

Hoofdstuk 1 geeft als algemene inleiding een overzicht van de pathogenese, epidemiologie, klinische kenmerken en het ziekteverloop van sarcoïdose. Tevens wordt de mogelijke rol van fysieke metingen voor het in kaart brengen van de lichamelijke situatie en de rol van fysieke training in de begeleiding van sarcoïdosepatiënten besproken. Tenslotte wordt een overzicht van de inhoud van dit proefschrift gepresenteerd.

Hoofdstuk 2 geeft een literatuuroverzicht omtrent de prevalentie, het vaststellen en behandelen van spierzwakte en inspanningsintolerantie bij patiënten met sarcoïdose en de relaties tussen deze fysieke beperkingen enerzijds en vermoeidheid, kortademigheid en KvL anderzijds.

Spierzwakte en inspanningsintolerantie bij sarcoïdose blijken frequent voorkomende problemen te zijn met een aanhoudend karakter. De resultaten van de gebruikelijke klinische testen, zoals longfunctietesten en thoraxfoto's, blijken deze fysieke gezondheidsklachten niet goed in kaart te brengen. Fysieke testen zijn wel geschikt om de aanwezigheid van spierzwakte en inspanningsintolerantie aan te tonen. Tevens kunnen inspanningstesten bruikbaar zijn in de vroegdiagnostiek van longbetrokkenheid en in de diagnostiek van sarcoïdose geassocieerde pulmonale hypertensie. Gesuggereerd wordt dat zowel spierzwakte als inspanningsintolerantie onderliggende oorzaken kunnen zijn voor het ontstaan van vermoeidheid en kortademigheidsklachten. Daarom dienen artsen zich er van bewust te zijn dat patiënten met vermoeidheids- en/of kortademigheidsklachten mogelijk ook fysieke beperkingen hebben, welke kunnen leiden tot een verminderde KvL. Dit hoofdstuk benadrukt dan ook de klinische relevantie van het gebruik van fysieke testen in de begeleiding van sarcoïdosepatiënten.

Ondanks het feit dat fysieke training zijn meerwaarde heeft bewezen bij verschillende chronische longaandoeningen ter behandeling van fysieke beperkingen, zijn de effecten van training nauwelijks onderzocht in een representatieve populatie van sarcoïdosepatiënten. Onderzoek naar de klinische meerwaarde van een multidisciplinair revalidatie programma binnen de begeleiding van sarcoïdosepatiënten is daarom noodzakelijk. 
In hoofdstuk 3 is de prevalentie van inspanningsintolerantie, spierzwakte en vermoeidheid bij 124 sarcoïdosepatiënten onderzocht. Daarnaast is geanalyseerd of de optredende vermoeidheidsklachten te verklaren zijn door inspanningscapaciteit, spierkracht, demografische (geslacht, leeftijd, body mass index, vet vrije massa en tijd van diagnose) en klinische (longfunctietesten, ontstekingsparameters, röntgenfoto's van de thorax en medicatiegebruik) factoren. Daarvoor hebben de patiënten een zesminuten wandeltest (6MWT) uitgevoerd en tevens werd de perifere spierkracht gemeten (de handknijpkracht (HGF), de kracht van de elleboogflexoren (EFMS), quadriceps (QPT) en hamstrings (HPT)). Daarnaast is de maximale inademingsdruk (PImax) bepaald. Tevens is gevraagd naar de mate van vermoeidheid aan de hand van de Fatigue Assessment Scale (FAS). De data van 62 gezonde controle personen zijn in dit onderzoek gebruikt als referentiewaarden voor de fysieke testresultaten.

Dit onderzoek liet zien dat in $45 \%$ van de onderzoekspopulatie de loopafstand gedurende de 6MWT was verminderd, terwijl de HGF, EFMS, QPT en HPT waren verminderd in respectievelijk $15 \%, 12 \%, 27 \%$ en $18 \%$ van de onderzoekspopulatie. De PImax was verminderd in $43 \%$ van de sarcoïdosepatiënten. Ruim $80 \%$ van de patiënten rapporteerde vermoeidheidsklachten. Inspanningsintolerantie en spierzwakte kwamen zowel voor bij patiënten met als zonder vermoeidheidsklachten. Patiënten met verminderde perifere spierkracht, van zowel de bovenste als de onderste extremiteiten, bleken meer vermoeid. Deze groep onderscheidde zich tevens van patiënten zonder beperkingen in spierkracht door een verminderde longfunctie, lagere vet vrije massa, verminderde PImax, 6MWT en KvL. Vermoeidheid daarentegen werd niet voorspeld door inspanningscapaciteit en spierkracht, noch door demografische of klinische factoren.

Samenvattend laten deze onderzoeksresultaten zien dat vermoeidheid, inspanningsintolerantie en spierzwakte frequent voorkomende problemen zijn bij sarcoïdose. In tegenstelling tot regulier uitgevoerde klinische testen, zoals longfunctietesten en thoraxfoto's, zijn fysieke testen geschikt om fysieke beperkingen in kaart te brengen. Het wordt daarom aanbevolen om fysieke testen deel uit te laten maken van de multidisciplinaire begeleiding van sarcoïdosepatiënten, zelfs bij patiënten zonder vermoeidheidsklachten. Toekomstig onderzoek blijft noodzakelijk om het vastleggen van fysieke beperkingen bij sarcoïdose te standaardiseren.

Om de effectiviteit van een therapeutische interventie op waarde te kunnen schatten is het tevens van belang om het natuurlijk beloop van deze beperkingen in de tijd te kennen, aangezien een fysiotherapeutische interventie van meerwaarde kan zijn bij patiënten met aanhoudende fysieke beperkingen. Hoofdstuk 4 geeft middels een longitudinale studie de veranderingen in prevalentie weer van inspanningscapaciteit, spierkracht en vermoeidheid en tevens de individuele veranderingen van deze parameters bij sarcoïdosepatiënten in een tijdsbestek van twee jaar.

Hiervoor werden alle deelnemers van het in hoofdstuk 3 gepresenteerde onderzoek, die woonachtig waren in het zuiden van Nederland $(n=104)$, uitgenodigd om deel te nemen aan de follow-up meting. Veertien patiënten waren niet in staat om 
deel te nemen, waardoor uiteindelijk 90 sarcoïdosepatiënten hebben deelgenomen aan dit onderzoek. Tijdens de follow-up meting na 2 jaar werden opnieuw de fysieke testen uitgevoerd en de vragenlijsten ingevuld, zoals reeds vermeld in hoofdstuk 3.

Zowel bij aanvang als bij de follow-up meting liet een aanzienlijk deel van de patiënten een verminderde loopafstand (6MWT: respectievelijk $41.6 \%$ en $34.8 \%$ ), verminderde perifere spierkracht (EFMS: $6.7 \%$ en $14.6 \%$, QPT: $21.3 \%$ en $18.0 \%$ en HPT: $13.5 \%$ en $12.4 \%$ ) en PImax (respectievelijk $45.9 \%$ en $48.6 \%$ ) zien. Zowel aan het begin (86\%) als aan het eind $(77 \%)$ rapporteerde de meerderheid van de patiënten vermoeidheidsklachten. Ondanks dat veranderingen op individueel niveau waarneembaar waren, bleven de fysieke beperkingen op groepsniveau stabiel tijdens de follow-up periode. De literatuur vermeldt echter dat ongeveer twee derde van de sarcoïdosepatiënten een spontane remissie laat zien in de eerste twee jaar na de diagnose, terwijl sarcoïdose in $10-30 \%$ een chronisch (>twee jaar) of progressief karakter heeft. In dit onderzoek bleek de prevalentie van fysieke beperkingen bij patiënten die minder dan twee jaar geleden gediagnosticeerd werden met sarcoïdose gelijk te zijn aan die bij patiënten met een langere ziektegeschiedenis.

Dit onderzoek benadrukt dan ook dat inspanningsintolerantie, spierzwakte en vermoeidheid frequent voorkomende problemen zijn met een stabiel en aanhoudend karakter bij symptomatische sarcoïdosepatiënten.

Voor het objectiveren van fysieke beperkingen zijn valide en betrouwbare meetinstrumenten onmisbaar. Röntgenfoto's van de thorax, longfunctie- en bloedonderzoek blijken in veel gevallen ongeschikt te zijn om fysieke beperkingen en KvL bij sarcoïdose te verklaren. Op basis van een onderzoek bij 160 symptomatische sarcoïdosepatiënten wordt in hoofdstuk $\mathbf{5}$ de meerwaarde van een cardiopulmonale inspanningstest (CPET) op een fietsergometer met bloedgasanalyse beschreven. De CPET wordt vergeleken met het meten van de diffusie capaciteit van de long voor koolmonoxide in rust (DLCO) voor het opsporen van verminderde pulmonale gasuitwisseling. In 69.7\% van de patiënten met een normale DLCO ( $n=99,61.9 \%)$ liet de alveolaire-arteriële zuurstofspanningsgradiënt $\left(\mathrm{P}(\mathrm{A}-\mathrm{a}) \mathrm{O}_{2}\right)$ bij maximale inspanning een matige toename ( $>2.5 \mathrm{kPa}$ ) zien en bij $18.2 \%$ een forse toename ( $>4.7 \mathrm{kPa})$. Pulmonale gaswisselingsstoornissen (PGEI) waren meer uitgesproken bij patiënten met lage DLCO waarden. Een DLCO waarde beneden de $60 \%$ van voorspeld was zelfs een indicatie voor een aanzienlijke gaswisselingsstoornis. De arteriële zuurstofspanning in rust, DLCO, de geforceerde vitale capaciteit (FVC) als percentage van voorspeld en de afwijkingen op de thoraxfoto's ingedeeld in verschillende stadia (0-IV) voorspelden $40 \%$ van de PGEI tijdens maximale inspanning.

We kunnen dan ook concluderen dat een normale DLCO waarde een eventuele pulmonale gaswisselingsstoornis tijdens maximale inspanning niet kan uitsluiten. Dit suggereert dat een normale DLCO waarde gemeten in rust minder geschikt is als voorspeller voor een abnormale pulmonale gaswisseling tijdens inspanning dan een CPET. Bij sarcoïdosepatiënten met onverklaarbare en beperkende symptomen wordt 
een CPET dan ook aanbevolen voor het opsporen van een gaswisselingsstoornis tijdens inspanning.

Hoofdstuk 6 beschrijft het verband tussen KvL en fysieke functies bij sarcoïdose en tevens wordt geëvalueerd of dit verband verandert gedurende een onderzoeksperiode van twee jaar. In totaal hebben 88 sarcoïdosepatiënten deelgenomen aan dit onderzoek, aangezien twee patiënten van de in hoofdstuk 4 beschreven populatie de World Health Organization Quality of Life-BREF (WHOQOL-BREF) vragenlijst niet hadden ingevuld. Zowel aan het begin als bij de follow-up meting voerden de patiënten fysieke testen uit (zie hoofdstuk 3). Daarnaast werden ze ook gevraagd de WHOQOL-BREF en de FAS in te vullen.

De KvL van sarcoïdosepatiënten was verminderd in vergelijking met die van een gezonde controle groep, in het bijzonder was dit het geval voor het domein van de fysieke gezondheid. De KvL van sarcoïdosepatiënten veranderde niet gedurende de onderzoeksperiode van twee jaar. Zowel bij de aanvangsmeting als bij de follow-up meting lieten vermoeidheid en de zes-minuten loopafstand sterke verbanden zien met KvL. Vermoeidheid en inspanningscapaciteit voorspelden de scores van het domein fysieke gezondheid van de WHOQOL-BREF tijdens de aanvangsmeting (59\%) en followup (64\%) meting. KvL gemeten bij aanvang was hierbij de beste voorspeller voor de KvL gemeten bij follow-up.

Aangezien vermoeidheid en inspanningscapaciteit belangrijke stabiele verbanden vertoonden met $\mathrm{KvL}$ is het aan te raden om deze aspecten op te nemen in het begeleidingsprogramma van sarcoïdosepatiënten. Immers deze resultaten suggereren dat vermoeidheid en inspanningscapaciteit een grote invloed hebben op KvL en daarmee belangrijke interventieparameters kunnen zijn om de KvL van sarcoïdosepatiënten positief te beïnvloeden. Toekomstige onderzoeken zijn noodzakelijk om te beoordelen of fysieke training effectief kan zijn ter verbetering van fysieke beperkingen en daarmee ook van KvL.

Ondanks dat longrevalidatie tot de standaard zorg is gaan behoren voor patiënten met chronisch obstructieve longziekten (COPD) is het aantal wetenschappelijke onderzoeken naar de effectiviteit van fysieke training bij sarcoïdose schaars. In hoofdstuk 7 worden de resultaten gepresenteerd van een pilot onderzoek naar de invloed van een 13 weken durend fysiek trainingsprogramma op de mate van vermoeidheid, fysieke functies en KvL bij 18 sarcoïdosepatiënten met vermoeidheids-klachten en/of een verminderde inspanningscapaciteit.

De FAS, WHOQOL-BREF, Medical Research Council (MRC) dyspnoeschaal, Visual Analogue Scale (VAS), 6MWT, submaximale fietstest en spierkracht van de quadriceps en elleboogflexoren werden voorafgaand en na afloop van het programma gemeten.

Dit onderzoek liet zien dat na afloop van het trainingsprogramma de FAS-scores afgenomen waren (gemiddeld verschil -2.7 punten, 95\% BI -4.4 tot -1.1). Tevens waren zowel de score in het domein psychologische gezondheid van de WHOQOL-BREF (gemiddelde verschil 0.9 punten, $95 \% \mathrm{BI} 0.2$ tot 1.7 ) als de MRC dyspnoe score (gemiddeld verschil -0.4 punten, $95 \% \mathrm{BI}-0.8$ tot -0.1 ) verbeterd. De loopafstand op de 
6MWT verbeterde met 34.6 meter (95\% BI 20.3 tot 49.0) en tevens verminderde de gemiddelde hartslag tijdens de fietstest (gemiddeld verschil 8.4 slagen/minuut, $95 \% \mathrm{BI}$ -13.8 tot -3.0 ) en verbeterde de kracht van de quadriceps (gemiddeld verschil $10.7 \mathrm{~kg}$, $95 \%$ BI 5.5 tot 15.9). Er werden geen veranderingen in VAS score of spierkracht van de elleboogflexoren waargenomen.

Alhoewel de trainingseffecten klein waren mag geconcludeerd worden dat fysieke training bij sarcoïdosepatiënten lijkt te resulteren in een vermindering van vermoeidheidsklachten en een verbetering van zowel de psychologische gezondheid als de fysieke functies. Door de beperkingen van het gebruikte onderzoeksdesign blijven toekomstige onderzoeken met een hoger niveau van bewijskracht, zoals een gerandomiseerd effectonderzoek, noodzakelijk om de klinische relevantie van fysieke training bij sarcoïdose in kaart te brengen.

Hoofdstuk 8 bevat de Engelstalige samenvatting met daarin de belangrijkste bevindingen van dit proefschrift en de algemene discussie. Verscheidene aspecten van de in dit proefschrift gepresenteerde studies, waaronder de interne validiteit van de literatuurstudie en de gebruikte studiedesigns, worden bediscussieerd.

Dit proefschrift beschrijft de prevalentie en het beloop van fysieke beperkingen bij patiënten met sarcoïdose en de meerwaarde van fysieke testen voor het opsporen van deze beperkingen. Ondanks dat fysieke testen worden aanbevolen in de begeleiding van sarcoïdosepatiënten bestaan tot op heden geen richtlijnen voor de wijze van het in kaart brengen van fysieke beperkingen bij sarcoïdose. De praktische toepasbaarheid van de fysieke metingen binnen de klinische praktijk wordt dan ook bediscussieerd en mogelijke alternatieven worden aangedragen. De meerwaarde van een fysiek trainingsprogramma voor patiënten met sarcoïdose was minder dan vooraf verwacht. Mogelijk onderliggende oorzaken voor dit tegenvallend resultaat komen hier ter sprake.

Voor een optimale behandeling van fysieke beperkingen bij patiënten met sarcoïdose is het noodzakelijk om de primaire oorzaak hiervan te kennen. Helaas is dit tot op heden onbekend en zal toekomstig onderzoek zich moeten richten op het ontrafelen van dit probleem.

Aan de hand van de onderzoeksresultaten worden vervolgens aanbevelingen gedaan voor de hedendaagse praktijkvoering. Aanbevolen wordt om fysieke testen uit te voeren aansluitend aan de diagnose en tijdens de begeleiding van sarcoïdosepatiënten. Aanbevolen worden: een submaximale inspanningstest, spierkrachttest voor zowel de inademingsspieren als de spieren van de onderste extremiteiten en een vragenlijst om vermoeidheidsklachten goed in kaart te brengen. Bij patiënten met onverklaarbare fysieke beperkingen kan tevens een cardiopulmonale inspanningstest van meerwaarde zijn. Ondanks dat meer onderzoek naar de effectiviteit van fysieke training bij sarcoïdose noodzakelijk is, kan training een zinvolle aanvulling zijn voor patiënten met fysieke beperkingen.

Toekomstig onderzoek is noodzakelijk voor zowel het vaststellen als het optimaliseren van behandelopties van sarcoïdose geassocieerde fysieke beperkingen. Dit is van belang om onnodige blootstelling van patiënten aan klinische metingen en 
(para-) medische behandelingen zoveel mogelijk te voorkomen. Hierbij dient tevens aandacht te zijn voor de kwalitatieve aspecten, de praktische toepasbaarheid en de kosten van de metingen en behandelstrategieën. Altijd dient hierbij het belang en daarmee de verbetering van KvL van de patiënt voorop te staan. 
Valorisatie

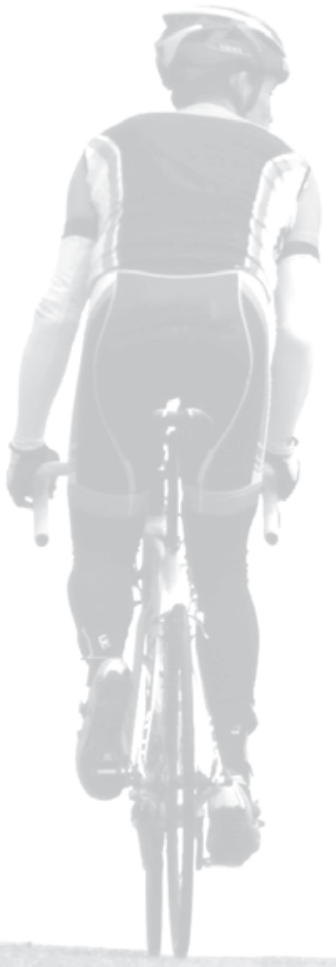




\section{Valorisatie}

\section{Inleiding}

Sarcoïdose behoort tot de groep van de diffuse oftewel interstitiële longaandoeningen (ild). Anders dan de term 'interstitiële longaandoeningen' doet vermoeden zijn bij sarcoïdose niet uitsluitend de longen betrokken. In principe kunnen alle organen van het menselijk lichaam betrokken raken bij de aandoening. Veelal betreft het de longen, maar ook de ogen, huid, het lymfe- en spier-skeletsysteem zijn veelvuldig aangedaan. Sarcoïdose is dan ook een multisysteemaandoening, die gekenmerkt wordt door ontstekingsactiviteit met de vorming van niet-verkazende granulomen. Granulomen zijn ophopingen van afweercellen die in het gehele lichaam kunnen voorkomen en op den duur kunnen leiden tot functievermindering van de betrokken organen. Naast orgaanspecifieke symptomen presenteren sarcoïdosepatiënten zich bij de arts met niet orgaan-specifieke symptomen, zoals pijn, vermoeidheid, algehele malaise en inspanningsintolerantie. Deze symptomen hebben veelal een subjectief en vaag karakter, waardoor deze moeilijk te diagnosticeren zijn. Deze (fysieke) beperkingen kunnen wel grote gevolgen hebben voor het dagelijks leven en daarmee voor de kwaliteit van leven (KvL). Een mogelijke behandeloptie voor fysieke beperkingen bij sarcoïdose is een (fysiotherapeutisch) trainingsprogramma ter verbetering van de fysieke fitheid. Ondanks dat patiënten vanwege fysieke beperkingen naar een fysiotherapeut worden verwezen is de evidentie met betrekking tot de effectiviteit van deze behandeloptie bij sarcoïdose beperkt. $\mathrm{Er}$ is dan ook dringend behoefte aan de wetenschappelijk onderbouwing hiervan. Voordat het mogelijk is deze vraag te beantwoorden dienen eerst enkele basisvragen beantwoord te worden. Wat is de prevalentie van fysieke beperkingen bij patiënten met sarcoïdose en wat is de meerwaarde van het gebruik van fysieke testen binnen de begeleiding van sarcoïdosepatiënten?

\section{Resultaten}

Regelmatig geven sarcoïdosepatiënten bij hun arts aan te kampen met fysieke beperkingen. Tot op het moment van het starten van ons onderzoek waren er geen uitgebreide studies voorhanden over het voorkomen van deze beperkingen bij sarcoïdose. Ons onderzoek laat zien dat een aanzienlijk deel van de patiënten te kampen heeft met inspanningsintolerantie, spierzwakte en vermoeidheid en dat deze beperkingen veelal een aanhoudend karakter hebben. De standaard uitgevoerde klinische testen, zoals longfunctietesten, bloedonderzoek of röntgenfoto's van de longen, blijken niet goed in staat om deze fysieke beperkingen in kaart te brengen. Fysieke testen blijken daarentegen wel in staat om de voorheen subjectieve klachten te objectiveren. Zo sluit een normale diffusie capaciteit van de longen (DLCO) gemeten in rust een eventuele pulmonale gaswisselingsstoornis tijdens maximale inspanning niet uit. Een cardiopulmonale inspanningstest lijkt hiervoor een betere voorspeller te zijn. 
Daarnaast wordt de $\mathrm{KvL}$ in ons onderzoek in grote mate voorspeld door de mate van vermoeidheid en inspanningscapaciteit. Deze resultaten geven aan dat dit belangrijke interventieparameters zijn voor het verbeteren van de KvL. Vanwege bovenstaande onderzoeksresultaten wordt aanbevolen om fysieke testen deel uit te laten maken van de multidisciplinaire begeleiding van patiënten met sarcoïdose.

Het laatste onderzoek van dit proefschrift gaat in op de meerwaarde van een fysiek trainingsprogramma bij sarcoïdosepatiënten met vermoeidheidsklachten en/of verminderde inspanningscapaciteit. Ondanks de beperkingen van het onderzoeksdesign lijkt een trainingsprogramma te resulteren in een vermindering van vermoeidheids-klachten en een verbetering van zowel de psychologische gezondheid als de fysieke functies.

\section{Maatschappelijk relevantie}

Sarcoïdose komt over de hele wereld voor, bij zowel mannen als vrouwen. De aandoening kan zich voordoen op iedere leeftijd, maar heeft een voorkeur voor jong volwassenen in de leeftijdscategorie van 25-45 jaar. Na astma is het de tweede meest voorkomende aandoening bij jong volwassenen. De incidentie van sarcoïdose in Nederland wordt geschat op 20 per 100.000 inwoners en de prevalentie op 50 per 100.000 inwoners, dat komt dus neer op een geschat aantal van 8000 sarcoïdosepatiënten in Nederland. Sarcoïdosepatiënten staan over het algemeen volop in het leven, waarbij op verscheidene gebieden veel van hen wordt gevraagd. Hierbij valt te denken aan studeren, opbouwen van een carrière en participeren in een gezin. Fysieke klachten kunnen grote gevolgen hebben voor het dagelijks functioneren en de KvL. Deze klachten kunnen zelfs leiden tot geheel of gedeeltelijke arbeidsongeschiktheid met financiële consequenties voor zowel de patiënt als de werkgever tot gevolg. Hierbij valt voor de patiënt te denken aan een lager maandinkomen, problemen bij het afsluiten van een hypotheek, maar ook aan een toename van zorgkosten. De werkgever krijgt te maken met arbeidsverzuimkosten.

In veel gevallen komen de ervaren fysieke klachten van de patiënt niet overeen met de resultaten van standaard uitgevoerde medische onderzoeken. Dit leidt bij veel patiënten tot een gevoel van onbegrip. Onze onderzoeksresultaten hebben aangetoond dat fysieke beperkingen frequent voorkomen bij sarcoïdose en deze klachten veelal een aanhoudend karakter hebben. Verder bleek uit ons onderzoek dat deze beperkingen van grote invloed kunnen zijn op de KvL. Om erkenning te krijgen voor de klachten dienen medisch specialisten zich bewust te zijn van het feit dat sarcoïdosepatiënten te maken kunnen krijgen met fysieke beperkingen en dit ook als zodanig te laten testen. Het tijdig opsporen van fysieke beperkingen en het op de juiste wijze behandelen of begeleiden van deze patiënten kan een positieve werking hebben op de ervaren fysieke klachten, het psychosociaal welzijn, het dagelijks functioneren en de KvL van de patiënt en daarmee ook op financiële en arbeidsgerelateerde factoren. Alhoewel vervolgonderzoek noodzakelijk is laat ons onderzoek zien dat fysieke training in de toekomst wellicht uitkomst kan bieden voor het verhelpen van deze klachten. Het streven is om 
de zorg voor sarcoïdosepatiënten steeds meer een preventief karakter te geven, immers voorkomen is beter dan genezen.

\section{Doelgroepen}

Het doel van klinisch onderzoek dient (in-)direct altijd in het teken te staan van de patiënt door verbetering in de zorgverlening en daarmee tot verbeteringen in het patiënten welzijn. De belangrijkste doelgroep waarvoor deze onderzoeken zijn uitgevoerd betreft de patiënten met sarcoïdose.

De onderzoeksresultaten in dit proefschrift dienen daarnaast de medisch specialisten meer bewust te maken van het bestaan van fysieke beperkingen bij patiënten met sarcoïdose en de wijze waarop deze in kaart gebracht kunnen worden. En het feit dat niet-medicamenteuze behandelopties overwogen moeten worden bij de behandeling van fysieke beperkingen.

Zowel voor het in kaart brengen van fysieke beperkingen als het trainen van sarcoïdosepatiënten lijkt de fysiotherapeut de aangewezen persoon. Begeleiding van sarcoïdosepatiënten met hun verscheidenheid aan klachten vereist immers specifieke kennis van het menselijk bewegingsapparaat, de pathologie sarcoïdose en trainingsleer. Richtlijnen over fysieke training bij chronische longaandoeningen zijn veelal gebaseerd op onderzoeken bij COPD patiënten. Voor sarcoïdosepatiënten, met name voor degenen met een chronisch karakter, zijn KvL en een zo optimaal mogelijke participatie in de maatschappij heel belangrijk. Fysiotherapeuten dienen zich te realiseren dat meer onderzoek op dit gebied noodzakelijk is om de effectiviteit van een trainingsprogramma te onderzoeken en het programma af te stemmen op voor sarcoïdosepatiënten specifieke klachten en behoeftes.

\section{Kennisdeling}

Veelal verloopt de implementatie van onderzoeksresultaten zeer moeizaam. In tegenstelling tot fundamenteel onderzoek is het voordeel van toegepast onderzoek, waarbij klinische vraagstellingen aan de basis liggen, dat relevante bevindingen van directe waarde zijn voor de behandelaars van sarcoïdosepatiënten. Dit proefschrift bevat dan ook uitsluitend toegepast onderzoek. Gestreefd wordt om de onderzoeksresultaten te implementeren in de zorg met als hoger doel verbetering van de zorgverlening aan de sarcoïdosepatiënt. Een voorwaarde voor het implementeren van de onderzoeksresultaten is dat zowel behandelaars als sarcoïdosepatiënten bekend zijn met de nieuwste wetenschappelijke inzichten. Aangezien het begeleiden van sarcoïdosepatiënten een multidisciplinair karakter heeft is het de uitdaging om zoveel mogelijk disciplines te bereiken.

Alle onderzoeken in dit proefschrift zijn momenteel gepubliceerd of zijn reeds geaccepteerd voor publicatie in internationale tijdschriften. Tevens hebben de onderzoeksresultaten geleid tot wetenschappelijke voordrachten op zowel nationale (Koninklijk Nederlands Genootschap voor Fysiotherapie (KNGF)) als internationale 
(European Respiratory Society (ERS), World Association of Sarcoidosis and Other Granulomatous Disorders (WASOG) en World Confederation of Physical Therapy (WCPT)) congressen met een verscheidenheid aan (para-) medische disciplines. Middels refereerbijeenkomsten zijn de onderzoeksresultaten teruggekoppeld naar de directe collega's van de afdeling fysiotherapie van het MUMC, maar ook naar collega fysiotherapeuten elders in het land. Mede hierdoor zijn de resultaten beschikbaar gekomen voor behandelaars betrokken bij de zorg van sarcoïdosepatiënten.

De patiënt anno 2015 is over het algemeen een patiënt die actief betrokken wil zijn bij zijn/haar behandeling en op de hoogte wil blijven van de nieuwste medische ontwikkelingen. Dit hebben we getracht na te streven door lezingen te verzorgen voor de leden van de Sarcoïdose Belangenvereniging Nederland. Tijdens deze bijeenkomsten werden de onderzoeksbevindingen besproken en kritisch bediscussieerd en na afloop waren de patiënten en hun partners in de mogelijkheid tot het stellen van vragen.

Niet alleen de fysiotherapeut van nu, maar ook die van de toekomst dient kennis te maken met het ziektebeeld sarcoïdose en de wetenschappelijk ontwikkelingen op dit gebied. Vanuit dit oogpunt zijn de onderzoeksresultaten gepresenteerd tijdens bijeenkomsten op de Zuyd Hogeschool.

\section{Innovatie}

Op dit moment ontbreken aanbevelingen over het gebruik van fysieke testen in nationale en internationale richtlijnen vanwege het gebrek aan wetenschappelijke onderbouwing. Ook evaluatie van gepast gebruik van fysiotherapie bij sarcoïdosepatiënten met een fysieke beperking is tot op heden niet mogelijk gebleken, aangezien geen relevante data voorhanden waren. Het vernieuwende van onze onderzoeken is dat nu duidelijk is dat bij sarcoïdosepatiënten wel degelijk fysieke beperkingen aanwezig zijn en dat deze meetbaar zijn mits gebruik wordt gemaakt van de juiste meetmethodes. Dit voortschrijdend inzicht is niet alleen van belang voor de begeleidende zorgverleners, maar zeker ook voor de patiënt aangezien hier een stuk erkenning door wordt gerealiseerd. Aan de hand van een pilot studie zijn we gaan kijken naar de meerwaarde van een trainingsprogramma bij sarcoïdose. Voor het uitvoeren van de onderzoeken in dit proefschrift hebben wij gebruik gemaakt van bestaande meetinstrumenten en trainingsapparatuur. Het belang van bewegen en life style wordt bij chronische ziekten als sarcoïdose steeds belangrijker. Patiënten hebben een eigen verantwoordelijkheid en ook wordt benadrukt dat ze zelf een belangrijke rol kunnen spelen in het genezingsproces in relatie tot hun omgeving (zelfeffectiviteit).

\section{Toekomstvisie}

De aanbeveling die voortkomt uit de resultaten beschreven in dit proefschrift is om naast de regulier uitgevoerde klinische testen ook fysieke testen op te nemen in het multidisciplinaire management programma van deze patiëntenpopulatie. De transitie dient plaats te vinden van aanbeveling naar implementatie van de bevindingen in de 
patiëntenzorg. Het streven is om de bevindingen op te nemen in nationale en internationale zorgrichtlijnen. Hiervoor dienen onze aanbevelingen gesteund te worden door de diverse beroepsorganisaties, zoals de Nederlandse Vereniging van Artsen voor Longziekten en Tuberculose (NVALT) en het KNGF, die betrokken zijn bij de zorg van sarcoïdosepatiënten. Ondanks deze aanbeveling zou standaardisering en operationalisering van het gebruik van fysieke testen binnen de begeleiding van sarcoïdosepatiënten in de toekomst aandacht dienen te krijgen.

Moeheid is een van de grootste problemen van sarcoïdosepatiënten en daarbij moeilijk behandelbaar. Uit onze onderzoeksresultaten blijkt dat moeheid, fysieke functies en KvL bij sarcoïdose mogelijk beïnvloedbaar zijn met een trainingsprogramma. Ondanks dat de wetenschappelijke bewijskracht met betrekking tot de effectiviteit van fysieke training bij sarcoïdose beperkt is en meer onderzoek vereist is (bijvoorbeeld een gerandomiseerd effectonderzoek), kan dit een mogelijke behandeloptie zijn bij patiënten met vermoeidheidsklachten en fysieke beperkingen.

Toekomstig onderzoek dient zich te richten op de frequentie, duur, intensiteit en lange termijn effecten van training bij sarcoïdose. Maar ook de meerwaarde van een multidisciplinair revalidatieprogramma dient onderzocht te worden en tevens de inzet van e-health faciliteiten binnen de revalidatie. Naast de mogelijke gezondheidswinst dient middels een kosten-effectiviteitsstudie onderzocht te worden of ook nog een economisch belang in de vorm van kostenbesparing kan worden bereikt. Immers de verwachting is dat fysieke training een goedkopere behandeloptie is voor vermoeidheidsklachten in vergelijking met medicamenteuze therapie. De keuze voor de behandeling hangt af van symptomen en ernst van functionele stoornissen en wordt in overleg tussen arts en patiënt bepaald. Met andere woorden is de klacht daadwerkelijk een probleem? Medicamenteuze therapie is in veel gevallen ontoereikend voor adequate behandeling van fysieke beperkingen. Training kan een goede aanvulling zijn op de huidige standaard behandelopties.

Om deze bevindingen uiteindelijk toe te kunnen voegen aan het standaard zorgpakket van sarcoïdosepatiënten dient vervolgonderzoek verricht te worden, waarna implementatie in de klinische praktijk kan plaatsvinden. Hiervoor is het essentieel om duidelijke afspraken te maken met de zorgverzekeraars. Zij bepalen of fysiotherapeutische interventies worden opgenomen in het chronisch zorgpakket voor sarcoïdosepatiënten en daarmee in aanmerking komen voor financiële vergoeding. Dit is voor de patiënten en het uiteindelijke effect op lange termijn van groot belang. 


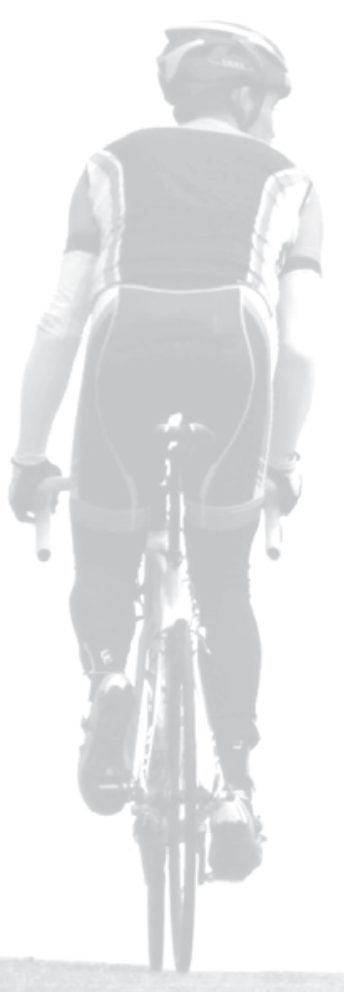

Dankwoord 


\section{Dankwoord}

Het lezen van dit dankwoord betekent dat de verdediging van mijn proefschrift en daarmee de afsluiting van een bijzondere periode in mijn leven dichtbij is. De laatste jaren hebben veelvuldig in het teken gestaan van mijn promotietraject, waarvan nu het resultaat voor $u$ ligt. Aan het begin van dit traject dacht ik alle tijd van de wereld te hebben, maar voordat je het weet is het voorbij. Ik kijk dan ook terug op een hectische, maar vooral zeer leerzame tijd met als resultaat mijn naam pronkend op de voorkant van dit proefschrift. Vele personen hebben bijgedragen aan de totstandkoming van dit proefschrift en neem van mij aan dat zonder hun medewerking dit proefschrift waarschijnlijk niet voor u lag. Het allerliefst zou ik alle personen die op welke manier dan ook hebben bijgedragen aan de totstandkoming van dit proefschrift persoonlijk willen bedanken, maar dat is helaas niet mogelijk. Voordat ik deze periode ga afsluiten wil ik enkele personen in het bijzonder bedanken.

Allereerst wil ik mijn dank uitspreken voor mijn promotor prof. dr. M. Drent en copromotor dr. A.F. Lenssen.

Beste Marjolein, ik herinner mij ons eerste gesprek op de kamer van Ton nog als de dag van vandaag. Ik werd onderworpen aan een grondig verhoor, want was ik wel geschikt voor dit promotietraject. Normaal gesproken kwamen promovendi immers eerst bij jou op sollicitatiegesprek. Ik hoop dat deze twijfel na verloop van tijd is weggenomen. Naar mijn idee had ik geen betere promotor kunnen treffen! Wat ben jij gedreven, volhardend en een bron van motiverende ideeën, zowel in het onderzoek als in de patiëntenzorg. Vierentwintig uur per dag, zeven dagen per week was je bereikbaar. Zelfs op vakantie was je niet veilig. Dit heeft geleid tot een snelle voortgang van mijn onderzoeken. Mocht ik dan toch even verslappen dan klonk de computer en zag ik in mijn mailbox m.drent@.....

Beste Ton, jij mailde mij ooit met de wijze woorden: "Het leven van een onderzoeker gaat niet over rozen. Onderzoek doen is als het fietsen van Parijs-Roubaix, met vallen en opstaan". Nou dat heb ik ondervonden. Gelukkig wist jij mij telkens weer op de fiets te krijgen en de tocht te laten volbrengen. Ik heb veel geleerd van jouw kritische houding en onze lange discussies. Veelvuldig moest ik toegeven dat je weer eens gelijk had en dat viel niet altijd mee. Jij stimuleerde mij in vele opzichten na te denken over mijn toekomst, waarvoor mijn dank. Natuurlijk kwamen ook serieuze onderwerpen ter sprake, zoals 'wielrennen'. Helaas heb ik jou nooit zover gekregen om een 'echte' toertocht te fietsen, maar wie weet is dit een volgende uitdaging! 
Graag wil ik de leden van de beoordelingscommissie, prof. dr. F.J.W.M. Smeenk, prof. dr. R. Gosselink, prof. dr. H. Kuipers, prof. dr. M.W.G. Nijhuis-van der Sanden en prof. dr. R.J.E.M. Smeets, bedanken voor het lezen en het kritisch beoordelen van het manuscript.

De uitvoering van mijn onderzoeken was natuurlijk nooit mogelijk geweest zonder de medewerking van een groot aantal gemotiveerde en enthousiaste sarcoïdosepatiënten. Ondanks de vele lichamelijke klachten kwamen zij van heinde en ver om deel te nemen aan de onderzoeken. Daarvoor wil ik hen hartelijk bedanken en ik hoop dat mijn onderzoeken een bijdrage hebben geleverd aan het oplossen van de puzzel die 'sarcoïdose' heet.

Een speciaal woord van dank gaat uit naar mijn afdelingshoofd George Roox. Ondanks de toenemende werkdruk op de afdeling heb je mij al die jaren de mogelijkheid gegeven om aan mijn onderzoeken te werken. Zoals ooit afgesproken zou ik mijn proefschrift afgerond hebben voordat jij met pensioen zou gaan. Gelukkig heb ik die belofte waar kunnen maken.

De onderzoeken in dit proefschrift zijn financieel ondersteund door de ild care foundation en de Sarcoïdosebelangenvereniging Nederland (SBN). Waarbij speciale aandacht uit gaat naar de prestatie van Ange van Ommen, aangezien de subsidiegelden van de SBN deels verkregen zijn middels een sponsorloop naar Santiago de Compostela. Normaal gesproken is dit al een geweldige prestatie, maar voor iemand met sarcoïdose is dit een super prestatie.

Prof. dr. J. De Vries, beste Jolanda, vanuit Tilburg heb je als co-auteur bijgedragen aan de totstandkoming van menig artikel van mij. Ik wil je dan ook bedanken voor de veelvuldig geboden statistische hulp en het kritisch beoordelen van mijn artikelen.

Dr. Petal Wijnen, wat ben ik blij dat je altijd bereid was om mij te helpen in noodsituaties. Veelvuldig heb ik gebruik gemaakt van jouw noodnummer als mijn computer weer eens weigerde, de SPSS of Excell database een puinhoop dreigde te worden, Endnote niet deed wat ik vroeg, enzovoorts. Tijdens onze uitstapjes naar congressen maakte ik kennis met een andere hobby van jou, namelijk fotograferen. De foto op de voorkant van dit proefschrift is dan ook gemaakt door de artistieke dr. Petal Vini. Bedankt voor alle hulp in de afgelopen jaren en de volgende Weizenbier is voor mijn rekening.

Michiel de Vries, ondanks je drukke werkzaamheden als longarts in het Orbis MC te Sittard was je keer op keer bereid je medewerking te verlenen aan mijn onderzoeken. Graag wil ik je hiervoor bedanken en natuurlijk voor de gastvrijheid bij jou thuis. Zoals afgesproken zal voor jou een lekker glas wijn klaar staan. 
Stephan Kleynen, als student fysiotherapie van de Zuyd Hogeschool ben je betrokken geraakt bij mijn onderzoeken en heb je mij veel werk uit handen genomen. Op het moment dat je als collega bij de afdeling fysiotherapie kwam werken kon ik wederom op je terugvallen voor mijn onderzoeken. Ik ben dan ook blij dat je nu deel uit maakt van ons team.

Melanie van der Veeke en dr. Ilse Mesters, bedankt voor de samenwerking die heeft geleid tot het laatste artikel van mijn proefschrift. Heel veel succes bij de voortzetting van de onderzoeken op het gebied van sarcoïdose. Melanie, de weg die leidt naar de promotie is lang, maar met de juiste hulp is deze een stuk korter.

Marjon Elfferich, tijdens mijn eerste onderzoek hebben wij intensief samengewerkt om de sarcoïdose patiënten fysiek in kaart te brengen. Dit was met momenten een hele klus, maar het resultaat mocht er zijn. Tevens wil ik je bedanken voor alle hulp achter de schermen.

Kathrin Foerster, Sarah Kassim en Yoeri Bemelmans, in het kader van jullie afstudeerproject voor de opleiding fysiotherapie aan de Zuyd Hogeschool hebben jullie voor mijn onderzoeken vele metingen uitgevoerd. Bedankt voor jullie geweldige inzet en betrokkenheid bij mijn onderzoeken.

Tevens wil ik ook alle overige co-auteurs bedanken voor hun kritische beoordeling van mijn manuscripten en natuurlijk de prettige samenwerking die heeft geleid tot dit mooie resultaat. I would also like to thank the remaining co-authors for their critical review of the manuscripts and of course for their pleasant cooperation, that has led to this great result.

Zonder de hulp van mijn collega's van de afdeling fysiotherapie van het MUMC was dit promotietraject voor mij nooit zo'n groot succes geworden. Steeds weer hebben jullie er voor gezorgd dat ik tijd kon steken in mijn onderzoeken door het overnemen van mijn zorgtaken. Bedankt voor alle hulp van de afgelopen jaren!

Sita Pisana, mailtje hier, telefoontje daar en mocht dat niet voldoende zijn dan kregen de sarcoïdosepatiënten een brief. Mede dankzij jouw doorzettingsvermogen hebben veel patiënten kunnen deelnemen aan mijn onderzoeken.

Dr. Anne Cremers en dr. Rémy Mostard, bedankt voor jullie hulp op weg naar de afronding van mijn proefschrift en voor de gezellige momenten tijdens de meetings op de kamer van Marjolein en tijdens de congressen in Barcelona en Parijs. 
De medewerkers van de longfunctieafdeling van het MUMC wil ik bedanken voor hun getoonde flexibiliteit bij het plannen en verrichten van aanvullende longfunctie onderzoeken.

Tiny Wouters, vol overgave heb jij je gestort op de lay-out van mijn proefschrift. Zoals jezelf aangaf lekker in de avonduren op zoek gaan naar 'fouten' in het proefschrift van welke aard dan ook. Bedankt voor alle hulp en goede adviezen die hebben geleid tot dit mooie resultaat.

Ik ben ook erg blij met de personen die in grote getalen belangeloos hebben deelgenomen aan de metingen voor de controle groep op een moment dat ik deze zo hard nodig had.

Danielle Berghmans, bedankt dat je als kamergenoot altijd een luisterend oor had en dat je bereid was om mee te denken over moeilijke kwesties. Als volgende promovendus van de afdeling fysiotherapie wens ik je heel veel succes met het afronden van je promotie.

Ik wil de collega's van de opleiding fysiotherapie van de Zuyd Hogeschool in Heerlen bedanken voor de getoonde interesse tijdens het afgelopen anderhalf jaar.

Ik wil ook mijn vrienden en vriendinnen oet Hôrs bedanken voor de interesse en betrokkenheid die zij hebben getoond in mijn werkzaamheden. De laatste jaren hebben jullie regelmatig klaar gestaan voor mij! Wellicht zonder dat jullie het weten waren de gesprekken en de feestjes met de nodige gezelligheid een mooie bron van afleiding.

Leo Jacobs en Gerd-Jan Coenen, bedankt voor jullie morele steun en aanmoediging tijdens de moeilijke momenten in dit traject.

En dan is het nu de beurt aan mijn paranimfen. Kenneth, de weggesleepte auto bij ons bezoek aan de Deutsche Sporthochschule in Köln, prins carnaval van voetbalvereniging Boekoel en Kenneth's bekende uurtje te laat. Maarten, met een foto in de krant na Rowwen Hèze, knak opwarmen tijdens een wandeltocht op de Hoge Venen, samen op vakantie en natuurlijk ons survival weekend in de Ardennen. Menig keer hebben we hier onder het genot van een drankje (enkele drankjes) kostelijk om kunnen lachen. Ik ben dan ook blij dat jullie mij in deze spannende situatie bijstaan, zodat we deze ervaring kunnen toevoegen aan deze rijtjes.

Beste pap en mam, als geen ander weten wij dat het leven vol onzekerheden zit. Maar één zekerheid is dat zonder jullie dit proefschrift niet zou bestaan. Jullie hebben mij onvoorwaardelijk gesteund in al mijn keuzes en laten zien wat doorzettingsvermogen is. Dit heeft mij gebracht tot waar ik nu ben. 
Beste pap, Truus, Jo, Tonnie, Joost, Miranda, Ankie, Marcel en de kids, de laatste tijd was mijn proefschrift regelmatig onderwerp van gesprek. Veelvuldig heb ik een poging gedaan om jullie uit te leggen waar ik zo al mee bezig was in mijn onderzoeken. Dit waren mooie momenten om mijn hart te luchten. Bedankt voor de getoonde interesse in mijn onderzoeken over de afgelopen jaren. Ik hoop dat het lezen van dit proefschrift meer inzicht geeft in mijn werkzaamheden.

Als laatste in de rij, maar met stip op nummer 1 in mijn gedachte staat mijn gezin. Lieve Annemarie en Fenna, de afgelopen periode hebben we een zeer hectische tijd doorgemaakt met hele mooie, maar zeer zeker ook minder leuke momenten. Ik heb de laatste tijd veel van jullie gevraagd, maar gelukkig bleven jullie altijd achter mij staan. Fenna, onze kleine meid, is voor mij een bron van inspiratie en vreugde. Immers een glimlach van een kind doet je beseffen dat je leeft. Annemarie, ik kan een poging doen om je te bedanken, maar dit zal nooit de lading dekken. 
Curriculum vitae

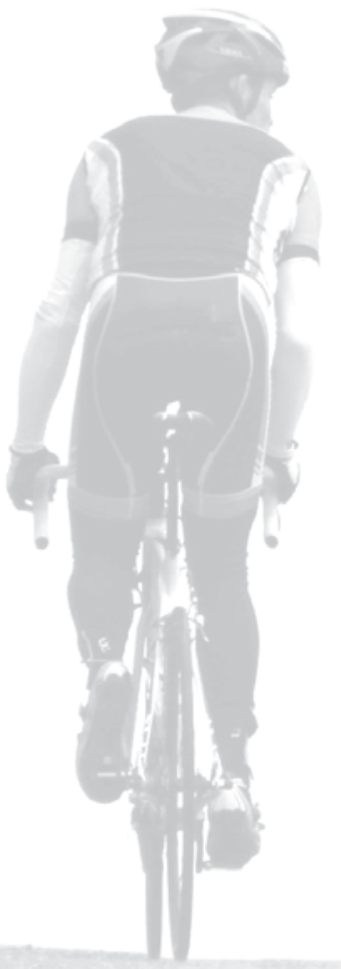




\section{Curriculum vitae}

Rik (Gerardus Josef) Marcellis was born on November $30^{\text {th }}, 1981$, in Venray, the Netherlands. In 2000, he completed his secondary education at the Atheneum of the Dendron College in Horst. In the same year he started studying health sciences, specializing in movement sciences, at Maastricht University (Maastricht; the Netherlands), and in 2003 he enrolled in the physical therapy program at Hogeschool Zuyd (Heerlen; the Netherlands). He graduated in physical therapy and obtained his Masters degree in health sciences in 2006. Since May 2006 he has been working at the Department of Physical Therapy of Maastricht University Medical Centre (MUMC) as a physical therapist, focusing on the treatment of patients with neurologic disorders and cystic fibrosis. In November 2013, he became a part-time teacher at Zuyd Hogeschool (Heerlen, the Netherlands). The research project described in this thesis started in 2009 at MUMC, with Prof. Marjolein Drent and Dr. Ton Lenssen as his supervisor and cosupervisor, respectively. At the WASOG/BAL Conference in Maastricht in June 2011, he received the award from the Foundation for Sarcoidosis Research USA and the ild care foundation for Excellence in Sarcoidosis Research in the Netherlands. He lives with his girlfriend Annemarie van Wijk and daughter Fenna in Sibbe (Valkenburg, the Netherlands). 


\section{List of publications}

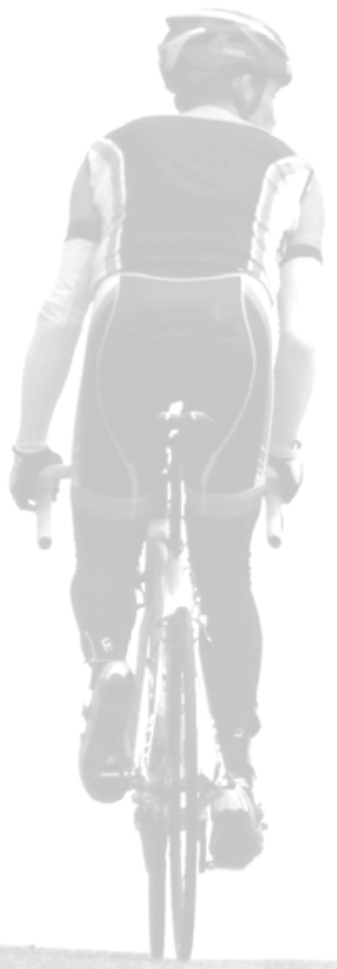




\section{List of publications}

Marcellis RGJ, Van Steyn MJA, Van Uden CJT, Lenssen AF. Oefenprogramma bij patiënten met knie- en/of heupartrose. Stimulus 2007;26:402-15.

Braun SM, Beurskens AJ, Schack T, Marcellis RGJ, Oti KC, Schols JM, Wade DT. Is it possible to use the Structural Dimension Analysis of Motor Memory (SDA-M) to investigate representations of motor actions in stroke patients? Clin Rehabil 2007;21: 822-32.

Marcellis RGJ, Lenssen AF, Elfferich MDP, De Vries J, Kassim S, Foerster K, Drent M. Exercise capacity, muscle strength and fatigue in sarcoidosis. Eur Respir J 2011;38: 628-34.

Marcellis RGJ, Lenssen AF, De Vries GJ, Baughman RP, Van der Grinten CP, Verschakelen JA, De Vries J, Drent M. Is there an added value of cardiopulmonary exercise testing in sarcoidosis patients? Lung 2013;191:43-52.

Marcellis RGJ, Lenssen AF, Kleynen S, De Vries J, Drent M. Exercise capacity, muscle strength, and fatigue in sarcoidosis: a follow-up study. Lung 2013;191:247-56.

Marcellis RGJ, Lenssen AF, De Vries J, Drent M. Reduced muscle strength, exercise intolerance and disabling symptoms in sarcoidosis. Curr Opin Pulm Med 2013;19: 524-30.

Marcellis RGJ, Lenssen AF, Drent M, De Vries J. Association between physical functions and quality of life in sarcoidosis. Sarcoidosis Vasc Diffuse Lung Dis 2014;31;117-28.

Marcellis RGJ, Van der Veeke MAF, Mesters I, Drent M, De Bie RA, De Vries GJ, Lenssen AF. Does physical training reduce fatigue in sarcoidosis? Sarcoidosis Vasc Diffuse Lung Dis 2015; in press. 
Abbreviations

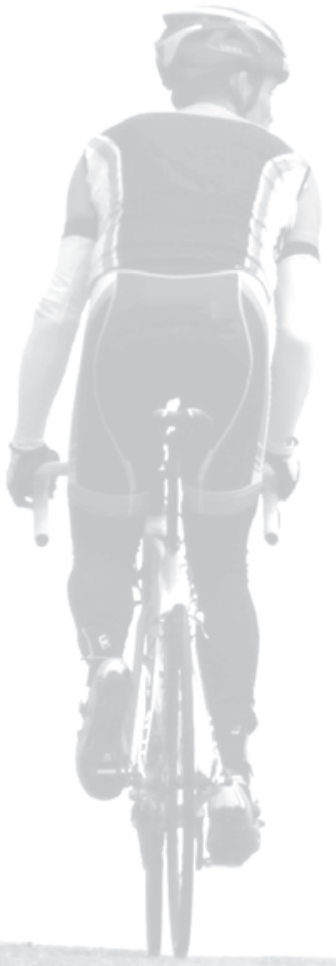




\section{Abbreviations}

\begin{tabular}{|c|c|}
\hline ACE & angiotensin converting enzyme \\
\hline $\mathrm{Ag}$ & antigen \\
\hline ANOVA & analysis of variance \\
\hline B & unstandardized regression coefficient \\
\hline$\beta$ & standardized regression coefficient \\
\hline $\mathrm{BI}$ & betrouwbaarheidsinterval \\
\hline BMI & body mass index \\
\hline $\mathrm{Cl}$ & confidence interval \\
\hline COPD & chronic obstructive pulmonary disease \\
\hline CPET & cardiopulmonary exercise testing \\
\hline CRP & C-reactive protein \\
\hline CT & computed tomography \\
\hline CV & coefficient of variation \\
\hline$\Delta$ & difference \\
\hline df & degrees of freedom \\
\hline DLCO & diffusing capacity of the lung for carbon monoxide \\
\hline DSP & distance-saturation product \\
\hline ECG & electrocardiogram \\
\hline EFMS & elbow flexor muscle strength \\
\hline ERS & European Respiratory Society \\
\hline FAS & Fatigue Assessment Scale \\
\hline $\begin{array}{l}\text { FEV }_{1} \\
{ }^{18} \text { F-FDG }\end{array}$ & $\begin{array}{l}\text { forced expiratory volume in one second } \\
\text { fluorine18-fluoro-deoxyglucose }\end{array}$ \\
\hline FFM & fat-free mass \\
\hline FVC & forced vital capacity \\
\hline HGF & handgrip force \\
\hline HLA & human leukocyte antigen \\
\hline HPT & hamstrings peak torque \\
\hline$H R$ & heart rate \\
\hline HRCT & high-resolution computed tomography \\
\hline IFN- $\gamma$ & interferon gamma \\
\hline IL & interleukin \\
\hline ild & interstitial lung disease \\
\hline IPF & idiopathic pulmonary fibrosis \\
\hline KNGF & Koninklijk Nederlands Genootschap voor Fysiotherapie \\
\hline KSQ & King's Sarcoidosis Questionnaire \\
\hline KvL & kwaliteit van leven \\
\hline MBS & modified Borg scale \\
\hline MCID & minimal clinically important difference \\
\hline MEC & Medical Ethics Committee \\
\hline
\end{tabular}




\begin{tabular}{|c|c|}
\hline microFET & micro Force Evaluating and Testing \\
\hline MRC & Medical Research Council \\
\hline 6MST & six-minute stepper test \\
\hline MSWT & modified shuttle walk test \\
\hline MTX & methotrexate \\
\hline MUMC & Maastricht University Medical Centre \\
\hline 6MWD & six-minute walking distance \\
\hline 6MWT & six-minute walk test \\
\hline $\mathrm{n}$ & number \\
\hline NA & not applicable \\
\hline$\Delta \mathrm{P}(\mathrm{A}-\mathrm{a}) \mathrm{O}_{2}$ & $\begin{array}{l}\text { difference in alveolar-arterial oxygen pressure gradient between rest } \\
\text { and maximal exercise }\end{array}$ \\
\hline $\mathrm{P}(\mathrm{A}-\mathrm{a}) \mathrm{O}_{2} \mathrm{max}$ & alveolar-arterial oxygen pressure difference at maximal exercise \\
\hline $\mathrm{P}(\mathrm{A}-\mathrm{a}) \mathrm{O}_{2}$ rest & alveolar-arterial oxygen pressure difference at rest \\
\hline$\triangle \mathrm{PaCO}_{2}$ & $\begin{array}{l}\text { change in arterial carbon dioxide pressure between rest and maximal } \\
\text { exercise }\end{array}$ \\
\hline $\mathrm{PaCO}_{2}$ max & arterial carbon dioxide pressure at maximal exercise \\
\hline $\mathrm{PaCO}_{2}$ rest & arterial carbon dioxide pressure at rest \\
\hline$\Delta \mathrm{PaO}_{2}$ & change in arterial oxygen pressure between rest and maximal exercise \\
\hline $\mathrm{PaO}_{2} \mathrm{max}$ & arterial oxygen pressure at maximal exercise \\
\hline $\mathrm{PaO}_{2}$ rest & arterial oxygen pressure at rest \\
\hline PEmax & maximal expiratory mouth pressure \\
\hline PET & positron emission tomography \\
\hline PGEI & pulmonary gas exchange impairment \\
\hline PImax & maximal inspiratory mouth pressure \\
\hline PR & pulmonary rehabilitation \\
\hline$\%$ pred & percentage of predicted \\
\hline PRP & pulmonary rehabilitation program \\
\hline QoL & quality of life \\
\hline QPT & quadriceps peak torque \\
\hline r & Pearson correlation coefficient \\
\hline $\mathrm{R}^{2}$ & coefficient of determination \\
\hline RFI & respiratory functional impairment \\
\hline RLD & restrictive lung disease \\
\hline SAPH & sarcoidosis-associated pulmonary hypertension \\
\hline SD & standard deviation \\
\hline SE & standard error \\
\hline SF-36 & Medical Outcomes Study 36-item Short-Form Health Survey \\
\hline SFN & small fiber neuropathy \\
\hline SGRQ & St. George's Respiratory Questionnaire \\
\hline $\mathrm{SHQ}$ & Sarcoidosis Health Questionnaire \\
\hline SIL-2R & soluble interleukin-2 receptor \\
\hline
\end{tabular}




$\begin{array}{ll}\text { SIP } & \text { Sickness Impact Profile } \\ \text { SPSS } & \text { Statistical Package for the Social Sciences } \\ \text { t0 and t1 } & \text { time at baseline and follow-up } \\ \text { TCR } & \text { T-cell receptor } \\ \text { Th cell } & \text { T helper cell } \\ \text { TNF } & \text { tumor necrosis factor } \\ \text { VAS } & \text { Visual Analogue Scale } \\ \text { VO }{ }_{2} \text { max } & \text { maximal oxygen uptake } \\ \text { WASOG } & \text { World Association of Sarcoidosis and Other Granulomatous Disorders } \\ \text { WCPT } & \text { World Confederation of Physical Therapy } \\ \text { WHOQOL-100 } & \text { World Health Organization Quality of Life assessment instrument-100 } \\ \text { WHOQOL-BREF } & \text { World Health Organization Quality of Life assessment instrument-BREF } \\ \text { Wmax } & \text { maximal workload } \\ \text { X-RM } & \text { multiple-repetition maximum } \\ X^{2} \text { test } & \text { chi-squared test } \\ \text { yrs } & \text { years }\end{array}$




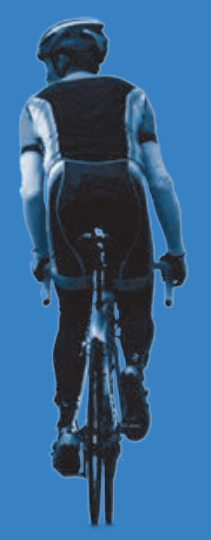

